$11-1-2021$

\title{
Resultados del estudio sobre violencia en la era COVID-19 (VoCes-19): Línea base reporte
}

\author{
Silvana Larrea-Schiavon \\ Population Council \\ Lina López-Lalinde \\ Isabel Vieitez Martínez \\ Population Council \\ Ricardo Regules \\ Population Council \\ Juan Pablo Gutiérrez
}

See next page for additional authors

Follow this and additional works at: https://knowledgecommons.popcouncil.org/departments_sbsr-pgy

Part of the Domestic and Intimate Partner Violence Commons, and the Family, Life Course, and Society Commons

How does access to this work benefit you? Let us know!

\section{Recommended Citation}

Larrea-Schiavon, Silvana, Lina López-Lalinde, Isabel Vieitez Martínez, Ricardo Regules, Juan Pablo Gutiérrez, René Nevárez, Cristina Mac Gregor, Pablo López, Nicole Haberland, and Thoai Ngo. 2021. "Resultados del estudio sobre violencia en la era COVID-19 (VoCes-19): Línea base reporte." Mexico: Population Council. 


\section{Authors}

Silvana Larrea-Schiavon, Lina López-Lalinde, Isabel Vieitez Martínez, Ricardo Regules, Juan Pablo Gutiérrez, René Nevárez, Cristina MacGregor, Pablo López, Nicole Haberland, and Thoai Ngo 


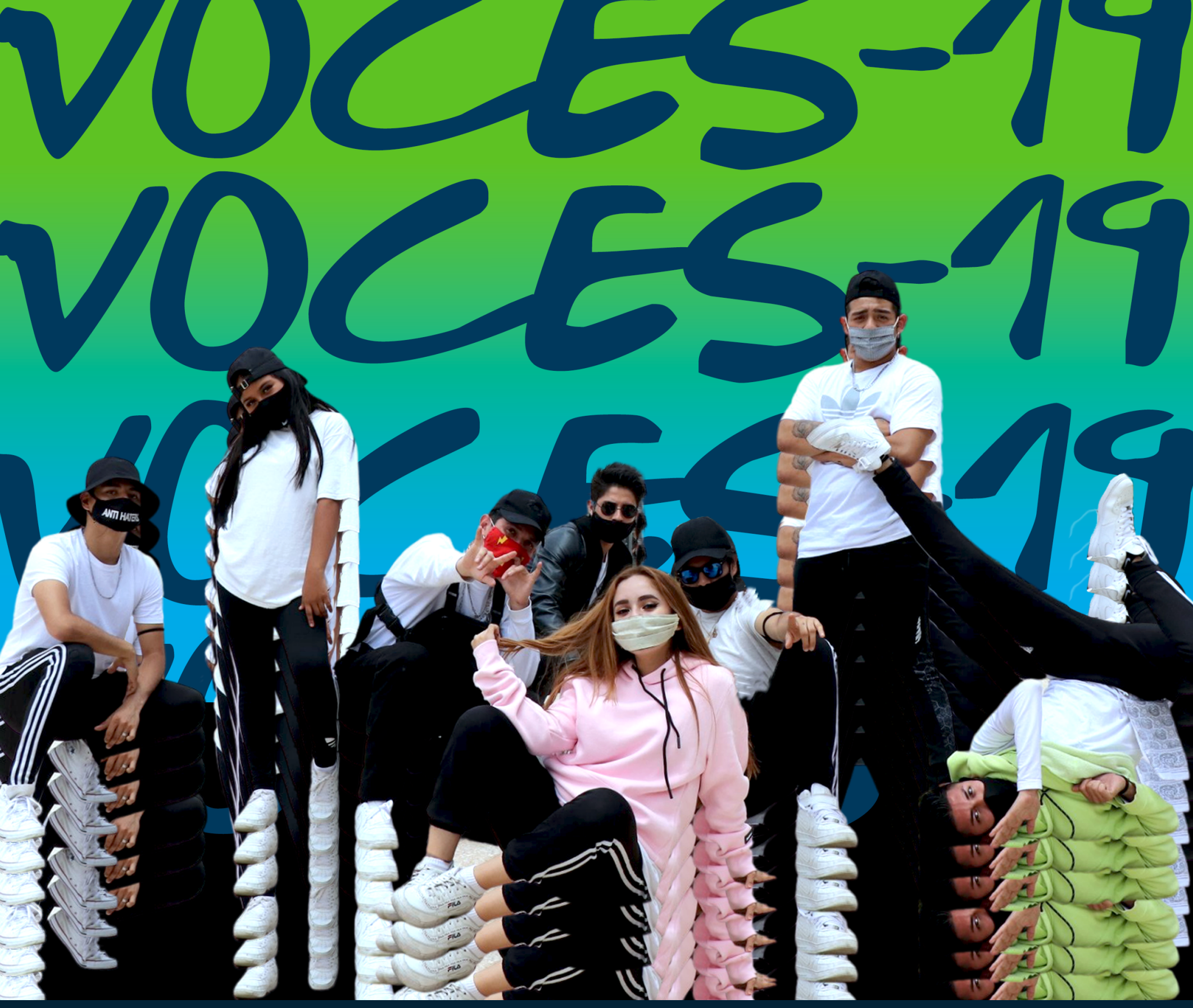

\section{Resultados del estudio sobre violencia en la era COVID-19 (VoCes-19)}

LÍNEA BASE | REPORTE NOVIEMBRE 2021

Silvana Larrea-Schiavon • Lina López-Lalinde • Isabel Vieitez Martínez • Ricardo Regules García • Juan Pablo Gutiérrez • René Nevárez • Cristina Mac Gregor • Pablo López • Nicole Haberland • Thoai Ngo 
El Population Council se enfrenta a cuestiones críticas de salud y desarrollo, desde detener la propagación del VIH hasta mejorar la salud reproductiva y garantizar que las y los jóvenes tengan una vida plena y productiva. A través de la investigación biomédica, de ciencias sociales y de salud pública en 50 países, trabajamos con nuestros socios para ofrecer soluciones que conduzcan a políticas, programas y tecnologías más eficaces que mejoren la vida en todo el mundo. Fundado en 1952 y con sede en Nueva York, el Consejo es una organización no gubernamental sin fines de lucro regida por un consejo de administración internacional.

Population Council México

Blvd. Adolfo Ruiz Cortines 3720, Torre III, Piso 8, Oficina 8A123

Ciudad de México, 01900

México

(c) 2021 The Population Council, Inc.

popcouncil.org 


\section{Tabla de contenido}

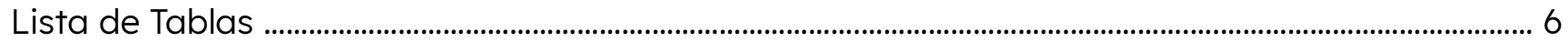

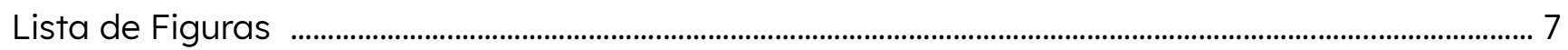

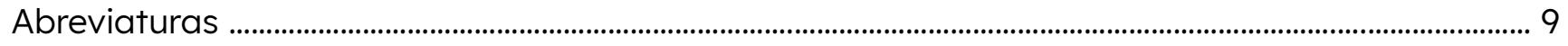

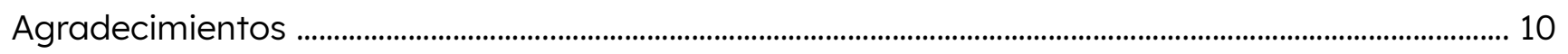

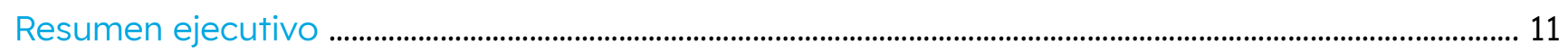

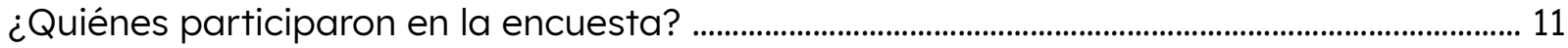

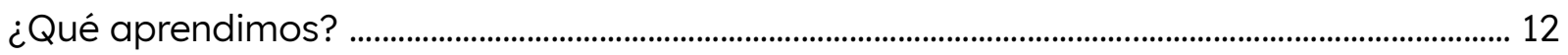

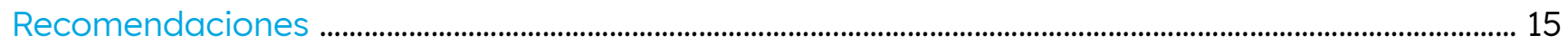

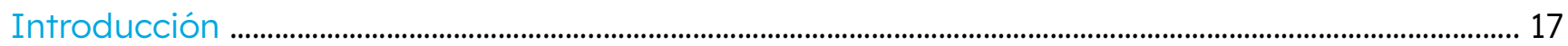

La pandemia de la COVID-19 en México ..................................................................................................... 17

El contexto mexicano: desigualdades y aspectos en la salud

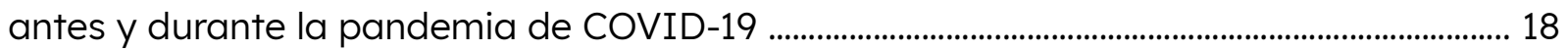

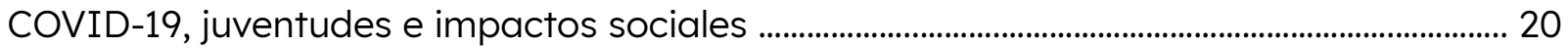

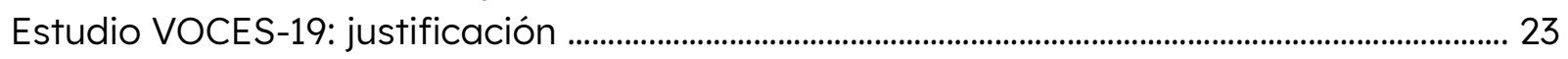

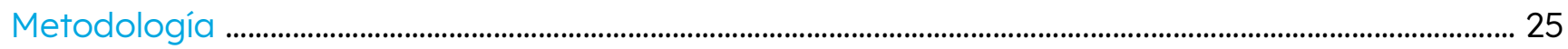

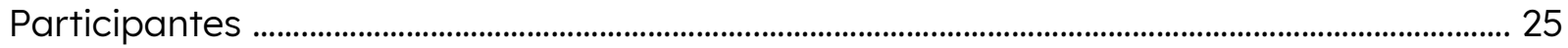

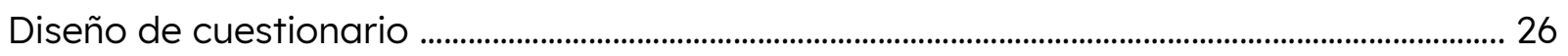

Estrategias implementadas para llegar a las personas participantes ...................................... 28

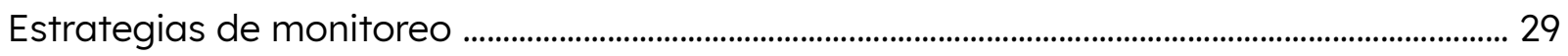

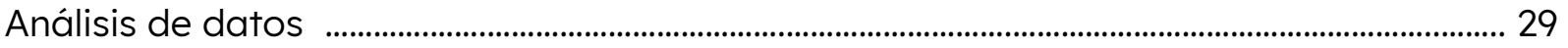

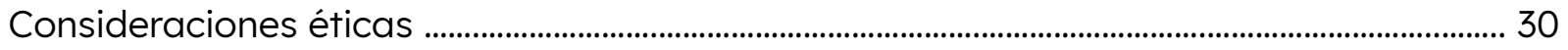

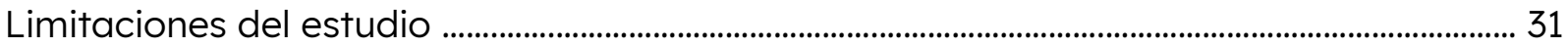

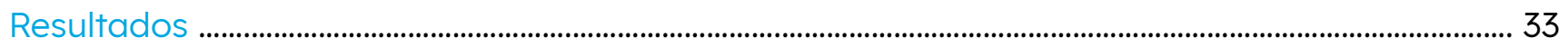

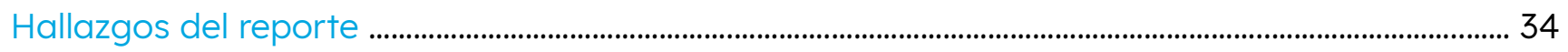

¿Quiénes son las personas participantes de VoCes-19? ..................................................................................... 35

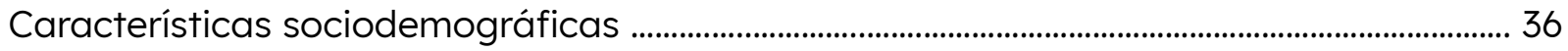

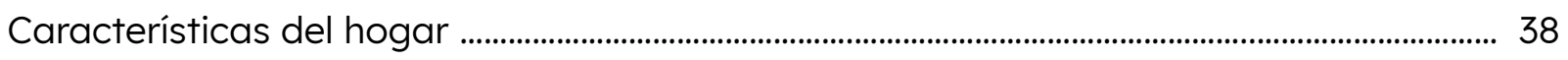

Cumplimiento de las medidas de mitigación de COVID-19....................................................................... 39

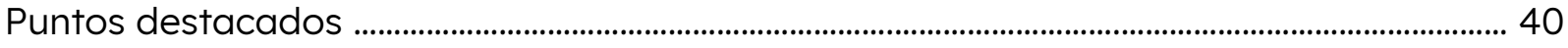

¿Cuál fue el nivel de cumplimiento de las medidas de mitigación

recomendadas por el gobierno? ............................................................................................................... 42

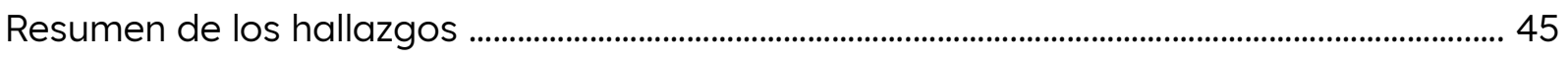




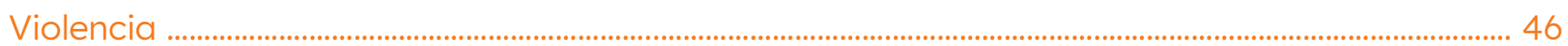

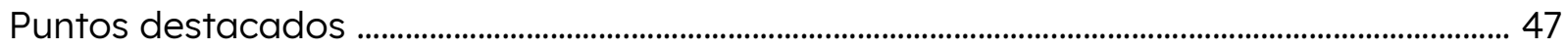

¿Qué impacto tuvieron las medidas de distanciamiento social en las

percepciones y experiencias de violencia de las personas participantes?

¿Existe relación entre el aumento en la frecuencia y/o gravedad de la violencia

interpersonal en el hogar y la equidad en las dinámicas del hogar de las personas

participantes?

¿Cómo afectó la pandemia las percepciones de la seguridad en el hogar

y la comunidad por parte de adolescentes y jóvenes? ..................................................................... 55

Resumen de los hallazgos .................................................................................................................. 58

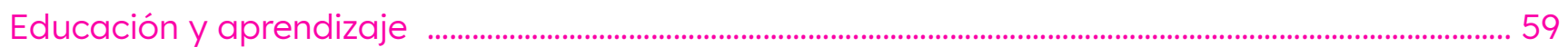

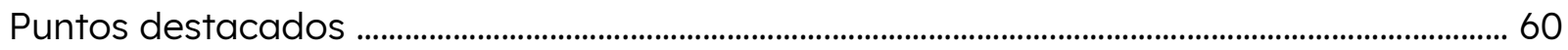

¿Cómo afectó la pandemia a la inscripción en las escuelas? ........................................................... 61

¿Cómo el cambio a educación a distancia impactó en

la participación y aprendizaje de las y los estudiantes?...................................................................... 64

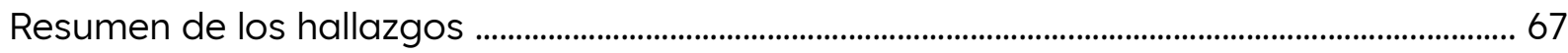

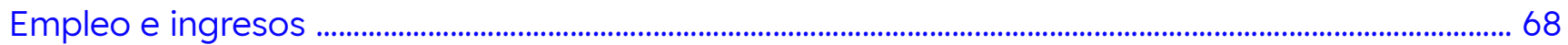

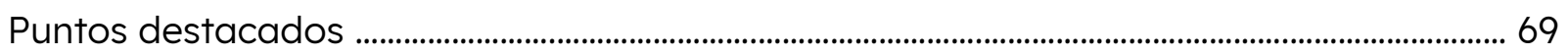

¿Cuál era el estatus laboral de las personas participantes de VOCES-19

a 8 meses de iniciar la pandemia?............................................................................................................... 71

¿Cómo ha impactado la pandemia las condiciones de empleo e ingresos

en los hogares de las personas participantes de VOCES-19? ......................................................... 73

¿Cómo lidiaron los hogares de las personas participantes

con los impactos financieros de la pandemia de COVID-19? ................................................. 77

Resumen de los hallazgos .......................................................................................................................... 78

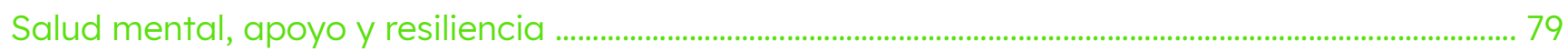

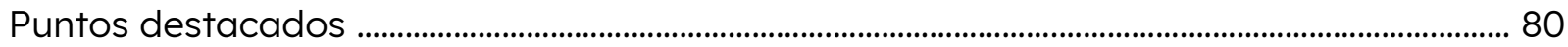

¿Cuál es el estado de la salud mental entre adolescentes y jóvenes? ...................................... 82

¿La pandemia ha impactado en la salud mental de adolescentes y jóvenes? ...................... 84

¿Cuáles fueron las principales preocupaciones de

los participantes sobre el futuro tras el inicio de la pandemia?

¿Cómo impactó la pandemia el uso de redes sociales, las prácticas de

socialización y el uso de servicios de apoyo entre adolescentes y jóvenes?........................ 86

¿Qué estrategias han implementado las personas adolescentes

y jóvenes para lidiar con sentimientos problemáticos

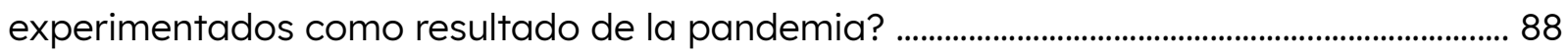

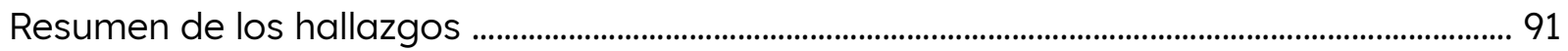

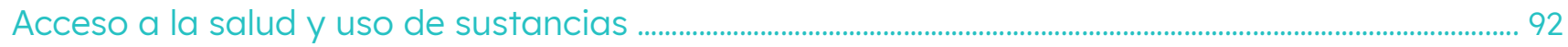

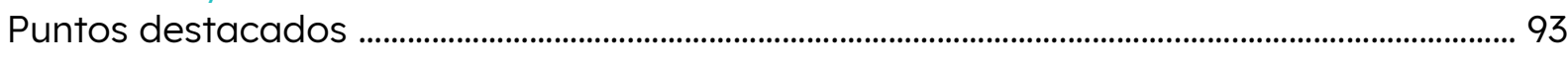


¿Cuáles son las percepciones de adolescentes y jóvenes sobre el impacto de la pandemia en el acceso a servicios de salud?

¿Las personas adolescentes y jóvenes percibieron que su consumo de sustancias ha cambiado desde el inicio de la pandemia?

Resumen de los hallazgos

\section{Recomendaciones}

Programas de apoyo a las juventudes relacionados a la violencia ......................................... 104

Estrategias para la recuperación educativa.................................................................................... 104

Apoyo a la economía de las mujeres y familias de bajos ingresos .......................................... 105

Incrementar el acceso a la salud para las comunidades de bajos recursos e implementar intervenciones dirigidas a la salud mental para jóvenes, mujeres y poblaciones no binarias 


\section{Lista de Tablas}

¿Quiénes son las personas participantes de VoCes-19?

Tabla 1: Participantes por estado 36

Tabla 2: Características de los participantes de VOCES-19

Cumplimiento de las medidas de mitigación de COVID-19

Tabla 3: Cumplimiento de las medidas de mitigación de COVID-19, por grupo de edad y género ............. 118

Tabla 4: Cumplimiento de las medidas de mitigación , por grupo de edad y origen étnico ........................... 119

Tabla 5: Cumplimiento de las medidas de mitigación de COVID-19, por grupo de edad y NSE ................. 120

\section{Violencia}

Tabla 6: Impacto de las medidas de mitigación de COVID-19 en la exposición a la violencia, por grupos de edad y género

Tabla 7: Impacto de las medidas de mitigación de COVID-19 en la exposición a la violencia, por grupo de edad y origen étnico

Tabla 8: Impacto de las medidas de mitigación de COVID-19 en la exposición a la violencia, por grupos de edad y NSE

\section{Educación y aprendizaje}

Tabla 9: Impacto de las medidas de mitigación de COVID-19 en las experiencias de educación y aprendizaje, por edad y género

Tabla 10: Impacto de las medidas de mitigación de COVID-19 en las experiencias de educación y aprendizaje, por grupo de edad y origen étnico...

Tabla 11: Impacto de las medidas de mitigación de COVID-19 en las experiencias de educación y aprendizaje, por grupos de edad y NSE

Empleo e ingresos

Tabla 12: Impacto de las medidas de mitigación de COVID-19 en el empleo y

la salud financiera familiar, por grupo de edad y género

Tabla 13: Impacto de las medidas de mitigación de COVID-19 en el empleo y

la salud financiera familiar, por grupo de edad y origen étnico

Tabla 14: Impacto de las medidas de mitigación de COVID-19 en el empleo y

la salud familiar financiera, por grupo de edad y NSE.

\section{Salud mental, apoyo y resiliencia}

Tabla 15: Impacto de las medidas de mitigación de COVID-19 en aspectos de resiliencia, por grupo de edad y género

Tabla 16: Impacto de las medidas de mitigación de COVID-19 en aspectos de resiliencia, por grupo de edad y origen étnico.

Tabla 17: Impacto de las medidas de mitigación de COVID-19 en aspectos de resiliencia,

por grupo de edad y NSE

\section{Acceso a la salud y uso de sustancias}

Tabla 18: Impacto de las medidas de mitigación de COVID-19 en aspectos relacionados a la salud, por grupo de edad y género

Tabla 19: Impacto de las medidas de mitigación de COVID-19 en aspectos relacionados a la salud, por grupo de edad y origen étnico

Tabla 20: Impacto de las medidas de mitigación de COVID-19 en aspectos relacionados a la salud, por grupo de edad y NSE 


\section{Lista de Figuras}

¿Quiénes son las personas participantes de VoCes-19?

Figura 1. Características sociodemográficas de participantes VOCES-19

Figura 2. Orientación sexual de participantes VOCES-19, por género. Porcentajes.

Figura 3. Participantes que se casaron y / o empezaron a vivir con su pareja antes de los 18 años, por grupo de edad y sexo. Porcentajes.

\section{Cumplimiento de las medidas de mitigación de COVID-19}

Figura 4. Diferencia en puntos porcentuales en el cumplimiento de las medidas de mitigación en adolescentes por NSE

Figura 5. Diferencia en puntos porcentuales en el cumplimiento de las medidas de mitigación en personas jóvenes, por NSE.

\section{Violencia}

Figura 6. Diferencias en puntos porcentuales en la percepción de adolescentes de una mayor exposición a la violencia en el hogar durante la pandemia (entre las personas que han declarado haber experimentado algún tipo de violencia en el hogar a lo largo de su vida), por origen étnico

Figura 7. Diferencias en puntos porcentuales en la percepción de adultos jóvenes de una mayor exposición a la violencia en el hogar durante la pandemia (entre las personas que han declarado haber experimentado algún tipo de violencia en el hogar a lo largo de su vida), por NSE

Figura 8. Porcentajes de adolescentes que percibieron cambios

en la seguridad del hogar y del vecindario desde el inicio de la pandemia, por género 56

Figura 9. Diferencias en puntos porcentuales en la percepción de personas jóvenes sobre cambios de seguridad en el hogar y en el vecindario desde el inicio de la pandemia, por NSE

\section{Educación y aprendizaje}

Figura 10. Diferencias en puntos porcentuales en la percepción de adolescentes sobre el acceso a las clases remotas desde el cierre de las instalaciones escolares (entre los encuestados inscritos en la escuela actualmente), por NSE

Figura 11. Diferencias en puntos porcentuales en la percepción de personas jóvenes sobre el acceso a las clases remotas desde el cierre de las instalaciones escolares (entre los encuestados inscritos en la escuela actualmente), por NSE

Empleo e ingresos

Figura 12. Diferencia en puntos porcentuales en el impacto financiero de las medidas

de mitigación de COVID-19 entre adolescentes, por NSE

Figura 13. Diferencias en puntos porcentuales en el impacto financiero de las medidas

de mitigación de COVID-19 entre adolescentes, por origen étnico

Figura 14. Diferencias en puntos porcentuales en el impacto financiero de las medidas

de mitigación del COVID-19 entre jóvenes, por NSE

Figura 15. Diferencias en puntos porcentuales en el impacto financiero de las medidas

de mitigación de COVID-19 entre jóvenes, por origen étnico 
Figura 16. Porcentaje de adolescentes con síntomas depresivos y de ansiedad, por género 82

Figura 17. Porcentaje de adultos jóvenes con síntomas depresivos y de ansiedad, por género

Figura 18. Estrategias de afrontamiento usadas entre adolescentes, por género. Porcentajes.

Figura 19. Diferencias en puntos porcentuales en las estrategias de afrontamiento

usadas entre adolescentes, por NSE 89

Figura 20. Estrategias de afrontamiento usadas por adultos jóvenes, por género. Porcentajes. 90

Figura 21. Diferencia en puntos porcentuales en las estrategias de afrontamiento usadas entre adultos jóvenes, por NSE . .90

\section{Acceso a la salud y uso de sustancias}

Figura 22. Diferencias en puntos porcentuales en la percepción de los adolescentes sobre el acceso deficiente a los servicios de salud desde el inicio de la pandemia, por NSE

Figura 23. Diferencias en puntos porcentuales en la percepción de las personas jóvenes sobre el acceso deficiente a los servicios de salud desde el inicio de la pandemia, por NSE 96 Figura 24. Diferencias en puntos porcentuales en el aumento de la ingesta de sustancias desde el inicio de la pandemia entre los adolescentes. Porcentajes...

Figura 25. Diferencias en puntos porcentuales en el aumento de la ingesta de sustancias desde el inicio de la pandemia entre las personas jóvenes. Porcentajes. 98 


\section{Abreviaturas}

CNEGSR

COVID-19

ENIGH

I/AD

IMJUVE

INEGI

ONG

No I/AD

SE

SEP

NSE

SSR

UNICEF

CNEGSR
Centro Nacional de Equidad de Género y Salud Reproductiva

Enfermedad por Coronavirus 2019

Encuesta Nacional de Ingresos y Gastos de los Hogares

Indígena y/o Afrodescendiente

Instituto Mexicano de la Juventud

Instituto Nacional de Estadística y Geografía

Organización no gubernamental

No Indígena y/o Afrodescendiente

Socioeconómico

Secretaría de Educación Pública

Nivel Socioeconómico

Salud Sexual y Reproductiva

Fondo de las Naciones Unidad para la Infancia (por sus siglas en inglés)

Estudio sobre Violencia en la Era COVID-19 (por sus siglas en inglés) 


\section{Agradecimientos}

\section{En primer lugar, nos gustaría agradecer a todas las personas jóvenes que aceptaron voluntariamente participar en el estudio y compartir con nosotros cómo la pandemia les había afectado de manera particular y en numerosas dimensiones de sus vidas.}

Les agradecemos que también compartieran con nosotros sus comentarios sobre la encuesta y cómo les ayudó a darse cuenta de lo mucho que la pandemia les estaba afectando de diferentes maneras, así como cómo sintieron que la encuesta era una salida para expresar y compartir sus voces en relación con este momento tan complejo de sus vidas.

También queremos agradecer al Instituto Mexicano de la Juventud de México (IMJUVE) y al Centro Nacional de Equidad de Género y Salud Reproductiva (CNEGSR). Sin la colaboración y el trabajo realizado por estas dos instituciones, el proyecto no habría podido llegar a los más de 112.000 jóvenes que accedieron a la encuesta. Su apoyo también fue clave para construir la página web de VOCES-19, principalmente la sección de recursos para jóvenes.

Muchas gracias también a todos los socios que nos ayudaron con la difusión de la encuesta, principalmente Fundación de Apoyo a la Juventud, Red Viral, Construye-T, Jóvenes Construyendo el Futuro, la Secretaría de Educación y el Colegio de Bachilleres. Pudimos llegar a jóvenes a los que no habría sido posible llegar sin su continua colaboración y la difusión activa del estudio.

Además, nos gustaría agradecer al equipo de comunicación y diseño de VOCES-19: Ludivine Cicolella, Valeria García Trejo, Daniela Martínez, Juan Carlos Figueroa, Catalina Hernández, Andrea Garay, Sandra Govill y el equipo de Atreyu. Su creatividad y compromiso con el proyecto fue clave para lograr los resultados e involucrar a los jóvenes a participar en el estudio. 


\section{Resumen Ejecutivo}

Este informe presenta los resultados de la encuesta basal del estudio VOCES-19. El estudio, realizado por el Population Council México en colaboración con el Instituto Nacional de la Juventud (IMJUVE) y el Centro Nacional de Equidad de Género y Salud Reproductiva (CNEGSR), tiene como objetivo comprender el impacto de la pandemia de COVID-19 y las medidas de mitigación que la acompañan en la experiencia y la percepción de la violencia entre las y los jóvenes de 15 a 24 años que viven en México, así como otros impactos sociales, económicos y relacionados con la salud. Los objetivos principales de esta primera ronda de encuestas fueron recopilar una línea base de información sobre varios resultados de interés, evaluar los efectos diferenciales por género, etnicidad y estatus socioeconómico, y establecer una cohorte de adolescentes y personas adultas jóvenes para medir los impactos de la pandemia a lo largo del tiempo.

\section{¿Quiénes participaron en la encuesta?}

\section{Los datos se recogieron mediante encuestas en línea entre noviembre de 2020 y febrero de 2021. Durante este período, más de 120.000 jóvenes accedieron a la plataforma de la encuesta, y un total de 55.692 adolescentes y personas adultas jóvenes de los 32 estados de México completaron el cuestionario.}

El $31 \%$ de las y los participantes eran adolescentes de entre 15 y 17 años, mientras que el $69 \%$ restante eran personas jóvenes de entre 18 y 24 años, con un promedio de edad de 19.2 años. Aproximadamente la mitad (51\%) de las personas encuestadas se identificó como mujer, el $48 \%$ como hombre y el $1.3 \%$ como persona no binaria o con otra identidad de género1. Cerca de un tercio (30\%) de las personas participantes se identificaron al menos en parte como indígenas y/o afrodescendientes (I/AD).

Muchas de las personas encuestadas vivían en condiciones de pobreza, y una de cada cuatro (28\%) residía en un hogar con hacinamiento (2.5 habitantes o más por dormitorio). Aproximadamente un tercio (37\%) declaró que una mujer era jefa del hogar y $9.8 \%$ mencionó estar casada o cohabitar con una pareja.

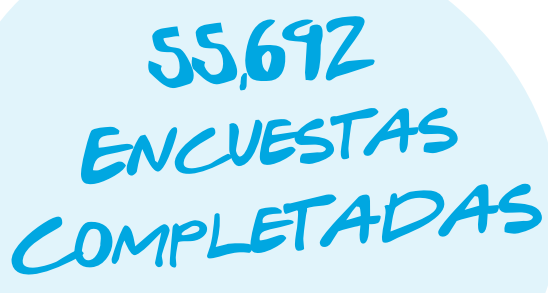

\footnotetext{
1 En la encuesta se preguntó: “¿Con cuál de los siguientes géneros te identificas?” Los participantes podían seleccionar una de las siguientes opciones: 1) Hombre, 2) Mujer, 3) Hombre transgénero/hombre trans/de mujer a hombre (FTM), 4) Mujer transgénero/mujer trans/de hombre a mujer (MTF), 5) Queer o no binario y 6) Otro (especifica). Para el análisis de los datos y la comprobación de las diferencias entre los grupos de género, se colocó a los participantes en la categoría de su identidad de género seleccionada. Por ejemplo, los hombres transgénero se colocaron en la categoría "masculino". Los individuos colocados en la categoría de "no binario u otro" fueron los que declararon que se identificaban como "queer" o "no binario", así como los que escribieron otra identidad de género. Entre los ejemplos de "otras" identidades de género que escribieron los participantes se encuentran "género fluido" y "a género".
} 


\section{La tasa de cumplimiento de las medidas para la mitigación del COVID-19 fue alta}

Casi la mitad de las y los adolescentes y personas jóvenes (45\%) declararon haber cumplido con las cinco medidas de mitigación recomendadas sobre las que se preguntó en la encuesta, incluyendo quedarse en casa y el distanciamiento social. Casi todas las personas participantes (96\%) declararon seguir el mandato de usar cubrebocas cuando salían de casa. Las tasas de cumplimiento autodeclaradas para cada medida de mitigación por separado fueron mayores entre las mujeres en comparación con los hombres en ambos grupos de edad, así como entre las personas participantes de hogares con mayores ingresos, en comparación con las personas de hogares con menores ingresos.

\section{La violencia aumentó}

La pandemia de COVID-19 aumentó el ejercicio de la violencia en contra de las personas jóvenes en México. Más de una de cada cuatro (28\%) personas participantes que habían experimentado violencia interpersonal en el hogar, informaron que la gravedad o la frecuencia de la violencia había aumentado desde el comienzo de la pandemia. Los hombres tuvieron una diferencia de 25 puntos porcentuales más, comparado con las mujeres, al reportar dicho incremento en la violencia sexual ( $35 \%$ vs. $10 \%$ )

La mitad (51\%) de las personas participantes que habían sufrido acoso en línea informaron de un incremento en la frecuencia y/o severidad de estos actos desde el inicio de la pandemia. Las y los adolescentes y personas jóvenes que se autoidentificaron como I/AD, así como las personas participantes de hogares con bajos ingresos, reportaron los mayores aumentos en las experiencias de violencia. Las personas participantes, especialmente las niñas/mujeres, I/ $A D$, y las que viven en hogares más pobres también informaron de que se sentían menos seguras en sus barrios en comparación con antes de la pandemia.

\section{La escuela se tornó en línea para la mayoría de los estudiantes}

Casi todas (99\%) los personas adolescentes y la mayoría (75\%) de las personas jóvenes estaban inscritas en la escuela al momento de la encuesta. Entre estas últimas, la razón más citada para no estar inscritas en la escuela fue haber terminado todos los estudios que querían completar (56\%).

Tras el cierre de las escuelas en todo el país en marzo de 2020 , el $99 \%$ de las personas participantes de VOCES-19 inscritas en la escuela recibieron sus clases a distancia a través de una plataforma en línea, y muy pocas declararon haber recibido sus clases a través de la radio, la televisión o cuadernillos para llevar a casa. Aunque la mayoría de las personas participantes coincidieron en que disponían de los medios necesarios para acceder a las tareas en línea y presentarlas a lo largo de la pandemia, existen grandes desigualdades basadas en el ingreso y la etnicidad para estos indicadores. Por ejemplo, las personas del quintil socioeconómico más alto fueron 48 puntos porcentuales más propensas a reportar que podían acceder a sus tareas durante la pandemia comparadas con sus pares del quintil más bajo (79\% frente al 31\%). 


\section{La vulnerabilidad económica incrementó}

La mayoría de las personas participantes en VOCES-19 (71\%) consideraron que era algo probable o muy probable que su hogar recibiera menos ingresos en el año en curso (2020-2021) en comparación con el año anterior (2019). Estas preocupaciones económicas fueron señaladas con mayor frecuencia por las mujeres en comparación con los hombres, por las personas participantes I/ $A D$ en comparación con aquellas que no son I/ $A D$, y por las personas con menores ingresos en comparación con las personas con mayores ingresos.

Los resultados del estudio también muestran importantes desigualdades basadas en la riqueza y etnicidad para otros indicadores económicos de los hogares durante la pandemia. Por ejemplo, $16 \%$ de las personas encuestadas pertenecientes al quintil socioeconómico más bajo declaró que su hogar casi nunca o nunca pudo pagar cuentas importantes, como la renta, durante la pandemia, en comparación con sólo $2.6 \%$ del quintil más alto. Las personas participantes I/ AD también reportaron con mayor frecuencia lo anterior en comparación con las personas participantes que no son I/AD (11\% vs. $6.2 \%$ ).

\section{La salud mental y las relaciones sociales sufrieron}

Los resultados del estudio muestran que $69 \%$ de las y los adolescentes y personas jóvenes experimentaron síntomas asociados con depresión, mientras que $62 \%$ experimentó síntomas asociados con ansiedad. El 57\% de las personas participantes informó haber experimentado ambos. La prevalencia de sintomas asociados a depresión y ansiedad fue significativamente mayor entre adolescentes mujeres, mujeres jóvenes y personas no binarias, que entre los adolescentes hombres y hombres jóvenes.

Además, las personas adolescentes y jóvenes percibieron que a lo largo de la pandemia pasaron más tiempo en las redes sociales que antes (55\%) y que mantuvieron menos contacto con sus amigos que antes (51\%). Los resultados también ilustran algunas diferencias basadas en la etnicidad y la riqueza en el uso de ciertas estrategias de afrontamiento para lidiar con sentimientos problemáticos que han sentido desde el comienzo de la pandemia. Por ejemplo, casi $11 \%$ de las personas participantes del nivel socioeconómico más alto declararon haber recibido algún tipo de terapia psicológica por teléfono o mediante sesiones virtuales en algún momento desde el inicio de la pandemia, en comparación con $4.6 \%$ de las personas participantes del nivel socioeconómico más bajo.

\section{Los indicadores de salud también se vieron impactados}

La pandemia afectó la capacidad de las personas participantes de VOCES-19 y sus familias para acceder a los servicios de salud generales, así como a los servicios de salud sexual y reproductiva (SSR). Entre las que declararon que ellas/ellos o un miembro de su familia habían intentado utilizar un servicio de salud general después de marzo de 2020 , dos tercios (69\%) informaron que su acceso se había visto afectado de alguna manera, con tasas más altas reportadas por las participantes mujeres en comparación con los hombres, por adolescentes no binarios frente a los binarios, y por las personas participantes de los hogares de menores ingresos frente a las de mayores ingresos. 
Además, $20 \%$ de las y los adolescentes y $38 \%$ de las personas adultas jóvenes que intentaron obtener servicios de salud sexual y reproductiva (SSR) informaron que su acceso a estos servicios se había visto afectado de alguna manera por la pandemia. Los porcentajes fueron más altos entre las personas participantes de hogares con ingresos bajos comparadas con aquellas de ingresos altos.

Por último, entre las y los adolescentes que declararon haber consumido alguna sustancia al menos una vez en su vida, los opiáceos y otras drogas duras fueron las sustancias cuyo consumo aumentó más desde el inicio de la pandemia (18\%). En el caso de las persons jóvenes, el aumento del consumo de cannabis fue el más reportado (21\%).
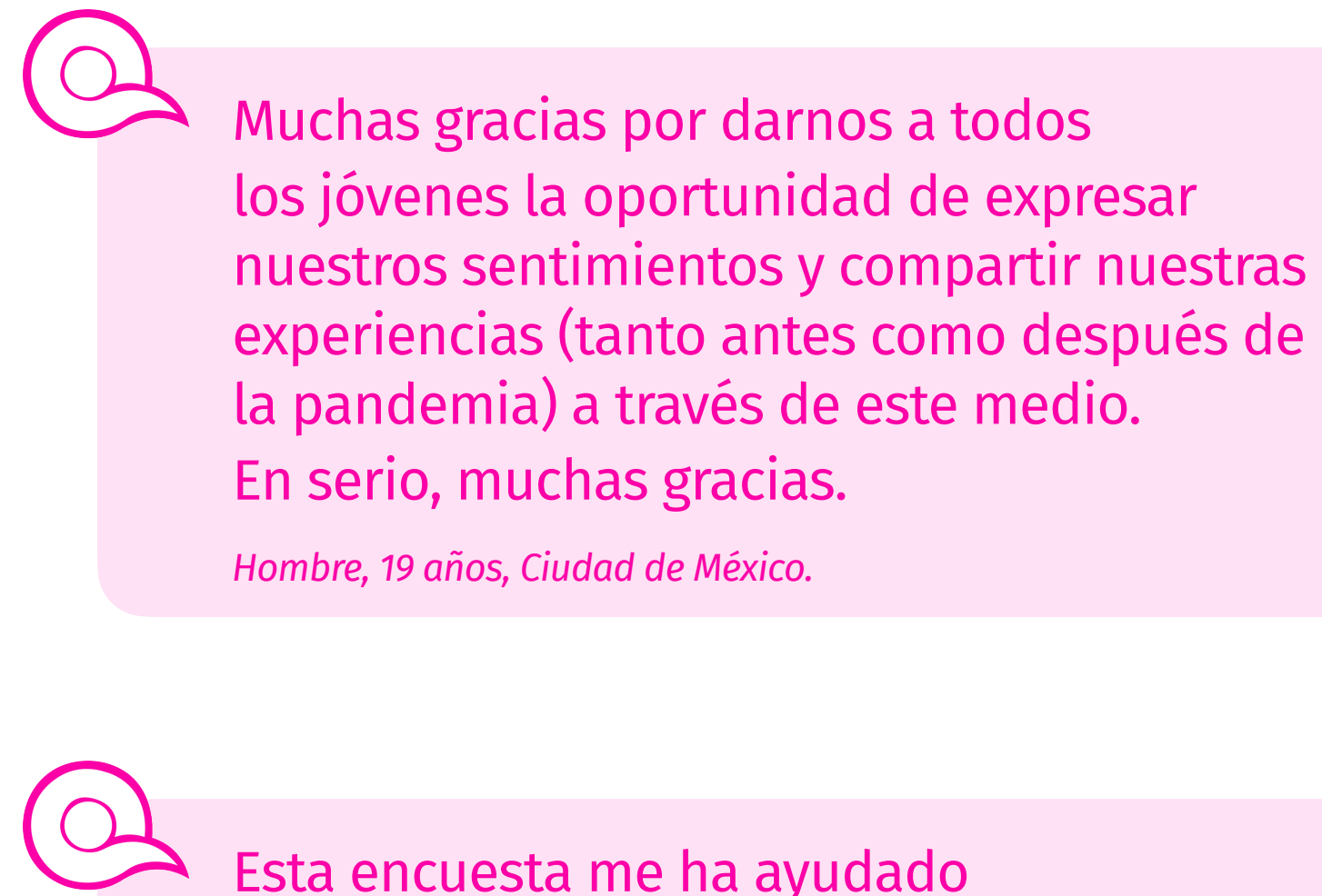

Esta encuesta me ha ayudado personalmente a reflexionar sobre lo que ha sucedido en mi vida y mi entorno durante la pandemia y a encontrar soluciones para mejorar mi salud emocional.

Mujer, 22 años, Chiapas. 


\section{Recomendaciones}

Al momento de redactar este informe, México se encontraba en medio de la tercera ola de la pandemia, con un número diario de nuevos casos superior a los picos anteriores. Si bien la letalidad general ha disminuido debido a la vacunación, esta tercera ola está afectando más directamente a las poblaciones más jóvenes, aumentando los casos sintomáticos entre niñas, niños, adolescentes y jóvenes.

Encontramos que los efectos indirectos de la COVID-19 y las medidas de mitigación asociadas también siguen afectando gravemente a las personas adolescentes y jóvenes mexicanas, a menudo de manera diferenciada según el género, la etnicidad y el estatus socioeconómico. Es probable que si no son abordadas, las desigualdades exacerbadas en el último año y medio permanezcan mucho tiempo después de que la pandemia haya terminado. La respuesta pública a la pandemia y a sus impactos multidimensionales debe reflejar esta realidad con intervenciones dirigidas a mejorar las condiciones de los grupos en mayor situación de vulnerabilidad.

\section{Programas de apoyo a las personas adolescentes y jóvenes relacionados con}

la violencia. Los resultados del estudio ponen de manifiesto la necesidad de prevenir y responder a tiempo a la violencia dirigida no sólo a las niñas y mujeres jóvenes, sino también a los adolescentes y jóvenes, así como a personas no binarias. Los hombres que participaron en el estudio se mostraron especialmente expuestos al aumento de la violencia sexual perpetrada contra ellos por alguien de su hogar, lo que señala la necesidad de centrar la atención en este asunto y aumentar nuestra comprensión de por qué se produce y cómo puede prevenirse. Otra necesidad identificada por VOCES-19 fue la de aumentar la información sobre cómo identificar, prevenir y evitar el acoso virtual, así como la de proteger los datos personales.

Estrategias de recuperación de la educación. En el futuro, las estrategias educativas deben estar diseñadas para satisfacer las necesidades de las personas en mayor situación de vulnerabilidad y estar dirigidas a minimizar los impactos negativos a largo plazo asociados con la pérdida de más de un año de educación de calidad. Dependiendo del entorno particular, las soluciones basadas en la evidencia serán fundamentales para garantizar que las personas más vulnerables no abandonen la escuela prematuramente (por ejemplo, proporcionando transferencias de dinero en efectivo), y evaluando los niveles de aprendizaje de las y los estudiantes cuando regresen a la escuela con el fin de abordar mejor lo que pueden ser niveles significativos de pérdida de aprendizaje.

Brecha digital. El acceso desigual a Internet también seguirá teniendo repercusiones educativas para las personas jóvenes que forman parte de grupos étnicos minoritarios y los de menor nivel socioeconómico, agravando aún más las brechas educativas preexistentes. Aumentar el acceso a puntos gratuitos de Internet y aplicar estrategias alternativas a la enseñanza a distancia en las comunidades rurales y de difícil acceso podría ser una forma de reducir esta brecha. 
Empoderamiento económico para adolescentes y jóvenes. La incrementada vulnerabilidad de las personas jóvenes que viven en pobreza debe ser considerada en el diseño e implementación tanto de las políticas nacionales de recuperación económica de COVID como de los programas sociales y de salud dirigidos a las juventudes. México tiene una rica experiencia en programas de empoderamiento económico. Necesitamos una investigación rigurosa para entender mejor qué programas son más efectivos para los diferentes subsectores de la juventud, y qué enfoques fueron efectivos para mitigar los impactos de la pandemia de COVID-19 en particular.

\section{Aumentar el acceso a la atención a la salud para las comunidades de bajos} ingresos y poner en marcha intervenciones de salud mental específicas para las personas jóvenes, las mujeres y las poblaciones no binarias. El impacto de la pandemia en la salud mental de las juventudes tendrá un efecto duradero. Como primer paso, debemos difundir ampliamente -a las principales partes interesadas y al público en general- información sobre los retos de salud mental a los que se enfrentan las personas adolescentes y jóvenes. Necesitamos una investigación rigurosa sobre cuáles son los enfoques más eficaces para que los servicios de salud, incluidos los de salud mental, sean más accesibles para todas las personas. Esto debería implicar una consideración explícita de las necesidades y perspectivas diferenciadas basadas en el género, la edad, la etnicidad y los recursos.

En cuanto al acceso a los servicios de salud sexual y reproductiva, el asesoramiento y el acceso a una amplia gama de métodos anticonceptivos son fundamentales ahora más que nunca.

El acceso debe incluir no sólo métodos anticonceptivos, sino también servicios de asesoramiento para que las personas jóvenes puedan elegir el mejor método anticonceptivo para ellas. Es necesario investigar la mejor manera de proporcionar información y asesoramiento sobre salud sexual y reproductiva a través de diversos canales, incluidos los servicios de telemedicina y las estrategias basadas en la comunidad.

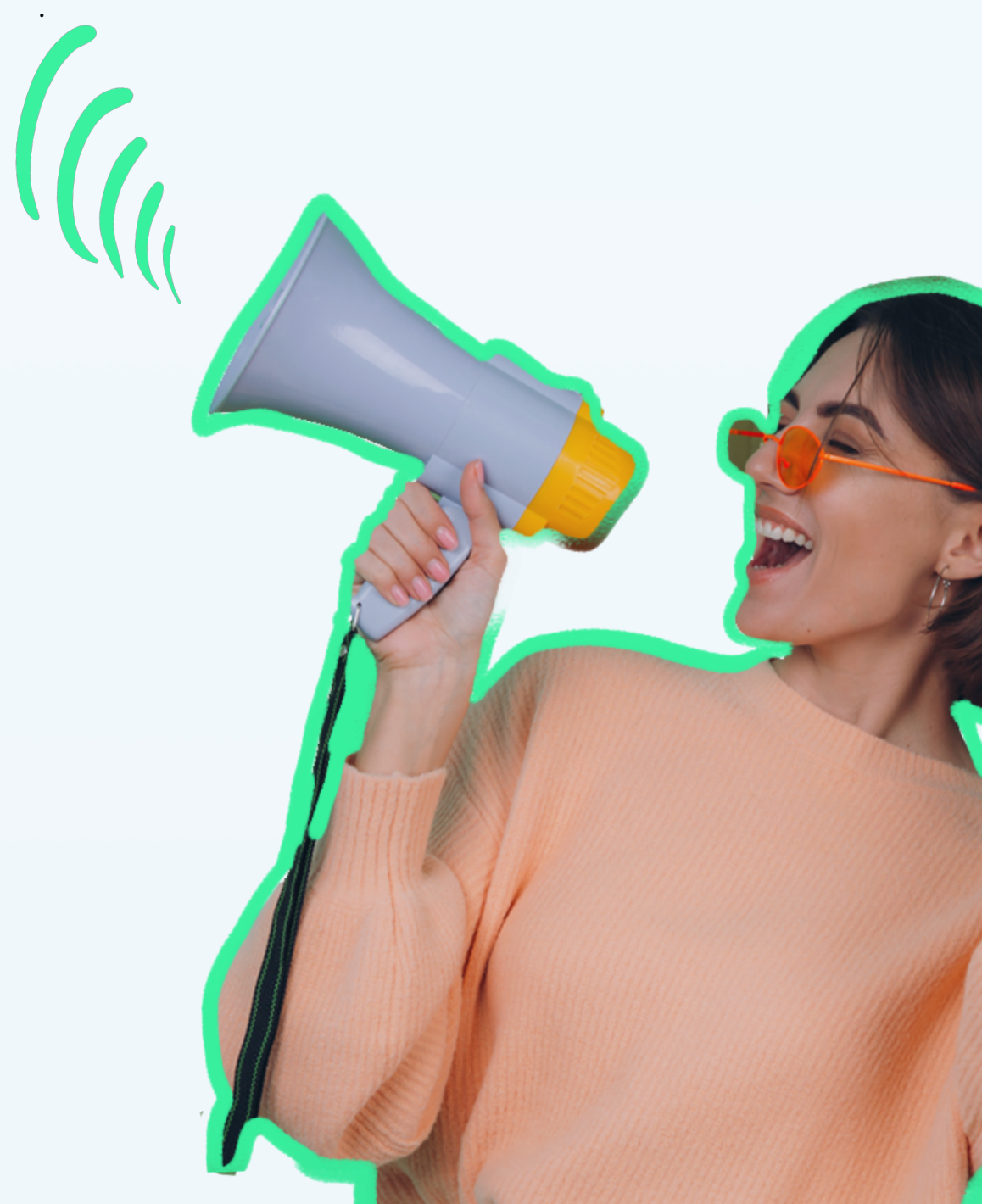




\section{Introducción}

\section{La pandemia de la COVID-19 en México}

\section{México se encuentra entre los 20 países con mayor número de muertes por COVID-19 por}

cada 100.000 habitantes. Hasta el 19 de octubre de 2021, el país tenía un total de 3.76

millones de casos confirmados acumulados de COVID-19 y 284,477 muertes confirmadas

(Pettersson, Manley, \& Hernandez, 2021).

Los casos confirmados y las hospitalizaciones en México se concentran principalmente en personas de más de 50 años. Aproximadamente el $3.9 \%$ del total de casos confirmados se ha identificado en niñas, niños y adolescentes de 17 años o menos (Secretaría de Salud, 2021). Adicionalmente, se ha estimado un total de 686,879 muertes excedentes de COVID-19 en el país por el Institute of Health Metrics and Evaluation, con base en el escenario actual de proyección para el 1 de diciembre de 2021 (IHME, 2021).

El primer caso de COVID-19 en el país se registró el 27 de febrero de 2020, y la primera muerte causada por esta enfermedad el 18 de marzo de 2020. Después de esta fecha, el país aplicó varias estrategias lideradas por los gobiernos federal y locales para contener la propagación del virus. La primera estrategia fue la Jornada Nacional de Sana Distancia, implementada del 23 de marzo al 30 de mayo de 2020, cuyo objetivo era contener la pandemia del COVID-19. El cierre de escuelas fue obligatorio a nivel nacional, seguido de otras medidas que incluían 1) la promoción de medidas preventivas básicas entre la población (lavado frecuente de manos, estornudo de etiqueta, distanciamiento social y aislamiento en caso de síntomas); 2) la suspensión temporal de actividades no esenciales en los sectores público, privado y social; 3) la cancelación de eventos masivos con más de 5,000 personas; $y, 4$ ) la protección de las personas adultas mayores, y la reorganización del sistema de salud para aumentar la capacidad de atención a pacientes con COVID-19 severo (Secretaría de Salud, 2021). Se fomentó el uso de cubrebocas principalmente en espacios cerrados. Debido a los efectos previsibles de estas medidas en el acceso a los servicios de salud, el gobierno también puso en marcha políticas para mitigar las barreras, como la implementación de líneas telefónicas para apoyar a las y los pacientes con información sobre la COVID-19 y remitirlos a los servicios de salud, de apoyo/prevención de la violencia y de atención a la salud mental.

En junio de 2020, el gobierno federal implementó un sistema de monitoreo de "semáforo de riesgo epidemiológico" de cuatro colores, para alertar a las personas sobre los riesgos epidemiológicos en cada una de las 32 entidades federativas del país y orientar sobre la posibilidad de permitir ciertas actividades sociales y económicas. Esto incluía la reapertura de escuelas, que se permitía en los municipios coloreados en verde, ya que se consideraban de bajo riesgo epidemiológico (Secretaría de Educación Pública, 2021). Aunque la estrategia del semáforo orientó las medidas de 
mitigación del COVID-19, el grado de implementación varió entre los municipios y los estados.

También hubo una amplia cobertura por parte del gobierno en los medios de comunicación en relación con la pandemia de COVID-19. Se realizaron conferencias de prensa diarias en la televisión de acceso público para informar al

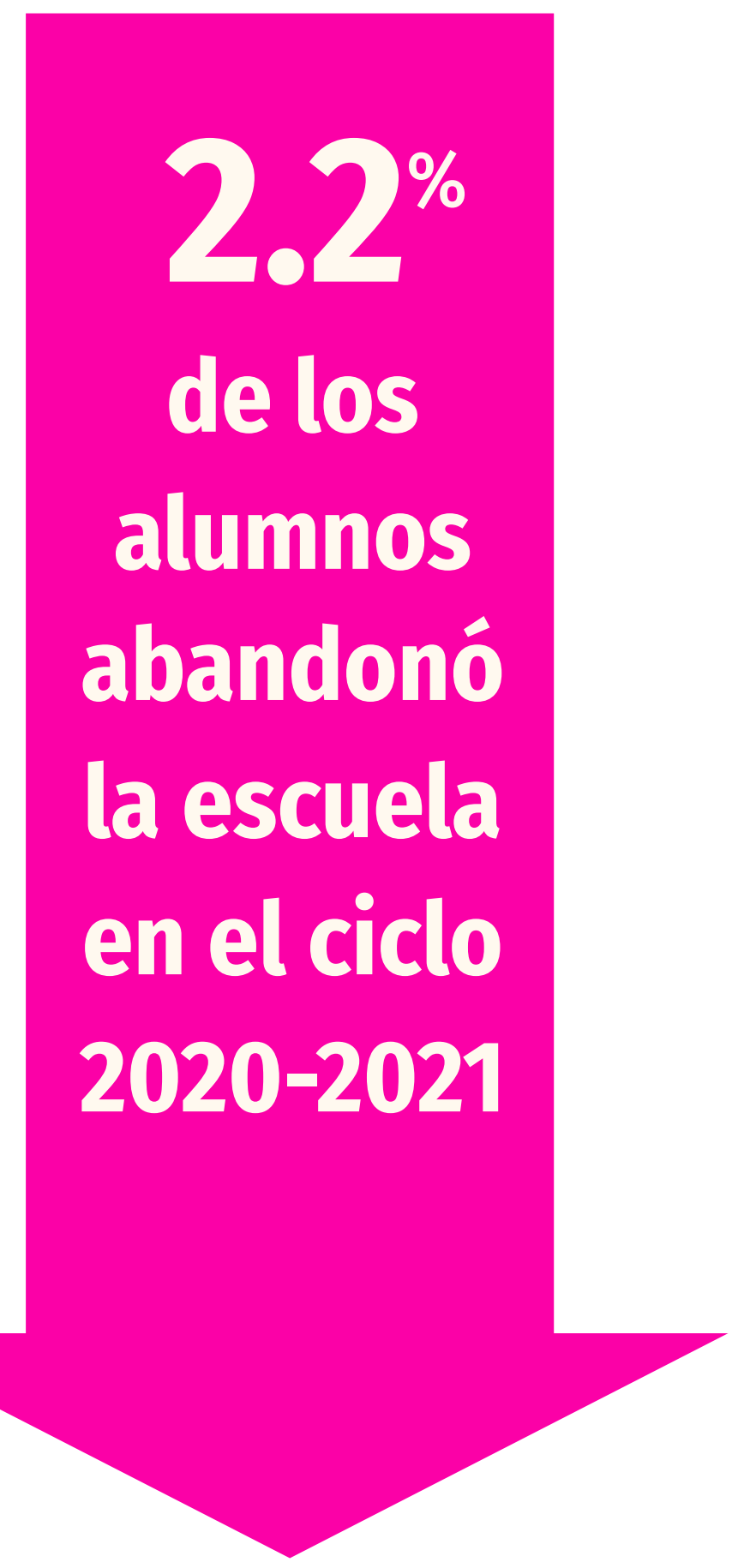

público sobre la progresión de la pandemia en el país.

El 23 de agosto de 2021 se reanudaron las clases presenciales en las escuelas públicas a nivel nacional (Secretaría de Educación Pública, 2021). Como ejemplo del impacto de las medidas de mitigación en la educación, del total de alumnos inscritos en el ciclo escolar 2020-2021, el 2.2\% abandonó la escuela; el $58.9 \%$ de ellos mencionó la pandemia del COVID-19 como razón para abandonar la escuela y el $8.9 \%$ señaló la falta de recursos (INEGI, 2020b).

\section{El contexto mexicano: desigualdades y aspectos en la salud antes y durante la pandemia de COVID-19}

Las brechas de ingresos han caracterizado durante mucho tiempo a la economía mexicana. Según el índice GINI, México es uno de los países más desiguales de la OCDE, sólo después de Chile y Costa Rica (OECD, 2021). En 2020, el $43.9 \%$ de la población vivía en pobreza, frente al $41.9 \%$ en 2018 (CONEVAL, 2021). Estas situaciones son más críticas en las zonas rurales, donde el $56.8 \%$ de la población se considera pobre y el $16.7 \%$ se considera extremadamente pobre (CONEVAL, 2021).

Las desigualdades educativas, laborales, de género, étnicas y económicas también están presentes desde hace tiempo en el escenario socioeconómico mexicano. Por ejemplo, el promedio de años de escolaridad en el año 2000 era de 7.5 años. Sin embargo, algunos de los estados con mayor rezago económico, como Chiapas, tenían un nivel educativo significativamente menor (5.4 años), 
especialmente para las mujeres (4.9 años). En 2020 esta brecha se mantuvo: según el reciente censo (2020), el promedio de años de escolaridad en el país era de 9.7; sin embargo, en Chiapas era de 7.8. Hay una brecha de 3.7 años entre este estado y el promedio de la Ciudad de México (11.5), que tiene las tasas de educación más altas del país (INEGI, 2020a).

En términos de acceso a la atención a la salud, México se enfrenta a varias barreras estructurales e institucionales: el bajo gasto en salud (3.2\% del PIB total en comparación con el $6 \%$ recomendado), la fragmentación del sistema de salud, las deficiencias de recursos presentes incluso antes de la pandemia y la implementación aún incompleta de un sistema de salud centrado en la atención comunitaria y primaria. Además, debido a la configuración fragmentada del sistema de salud, los cambios en las tasas de empleo representan cambios en la disponibilidad de estos servicios para las personas y sus familias.

En 2020, las tasas de desempleo aumentaron de 43.9 en abril a 48.4 en junio (Consejo Nacional de Evaluación de la Política de Desarrollo Social, 2021). Las tasas de afiliación al Instituto Mexicano del Seguro Social (IMSS), el mayor subsistema de salud y seguridad social para la población trabajadora, fueron 4.2 puntos porcentuales menores en el tercer trimestre de 2020 en comparación con el mismo trimestre de 2019, lo que representa las tasas de afiliación más bajas de los últimos 10 años (Consejo Nacional de
Evaluación de la Política de Desarrollo Social, 2021).

\section{En CDMX}

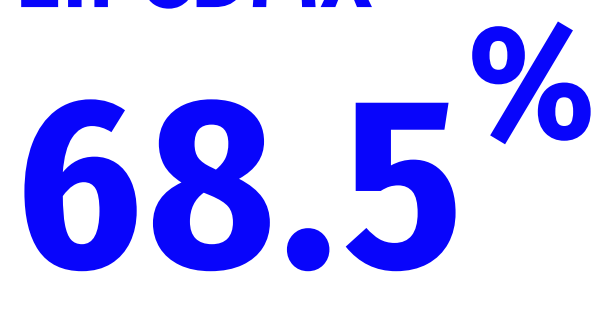

\section{de las familias}

con niños y

adolescentes

informaron

\section{de una disminución de sus ingresos durante la pandemia}

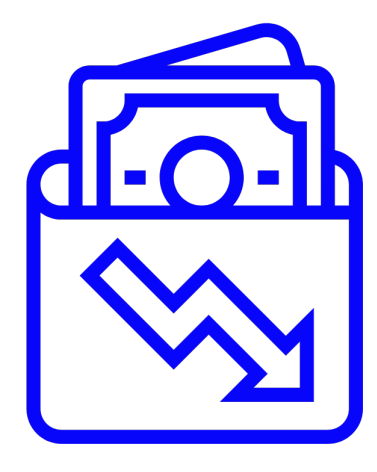


La pandemia también tuvo impactos diferenciados entre los distintos segmentos de la población en cuanto a los aspectos sociales, particularmente para los hogares con adolescentes y niños. Por ejemplo, en la Ciudad de México, el $68.5 \%$ de las familias con niños y adolescentes informaron de una disminución de sus ingresos durante la pandemia (Consejo Nacional de Evaluación de la Política de Desarrollo Social, 2021). El desempleo, principalmente en el sector informal, también fue mayor para las familias que viven en la Ciudad de México (10.2\%) en comparación con el promedio nacional (8.3\%) (Instituto Nacional de Estadística y Geografía, 2021). En cuanto a la seguridad alimentaria, la situación era preocupante, ya que el $26 \%$ de la población declaraba sufrir inseguridad alimentaria (UNICEF México, 2020).

La pandemia también ha exacerbado las desigualdades de género previamente existentes, aumentando la exposición a la violencia de género y la carga de trabajo no remunerado y las tareas del hogar para las mujeres (Peterman, O'Donnell, \& Palermo, 2020). Esto ha tenido impactos en el mercado laboral porque las barreras en un campo afectan al otro debido a la asignación de tiempo y al aumento del trabajo no remunerado (UNICEF México, 2020).

\section{COVID-19, juventudes e impactos sociales}

Los jóvenes se verán muy afectados por las consecuencias a largo plazo de la pandemia. Varias organizaciones internacionales y organismos de las Naciones Unidas han advertido del impacto duradero de la pandemia del COVID-19, aunado a los efectos del cambio climático, en la educación, la salud sexual y reproductiva (SSR), la salud mental, la exposición a la violencia y los aspectos laborales de las juventudes.

En México, así como en otros países del mundo, se ha identificado un aumento de la violencia de género contra mujeres y niñas desde el inicio de la pandemia. Datos en México, tras la aplicación de las medidas de distanciamiento social, identificaron un aumento en el número de llamadas realizadas al número de emergencias 911 de entre el $30 \%$ y el $100 \%$ (dependiendo del subanálisis realizado a nivel estatal). La Red de Refugios para atender casos de violencia de género también registró un incremento del $5 \%$ en los ingresos de mujeres y un aumento del $60 \%$ en el apoyo y asesoría brindada vía telefónica, por redes sociales y correos electrónicos (FernándezNieto, 2020).

\section{Entre $30 \%$ y $100 \%$ de aumento}

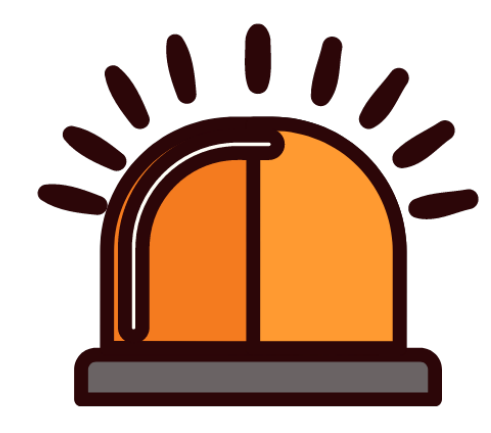

\section{en el número de}

llamadas realizadas

al número de

emergencia 911. 
Al comienzo de la pandemia, se esperaban grandes retrocesos en aspectos relacionados a la salud sexual y reproductiva, ya que aproximadamente 47 millones de mujeres y niñas de 114 países de ingresos bajos y medios no podrán acceder a medidas anticonceptivas debido a las medidas de distanciamiento social y a la falta de acceso a los servicios de SSR, con un aumento estimado de 7 millones de embarazos no deseados y potencialmente miles de muertes por abortos inseguros y partos complicados (UNFPA, 2020; Cousins, 2020). Una revisión exploratoria de los estudios realizados entre diciembre de 2019 y octubre de 2020 destacó que la pandemia había interrumpido el acceso a la SSR en todo el mundo. Por ejemplo, los estudios incluidos en la revisión informaron del acceso a las pruebas del VIH y del acceso a los antirretrovirales y a la prescripción de la PrEP, así como de la disminución del uso de métodos anticonceptivos. Además, casi todos los estudios que analizaron los comportamientos sexuales, informaron de una disminución en la frecuencia de las relaciones sexuales con parejas establecidas o casuales durante la pandemia en comparación con el período anterior (Afolabi Bolarinwa, et al., 2021).

Hasta la fecha, las personas han informado de elevados índices de estrés y ansiedad durante la pandemia. Sin embargo, a medida que la pandemia avanza y sigue afectando a las actividades habituales, las rutinas y los medios de vida, se espera un aumento de los niveles de soledad, depresión, consumo nocivo de alcohol y drogas, y conductas autolesivas o suicidas (Organización Mundial de la Salud, 2020). Además, muchos países informaron de la interrupción de servicios de salud mental esenciales, de emergencia y que salvan vidas. Los servicios ambulatorios centrados en la comunidad y los servicios de prevención y promoción de la salud mental, así como los servicios para grupos de edad específicos (por ejemplo, adultos mayores y niños), se encontraban entre los más gravemente impactados (Organización Mundial de la Salud, 2020).

Como se mencionó en el apartado anterior, el impacto de la pandemia en la educación y el abandono escolar también es de gran importancia.
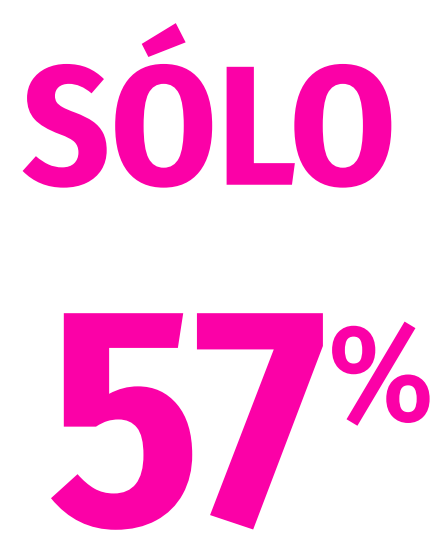

\section{de los estudiantes de 15 años en el país}

\section{tiene acceso}

\section{a una computadora en su casa}

La pandemia provocó el cierre masivo de las actividades escolares presenciales en las instituciones educativas, con más de 1.200 millones de estudiantes en todo el mundo, en todos los niveles, afectados por esta decisión. La mayoría de los países de la región de América Latina y el Caribe (LACAR) implementaron estrategias para seguir brindando educación (29 de 33 países). En 
México, el gobierno implementó varias

modalidades de educación a distancia (plataforma digital, radio y televisión). Sin embargo, de acuerdo con los hallazgos de la OCDE de 2018, sólo el 57\% de los estudiantes de 15 años en el país tiene acceso a una computadora en su casa y el $68 \%$ tiene acceso a una conexión a internet en su hogar (CEPAL-UNESCO, 2020). En los próximos años se deberán realizar estudios que produzcan evidencia sobre si y cómo la brecha académica debida a la pandemia impactará negativamente en el desarrollo a largo plazo de las personas adolescentes y jóvenes, así como si las estrategias de aprendizaje a distancia amplían la brecha de aprendizaje entre las personas jóvenes más y menos favorecidas.

La pandemia de COVID-19 ha exacerbado las desigualdades ya existentes en las sociedades y los diferentes grupos de población en casi todas las dimensiones sociales, económicas y sanitarias de la vida de las personas. Ya existe evidencia de cómo la distribución y la mortalidad del COVID-19 están asociadas a las condiciones ambientales y sociales preexistentes. Los impactos a corto, medio y largo plazo de la pandemia en las personas jóvenes también estarán probablemente asociados a estas desigualdades preexistentes, impactando a las personas de manera diferente dependiendo del género, la etnicidad y el estatus socioeconómico. Por ejemplo, un estudio llevado a cabo por el Instituto de Estudios Fiscales del Reino Unido encontró que las personas trabajadoras jóvenes, las de bajos ingresos y las autoempleados tenían más probabilidades de haber perdido su empleo o de haber experimentado un descenso de la actividad económica durante la pandemia (Blundell, Costa-Dias, Joyce, \& Xu, 2020).

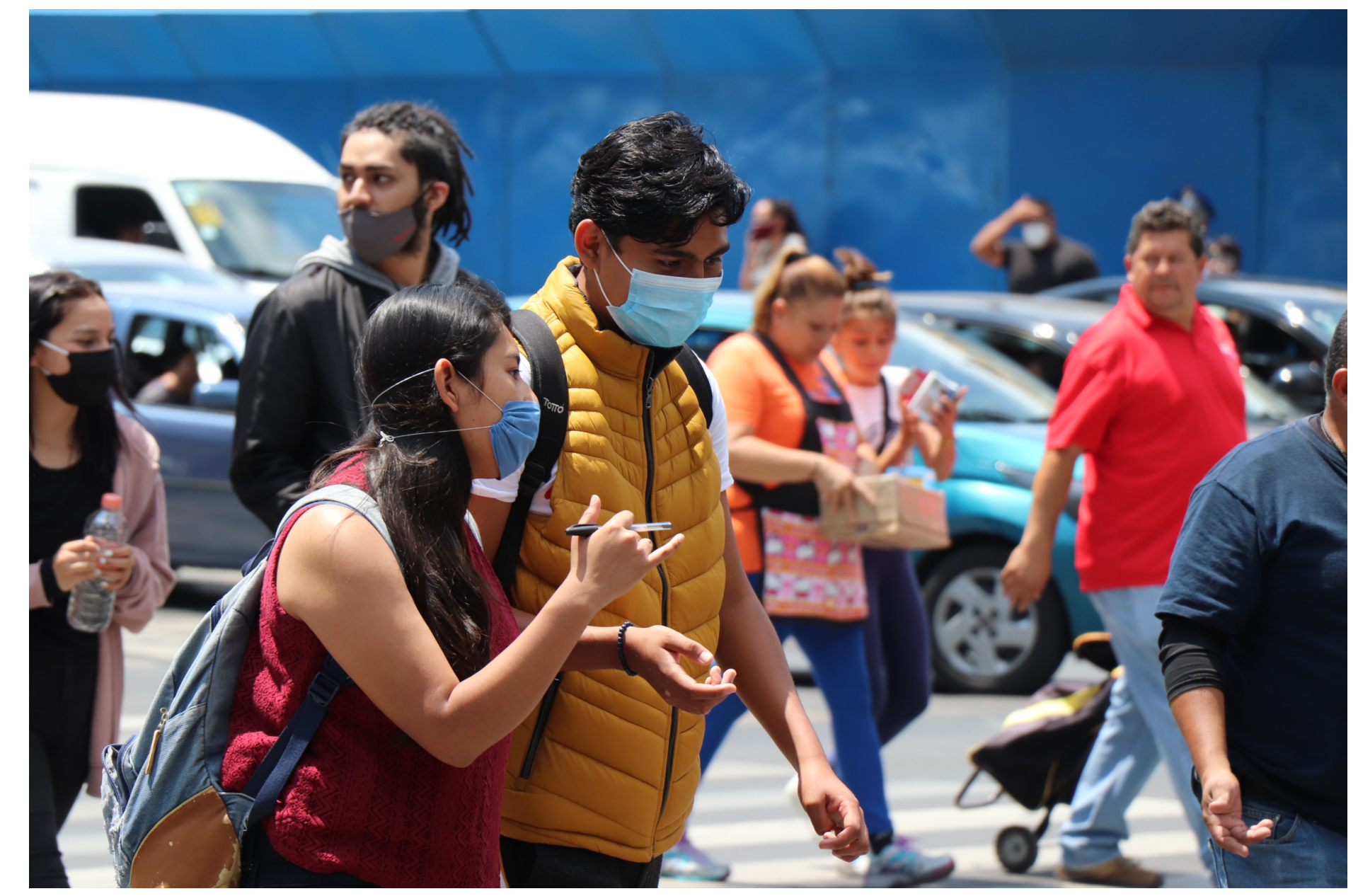


092103824634756344782368721931820 옥.

9o 0831849758467836784352983912019200

923754856748628978928928490921038246.

\section{Estudio VOCES-19: justificación}

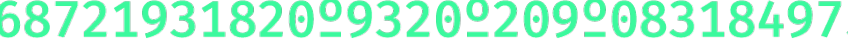
52983912019200382949237548567

En México y en muchos otros países, todavía hay poca evidencia sobre el impacto de la pandemia de COVID-19 en las experiencias de violencia entre personas adolescentes y jóvenes, así como el impacto de la pandemia en otros aspectos sociales, económicos y de salud relacionados con la violencia entre estos grupos de edad. Además, hay poca información sobre el impacto diferenciado de las medidas de mitigación del COVID-19 en función del género, el estatus socioeconómico y la etnicidad de adolescentes y jóvenes.

Otras instituciones en México han realizado encuestas en línea sobre experiencias de violencia y cambios en la dinámica familiar debido a las medidas de distanciamiento social implementadas durante la pandemia del COVID-19. Sin embargo, estos estudios se centran en la violencia de género en mujeres adultas. También se han realizado estudios por parte del Instituto Nacional de Estadística y Geografía (INEGI) sobre el impacto de la pandemia en los aspectos educativos y laborales.

Reunir información sobre los impactos no deseados de las medidas de distanciamiento social en las diferentes dimensiones de la vida de adolescentes y jóvenes no sólo proporciona datos descriptivos sobre la situación actual que viven estas poblaciones durante la pandemia, sino que también proporciona datos desglosados por género, etnicidad y estatus socioeconómico para que las personas responsables de las políticas públicas y las implementadoras de programas diseñen y apliquen estrategias de prevención y mitigación para reducir las consecuencias negativas a largo plazo de la pandemia en esta población tan importante.
978928928490921038246347563447823687

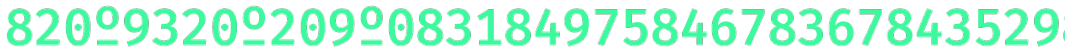
019200382949237548567486289789289284

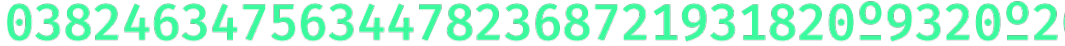
318497584678367843529839120192003829 548567486289789289284923578375468737 284983290921038246347563447823687219

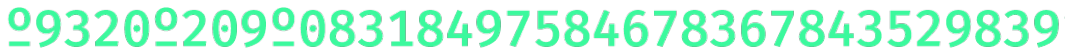
200382949237548567486289789289284909

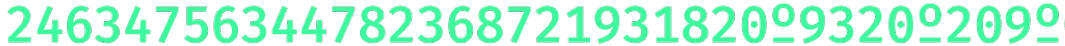
497584678367843529839120192003829492 567486289789289284909210382463475634 68721931820 -93200-2090083184975846783 529839120192003829492375485674862897 284909210382463475634478236872193182

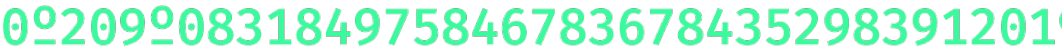
829492375485674862897892892849235783 737498292849832909210382463475634478

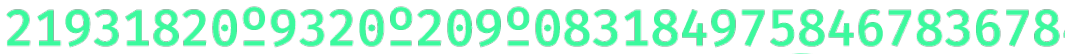

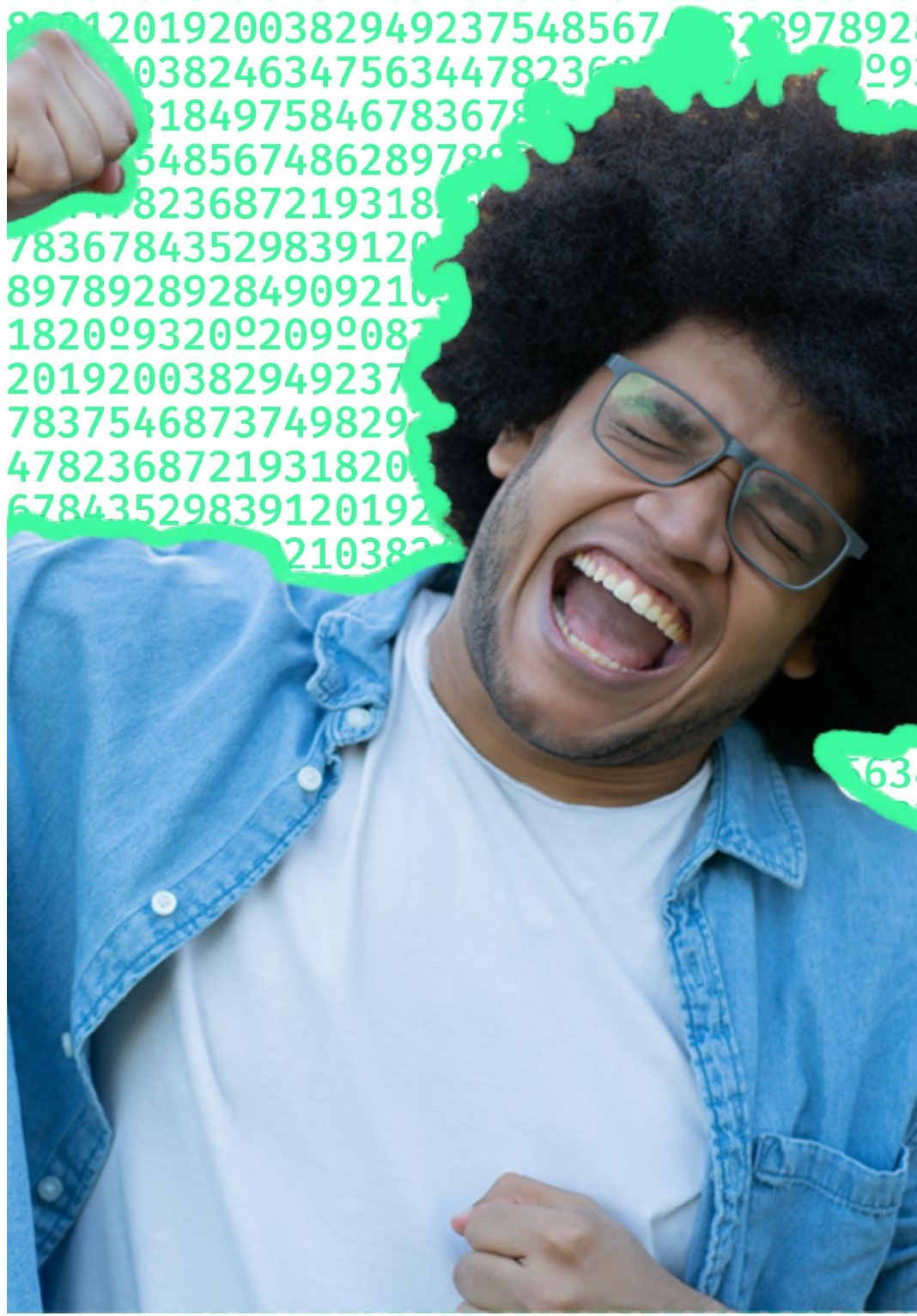


El objetivo general del estudio VOCES-19 es establecer una cohorte de adolescentes y jóvenes que vivan en México con el fin de comprender el impacto a corto y largo plazo de la pandemia COVID-19 en la experiencia y la percepción de la violencia en esta población, así como el impacto en otros aspectos sociales, económicos y de salud.

Prevemos que el estudio será dinámico y cambiante en respuesta a la situación, más que predeterminado. Sin embargo, a lo largo de todas las rondas de encuestas, mantendremos el enfoque en la exposición a la violencia y los factores que la impulsan entre adolescentes y jóvenes. A continuación, se presentan una serie de preguntas que guiaron la primera ronda de recolección de datos:

\footnotetext{
1 ¿Cuál es la prevalencia de la violencia experimentada por adolescentes y adultos jóvenes en sus hogares y en sus comunidades durante las medidas de distanciamiento social debido a la pandemia de COVID-19?
}

2 ¿Cómo están afectando las medidas de distanciamiento social por la pandemia de COVID-19 a las dimensiones social, económica y de salud mental de la vida de adolescentes y jóvenes? ¿Existe alguna diferencia en el impacto sobre estas dimensiones según el género, etnicidad y el nivel socioeconómico?

3 ¿Cuáles son los mecanismos de afrontamiento utilizados por adolescentes y jóvenes (diferenciando entre hombres y mujeres) para hacer frente a las situaciones adversas, incluida la violencia, durante las diferentes fases de la pandemia de COVID-19 (por ejemplo, mantener el contacto con amistades, comportamientos de búsqueda de ayuda, entre otros)?

En este reporte presentamos los resultados descriptivos de la primera ronda del estudio VOCES-19. Analizamos los datos por género, etnicidad y estatus socioeconómico para identificar qué subpoblaciones se han visto más afectadas por la pandemia. El informe está estructurado en cinco secciones:

1. Resumen ejecutivo

2. Introducción

3. Metodología

4. Resultados

5. Conclusiones y Recomendaciones 


\section{Metodología}

El estudio VOCES-19 fue diseñado para ser un estudio de cohorte longitudinal con al menos dos rondas de encuestas en línea. La primera ronda se llevó a cabo entre noviembre de 2020 y febrero de 2021. La segunda ronda se realizará entre noviembre de 2021 y febrero de 2022. Los resultados presentados en este informe son los de la primera ronda de encuestas.

El estudio se llevó a cabo en colaboración con el Instituto Nacional de la Juventud (IMJUVE) y el Centro Nacional de Equidad de Género y Salud Reproductiva (CNEGSR) de México, ambas instituciones gubernamentales con mandatos para trabajar con las juventudes a fin de mejorar sus condiciones de vida, incluida su salud sexual y reproductiva.

\section{Participantes}

Las poblaciones objetivo del estudio son personas adolescentes mexicanas de entre 15 y 17 años y personas jóvenes de entre 18 y 24 años que residían en México al momento del estudio.

El número de participantes necesario para la primera encuesta se definió en función de la prevalencia de la violencia en este grupo de edad. Como ésta es muy variable en todo el país, se siguió un enfoque conservador, buscando un tamaño de muestra que nos permitiera identificar una prevalencia del $50 \%$ con un margen de error del 5\%. Esto dio como resultado un tamaño de muestra de 384 participantes para cada área de estudio: 31 estados y 16 alcaldías de la Ciudad de México, con un número total previsto de 18.048 participantes en todo el país para la encuesta de línea base.

Para llegar a la población objetivo se utilizó tanto una invitación abierta a través de las redes sociales como una invitación dirigida a las personas jóvenes realizada por el IMJUVE y diferentes autoridades educativas. Posteriormente, las respuestas se ponderaron para el análisis con base en las características seleccionadas de la Encuesta del Censo 2020.

Dada la implementación en línea de la encuesta (para acceder a ella se requería tener acceso a una computadora con internet), incluso después de la ponderación post-estratificación (ver sección de Análisis de Datos), nuestra muestra aún difería de la mayoría de la población de personas jóvenes mexicanas en dos indicadores clave: el acceso a internet privado en sus hogares y la inscripción a la escuela, de acuerdo con la información recolectada en el Censo 2020 y otras encuestas nacionales realizadas por el Instituto Nacional de Geografía y Estadística (INEGI). Un mayor porcentaje de participantes en VOCES-19 reportó tener acceso a internet privado en sus hogares (78.8\%) en comparación con el porcentaje reportado por el INEGI de hogares en México que están conectados a internet (56.4\%) (Instituto Nacional de Estadística y Geografía, 2020).

Adicionalmente, $99 \%$ de adolescentes y $75 \%$ de jóvenes de nuestra muestra estaban inscritos en la escuela al momento de la encuesta, mientras que el INEGI reporta que sólo $63.1 \%$ de jóvenes de 16 a 18 años y $31.6 \%$ de 19 a 24 años estaban inscritos en el ciclo escolar 2020-2021 (Instituto Nacional de Estadística y Geografía, 2020). Estas diferencias deben ser consideradas al interpretar los resultados del estudio, ya que pueden no ser aplicables para una población sin acceso a internet. 


\section{Diseño del cuestionario}

El cuestionario empleado en la primera ronda incluyó los siguientes temas²:

Datos edad, estado de residencia, código postal, identidad de género, orientación sexual, sociodemográficos etnicidad, estado civil, y preguntas relacionadas a la educación y el trabajo.

Características tipo de hogar (familiar o no familiar), personas que viven en el hogar y acceso a del hogar diferentes servicios, incluida la conexión privada a Internet (Wi-Fi) en el hogar.

Preguntas relacionadas el cumplimiento de las medidas de mitigación

al COVID-19

Violencia exposición a la violencia en sus hogares perpetrada por alguien que vive con las personas participantes, presenciar actos de violencia contra otra persona miembro de la familia en el hogar, el acoso en línea, y la percepción de la seguridad en el hogar y en sus colonias/barrios.

Educación abandono escolar debido al COVID-19, estrategias para seguir estudiando en y aprendizaje casa, impacto de la educación a distancia en su capacidad para acceder y completar los deberes y las tareas escolares, impacto percibido en el aprendizaje e impacto en los planes a futuro relacionados con el aprendizaje.

Empleo y salud financiera familiar

no buscar trabajo debido a la COVID-19, percepción de perder su trabajo o ingresos en los meses siguientes debido a la COVID-19, pérdidas de trabajo en la familia debido a la COVID-19, percepción de reducción de los ingresos familiares desde el inicio de la pandemia, impacto en la capacidad del hogar para comprar alimentos, pagar facturas importantes o comprar medicamentos necesarios, y aplicación de medidas de prevención en el hogar desde el inicio de la pandemia de COVID-19.

Dinámicas del hogar y la división de las responsabilidades del hogar, la división de la toma de decisiones normas de género en el hogar, la administración de los ingresos del hogar, el abuso de sustancias de los padres y la salud mental de los padres, los cambios en el hogar, el Índice de Normas de Género y la condonación de la violencia contra las mujeres.

Salud el acceso a los servicios de salud, el bienestar y la salud mental (estrés, sensación de control sobre sus vidas, aislamiento, principales preocupaciones por su futuro, escalas PHQ-9 y GAD-7), y el consumo de sustancias.

Resiliencia recibir apoyos del Gobierno, mecanismos para lidiar con síntomas relacionados a la salud mental y contacto con amistades.

\footnotetext{
2 Para una revisión detallada de la encuesta, puedes acceder al siguiente enlace: https://dataverse.harvard.edu/dataset.xhtml?persistentld=doi:10.7910/DVN/X6JMPG
} 
Las preguntas fueron adaptadas de diferentes encuestas: la Encuesta Intercensal 2015 del Instituto Nacional de Estadística y Geografía (INEGI), el Censo 2020 (INEGI), la Encuesta Nacional de Juventud 2010 (IMJUVE), Household Pulse Survey 2020 (U.S. Census Bureau), COVID-19 Household Environment Scale (University of Miami), The Coronavirus Health Impact Survey (CRISIS), Epidemic - Pandemic Impacts Inventory (EPII), COVID-19 Kenya Study Round 4 (Population Council), Youth Truth Student Survey Students Weigh, COVID-19 Community Response Survey Guidance (JHU), ENCOVID (Universidad IBERO), Gender Attitudes Survey, Generation and Gender Survey, COVID-19 Impact on Health and Wellbeing Survey (Universidad de Texas), 2012 National Health Survey (INSP), Young People in Lockdown (The Prince's Trust y YouGov), Pew Research Center Online Harassment 2017, y la encuesta de las Naciones Unidas sobre la juventud de América Latina y el Caribe en el contexto de la pandemia de COVID-19. El Índice de Normas de Género fue adaptado de Björkman Nyqvist y Jayachandran (2017).

Para las escalas de depresión y ansiedad se utilizaron las escalas validadas en español de los cuestionarios PHQ-9 y GAD-7. Se utilizó una puntuación de corte de 5 o más puntos en ambas escalas para categorizar a participantes que presentaban o no presentaban síntomas depresivos o de ansiedad, respectivamente.

La encuesta se programó en Survey Monkey y se realizó una prueba piloto con aproximadamente 50 personas adolescentes y jóvenes, para evaluar si las preguntas eran comprensibles, el tiempo de respuesta y la relevancia de las preguntas formuladas.

Antes de que las personas participantes abrieran la encuesta, se les mostró un consentimiento informado para participar en ella. Al final de la encuesta también se preguntó sobre le interés de participar en las siguientes rondas de la encuesta. Se pidió información de contacto (correo electrónico y/o número de teléfono) a quienes aceptaron participar en las rondas de seguimiento.

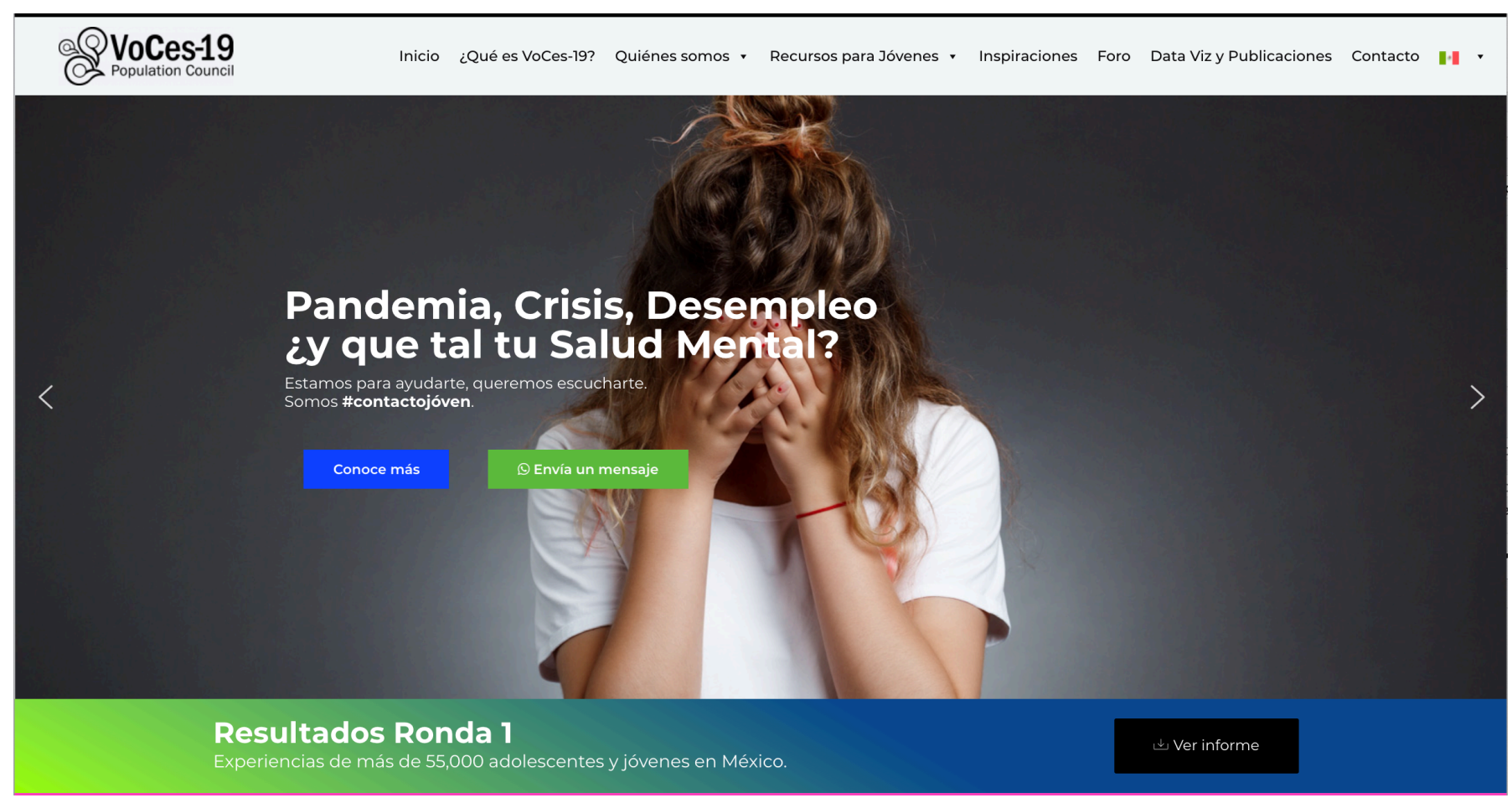

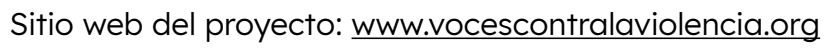




\section{Estrategias implementadas para llegar a las personas participantes}

Para alcanzar el número de participantes previsto, en septiembre de 2020 se creó una página web de VOCES-19 (https://vocescontralaviolencia.org), así como perfiles en Facebook e Instagram, para comenzar la difusión del estudio e iniciar la primera ronda de recolección de datos.

El enlace del cuestionario se distribuyó a través de diferentes estrategias: 1) Página web de VOCES-19 (https://vocescontralaviolencia.org) y redes sociales (Facebook e Instagram); 2) redes sociales del IMJUVE y contacto directo con los participantes de la Consulta Nacional de la Juventud (2019); 3) las plataformas de redes sociales del CNEGSR; 4) la página web de Jóvenes Construyendo el Futuro; 5) organizaciones y redes relacionadas con la juventud que el equipo del estudio contactó durante la aplicación de la encuesta (Fundación de Apoyo a la Juventud, IAP; Red Viral; programa del PNUD Construye-T); 6) anuncios de radio en diferentes estados en los que las tasas de respuesta eran bajas (Ciudad de México, Sinaloa y Sonora); 7) dos comunicados de prensa en enero y febrero de 2021; y, 8) a través de la Secretaría de Salud y la Secretaría de Educación y otras instituciones académicas (e.j. Colegio de Bachilleres), para que difundieran la información del estudio entre las y los estudiantes. En algunos estados, como Querétaro y Tabasco, las instituciones y organizaciones se enteraron del proyecto y lo compartieron con sus comunidades y socios, lo que llevó a un aumento importante de respuestas para estos estados.

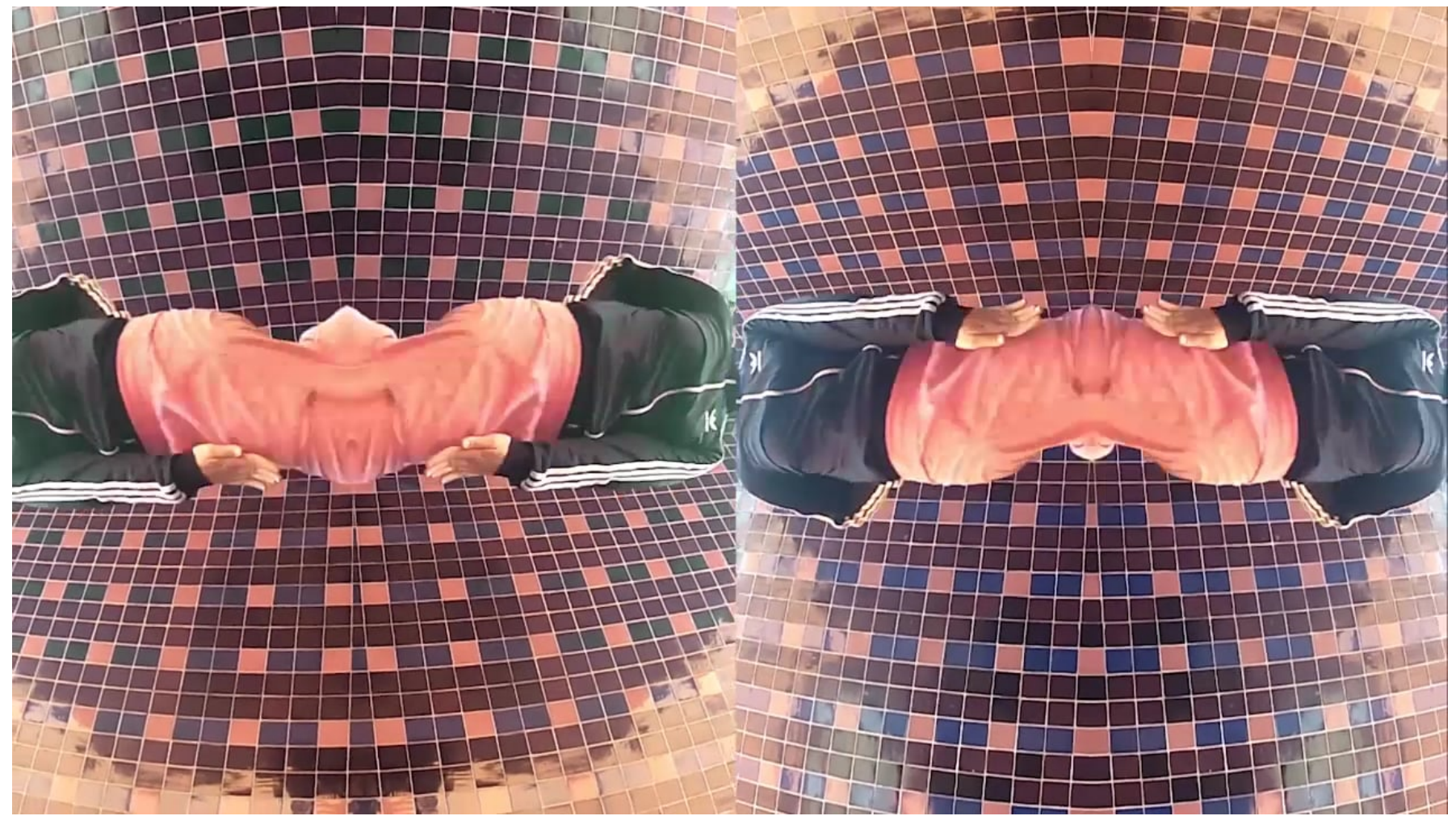

Vídeo de promoción de la primera ronda de la encuesta de VOCES-19 


\section{Estrategias de monitoreo}

Desde noviembre de 2020 hasta febrero de 2021, el equipo de investigación supervisó las respuestas diarias. Se desarrolló un monitor interactivo para analizar las respuestas con el fin de aplicar estrategias de difusión específicas adaptadas al grupo y a los Estados de los que estábamos recibiendo menos respuestas.

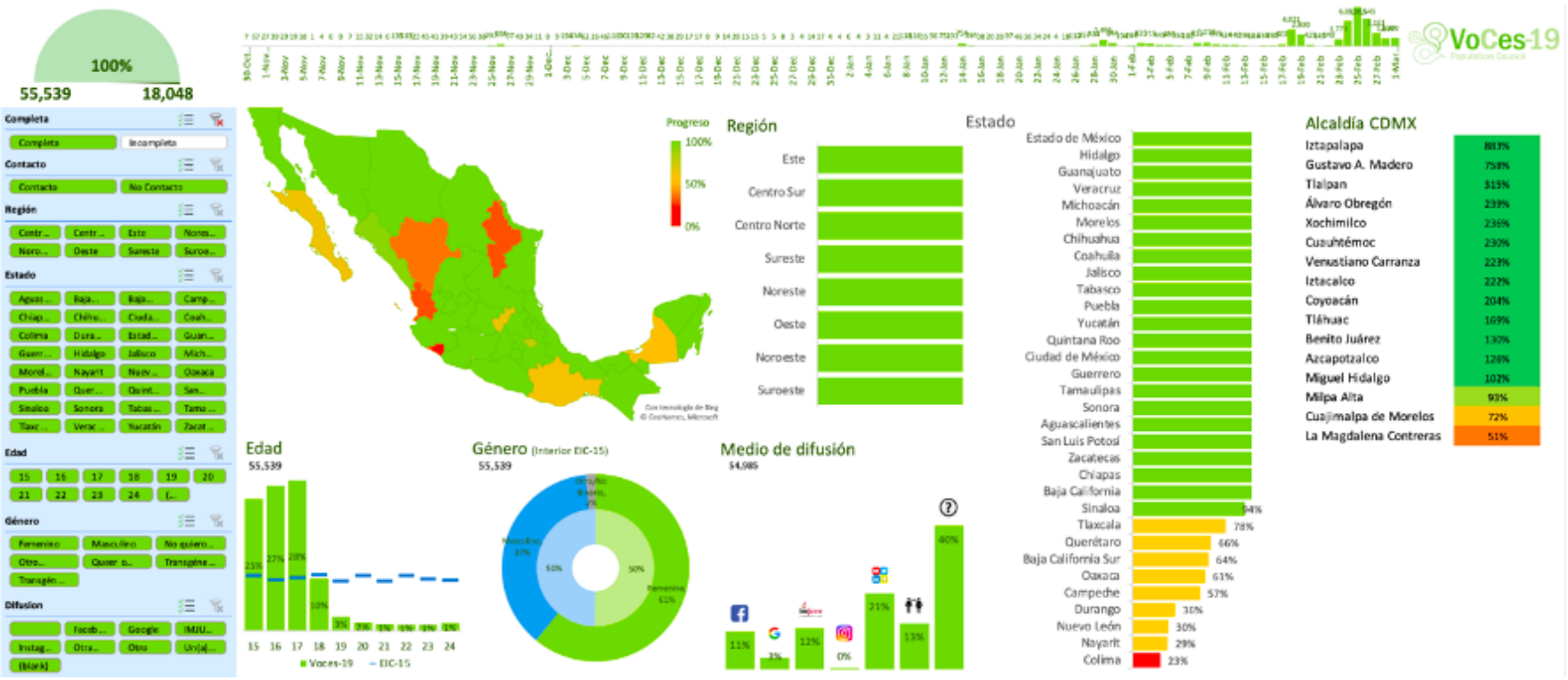

Monitor diario para la primera ronda del estudio VOCES-19

\section{Análisis de datos}

Una vez verificada la información del conjunto de datos y para dar cuenta de las diferencias en las distribuciones de las características sociodemográficas entre las personas entrevistadas y la población nacional de este rango de edad, para los análisis se aplicaron ponderaciones diferenciales para los individuos, con base en el estado de residencia, el nivel de ruralidad del municipio de residencia, el sexo y el grupo de edad. Este procedimiento aseguró que la contribución de cada observación en los indicadores presentados fuera equivalente al peso relativo del subgrupo específico en el total de la población entre 15 y 24 años de edad en México.

Después de aplicar las ponderaciones de postestratificación, realizamos un análisis descriptivo de las variables (frecuencias y promedios o medianas) y un análisis estadístico para comprobar las diferencias significativas por género (mujeres vs. hombres; y poblaciones binarias vs. no binarias). También se analizaron las diferencias entre los quintiles socioeconómicos más altos y más bajos, y entre los participantes indígenas y/o afrodescendientes (I/AD) y los no I/ AD.

Para realizar los análisis de los diferentes grupos socioeconómicos, se estimó una medida proxy del ingreso per cápita de los hogares para utilizarla como estratificador socioeconómico. Esta medida proxy es una imputación basada en las características del hogar y la vivienda y se utilizó como referencia la Encuesta Nacional de Ingresos y Gastos de México (ENIGH). Utilizando las variables disponibles tanto en las encuestas ENIGH y VOCES-19, se realizó una regresión del 
ingreso per cápita contra un conjunto de variables del hogar y la vivienda en la ENIGH y luego se utilizaron los coeficientes para imputar los valores de los participantes de VOCES-19. Los términos "quintil socioeconómico más alto", "hogares con ingresos altos" y "estatus socioeconómico más alto (SES) " se utilizan indistintamente en el informe para describir a las personas participantes de los hogares más ricos (quinto quintil). Los términos "quintil socioeconómico más bajo", "hogares de bajos ingresos" y "SES más bajo" se utilizan indistintamente en el informe para describir a las personas participantes de los hogares más pobres (primer quintil).

Para evaluar las diferencias en los promedios entre los grupos, se utilizó la prueba de Chicuadrada para las variables cualitativas y la prueba $U$ de Mann-Whitney para las variables cuantitativas. Diferencias con valores de $p \leq 0.05$ fueron consideradas significativas. Los intervalos de confianza del 95\% (IC 95\%) para todos los análisis se incluyen en las tablas descriptivas localizadas en el apéndice.

Por último, para incluir las voces de las juventudes en el informe, recuperamos los comentarios que las personas participantes dejaron al final de la encuesta. Aunque no aplicamos una estrategia formal de análisis cualitativo de los comentarios, sí (1) clasificamos los comentarios en dimensiones (educación, trabajo e ingresos, salud y violencia); (2) leímos todos los comentarios y resumimos los sentimientos generales de los participantes con respecto a esta dimensión; y (3) seleccionamos los comentarios que mejor representaban los sentimientos de los participantes con respecto a esa dimensión en particular.

\section{Consideraciones éticas}

El estudio fue aprobado por la Internal Review Board (IRB) del Population Council el primero de septiembre de 2020 (Número de Protocolo 949).

Antes de comenzar la encuesta, mostramos formularios de asentimiento (para adolescentes menores de 18 años) y de consentimiento (para jóvenes) a todas las personas participantes. En los formularios se explicaban los objetivos del estudio, la duración de la encuesta, los beneficios y los riesgos de participar, y la posibilidad de abandonar la encuesta en cualquier momento y no tener que responder a las preguntas que les hicieran sentirse incómodas o incómodos.

Al final de la encuesta, se mostró una lista de números de teléfono y sitios de Internet con información relevante sobre salud mental y violencia para que, si los participantes consideraban que necesitaban orientación sobre estos temas, pudieran tener la información a su disposición.

En cuanto a los beneficios de participar, sorteamos una tableta electrónica y 200 tarjetas telefónicas precargadas y distribuimos enlaces a clases gratuitas en línea (yoga, pintura, fitness y baile) entre las personas participantes que dejaron sus datos de contacto al final de la encuesta. Esto se mencionó explícitamente en los formularios de asentimiento y consentimiento y en diversos mensajes de difusión relacionados con la encuesta desde el inicio de las actividades de recolección de datos. 


\section{Limitaciones del estudio}

El presente estudio tiene varias limitaciones que vale la pena mencionar. La primera limitación es que los participantes no fueron parte de una muestra probabilística. Para tener en cuenta esta circunstancia, se aplicaron ponderaciones de post-estratificación a las observaciones, tal y como se ha comentado en la sección de análisis de datos.

La segunda limitación es el sesgo de selección inherente al diseño del estudio. Dado que VOCES-19 se realizó durante la pandemia de COVID-19 y cuando el gobierno mexicano estaba implementando el mandato de distanciamiento social, el estudio se conceptualizó como una encuesta en línea. Por lo tanto, sólo las personas jóvenes con acceso a Internet y a un teléfono celular, tableta o computadora podían participar en la encuesta. Esto excluyó del estudio a algunas de las poblaciones en mayor situación de vulnerabilidad y a otras con acceso limitado a Internet o a dispositivos electrónicos. En un esfuerzo por abordar al menos parcialmente esta limitación, el equipo de investigación decidió llevar a cabo un estudio paralelo con jóvenes en situación de calle en la Ciudad de México para capturar sus voces y experiencia, en el entendido de que este grupo comprende sólo una parte de la población a la que no pudimos llegar con la encuesta en línea. Este estudio se llevará a cabo en el último trimestre de 2021 y los resultados se presentarán en un informe separado.

La realización del estudio con encuestas en línea planteó limitaciones adicionales. Impidió al equipo de investigación realizar controles de calidad durante el proceso de recolección de datos y no pudimos validar algunas de las respuestas. No obstante, realizamos pruebas de consistencia interna para las escalas y los índices. El seguimiento de la cohorte también nos permitirá mitigar estas limitaciones.

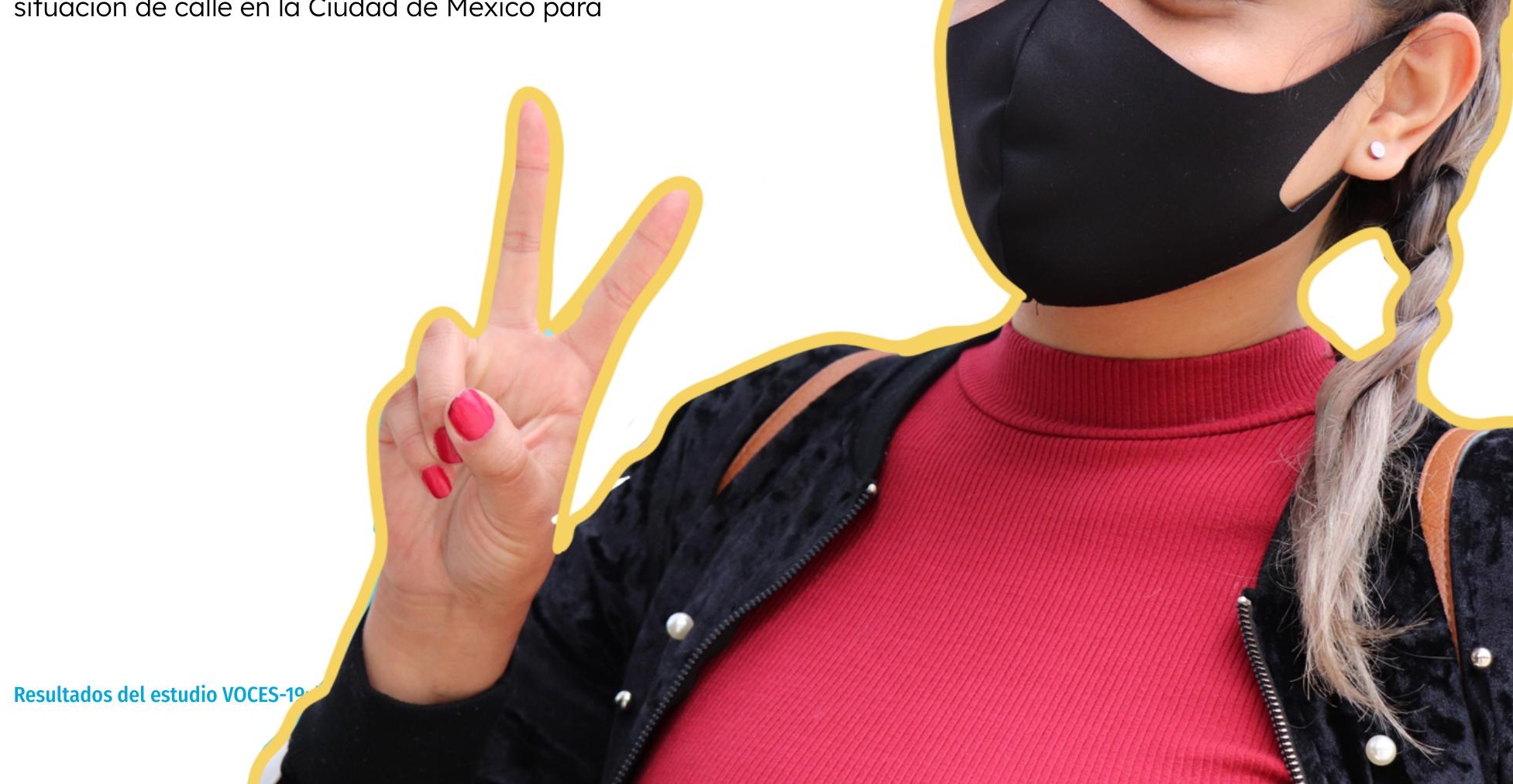


Otra limitación es que, para preservar el total anonimato de las respuestas, no recogimos las direcciones IP como parte de las encuestas en línea. Por lo tanto, no pudimos identificar las respuestas duplicadas o múltiples de las encuestas. El equipo de investigación analizó la información de las encuestas completadas en relación con el tiempo de finalización y las similitudes entre las respuestas de diferentes encuestados. Pudimos identificar 1.998 encuestas potencialmente duplicadas. Sin embargo, como no podíamos asegurar que estas respuestas fueran duplicadas, decidimos no eliminarlas.

Por último, es importante señalar que la implementación de las medidas de mitigación relacionadas con la pandemia difiere entre los municipios y a nivel estatal. Dado que las medidas de respuesta pública no fueron experimentadas de manera uniforme por las personas adolescentes y jóvenes en todo México, las afirmaciones hechas en este informe que conectan los resultados de la encuesta con las medidas de mitigación reflejan suposiciones por parte del equipo de investigación con respecto a las acciones públicas específicas a las que las personas participantes pueden haber estado expuestas.

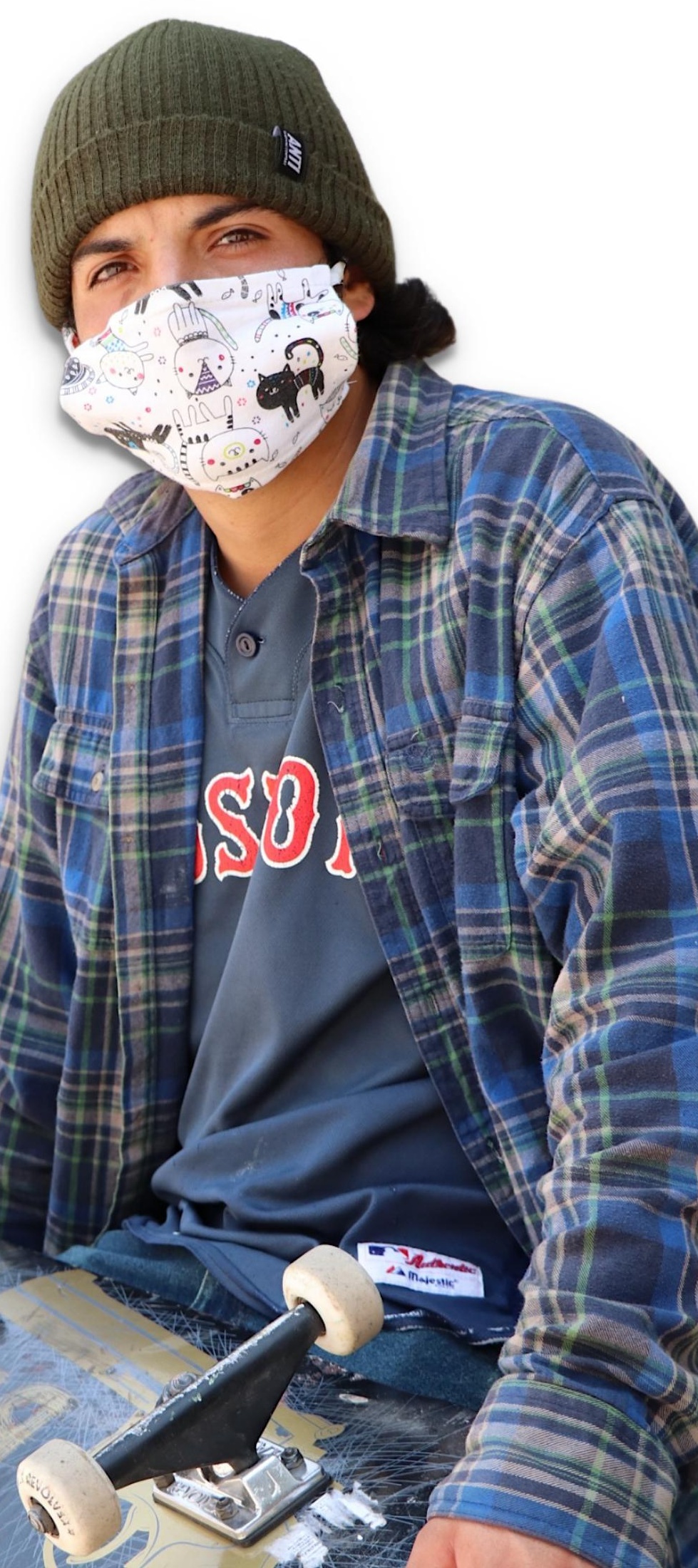




\section{Resultados}

Los principales hallazgos se reportan para cada una de las dimensiones estudiadas a través de la encuesta VOCES-19: cumplimiento de las medidas de mitigación de COVID-19, violencia, educación, empleo y salud financiera familiar, salud mental y resiliencia, y acceso a servicios de salud. Cada sección reporta los resultados descriptivos de las diferentes dimensiones e indicadores por separado para adolescentes y jóvenes, reconociendo las importantes diferencias en la etapa de la vida entre estas dos poblaciones.

En cada dimensión, se realizó un análisis para identificar diferencias significativas en indicadores específicos por identidad de género, etnicidad y estatus socioeconómico. Utilizamos tres categorías para la identidad de género: mujeres, hombres y personas no binarias. Para etnicidad, se hicieron comparaciones entre las personas participantes que se identificaban total o parcialmente como indígenas $\mathrm{y} / \mathrm{o}$ afrodescendientes (I/AD) y aquellas que no se identificaron con ninguno de los grupos étnicos (no I/AD). Por último, en cuanto al estatus socioeconómico, se analizaron las diferencias entre las personas participantes de los hogares con ingresos más bajos (primer quintil) y los más altos (quinto quintil). Para informar sobre estos últimos grupos, los términos "quintil socioeconómico más alto", "hogares con ingresos altos" y "estatus socioeconómico más alto (SES)" se utilizan indistintamente, al igual que los términos "quintil socioeconómico más bajo", "hogares con ingresos bajos" y "SES más bajo".

Todos los datos presentados en estas secciones son resultados ponderados, a menos que se indique lo contrario. Además, las diferencias indicadas en el texto y los gráficos de estas secciones son las que resultaron significativas al nivel de confianza del 95\%. Los resultados detallados y los intervalos de confianza de todos los indicadores se encuentran en la sección de apéndices al final de este informe.

\section{DIMENSIONES DEL ESTUDIO}
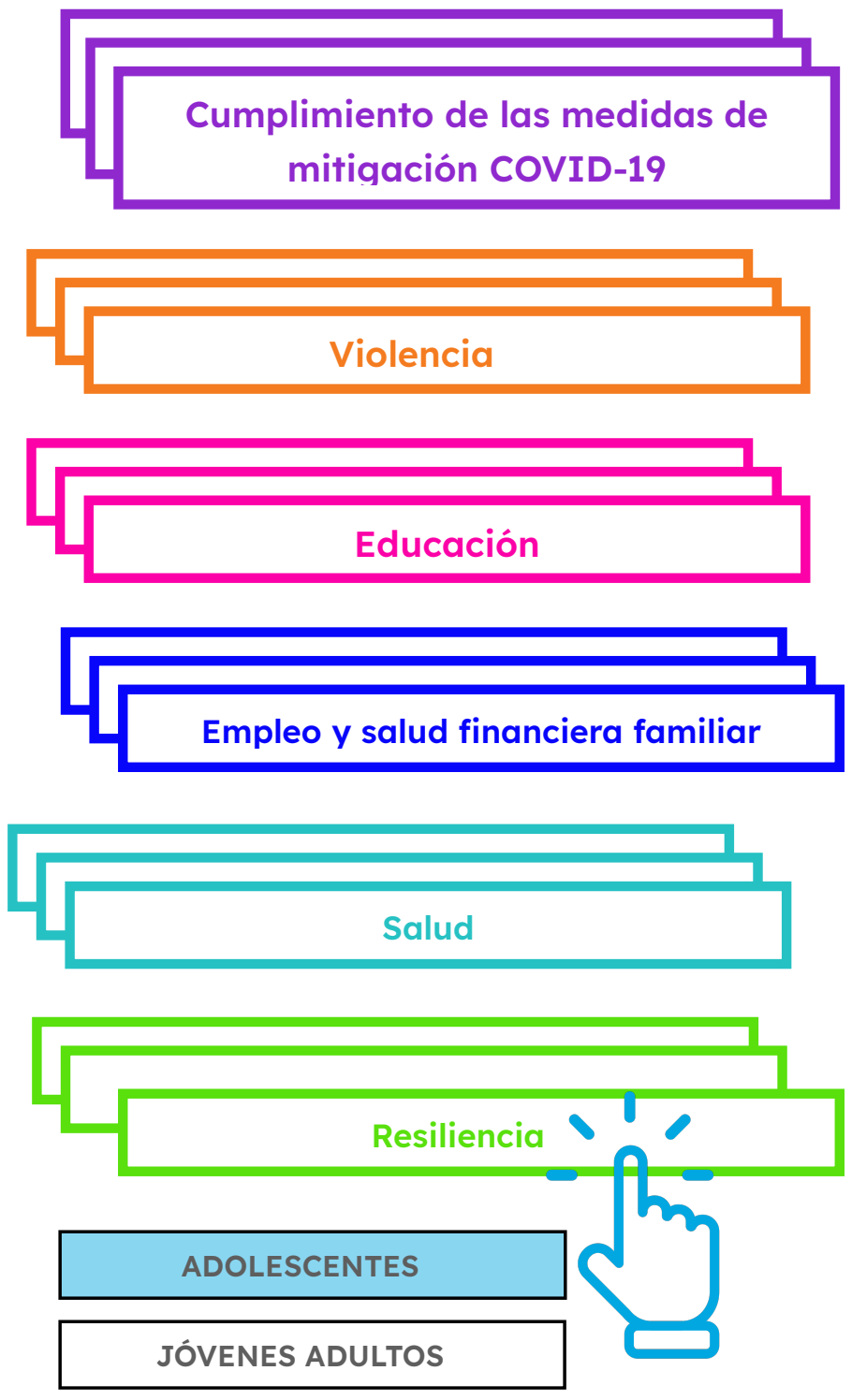

GÉNERO

ETNICIDAD

ESTATUS SOCIOECONÓMICO 
HALLAZGOS DEL REPORTE 


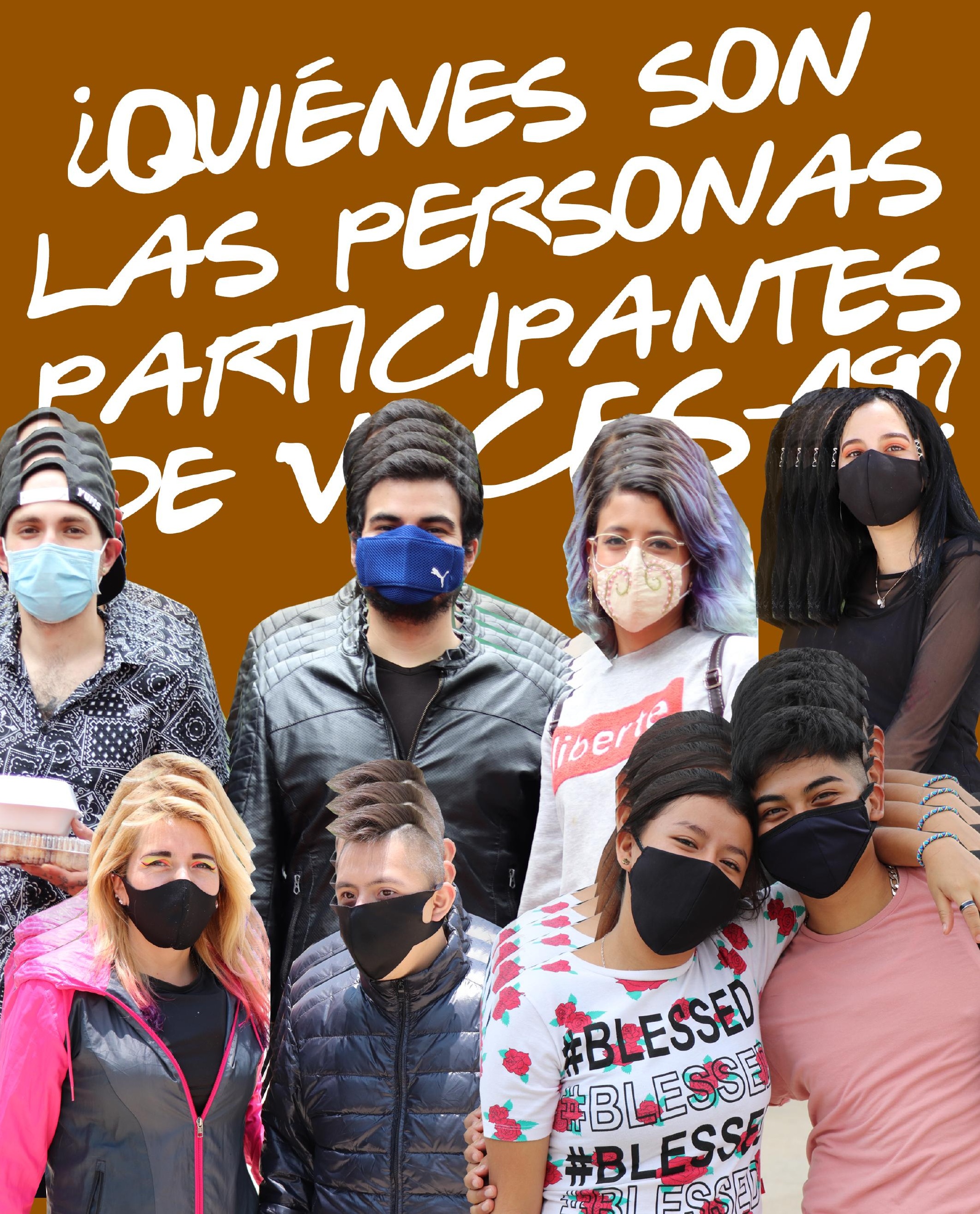




\section{Características sociodemográficas}

Desde noviembre de 2020 hasta febrero de 2021, 123,898 personas accedieron al cuestionario VOCES-19, y un total de 55,692 adolescentes y jóvenes de los 32 estados de México lo completaron. Los cinco estados con el mayor número de respuestas fueron la Ciudad de México $(n=16,228)$, el Estado de México $(n=10,893)$, Hidalgo $(n=3,588)$, Guanajuato $(n=3,127)$ y Veracruz $(n=2,086)$. Los cinco estados con el menor número de respuestas fueron Campeche $(n=217)$, Durango $(n=137)$, Nuevo León $(n=115)$, Nayarit $(n=113)$ y Colima $(n=89)$.

Las y los adolescentes de entre 15 y 17 años constituyeron el $31 \%$ de las personas participantes que completaron el cuestionario, mientras que las personas jóvenes de entre 18 y 24 años constituyeron el $69 \%$ restante. El promedio de la edad de las personas participantes fue de 19.2 años.

$51 \%$ de las personas encuestadas se identificó como mujer, $48 \%$ como hombre y $1.3 \%$ se definió como no binaria o con otra identidad de género. En cuanto a la etnicidad, $30 \%$ del total de participantes se autoidentificó total o parcialmente como indígena y/o afrodescendiente (ver Figura 1).
Tabla 1. Participación por estado

\begin{tabular}{|c|c|c|}
\hline Variable & $\mathbf{n}$ & Porcentaje \\
\hline Aguascalientes & 638 & 1.15 \\
\hline Baja California & 389 & 0.70 \\
\hline Baja California Sur & 245 & 0.44 \\
\hline Campeche & 217 & 0.39 \\
\hline Chiapas & 481 & 0.86 \\
\hline Chihuahua & 1,542 & 2.77 \\
\hline Coahuila & 1,532 & 2.75 \\
\hline Colima & 89 & 0.16 \\
\hline Mexico City & 16,228 & 29.1 \\
\hline Durango & 137 & 0.25 \\
\hline State of Mexico & 10,893 & 19.56 \\
\hline Guanajuato & 3,127 & 5.61 \\
\hline Guerrero & 985 & 1.77 \\
\hline Hidalgo & 3,588 & 6.44 \\
\hline Jalisco & 1,318 & 2.37 \\
\hline Michoacán & 1,625 & 2.92 \\
\hline Morelos & 1,560 & 2.80 \\
\hline Nayarit & 113 & 0.20 \\
\hline Nuevo León & 115 & 0.21 \\
\hline Oaxaca & 234 & 0.42 \\
\hline Puebla & 1,269 & 2.28 \\
\hline Querétaro & 252 & 0.45 \\
\hline Quintana Roo & 1,154 & 2.07 \\
\hline San Luis Potosí & 551 & 0.99 \\
\hline Sinaloa & 363 & 0.65 \\
\hline Sonora & 729 & 1.31 \\
\hline Tabasco & 1,315 & 2.36 \\
\hline Tamaulipas & 942 & 1.69 \\
\hline Tlaxcala & 300 & 0.54 \\
\hline Veracruz & 2,086 & 3.75 \\
\hline Yucatán & 1,157 & 2.08 \\
\hline Zacatecas & 518 & 0.92 \\
\hline Total & 55,692 & 100 \\
\hline
\end{tabular}

Figura 1. Características sociodemográficas de participantes VOCES-19. México.

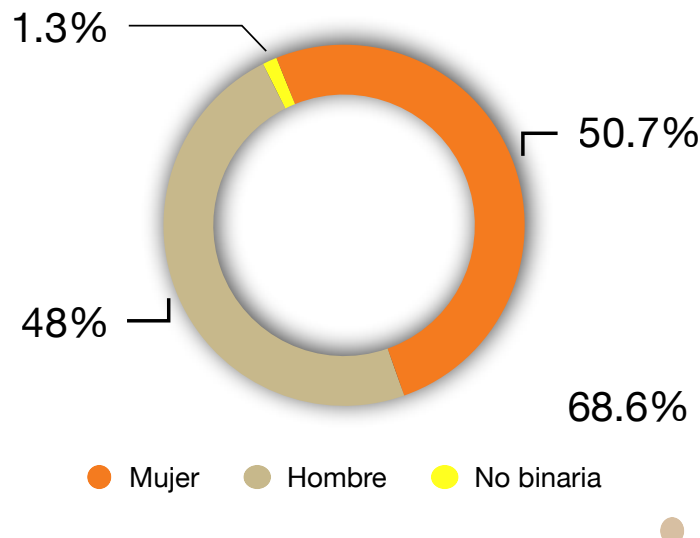

Género

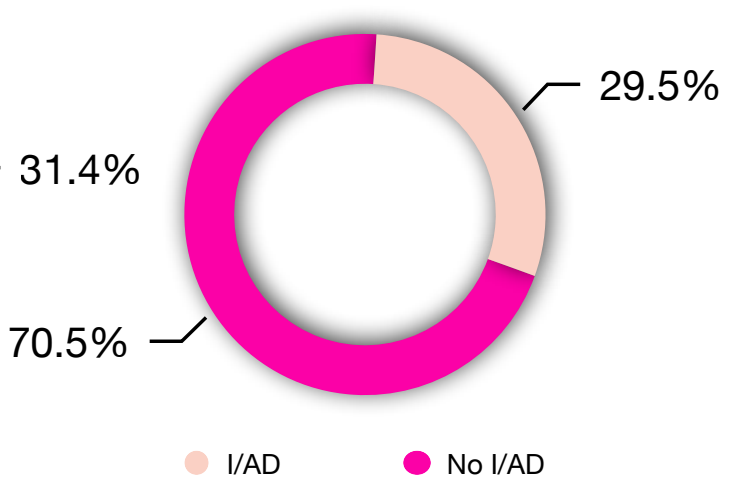

Etnicidad

\section{Grupo de edad}


La mayoría de las mujeres y hombres de ambos grupos de edad se identificaron como heterosexuales, con un mayor porcentaje de adolescentes masculinos heterosexuales en comparación con las adolescentes femeninas (90\% frente al $82 \%$ ). El 10\% de las personas adolescentes y jóvenes se identificaron como bisexuales, y $1.9 \%$ de adolescentes y $5.6 \%$ de jóvenes como homosexuales. Con respecto a la identidad de género, el $3.2 \%$ de las personas adolescentes y $2,3 \%$ de jóvenes se autoidentificaron con una identidad de género no binaria o con otra identidad de género (agénero, género fluido, entre otros). La mayoría de las personas participantes no binarias $(n=638$ ) en ambos grupos de edad se identifican como bisexuales $(55 \%$ en el caso de adolescentes y $50 \%$ en el de jóvenes) (ver Figura 2).

Figura 2. Orientación sexual de participantes VOCES-19, por género. Porcentajes. VOCES-19. México.

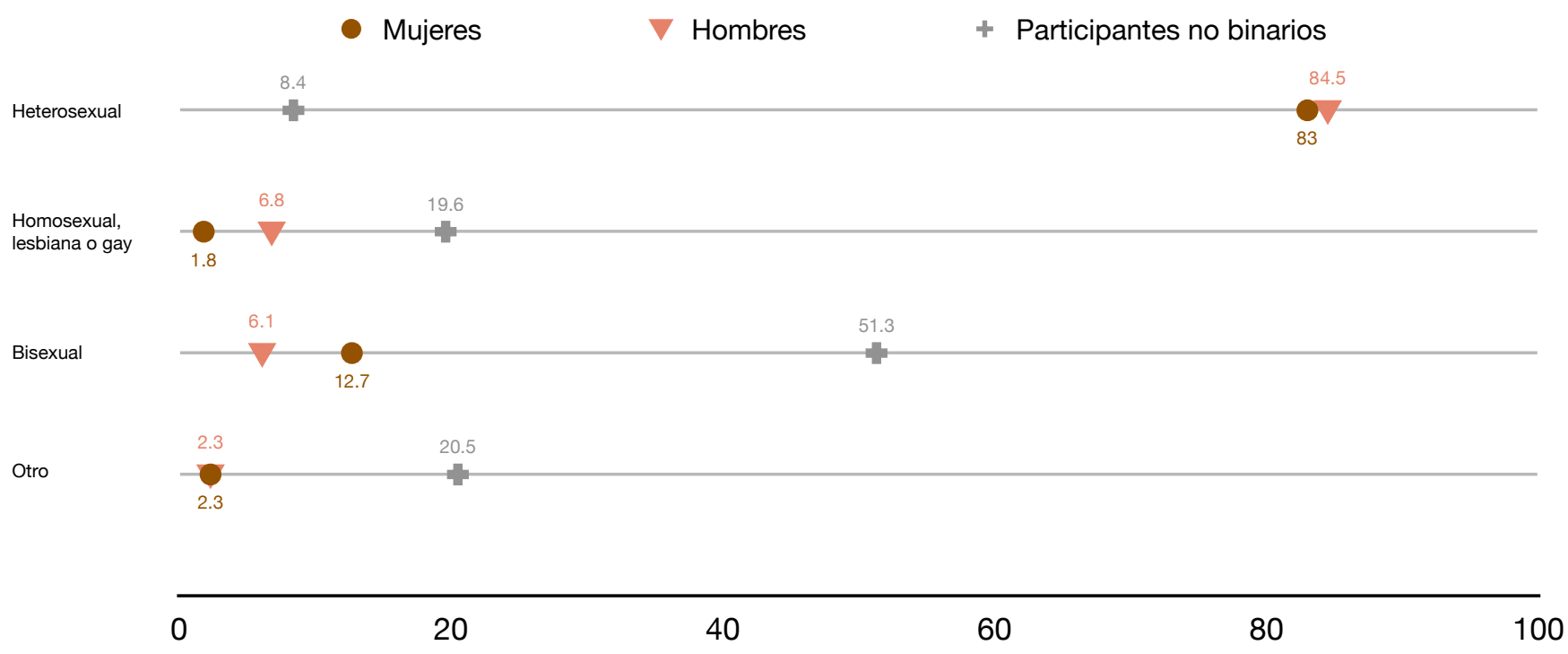

La orientación sexual aún no es una variable utilizada sistemáticamente en los censos y encuestas nacionales realizadas por instituciones gubernamentales en México. Sin embargo, encontramos que el porcentaje de hombres no heterosexuales participantes en nuestro estudio es mayor que el porcentaje encontrado en un estudio de 2014 sobre la seroprevalencia del VIH en la población mexicana entre 15 y 49 años (0.4\%) (Gutierrez, y otros, 2014). También es mayor que la orientación no heterosexual identificada por Moral de la Rubia (2011) en la Encuesta Nacional para la Juventud en México (ENJUVE, 2005): $2.5 \%$ entre los hombres y $1.1 \%$ entre las mujeres (Moral de la Rubia, 2011). Esta diferencia puede deberse en parte al cambio de las normas sociales y puede reflejar una mayor disposición de las juventudes a responder sobre su orientación sexual en comparación con hace unos años.

83\% de la población total estaba inscrita en la escuela en el momento de la encuesta $(99.5 \%$ de adolescentes y $75 \%$ de jóvenes). No se encontraron diferencias significativas en la situación de matriculación entre las personas participantes femeninas y masculinas de ambos grupos de edad. Además, $23 \%$ de personas adolescentes y $44 \%$ de jóvenes trabajaban o tenían un negocio propio en el momento de la encuesta, siendo este porcentaje mayor entre los hombres que entre las mujeres para ambos grupos de edad. El 9.1\% de las personas jóvenes y 0,7\% de las y los adolescentes declararon estar 
casados o convivir con una pareja, con el $1.7 \%$ de la población encuestada declarando haberse casado o haber empezado a convivir con su pareja antes de cumplir los 18 años (ver Figura 3).

Figura 3. Participantes que se casaron y / o empezaron a vivir con su pareja antes de los 18 años, por grupo de edad y sexo. Porcentajes. VOCES-19. México.

Mujeres $\quad$ Hombres $\quad+$ Participantes no binarios

Uniones tempranas de

adolescentes

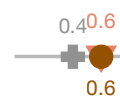

Uniones tempranas de

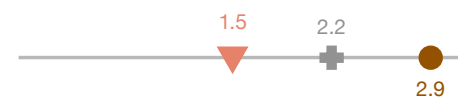

0

2.5

5

7.5

10

\section{Características del hogar}

Casi un tercio de las personas participantes (28\%) mencionó vivir en un hogar con hacinamiento (2.5 habitantes o más por dormitorio), con un porcentaje mayor entre las mujeres adolescentes frente a los hombres adolescentes (33\% frente a 30\%). Además, $99.5 \%$ de las personas participantes vive en un hogar familiar y $37 \%$ declaró que una mujer era la jefa del hogar, siendo este porcentaje mayor entre las mujeres frente a los hombres en ambos grupos de edad. Por último, $82 \%$ de las y los adolescentes y $77 \%$ de las personas jóvenes disponen de Internet privado (WiFi) en sus hogares, con un mayor porcentaje entre los hombres frente a las mujeres en ambos grupos de edad.

Crédito de la ilustración: Valeria García Trejo. Instagram grillolunar_vg.

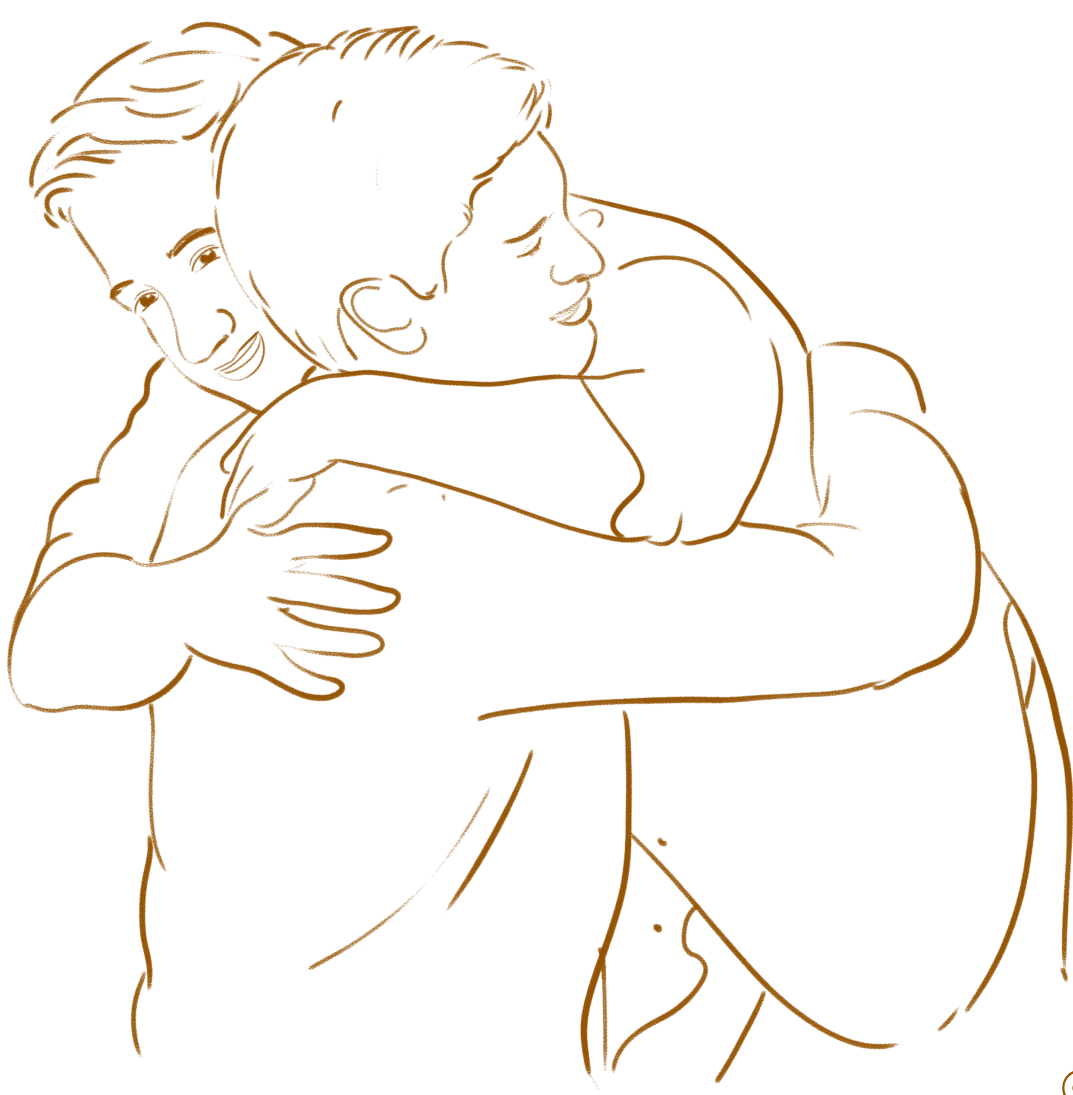




\section{CUMPLIMIENIO \\ DE LAS MEDIDAS \\ TaS ME MITGACION}

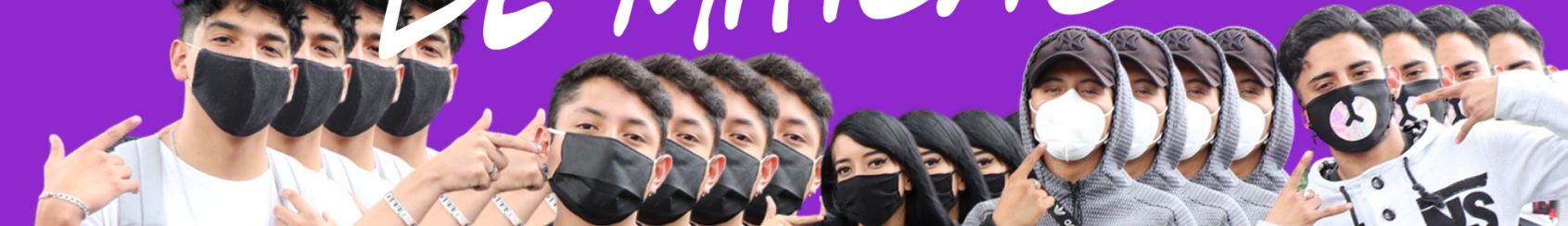

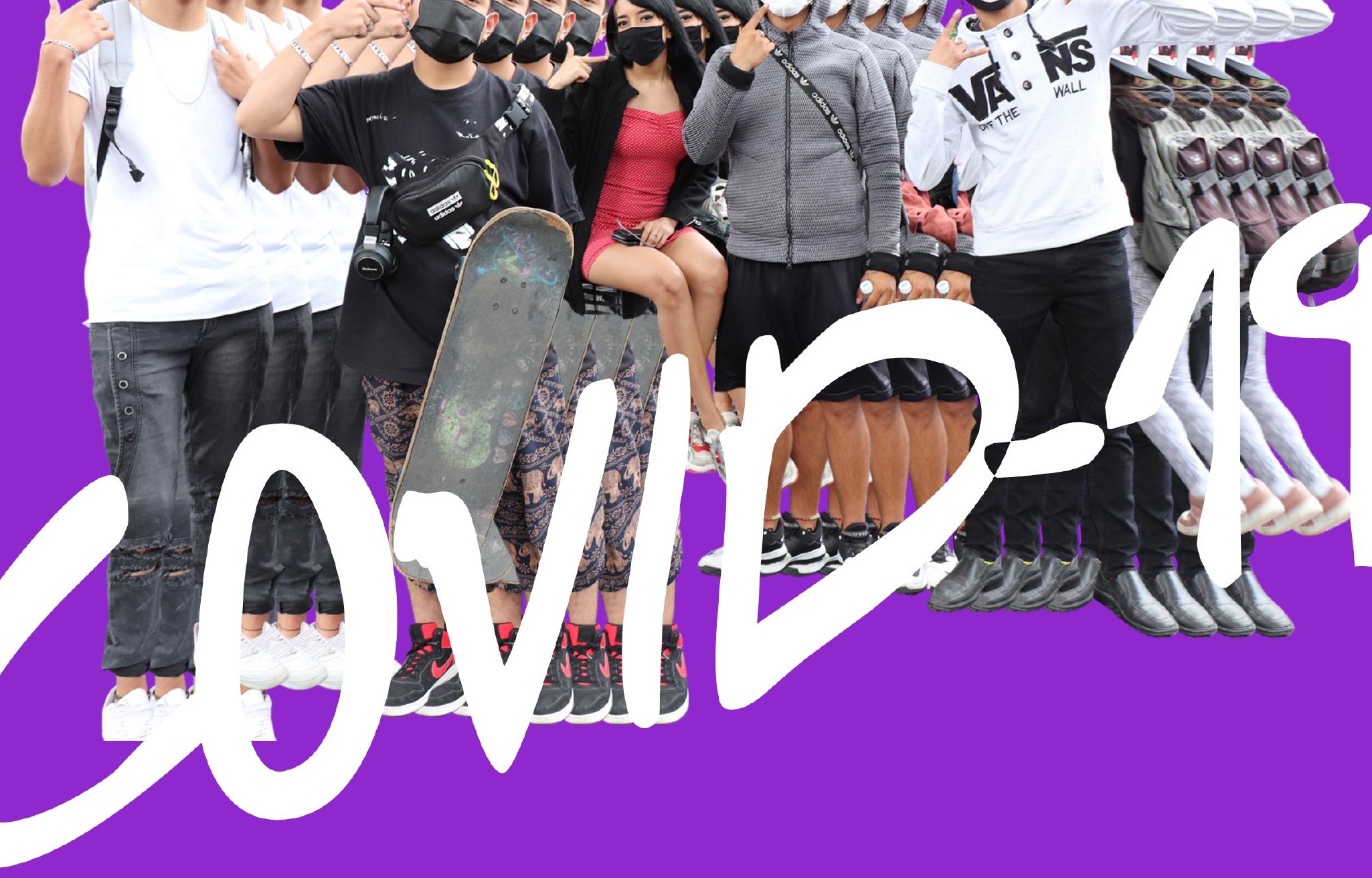




\section{Cumplimiento de las medidas de mitigación de COVID-19 Puntos destacados}
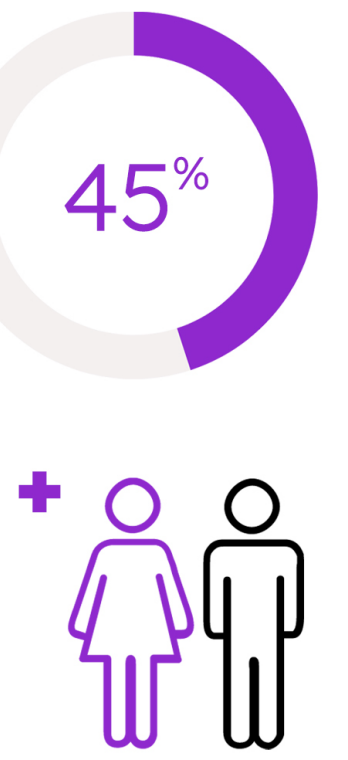

Casi la mitad de las personas adolescentes y jóvenes declararon cumplir con las cinco medidas de mitigación recomendadas para COVID-19 sobre las que se preguntó en la encuesta.

Para cada una de las cinco medidas de mitigación, un porcentaje significativamente mayor de mujeres en comparación con los hombres en ambos grupos de edad informó de su cumplimiento.

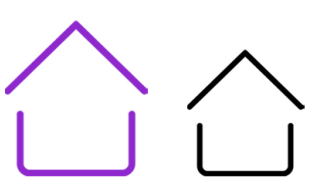

En comparación con las personas participantes no indígenas $\mathrm{y} / \mathrm{o}$ afrodescendientes (no I/AD), una menor proporción de participantes I/AD cumplió con las medidas de mitigación, como el mandato de uso de cubrebocas (95\% frente al $97 \%$ ) y el uso de alcohol en gel para las manos (85\% frente al 89\%).

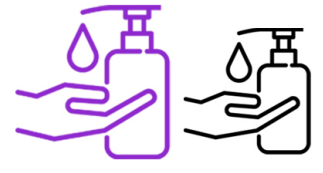

Una menor proporción de participantes de hogares de bajos ingresos, en comparación con sus pares de hogares de altos ingresos, informaron que cumplían con el mandato de usar cubrebocas $(93 \%$ vs. $98 \%$ ) y con el uso de alcohol en gel para manos ( $81 \%$ vs. $93 \%$ ).

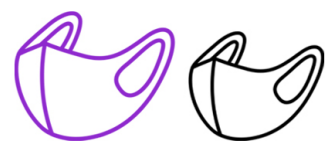

Las personas participantes I/AD (65\%) y del nivel socioeconómico (NSE) más bajo (79\%) fueron más propensas a informar que dejaban el hogar sólo por razones esenciales, en comparación con participantes no I/AD (54\%) y del NSE Superior (39\%), respectivamente.

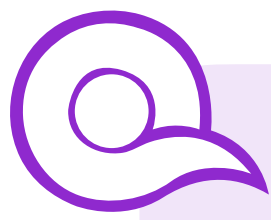

Veo a mi mamá triste por perder a su hermano debido al COVID-19, y eso me pone triste. Sé que lo va a superar, pero no sé cuando. Yo la amo mucho.

Mujer, 17 años, Tamaulipas. 
Siguiendo los lineamientos y planes estratégicos de preparación y respuesta al COVID-19 de la Organización Mundial de la Salud (Organización Mundial de la Salud, 2021), el gobierno mexicano implementó diferentes estrategias a nivel federal para contener la enfermedad y el número de muertes al inicio de la pandemia (Secretaría de Salud, 2020). Simultáneamente, los gobiernos locales (tanto de los estados como de los municipios) implementaron restricciones a la movilidad y toques de queda, así como estrategias para aumentar la capacidad de los servicios de salud para atender a los pacientes con COVID-19 grave, y políticas fiscales para impulsar la economía (Gobierno de México, 2020). Los lineamientos federales lanzados el 23 de marzo de 2020, establecían que las personas debían mantener la distancia entre sí, suspender las clases presenciales en las escuelas, permanecer en casa si se formaba parte de un grupo de población vulnerable y suspender las actividades no esenciales (por ejemplo, restaurantes, centros comerciales, gimnasios).

Estas estrategias y las respuestas públicas a ellas han disminuido las infecciones por COVID-19; sin embargo, no todas las medidas se aplicaron por igual en los 32 estados mexicanos (El Economista, 2021). En algunas comunidades con un porcentaje importante de población indígena, se decidió cerrar la entrada a las personas no locales y sólo permitir la entrada a los transportes que llevaban productos esenciales. Además, el uso de cubrebocas estaba más estigmatizado en estas comunidades que en las no indígenas, asociado a la creencia de que, si llevabas un cubrebocas, probablemente tenías COVID-19 (Vieitez-Martínez, Larrea, Romero, \& Cicolella, 2020).

Al momento de la encuesta, las escuelas y los negocios no esenciales llevaban casi 10 meses cerrados. El período comprendido entre diciembre de 2020 y febrero de 2021 (que coincidió con la recolección de datos), fueron los tres meses con mayor número de casos activos y muertes en México desde el inicio de la pandemia (Dirección General de Epidemiología, 2021). Con VOCES-19, queríamos saber más sobre el cumplimiento de las medidas de mitigación entre adolescentes y jóvenes, así como sobre las diferencias en los índices de cumplimiento según el género, la etnicidad y el nivel socioeconómico. VOCES-19 analizó el cumplimiento de cinco recomendaciones clave de mitigación que pueden aplicarse a nivel individual: 1) lavado de manos regular, 2) distanciamiento social, 3) permanecer en casa, 4) uso de cubrebocas y 5) uso de alcohol en gel para manos. El objetivo de este análisis es conocer el nivel de cumplimiento de las medidas a los ocho meses de iniciada la pandemia e identificar qué grupos de población cumplían menos con estas medidas, lo que podría estar relacionado con barreras de género, económicas y/o sociales para su cumplimiento. Todos los resultados se presentan por separado para adolescentes (15-17 años) y jóvenes (18-24 años).

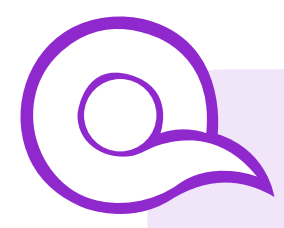

Yo trabajo para ganar dinero extra pero no por necesidad, es una manera de apoyar a mi comunidad haciendo viajes de mandados para asi evitar la salida de muchas personas de sus hogares.

Hombre, 17 años, Tabasco. 


\section{¿Cuál fue el nivel de cumplimiento de las medidas de mitigación recomendadas por el gobierno?}

\section{Adolescentes}

Las y los adolescentes reportaron niveles generales más altos de cumplimiento de las medidas recomendadas para mitigar la propagación de COVID-19. De las personas adolescentes que participaron en VOCES-19, 44\% declaró que cumplía las cinco medidas de mitigación que se preguntaron en la encuesta, mientras que menos del $1 \%$ declaró que no cumplía ninguna medida de mitigación. La medida de mitigación que las y los adolescentes declararon cumplir en mayor medida fue el mandato de usar cubrebocas ( $96 \%$ ), seguida del lavado de manos regular (91\%). La medida que menos cumplían era mantener el distanciamiento social (55\%).

También se preguntó a las personas adolescentes sobre el mandato de quedarse en casa y los motivos por los que habían salido de ella en el mes anterior a la realización de la encuesta. El $54 \%$ de las personas en este grupo de edad citaron sólo razones esenciales para salir de casa, como ir a comprar comida, suministros y/o medicamentos, acudir a una cita médica o ir a trabajar. Por el contrario, 8.3\% citó sólo motivos no esenciales (por ejemplo, ir a restaurantes, fiestas, al centro comercial, al gimnasio y/o a visitar a amigos y familiares).

\section{Las mujeres adolescentes mostraron una} tendencia a cumplir más con cada una de las medidas de mitigación, en comparación con sus pares hombres. La principal diferencia en el cumplimiento se observa en relación al uso de alochol en gel para manos ( $90 \%$ de las mujeres frente al $85 \%$ de los hombres), seguido de mantener la distancia social (57\% de las mujeres frente al 54\% de los hombres). Las mujeres adolescentes, en comparación con los hombres adolescentes, también eran más propensas a informar de que cumplían todas las medidas de mitigación ( $47 \%$ frente a $41 \%$ ), así como a informar que salían de casa sólo por razones esenciales (56\% frente a $52 \%$ )

En cuanto a las diferencias por etnicidad, las personas adolescentes I/AD eran ligeramente menos propensas a declarar el uso de alcohol en gel para manos ( $85 \%$ frente a $88 \%$ ) y de cubrebocas ( $95 \%$ frente a $96 \%$ ) que las y los adolescentes no I/AD. El primer grupo también era ligeramente más propenso a declarar que no cumplía con ninguna de las medidas de mitigación preguntadas en la encuesta (1.2\% frente a $0.7 \%$ ).

Las mayores diferencias en las tasas de cumplimiento de las medidas de mitigación se observaron entre las personas adolescentes de hogares con ingresos bajos en comparación con los de ingresos altos. Entre estos dos grupos, hubo una diferencia de 15 puntos porcentuales tanto en el uso declarado de alcohol en gel para manos (78\% para el primer quintil frente al $93 \%$ en el último quintil) como en el mantenimiento de la distancia social al salir del hogar ( $48 \%$ para el primer quintil frente al $62 \%$ para el último quintil). Sin embargo, las y los adolescentes de hogares con bajos ingresos eran más propensos a decir que salian del hogar sólo por razones esenciales (72\%), en comparación con sus pares de hogares con altos ingresos (38\%) (ver Figura 4). 
Figura 4. Diferencia en puntos porcentuales en el cumplimiento de las medidas de mitigación en adolescentes por NSE. VOCES-19. México.

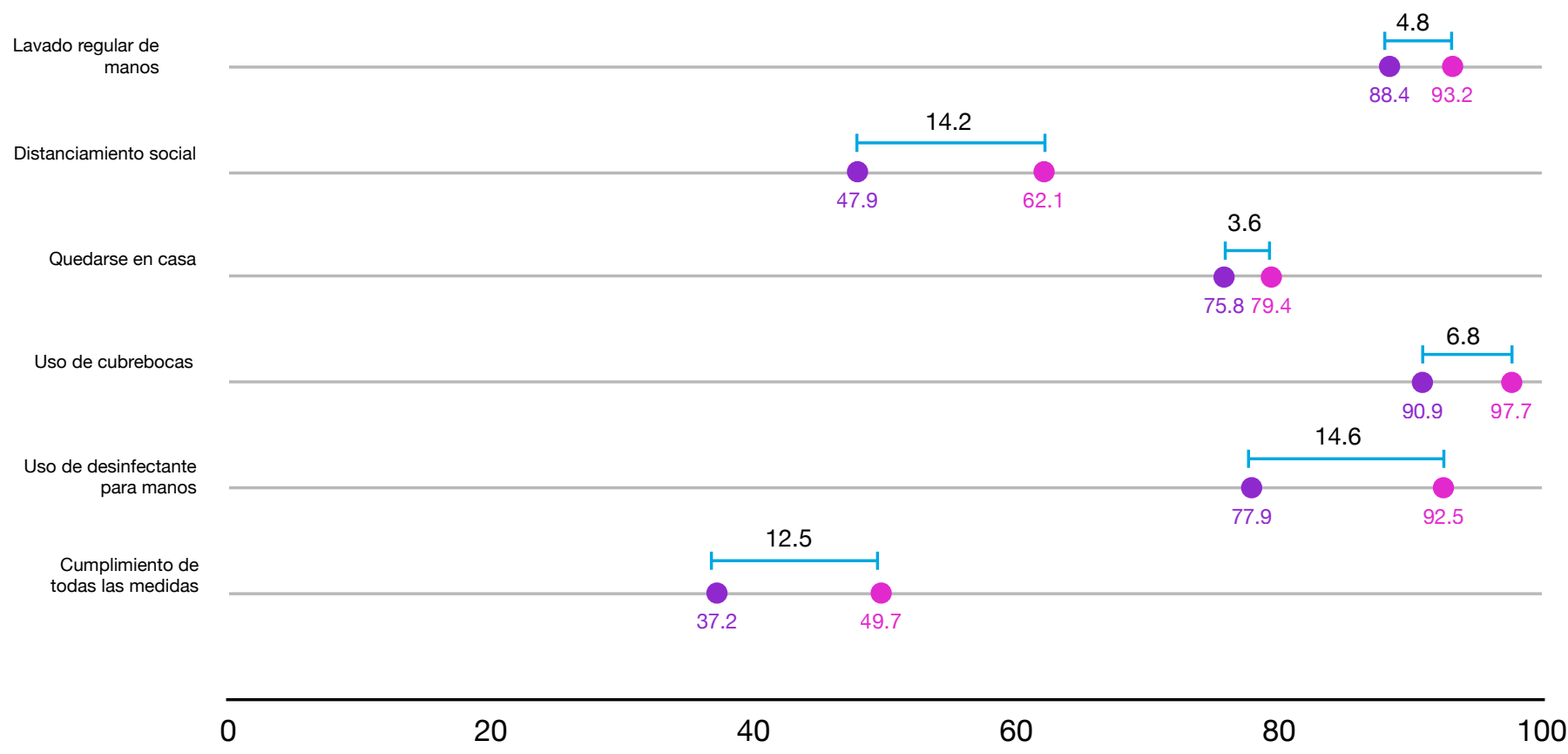

\section{Personas jóvenes}

Las personas jóvenes también informaron de altos índices de cumplimiento de la mayoría de las medidas de mitigación. De las personas jóvenes que participaron en VOCES-19, 46\% informó que cumplía con las cinco medidas de mitigación preguntadas en la encuesta, mientras que el $1 \%$ no cumplía con ninguna medida de mitigación. Los mayores índices de cumplimiento se observaron en los indicadores de uso de cubrebocas al salir de casa (96\%), lavado de manos regular (92\%) y uso de alcohol en gel para manos (88\%). La medida con los índices más bajos de cumplimiento fue mantener el distanciamiento social (57\%). Además, la mayoría de las personas jóvenes (59\%) declararon haber salido del hogar en el mes anterior a la encuesta sólo por razones esenciales y $3.8 \%$ sólo por razones no esenciales.
En el grupo de personas jóvenes, las mujeres eran más propensas a cumplir las medidas de mitigación que sus homólogos masculinos. Las principales diferencias reportadas entre las mujeres y los hombres jóvenes fueron para el uso de alcohol en gel para manos ( $90 \%$ de las mujeres frente al $86 \%$ de los hombres) y el mandato de quedarse en casa ( $83 \%$ de las mujeres frente al $79 \%$ de los hombres). También fue más frecuente que los hombres de este grupo de edad declararan que no cumplían ninguna medida de mitigación (1.4\% de los hombres frente al $0.6 \%$ de las mujeres), y menos frecuente que informaran que salían de casa sólo por razones esenciales ( $56 \%$ de los hombres frente al $61 \%$ de las mujeres).

Para la mayoría de las medidas sobre las que se preguntó, las personas jóvenes I/AD eran más propensas que sus pares no I/AD a informar sobre el cumplimiento, excepto en los 
indicadores de uso de alcohol en gel para manos (84\% frente a $89 \%$ ) y uso de cubrebocas (95\% frente a 97\%). Las personas jóvenes I/AD también fueron 13 puntos porcentuales más propensas a informar que salían de casa sólo por razones esenciales que las personas jóvenes I/ AD (68\% frente al 55\%).

Por último, las personas jóvenes de hogares con bajos ingresos fueron ocho puntos porcentuales menos propensas a afirmar que cumplían todas las medidas de mitigación (42\% frente al 50\%). En cuanto al cumplimiento de las medidas de mitigación individuales, las personas de nivel socioeconómico alto fueron más propensas a informar del uso de alcohol en gel para manos (12 puntos porcentuales de diferencia) y a mantener el distanciamiento social (10 puntos porcentuales de diferencia). Sin embargo, un mayor número de jóvenes del NSE más bajo declararon quedarse en casa (83\% frente al $79 \%$ ) y salir del hogar sólo por razones esenciales ( $81 \%$ frente al 40\%), en comparación con sus pares del NSE más alto (véase la Figura 5).

Figura 5. Diferencia en puntos porcentuales en el cumplimiento de las medidas de mitigación en personas jóvenes, por NSE. VOCES-19. México.

Hogares de ingresos más bajos (primer quintil) Hogares de ingresos más altos (quinto quintil)

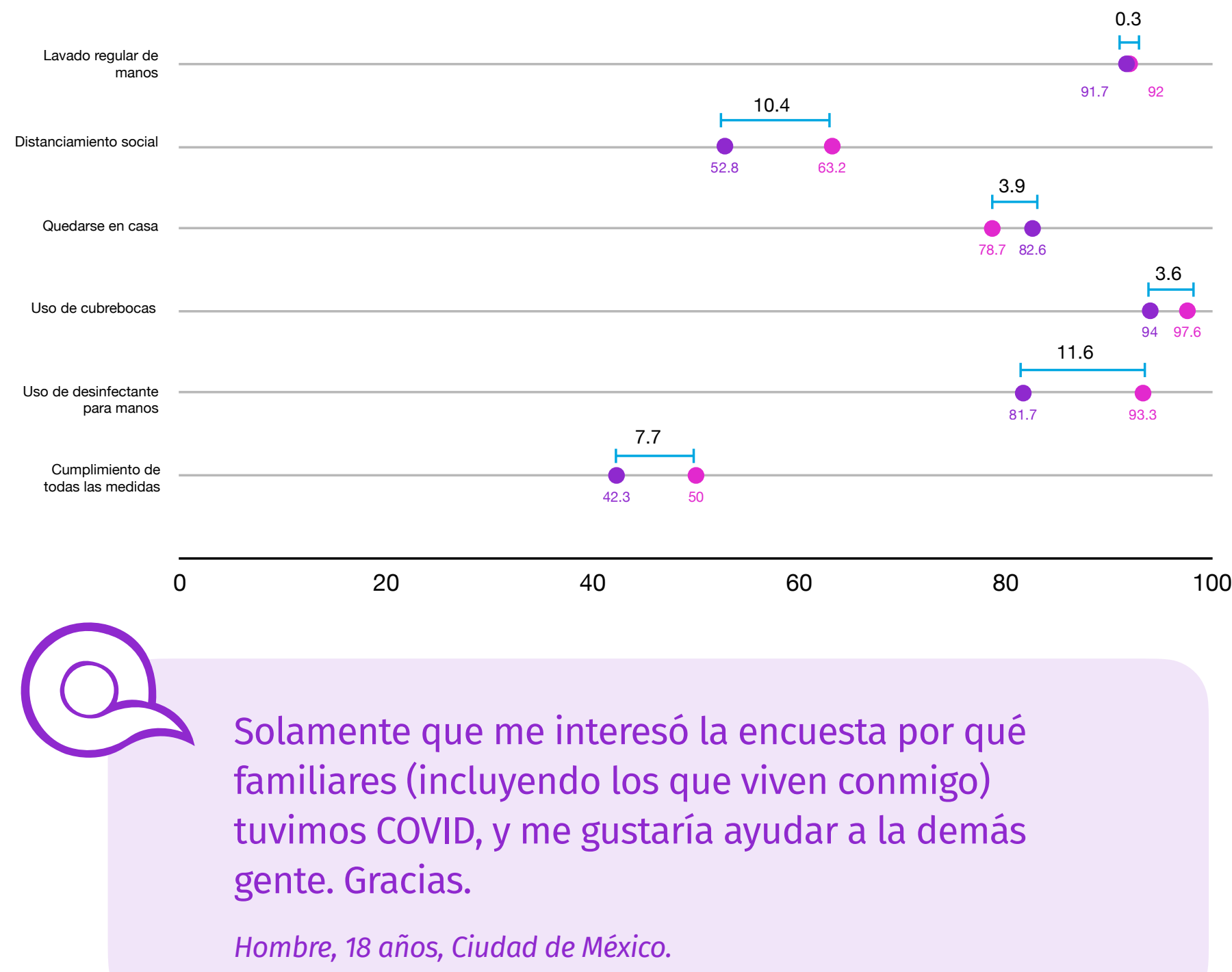




\section{Resumen de los hallazgos}

Los resultados del estudio VOCES-19 muestran que casi la mitad de adolescentes y jóvenes declararon cumplir con las cinco medidas de mitigación recomendadas para COVID-19 sobre las que se preguntó en la encuesta VOCES-19: lavarse las manos con regularidad, distanciamiento social, quedarse en casa, usar cubrebocas y usar alcohol en gel para las manos. Se encontraron diferencias en las tasas de cumplimiento entre los distintos grupos de comparación.

Para casi todas las medidas de mitigación por separado, las mujeres reportaron índices de cumplimiento más altos que los hombres. Además, las personas participantes I/AD y del nivel socioeconómico más bajo eran menos propensas a informar del cumplimiento del mandato de llevar cubrebocas y de usar alcohol en gel para las manos, pero eran más propensas a informar que salían de casa sólo por razones esenciales, en comparación con las personas participantes no I/AD y del nivel socioeconómico más alto, respectivamente.

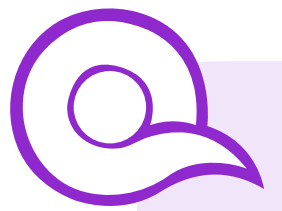

El 30 de diciembre fui a realizarme una prueba de COVID-19 con mi madre y salió positiva, inmediatamente nos aislamos y mantuvimos los cuidados necesarios. Actualmente aún tenemos secuelas y fue una situación bastante complicada ya que a pesar de que tuvimos el apoyo de mis abuelos, los ingresos económicos redujeron bastante por lo cual ahora estamos algo apretados de dinero. Yo estoy esperando mi beca para apoyar en la casa, poder ir al ginecólogo ya que tengo un implante que me ha generado muchos cambios hormonales que me afectan mucho, sumando todo eso con la situación actual ha sido muy complicada esta pandemia.

Mujer, 17 años, Ciudad de México. 


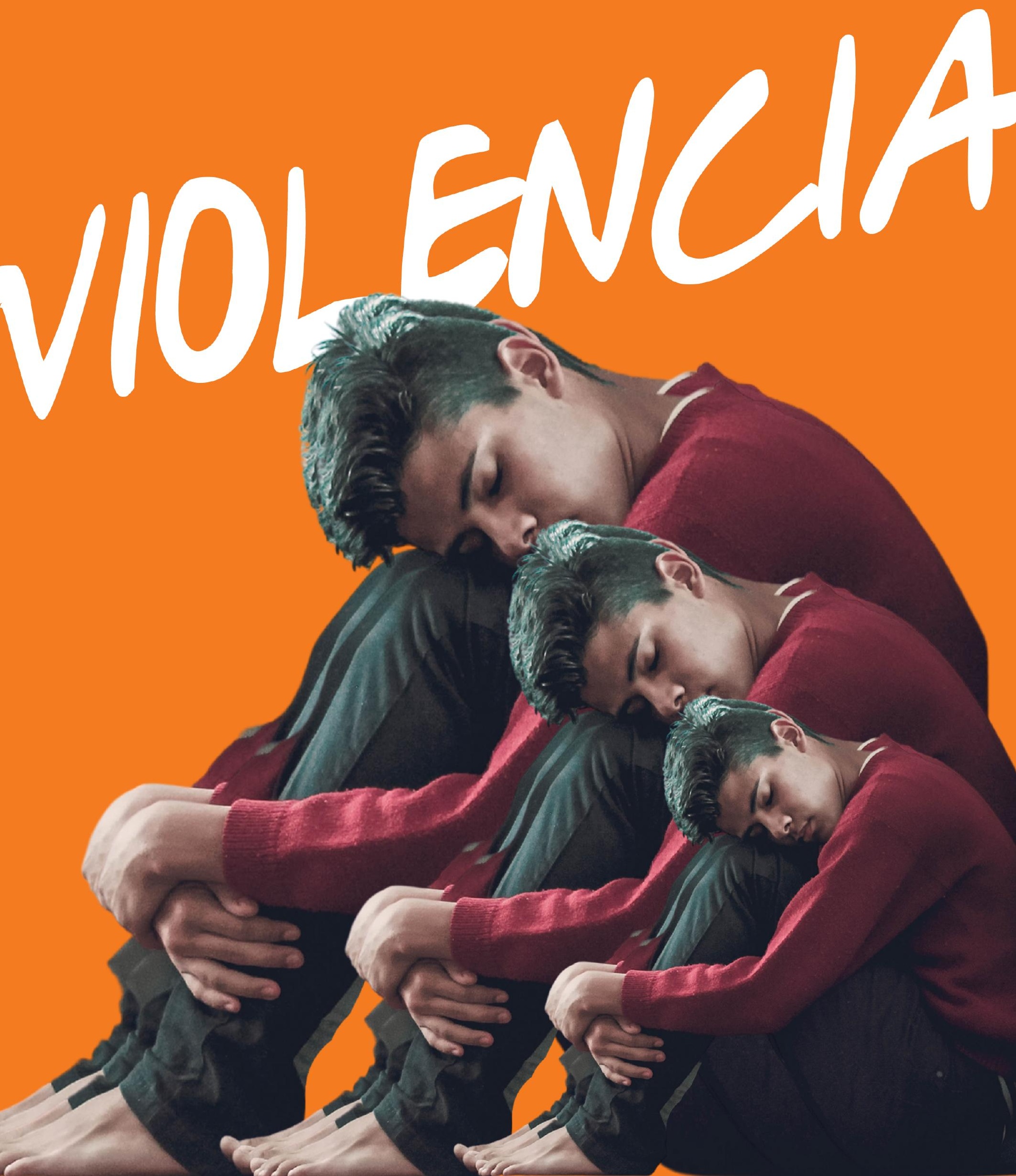




\section{Violencia \\ Puntos destacados}

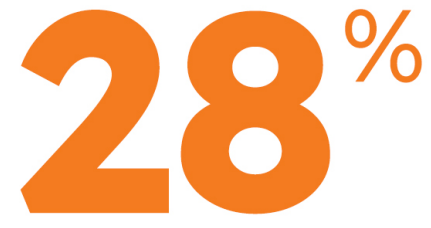

de las personas adolescentes y jóvenes que han experimentado violencia interpersonal en sus hogares, percibieron un aumento en la severidad y/o frecuencia de estos actos violentos tras el inicio de la pandemia.

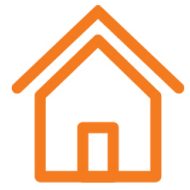

$9 \%$ de las personas

participantes

declaró que se ha sentido menos

segura en su hogar desde el comienzo de la pandemia.

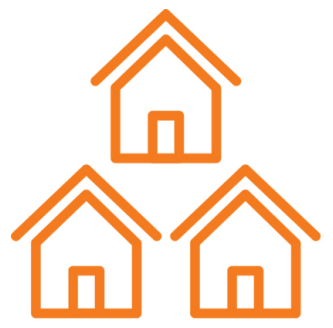

$24 \%$ declaró sentirse menos segura en sus barrios desde el comienzo de la pandemia en comparación con antes.
Un mayor número de hombres reportaron incrementos en la experiencia de ciertos tipos de violencia perpetrada por alguien en el hogar, en particular la violencia sexual, en comparación con las mujeres.

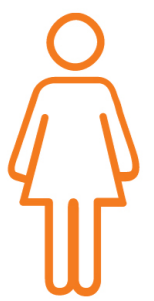

Las mujeres fueron más propensas que los hombres a percibir un aumento de la experiencia de acoso en línea desde el inicio de la pandemia (57\% frente al $49 \%$ ).

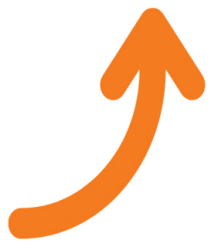

Las personas adolescentes de hogares más equitativos en cuanto a la división de responsabilidades y el poder de decisión fueron menos propensas a informar de un aumento de los actos violentos perpetrados hacia ellas tras el inicio de la pandemia. En las personas jóvenes se encontró una relación negativa similar entre las puntuaciones del índice de responsabilidad en el hogar y los informes de aumento de la violencia.

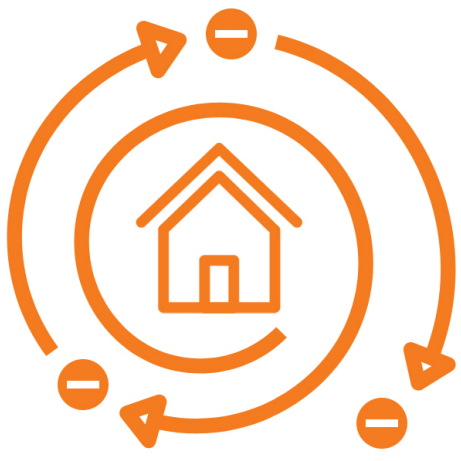

Los resultados muestran que las mujeres y las personas participantes no binarias, así como las personas participantes indígenas y/o afrodescendientes y de bajos ingresos también fueron más propensas a percibir los impactos negativos de la pandemia en la seguridad de su hogar y su vecindario que sus pares de grupos menos excluidos. 
Incluso antes de la pandemia, los niveles de violencia en México eran preocupantes. La tasa de homicidios en México en 2017 fue de $\mathbf{2 4 . 8}$ por cada 100.000 personas all año. El país ocupa el puesto 19 en la lista de las Naciones Unidas de países con la mayor tasa de homicidios intencionales (BBC, 2020). Cinco de las 10 ciudades más peligrosas en 2020, según la tasa de homicidios, se encontraban en México (Los Cabos, Acapulco, Tijuana, La Paz y Ciudad Victoria) (Statista, 2020). Estos datos se reflejan en la percepción de seguridad de la comunidad de la Encuesta Nacional de Victimización y Percepción de la Seguridad Pública (ENVIPE) 2019, donde 54.5\% de las mujeres y $46.2 \%$ de los hombres perciben su comunidad como insegura (Instituto Nacional de Estadística y Geografía, 2019).

En cuanto a la violencia contra las mujeres, los datos de la ENDIREH 2016 indican que $66 \%$ de las mujeres de 15 años o más en México ha experimentado al menos un incidente violento alguna vez; $43.9 \%$ ha experimentado violencia perpetrada por su pareja y $53.1 \%$ violencia por un perpetrador diferente (Instituto Nacional de Estadística y Geografía, 2016). Del total de mujeres que han sufrido al menos un incidente de violencia en su vida, $38.7 \%$ lo ha vivido en la comunidad, $26.6 \%$ en el trabajo, $25.3 \%$ en la escuela y el $10.3 \%$ en el ámbito familiar (Instituto Nacional de Estadística y Geografía, 2016). En cuanto a las tasas de violencia pre pandémica contra niñas, niños y adolescentes, los últimos datos disponibles son los de la Encuesta de Indicadores Múltiples por Conglomerados de 2015 realizada por UNICEF en colaboración con el Instituto Nacional de Salud Pública de México (INSP). En esta encuesta, $63.1 \%$ de los niños, niñas y adolescentes de entre uno y 14 años de edad, habían experimentado agresiones psicológicas o castigos físicos en sus hogares durante el mes anterior a la encuesta. Los hogares son el principal lugar donde se ejerce la violencia contra niños y niñas (UNICEF; Instituto Nacional de Salud Pública, 2015).

En México y otros países del mundo se ha detectado un aumento de la violencia de género contra mujeres y niñas desde el inicio de la pandemia. Factores como los mandatos de distanciamiento social, el cierre de escuelas, la reducción del acceso a los servicios relacionados con la violencia y a los servicios de salud, así como las limitaciones en las actividades económicas, aumentan la exposición de las personas jóvenes a la violencia en sus hogares. Las y los jóvenes podrían estar aún más expuestos en hogares con normas y roles de género rígidos y/o en los que los ingresos se han reducido considerablemente debido a la pandemia. Además, durante la pandemia, las personas jóvenes han estado muy expuestas a Internet y a las tecnologías de la comunicación, ya que esta fue la forma de continuar con las actividades diarias (como el trabajo y las actividades escolares) y de mantenerse en contacto con amigos y familiares. Sin embargo, la mayor exposición a este entorno digital podría incrementar el riesgo de acoso virtual en esta población (ECLAC-UNICEF, 2020).

Partiendo de la evidencia del aumento de la violencia contra las mujeres y las niñas y de los factores de riesgo asociados a un incremento de la violencia contra las juventudes durante la pandemia, el estudio VOCES-19 se centró en las diferencias por género, etnicidad y estatus socioeconómico de las personas adolescentes y jóvenes en cuanto a la exposición a la violencia interpersonal a nivel familiar, al acoso en línea, y a la percepción de los niveles de violencia en la comunidad. Este análisis tiene como objetivo identificar los grupos en mayor situación de vulnerabilidad en cada una de las dimensiones. Todos los resultados se presentan por separado para adolescentes (15-17 años) y jóvenes (18-24 años). 


\section{¿Qué impacto tuvieron las medidas de distanciamiento social en las percepciones y experiencias de violencia de las personas participantes?}

\section{Adolescentes}

A las personas participantes de VOCES-19 se les preguntó si habían sufrido alguna vez violencia en casa, perpetrada por alguien que vivía en el mismo hogar. El $35 \%$ de las personas adolescentes declaró haber sufrido violencia psicológica (insultos, gritos, humillaciones), 20\% violencia física (empujones, bofetadas u otras formas de agresión física) y $2.6 \%$ violencia sexual (ya sea agresión o acoso). En total, $37 \%$ de las personas adolescentes del estudio declararon haber sufrido al menos uno de estos tipos de violencia en su vida.

Las experiencias de las personas adolescentes con la violencia interpersonal en el hogar aumentaron durante la pandemia. Entre las y los adolescentes que declararon haber sufrido violencia en el hogar, $27 \%$ informó de un aumento en la frecuencia y/o la gravedad de estos actos. El aumento más comúnmente reportado fue el de la violencia psicológica: $30 \%$ de las personas adolescentes que la han experimentado alguna vez lo reportaron, mientras que $19 \%$ de las que han experimentado violencia física y $19 \%$ de las que han experimentado violencia sexual reportaron incrementos en estos tipos de violencia. Cabe destacar el hallazgo de que los adolescentes hombres eran casi 16 puntos porcentuales más propensos que las mujeres a haber experimentado un aumento de la violencia sexual tras el inicio de la pandemia (26\% frente al $10 \%$ ).

Las personas adolescentes también declararon haber presenciado un aumento de la violencia hacia otras personas en casa y aumento del acoso virtual. El 24\% informó de un aumento de los actos violentos contra sus hermanas/os o la pareja de su padre (que puede ser la madre o la madrastra de la persona participante) y $47 \%$ de las que han sufrido ciberacoso y acoso en línea declararon que estas conductas se habian vuelto más frecuentes y/o graves. La única diferencia significativa basada en el género en estos indicadores se encontró en la percepción del aumento del acoso virtual: las mujeres adolescentes fueron más propensas que los hombres a informar de este aumento (50\% frente al $45 \%)$.

El aumento de la violencia desde el inicio de la pandemia fue más prevalente entre las personas adolescentes I/AD y aquellas de hogares con menores ingresos, en comparación con sus pares menos excluidos. Por ejemplo, entre las personas I/AD que declararon haber experimentado violencia alguna vez en su vida, $5.6 \%$ declaró que estos actos se produjeron por primera vez tras el inicio de la pandemia, en comparación con el $3.7 \%$ de las personas no I/AD. Las personas participantes I/AD también eran más propensas a informar de un aumento en la frecuencia y/o gravedad de la violencia psicológica hacia ellas (32\% frente al 28\%), así como de un aumento del acoso en línea (51\% frente al 45\%) (ver Figura 6).

Además, 5.6\% de las personas participantes del NSE más bajo declararon haber experimentado violencia interpersonal a nivel familiar por primera vez durante la pandemia, en 
comparación con el 3.2\% de sus pares del NSE más alto. Las personas adolescentes de hogares con bajos ingresos también fueron significativamente más propensas que sus pares con altos ingresos a reportar aumentos en la frecuencia y/o severidad de todos los tipos de actos violentos que experimentaron en el hogar, incluyendo violencia psicológica (37\% vs. $26 \%$ ), física (27\% vs. $13 \%$ ) y sexual (26\% vs. $9 \%)$.

Figura 6. Diferencias en puntos porcentuales en la percepción de adolescentes de una mayor exposición a la violencia en el hogar durante la pandemia (entre las personas que han declarado haber experimentado algún tipo de violencia en el hogar a lo largo de su vida), por origen étnico. VOCES-19. México.

Indígenas y/o Afro-mexicanos No indígenas y/o Afro-mexicanos

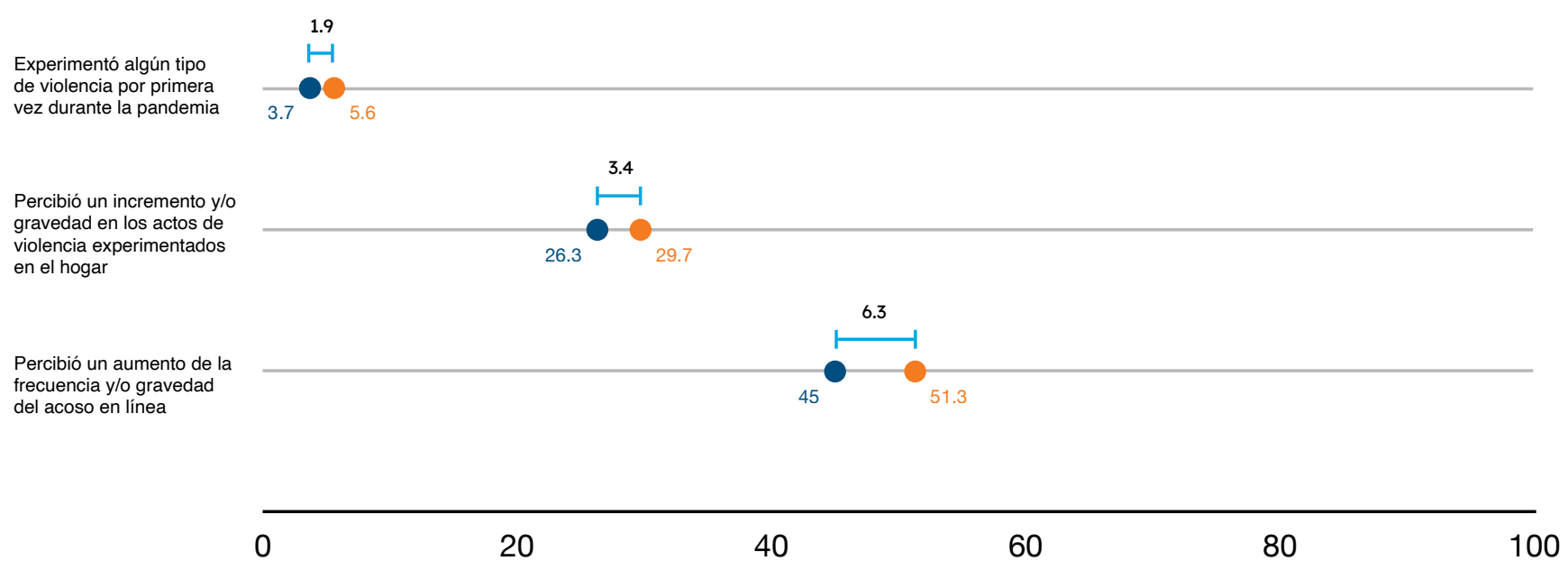

\section{Personas jóvenes}

Entre las personas participantes de 18 a 24 años, 44\% declaró haber estado expuesta a violencia psicológica en el hogar en algún momento de su vida, $25 \%$ a violencia física y $4.3 \%$ a violencia sexual. En total, $46 \%$ de las personas jóvenes declararon haber estado expuestas a algún tipo de violencia interpersonal en el ámbito familiar a lo largo de su vida y, de ellas, el 5\% experimentó estos actos violentos por primera vez tras el inicio de la pandemia.

Las personas participantes jóvenes percibieron un aumento de los actos violentos interpersonales en sus hogares tras el inicio de la pandemia en tasas similares a las de las personas adolescentes. El 28\% de las personas participantes que habían sufrido alguna vez violencia interpersonal en el ámbito familiar percibieron un aumento de los actos violentos contra ellas. Desglosado por tipo de violencia, $29 \%$ informó de un aumento de la violencia psicológica, $20 \%$ de la violencia física y $20 \%$ de la violencia sexual.

Los hombres jóvenes fueron significativamente más propensos que las mujeres a haber experimentado un aumento tanto de la violencia física (23\% frente al $17 \%$ ) como de la violencia sexual (37\% frente al $10 \%$ ) desde el inicio de la pandemia. De hecho, un alto porcentaje (23\%) de los participantes hombres que han sido víctimas de violencia sexual en el hogar declararon que estos actos se produjeron por primera 
vez tras el inicio de la pandemia y no antes, en comparación con sólo el 3.1\% de las mujeres que declararon esto.

Además, 24\% de las personas jóvenes percibió un aumento de los actos de violencia contra sus hermanos/as o la pareja de su padre y 53\% percibió un aumento del acoso en línea. Al igual que en el caso de las y los adolescentes, un mayor porcentaje de mujeres jóvenes percibió un aumento del acoso en línea en comparación con los hombres jóvenes (55\% frente al 51\%).

\section{El aumento de la violencia en el hogar fue más común entre las personas jóvenes de los grupos} étnicos más marginados. Entre los jóvenes de 18 a 24 años, un mayor porcentaje de las personas que se autoidentificaron como I/AD, en comparación con sus pares no I/AD, informaron de un aumento en la frecuencia y/o gravedad de la violencia psicológica (39\% frente al $26 \%$ ) y la violencia física (27\% frente al $17 \%)$. Este grupo también era más propenso a reportar un aumento de la violencia contra otro miembro de la familia (28\% frente al 22\%), y de un aumento del acoso en línea (59\% frente al $51 \%$ ) desde el comienzo de la pandemia.

En cuanto a las diferencias basadas en los ingresos, $9 \%$ de las personas participantes del NSE más bajo declararon que su primera experiencia de violencia en el hogar se produjo durante la pandemia, en comparación con $4 \%$ de las delNSE más alto. Las personas jóvenes de hogares con bajos ingresos tenían alrededor de 23 puntos porcentuales más de probabilidad de reportar un aumento de la violencia psicológica (44\% frente al $21 \%$ ), 26 puntos porcentuales más de probabilidad de reportar un aumento de la violencia física (38\% frente al 12\%), y 20 puntos porcentuales más de probabilidad de reportar

Figura 7. Diferencias en puntos porcentuales en la percepción de jóvenes de una mayor exposición a la violencia en el hogar durante la pandemia (entre las personas que han declarado haber experimentado algún tipo de violencia en el hogar a lo largo de su vida), por NSE. VOCES-19. México.

- Hogares de ingresos más bajos (primer quintil) - Hogares de ingresos más altos (quinto quintil)

Experimentó algún tipo vez durante la pandemia

Percibió un incremento y/o gravedad en los actos de violencia experimentados personalmente en el hoga

Percibió un aumento en la frecuencia y/o severidad de los actos violentos contra algún hermano/a o la pareja femenina de sus padres en el hogar

Percibió un aumento de la frecuencia y/o gravedad del del acoso en línea
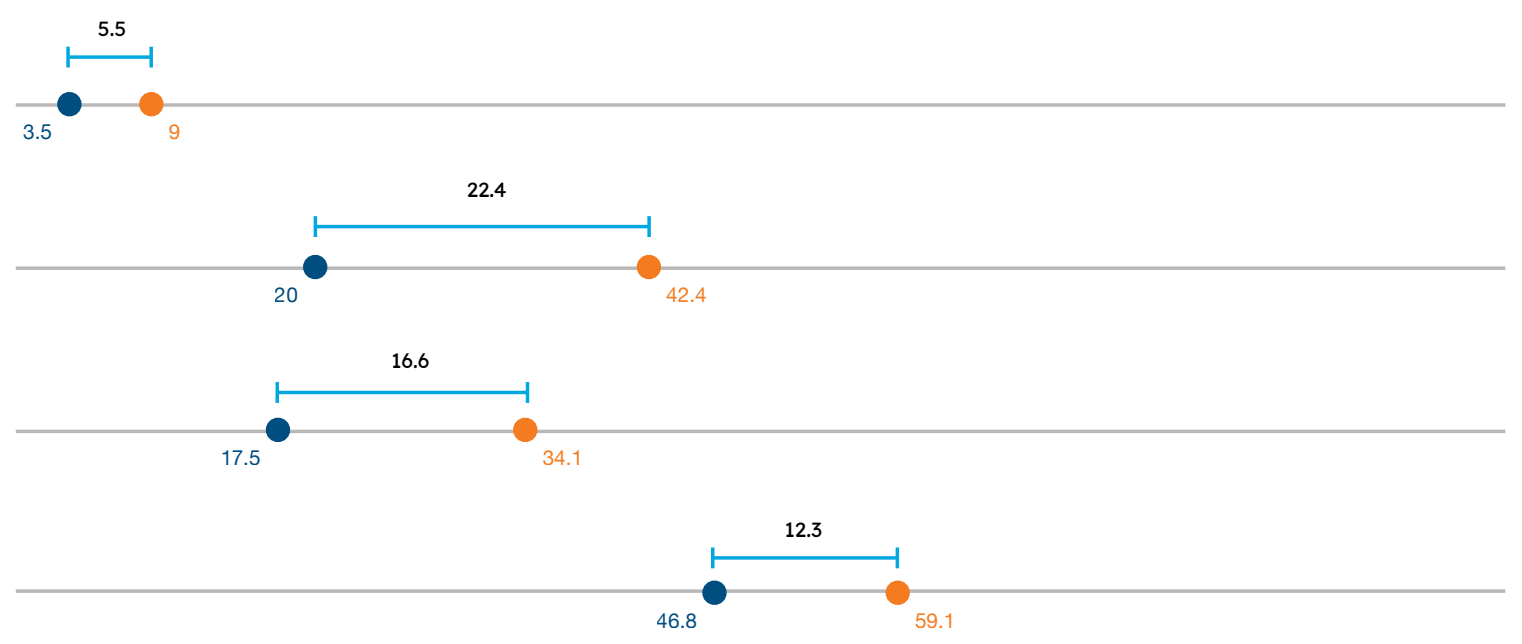
un aumento de la violencia sexual (30\% frente al $10 \%$ ) que sus pares en hogares con altos ingresos.

Por último, este grupo de bajos ingresos también percibió en mayor medida el aumento de la violencia contra otro miembro de la familia (34\% frente al $18 \%$ ) y del acoso en línea (59\% frente al $47 \%$ ) desde el inicio de la pandemia (ver Figura 7).

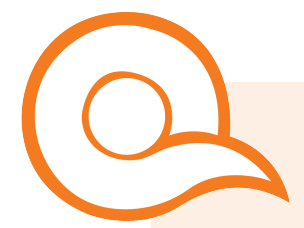

Sinceramente hay días que ya no puedo más, personas de mi entorno que pensé que me querían y me apoyarían me dañaron mucho emocionalmente. La violencia en la comunidad aumenta, los vicios siguen, pero así como todo lo "malo" está aumentado, mis ganas de seguir adelante y de no ser comol@s que me lastimaron seguirán aumentando más. Ya quiero ser independiente pero no tengo las bases aún. Seguiré estudiando para que en un futuro no muy lejano pueda tener mi libertad y mi soledad al mismo tiempo, porque no quiero disfrutar mi felicidad con nadie más, más que conmigo misma por que al final del día solamente me tengo a mi...

15 años, Ciudad de México. 


\section{¿Existe relación entre el aumento en la frecuencia y/ - gravedad de la violencia interpersonal en el hogar y la equidad en las dinámicas del hogar de las personas participantes?}

En VOCES-19, las dinámicas del hogar se midieron a través de dos índices. El índice de división de las responsabilidades y las tareas domésticas tiene como objetivo entender quién en el hogar (hombres, mujeres o ambos) es responsable de llevar a cabo las tareas domésticas. Se compone de nueve preguntas sobre cómo se dividen las tareas y responsabilidades domésticas entre mujeres y hombres. La puntuación del índice oscila entre 9 y 27 puntos. Las puntuaciones más bajas indican un reparto de responsabilidades que sigue las normas tradicionales de género, lo que significa que es más probable que sean las mujeres las que realicen la mayor parte de las tareas domésticas, en contraposición a los hombres o ambos juntos.

\section{El índice de división de la toma de decisiones} en el hogar tiene como objetivo comprender quién (hombres, mujeres o ambos) toma las diferentes decisiones en el hogar. Se compone de tres preguntas relativas a diferentes tipos de decisiones: la compra de alimentos rutinarios para la casa (comida, productos de limpieza), las compras ocasionales más caras y el tiempo que cada persona dedica a realizar trabajos remunerados. La puntuación del índice oscila entre 3 y 12 puntos. Las puntuaciones más bajas indican procesos de toma de decisiones más tradicionales, lo que significa que son los hombres los que toman la mayoría de las decisiones financieras importantes, en contraposición a que sean las mujeres o ambos juntos.

Las puntuaciones medias del índice de división de las responsabilidades y las tareas domésticas
(22.3 puntos para adolescentes y 22.0 puntos para jóvenes) y del índice de división de las responsabilidades de toma de decisiones en el hogar (8.2 puntos para adolescentes y 7.9 puntos para jóvenes), tanto en las personas adolescentes como en las jóvenes, muestran una tendencia hacia una división más equitativa de las responsabilidades y la toma de decisiones en lugar de una más tradicional.

Las y los investigadores de VOCES-19 estaban interesados en comprender si existe una asociación entre las puntuaciones de las personas participantes en estos índices de dinámicas del hogar y sus reportes de haber experimentado un aumento en la frecuencia y/o gravedad de la violencia en su hogar tras el comienzo de la pandemia.

Hay que tener en cuenta que este análisis se hizo sólo con participantes que declararon haber sufrido violencia interpersonal en casa en algún momento de su vida.

\section{Adolescentes}

Entre las y los participantes adolescentes que habían experimentado previamente violencia en el hogar, encontramos evidencia que sugiere que las personas participantes de hogares con una puntuación más alta en el índice de división de responsabilidades tenían menos probabilidades de haber experimentado un aumento de los actos violentos durante la pandemia. También detectamos una relación negativa entre las puntuaciones en el índice de división de la toma de decisiones en el hogar y los informes de 
aumento de la violencia. Esto significa que las personas adolescentes de los hogares más equitativos tanto en términos de división de responsabilidades como de poder de decisión eran menos propensas a percibir un aumento de la violencia hacia ellas tras el inicio de la pandemia.

\section{Personas jóvenes}

Entre las personas jóvenes de 18 a 24 años que declararon haber tenido alguna experiencia previa de violencia interpersonal en el hogar, encontramos una relación negativa similar entre las puntuaciones de las personas participantes en el índice de responsabilidad en el hogar y sus reportes sobre el aumento de la violencia, pero ninguna relación significativa entre estos informes y el índice de toma de decisiones. Al igual que en el caso de adolescentes, esto indica que las personas jóvenes de hogares con una división más equitativa de las tareas y responsabilidades fueron menos propensas a experimentar un aumento de la violencia en el hogar tras el inicio de la pandemia.

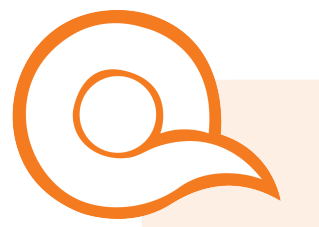

He leído, presenciado y escuchado de más casos de mujeres que sufren de violencia física, psicológica y sexual dentro de sus propias casas. La situación actual de la pandemia agrava la situación de las miles de mujeres que sufren violencia doméstica y nos hace sentir inseguras al resto de las mujeres ya que hay casos en donde desconocidos entran a las casas para violentar. No estamos seguras ni dentro ni fuera de nuestras casas.

Mujer, 16 años, Yucatán. 


\section{¿Cómo afectó la pandemia las percepciones de la seguridad en el hogar y la comunidad por parte de adolescentes y jóvenes?}

\section{Adolescentes}

La pandemia afectó a la sensación de seguridad percibida por las personas adolescentes participantes en sus barrios más que en sus hogares. Mientras que el $7 \%$ de las y los adolescentes declararon que desde el comienzo de la pandemia se habían sentido menos seguros en sus hogares, el 19\% declaró sentirse menos seguro en sus barrios. Además, $18 \%$ de las personas adolescentes percibió un aumento de la delincuencia y $13 \%$ percibió un aumento de la violencia en sus barrios desde el comienzo de la pandemia.

Las percepciones negativas de la seguridad del barrio eran más frecuentes entre las mujeres y las personas participantes no binarias que entre los hombres. Por ejemplo, $22 \%$ de las mujeres adolescentes y $30 \%$ de las personas adolescentes no binarias manifestaron una sensación de menor seguridad en el barrio, en comparación con el $17 \%$ de los hombres. Las mujeres adolescentes también percibieron un aumento de la delincuencia ( $21 \%$ frente al $15 \%$ ) y de la violencia ( $15 \%$ frente al $12 \%$ ) en sus barrios en mayor medida que los hombres adolescentes, aunque los hombres eran ligeramente más propensos a decir que se sentían menos seguros en casa que las mujeres ( $8 \%$ frente al $6 \%$ ) (ver

Figura 8).
Los resultados muestran de nuevo que las personas participantes I/AD y de bajos ingresos también eran más propensas a percibir los impactos negativos de la pandemia en la seguridad de su hogar y su vecindario que sus pares de grupos menos marginados. Las y los adolescentes I/AD fueron más propensos a decir que se sentían menos seguros en su hogar ( $9 \%$ frente al $6 \%$ ) y a percibir un aumento de la violencia en sus barrios desde el comienzo de la pandemia (15\% frente al $13 \%)$, en comparación con sus pares no I/AD.

Estas diferencias son aún mayores entre las personas participantes de los dos extremos socioeconómicos. El $10 \%$ de las y los adolescentes de los hogares con ingresos más bajos dijeron sentirse menos seguros en sus hogares, y el $23 \%$ dijeron sentirse menos seguros en sus barrios. Por el contrario, sólo $6 \%$ de las y los participantes más acomodados se sentían menos seguros en sus hogares y el $15 \%$ lo hacian en sus barrios. Por último, las personas adolescentes del NSE más bajo eran más propensas que las del NSE más alto a informar sobre un aumento tanto de la delincuencia (22\% frente a $14 \%$ ) como de la violencia (17\% frente a $10 \%$ ) en sus barrios tras el inicio de la pandemia.

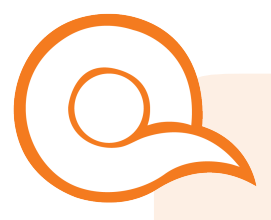

He visto muchos casos de violencia en redes sociales que me es preocupante. Mujer, 22 años, Campeche. 
Figura 8. Porcentaje de adolescentes que percibieron cambios en la seguridad del hogar y del vecindario desde el inicio de la pandemia, por género. VOCES-19. México.

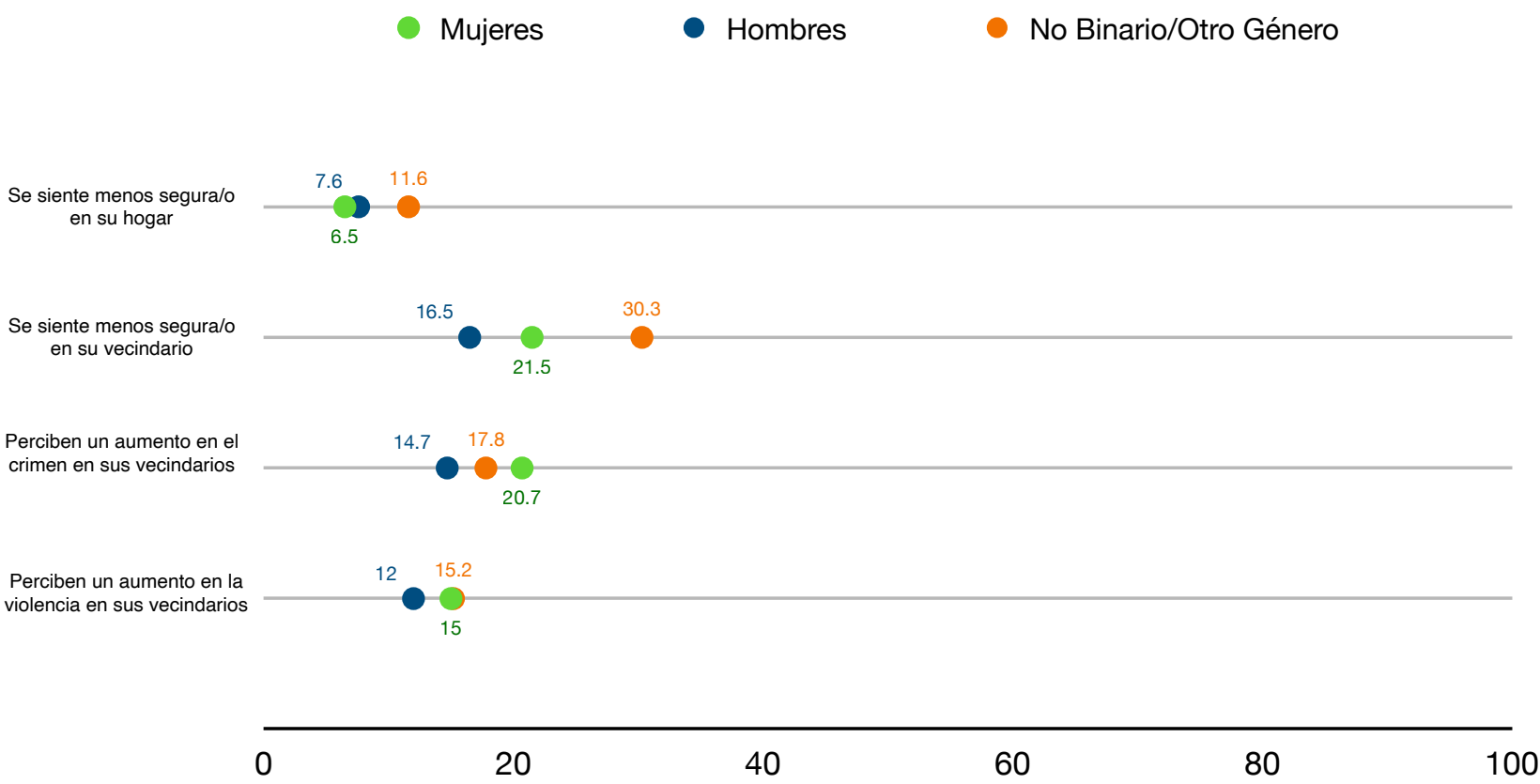

\section{Personas jóvenes}

Las personas jóvenes de 18 a 24 años también sintieron un mayor impacto negativo en la seguridad del vecindario como resultado de la pandemia y las medidas de distanciamiento social, que en la seguridad en sus hogares. Entre las personas participantes jóvenes, 10\% declaró que se había sentido menos segura en su hogar desde el comienzo de la pandemia, mientras que $26 \%$ declaró sentirse menos segura en su vecindario. Al igual que en el caso de las personas adolescentes, un mayor porcentaje de mujeres jóvenes adultas en comparación con los hombres jóvenes adultos (29\% frente al 23\%) informó de esta sensación de mayor inseguridad en el vecindario. Por último, $26 \%$ de jóvenes percibieron un aumento de la delincuencia y $22 \%$ un aumento de la violencia en sus barrios, con un mayor porcentaje de mujeres que percibieron un aumento de ambos.

Las personas jóvenes I/AD y de bajos ingresos también eran más propensas que sus pares mas favorecidos a afirmar que la delincuencia y la violencia habían aumentado en sus barrios como resultado de las medidas de mitigación de la pandemia. En concreto, las personas jóvenes I/AD declararon en mayor proporción que percibían un aumento de la delincuencia (28\% frente al $25 \%$ ) y un aumento de la violencia (25\% frente al $21 \%$ ) en sus barrios que sus pares no I/AD. Del mismo modo, las personas jóvenes del NSE más bajo declararon sentirse menos seguras en casa (12\% frente a $8 \%$ ) y en sus barrios (32\% frente a $21 \%$ ), así como de percibir un aumento tanto de la delincuencia (30\% frente a $23 \%$ ) como de la violencia (25\% frente a $20 \%$ ) en sus barrios, que sus pares del NSE más alto (ver Figura 9). 
Figura 9. Diferencias en puntos porcentuales en la percepción de personas jóvenes sobre cambios en la seguridad del hogar y del vecindario desde el inicio de la pandemia, por NSE. VOCES-19. México.

- Hogares de ingresos más bajos (primer quintil)

Hogares de ingresos más altos (quinto quintil)
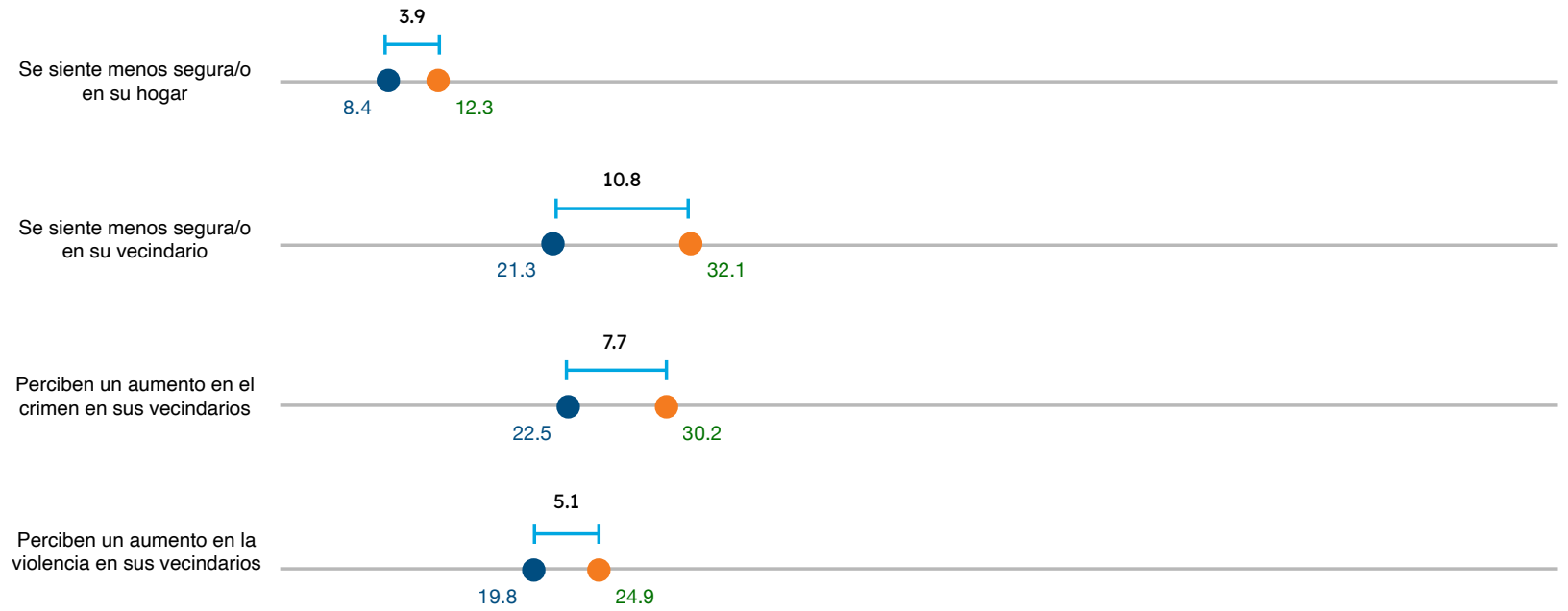

0

20

40

60

80

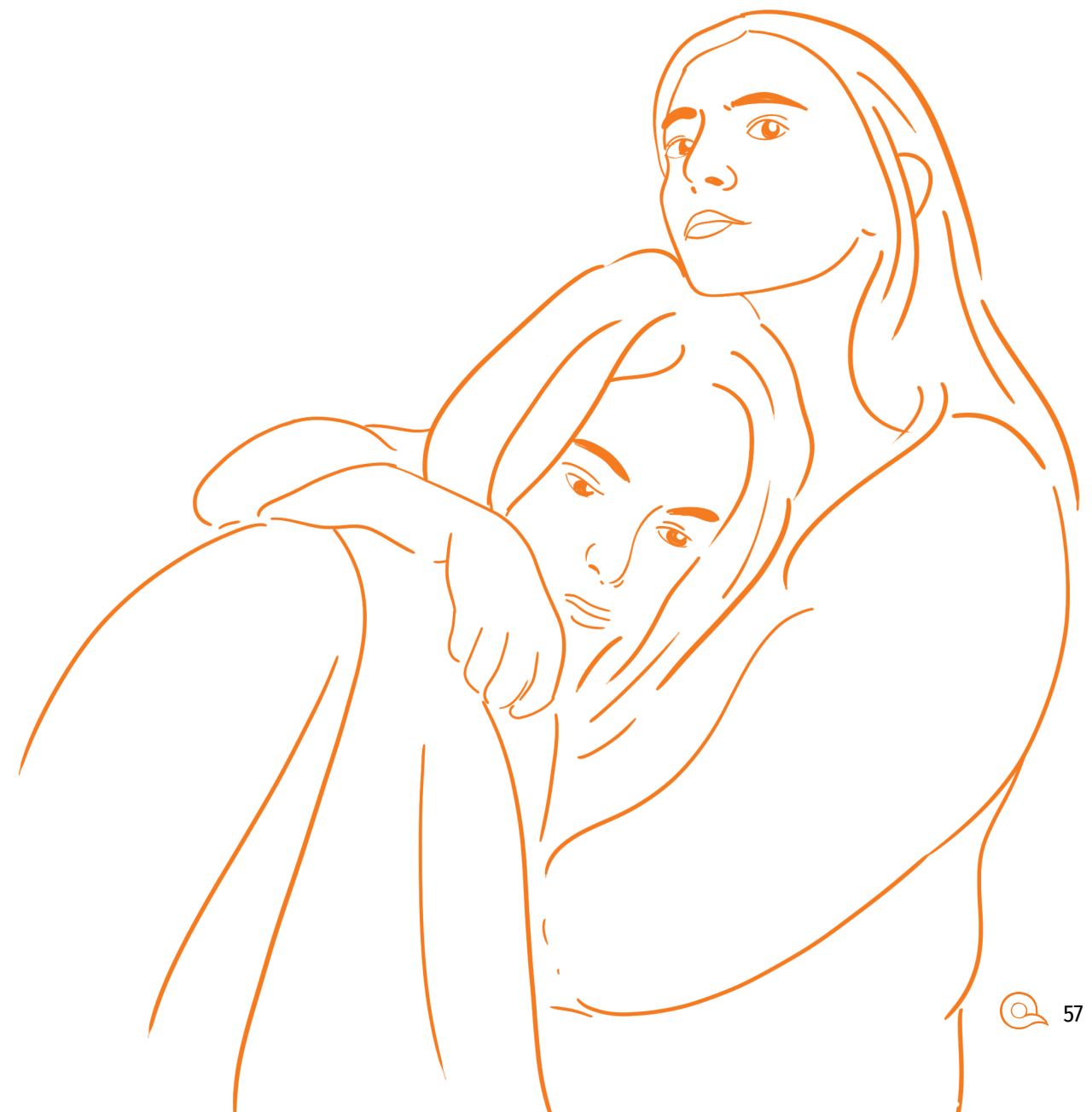




\section{Resumen de los hallazgos}

Los hallazgos de VOCES-19 muestran que la pandemia y las medidas de mitigación que la acompañan han tenido un impacto en las experiencias de violencia y en la percepción de la seguridad en el hogar y en el vecindario de adolescentes y jóvenes en México. Los aumentos reportados en las experiencias de ciertos tipos de violencia perpetrados por alguien en el hogar, particularmente la violencia sexual, fueron mayores entre los hombres que entre las mujeres. Las personas adolescentes y jóvenes que se autoidentificaron como indígenas y/o afrodescendientes y las y los participantes de hogares de bajos ingresos también fueron más propensos a reportar aumentos en la violencia interpersonal en el hogar que los individuos de grupos menos excluidos socialmente.

Los resultados también muestran una asociación entre las dinámicas del hogar y el aumento de la violencia: las personas adolescentes y jóvenes de hogares más equitativos en cuanto a la división de responsabilidades tenían menos probabilidades de informar de un aumento de la violencia hacia ellas tras el inicio de la pandemia. En otras palabras, los hogares en los que las mujeres realizan la mayor parte de las tareas eran más propensos a experimentar un aumento de la violencia durante la pandemia.

Además, las mujeres y las personas participantes no binarias de ambos grupos de edad percibieron un mayor aumento de la inseguridad en sus barrios desde el inicio de la pandemia en comparación con sus pares masculinos, declarando en mayor proporción que se sentían menos seguras en su barrio y, en el caso de las mujeres, que percibían un aumento tanto de la delincuencia como de la violencia en sus comunidades. Las personas I/AD y de bajos ingresos también fueron más propensas que sus pares más favorecidos a sentirse menos seguras en casa y a percibir un aumento de la violencia en el barrio.

Los resultados de esta dimensión siguen demostrando cómo la pandemia ha afectado de forma desproporcionada a los grupos marginados. Sin embargo, también revelan que los hombres no han sido inmunes al aumento de la violencia durante la pandemia. En particular, las elevadas tasas de hombres que declaran haber sufrido violencia sexual por primera vez tras el inicio de la pandemia y que declaran un aumento de la frecuencia y la gravedad de estos actos señalan la necesidad crítica de prestar atención a esta cuestión. El equipo de investigación de VOCES-19 seguirá ampliando el análisis y centrándose en los principales determinantes de la exposición a la violencia interpersonal a nivel familiar entre las personas participantes de VOCES-19. 


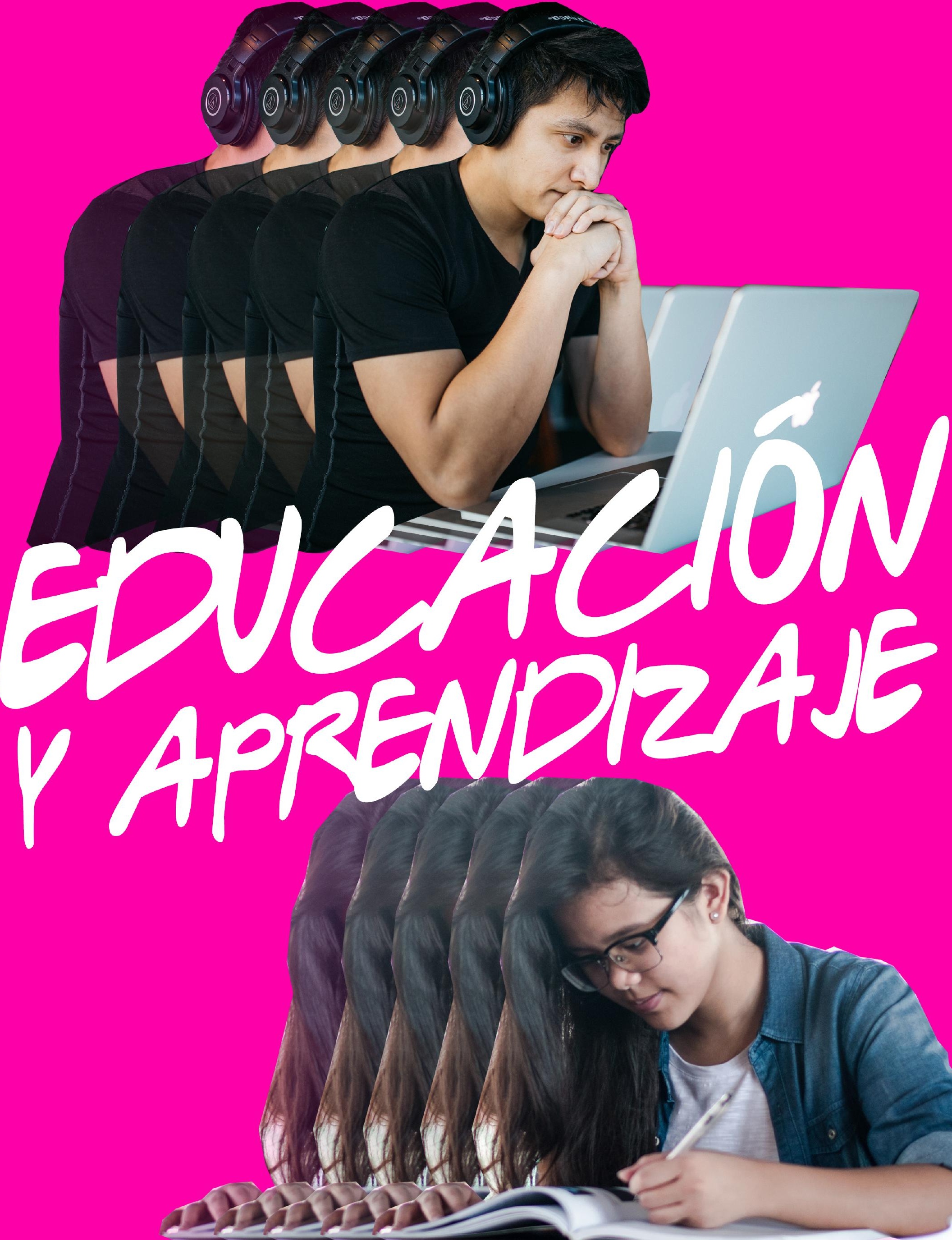




\section{Educación y aprendizaje}

\section{Puntos destacados}

El $99.5 \%$ de adolescentes y $75 \%$ de jóvenes participantes en el estudio VOCES-19 estaban inscritas en la escuela al momento de la encuesta.

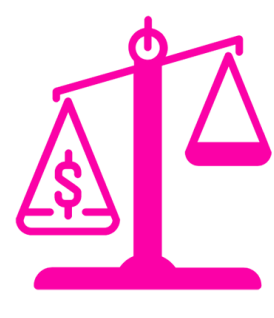

En el caso de las personas participantes que no estaban inscritas en la escuela al momento de la encuesta $(n=1,494)$, la pandemia fue la razón más comúnmente citada entre adolescentes para haber abandonado la escuela (42\%), aunque las personas adolescentes de menores ingresos e indígenas $\mathrm{y} / \mathrm{o}$ afrodescendientes fueron más propensas a declarar que dejaron la escuela por razones financieras que por la pandemia específicamente.

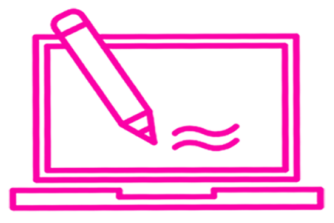

Desde el cierre de las escuelas, $99 \%$ de las personas participantes inscritas en ellas han recibido lecciones a distancia a través de una plataforma en línea. Pocos estudiantes declararon haber recibido lecciones a través de la radio, la televisión o cuadernillos para llevar a casa.

Los resultados muestran diferencias significativas basadas en la etnicidad y los ingresos en la capacidad de las y los estudiantes para mantenerse conectados a la escuela durante la pandemia. Por ejemplo, las personas del quintil socioeconómico más alto tenían $\mathbf{4 1}$ puntos porcentuales más de probabilidad de poder acceder a sus tareas durante la pandemia que sus pares de menores ingresos.

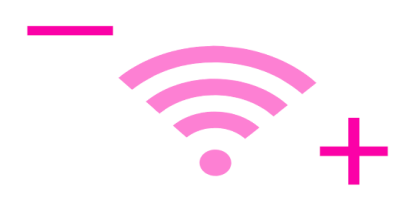

En general, las y los estudiantes tienen una percepción negativa de su aprendizaje a través de las clases en línea: sólo el $12,5 \%$ de todas las personas participantes consideraron que habían aprendido más durante la pandemia que cuando sus clases eran presenciales.

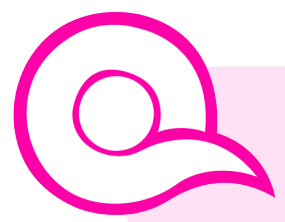

Desde que empezó la escuela tengo más preocupaciones y me he sentido peor, tengo menos tiempo para ayudar a la familia y otras cosas importantes, la escuela solo hizo que se complicara la pandemia para mí.

Hombre, 17 años, Morelos. 
Si bien en las últimas décadas la comunidad mundial ha dado grandes pasos para mejorar el acceso a la educación, la pandemia de COVID-19 ha supuesto una disrupción y un retroceso sin precedentes en este empeño. Según datos de UNICEF recogidos en abril de 2020, el cierre de escuelas y las medidas de clausura aplicadas al inicio de la pandemia dejaron sin clases a unos 1.600 millones de niñas y niños en más de 190 países y afectaron a más de 100 millones de docentes y personal escolar (UNESCO, 2021). Además, la crisis de salud pública ha puesto de manifiesto las desigualdades educativas preexistentes y ha tenido el mayor impacto en los alumnos en mayor situación de vulnerabilidad y marginación. A pesar de esta situación y de la gran necesidad de aumentar la financiación y la atención para garantizar la recuperación de la educación, un reciente informe conjunto de la UNESCO y el Banco Mundial reveló que dos tercios de los países de ingresos bajos y medio bajos han reducido el gasto público en educación desde el comienzo de la pandemia (UNESCO, 2021).

En México, las medidas públicas para mitigar la transmisión de la COVID-19 provocaron el cierre temporal de los planteles escolares a partir de la segunda semana de marzo de 2020 y por el resto del ciclo escolar 2019-2020, y luego para el ciclo escolar 2020-2021. De acuerdo con cifras del Instituto Nacional de Estadística y Geografía (INEGI), en el ciclo escolar 2019-2020 se inscribieron en las escuelas alrededor de 33.6 millones de estudiantes de entre 3 y 29 años, de los cuales 740 mil (2.2\%) no completaron el ciclo (Instituto Nacional de Estadística y Geografía, 2020).

A mediados de abril, la Secretaría de Educación Pública (SEP) de México estableció una plataforma de aprendizaje a distancia llamada "Aprende en Casa" para las y los estudiantes inscritos en la educación primaria y secundaria. Este programa se basó en la difusión de videos y actividades educativas basadas en el currículo nacional estandarizado a través de la televisión y plataformas digitales. Al mismo tiempo, las instituciones educativas, tanto públicas como privadas, también se vieron obligadas a adaptarse rápidamente para impartir contenidos educativos mediante el uso de las tecnologías de la información y la comunicación (Instituto Nacional de Estadística y Geografía, 2020). Esto situó a docentes, estudiantes, familias y personal administrativo en un entorno poco preparado para este cambio, en particular a las poblaciones en mayor situación de vulnerabilidad en el país que carecían de acceso a Internet y a electricidad.

Con VOCES-19, queríamos saber cómo las medidas de distanciamiento social y mitigación asociadas a la pandemia de COVID-19 aplicadas en México, en combinación con las desigualdades sociales y económicas preexistentes, afectaban a los aspectos educativos, como el abandono escolar, la asistencia, el uso de diferentes tecnologías para recibir clases, el acceso a los trabajos y tareas, y las percepciones de los estudiantes sobre el aprendizaje. Al igual que en las secciones anteriores, este análisis pretende desglosar estos resultados en función del género, la etnicidad y el nivel socioeconómico de las personas participantes. Todos los resultados se presentan por separado para adolescentes (15-17 años) y jóvenes (18-24 años). 


\section{¿Cómo afectó la pandemia a la inscripción en las escuelas?}

\section{Adolescentes}

Uno de los temas centrales de interés del estudio en relación con la educación era cómo se vería afectada la inscripción escolar de las personas adolescentes por la pandemia y el cierre de escuelas. El estudio se vio limitado en su capacidad de responder a esta pregunta crítica debido a la estrategia de reclutamiento de conveniencia utilizada para llegar a las potenciales personas participantes. Debido a que la encuesta fue difundida en gran medida en ciertos estados por la Secretaría de Educación y por instituciones académicas específicas, una gran proporción de personas encuestadas eran estudiantes. Como resultado, el promedio ponderado de participantes de 15 a 17 años de edad inscritos en la escuela en el momento de la encuesta fue de $99.5 \%$, en comparación con una cifra estimada de $63 \%$ para jóvenes de 16 a 18 años de edad que estaban inscritos en el ciclo escolar 2020-2021 en todo el país (Instituto Nacional de Estadística y Geografía, 2021).

Entre el reducido número de participantes de VOCES-19 de 15 a 17 años que declararon no estar escolarizados en el momento de la encuesta ( $n=157)$, la razón más común para haber dejado la escuela fue la pandemia de COVID-19 (42\%). Además, las personas participantes de mayores ingresos que no estaban inscritas en la escuela fueron significativamente más propensas que sus pares de menores ingresos a citar la pandemia como la razón por la que dejaron la escuela (88\% frente a $13 \%$ ), mientras que las personas participantes no indígenas $y / 0$ afrodescendientes (no I/AD) fueron más propensas que las personas I/AD a haber declarado esta razón (61\% frente a 14\%).

Para las personas adolescentes I/AD y las del quintil socioeconómico más bajo, la razón más citada para no estar matriculados en la escuela es que no podían permitirse continuar con sus estudios. El $21 \%$ de las y los adolescentes desescolarizados de los hogares de bajos ingresos señalaron esta razón para haber abandonado la escuela, en comparación con sólo $2 \%$ de los de los hogares de altos ingresos. Mientras tanto, el $19 \%$ de las y los adolescentes I/AD no escolarizados citaron esta incapacidad financiera como razón para haber dejado la escuela, en comparación con $7 \%$ de las y los adolescentes no I/AD.

\section{Personas jóvenes}

Al igual que en el caso de las y los adolescentes, las personas jóvenes de 18 a 24 años inscritas en la escuela estuvieron sobrerrepresentadas en este estudio. En el caso de las y los jóvenes, el promedio ponderado de los participantes de VOCES-19 fue del $75 \%$, en comparación con el $31.6 \%$ estimado de las y los jóvenes de 19 a 24 años inscritos en el país para el ciclo más reciente (Instituto Nacional de Estadística y Geografía, 2021).

Entre las personas jóvenes que no estaban inscritas en la escuela al momento de la encuesta $(n=1,337)$, sólo el $9.2 \%$ citó la pandemia como una de las razones por las que dejaron la escuela. Entre este grupo, la razón más común para estar fuera de la escuela fue haber terminado todos los estudios que querían completar (56\%). 
No hubo diferencias significativas basadas en los ingresos o en el origen étnico entre jóvenes en cuanto a haber citado la pandemia como razón para dejar la escuela. Sin embargo, estas diferencias estaban presentes en las menciones de otras razones para haber abandonado los estudios. Las personas jóvenes I/AD, por ejemplo, fueron unos 13 puntos porcentuales más propensas que las personas jóvenes no I/AD a decir que habían dejado la escuela porque no podían costear su continuidad (31\% vs. $18 \%$ ). Esta diferencia fue aún mayor entre las personas participantes de los dos extremos socioeconómicos: $33 \%$ de jóvenes que abandonaron los estudios y que procedían de hogares con bajos ingresos mencionaron la imposibilidad económica de seguir estudiando, en comparación con 9\% de jóvenes que procedían de hogares con altos ingresos.

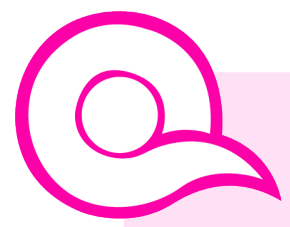

Nosotros (como escuelas, maestros, estudiantes) no estamos preparados para los estudios en línea. Me refiero a que no vamos a adquirir conocimientos grandes, ni los podemos poner en práctica como para adquirir más (hablo de las prácticas que se hacen al final de la preparatoria/bachillerato o universidad donde vas a una empresa por un tiempo a trabajar acerca de lo que estudiaste), muchas veces solo "estudiamos" porque tenemos que hacerlo, también hay mucha mas presión en los estudiantes, porque estamos más enfocados en "cumplir o entregar la actividad/tarea antes de cierto tiempo" que de adquirir los conocimientos. Yo en lo personal siento que voy a salir muy mal acerca de los conocimientos que ya debería de saber acerca de mi carrera técnica como para poder trabajar ya. También muchos de mis compañeros e inclusive yo, nos genera mucho conflicto no saber como resolver ciertas actividades y no saber a quién recurrir, porque también los profesores están ocupados. Los estudios en está pandemia se han vuelto pesados en muchas ocasiones, y para todos.

Mujer, 17 años, Morelos. 


\section{¿Cómo el cambio a educación a distancia impactó en la participación y aprendizaje de las y los estudiantes?}

\section{Adolescentes}

Para las personas que participaron en VOCES-19, el cierre de las escuelas al inicio de la pandemia de COVID-19 supuso un cambio repentino y masivo hacia nuevas modalidades para interactuar con sus comunidades escolares y recibir clases. Las y los adolescentes participantes inscritos en la escuela al momento de la encuesta declararon que, desde el cierre de las escuelas, han recibido principalmente clases en línea (99\%). Un porcentaje mucho menor recibió lecciones a través de otras modalidades, incluyendo materiales para llevar a casa (5\%), televisión $(3 \%)$ y radio ( $<1 \%)$. Entre todas las personas adolescentes que siguieron inscritas en la escuela y cambiaron a estas diferentes modalidades, sólo un pequeño porcentaje (12\%) consideró que han aprendido más de esta manera que cuando sus escuelas y clases eran presenciales.

En su mayor parte, las y los adolescentes del estudio declararon haber asistido a la mayoría de estas clases a distancia desde que se pasó a la enseñanza a distancia: 92\% dijo haber asistido al menos al $70 \%$ de sus clases. Sin embargo, los resultados sugieren que la asistencia constante a lo largo de la pandemia fue más difícil de lograr para las y los estudiantes de bajos ingresos. Las personas participantes de VOCES-19 en el quintil socioeconómico más bajo tuvieron alrededor de ocho puntos porcentuales menos de probabilidades de haber asistido al menos al $70 \%$ de sus clases que sus pares del quintil más alto (87\% frente al 95\%).

Desde el cierre de las instalaciones escolares, las personas adolescentes de los grupos marginados también tuvieron dificultades para acceder a sus deberes y tareas y entregarlos de forma constante. Por ejemplo, $53 \%$ de las y los adolescentes participantes I/ $A D$ declararon que sentían que tenían los medios para acceder a sus deberes durante la pandemia, en comparación con $63 \%$ de las y los adolescentes no I/AD. Del mismo modo, el $59 \%$ de las personas adolescentes I/AD consideraron que tenían los medios para entregar sus deberes, frente al $68 \%$ de sus pares no I/AD.

Las diferencias en cuanto a la capacidad de acceder y presentar las tareas eran aún mayores entre las personas participantes de los dos extremos socioeconómicos. Se observó que, entre las personas adolescentes del nivel socioeconómico más alto, 77\% estaba de acuerdo en que tenía los medios necesarios para trabajar en las tareas escolares, mientras que $81 \%$ estaba de acuerdo en que tenía los medios para presentarlas. Sin embargo, sólo el $36 \%$ y el $40 \%$ de las que se encontraban en el quintil más bajo del NSE percibieron lo mismo para cada una de estas afirmaciones, respectivamente (véase la Figura 10 ). 
Figura 10. Diferencias en puntos porcentuales en la percepción de adolescentes sobre el acceso a las clases remotas desde el cierre de las instalaciones escolares (entre las personas inscritas en la escuela actualmente), por NSE. VOCES-19. México.

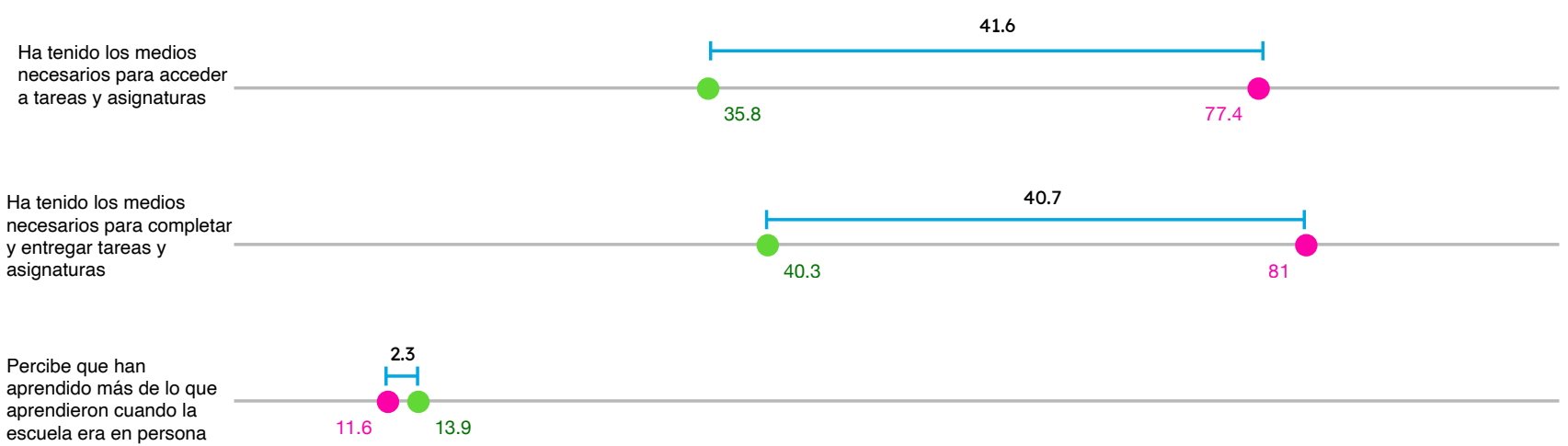

\begin{tabular}{llllll}
\hline 20 & 40 & 60 & 80 & 100
\end{tabular}

\section{Personas jóvenes}

Las personas participantes jóvenes de VOCES-19 también experimentaron un cambio drástico en su experiencia educativa causado por la rápida propagación de COVID-19. Al igual que las y los adolescentes, la gran mayoría de las personas del grupo de mayor edad informaron que, desde el cierre de sus instalaciones universitarias y escolares, habían recibido sus clases en línea (98\%). Muy pocas informaron que recibían las clases a través de televisión o la radio ( $<1 \%$ para ambas) o a través de materiales para llevar a casa (2\%).

Además, $90 \%$ de las personas jóvenes de 18 a 24 años declararon haber asistido a la mayoría (al menos al 70\%) de sus clases a distancia a lo largo de la pandemia, siendo las mujeres adultas jóvenes casi 4 puntos porcentuales más propensas que los hombres a decir que habían alcanzado este umbral de asistencia (92\% frente al 88\%). Las diferencias en las cifras de asistencia a lo largo de la pandemia fueron más amplias en función de las características étnicas y socioeconómicas. Por ejemplo, se observó que un porcentaje menor de participantes I/AD declararon haber asistido a la mayoría de sus clases (86\%) en comparación con participantes no I/AD (91\%). Asimismo, 93\% de participantes con mayores ingresos asistieron a la mayoría de sus clases, en comparación con $82 \%$ de personas participantes con menores ingresos.

Al igual que en el caso de las y los adolescentes, se observaron grandes desigualdades por etnicidad en el acceso de las personas jóvenes al aprendizaje a distancia. Las personas jóvenes no I/ $A D$ fueron significativamente más propensas que sus pares I/AD a estar de acuerdo en que tenían los medios necesarios para trabajar en tareas académicas durante la pandemia (63\% frente a 46\%), así como para entregar estas tareas (65\% frente a 51\%). En cuanto a las desigualdades basadas en la 
riqueza, se identificó que $80 \%$ de las personas con mayores ingresos estaban de acuerdo en que tenían los medios necesarios para trabajar en las tareas escolares, y $81 \%$ estaban de acuerdo o muy de acuerdo en que tenían los medios para entregarlas. Sin embargo, sólo el $28 \%$ de las personas participantes con ingresos más bajos estaba de acuerdo en que tenía los medios necesarios para trabajar en las tareas escolares y $32 \%$ estaba de acuerdo o muy de acuerdo en que tenía los medios para entregarlas (véase la Figura 11). En otras palabras, existe una brecha de 52 puntos porcentuales en la capacidad de estas personas jóvenes para acceder a las tareas y una brecha de 49 puntos porcentuales en su capacidad para trabajar en ellas.

Figura 11. Diferencias en puntos porcentuales en la percepción de jóvenes sobre el acceso a las clases remotas desde el cierre de las instalaciones escolares (entre las personas inscritas en la escuela actualmente), por NSE. VOCES-19. México.
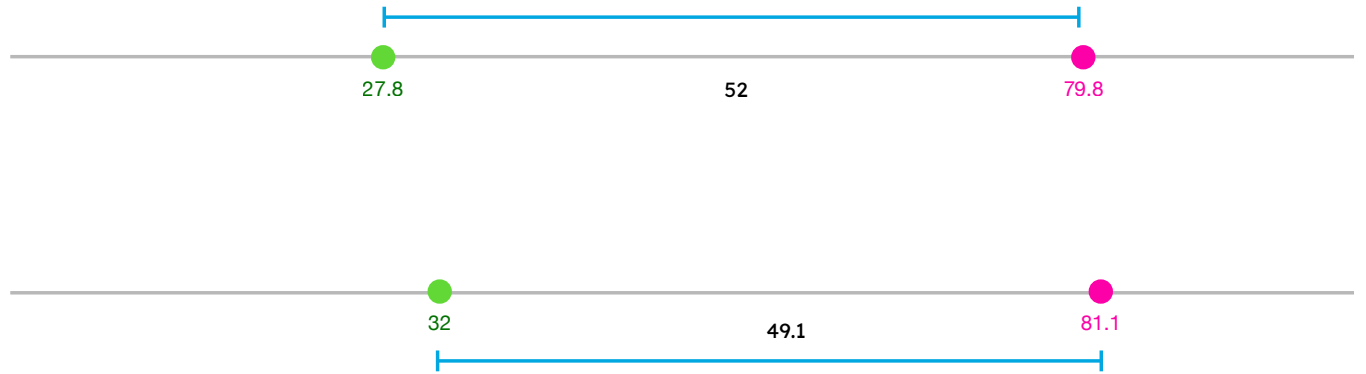

$$
0
$$

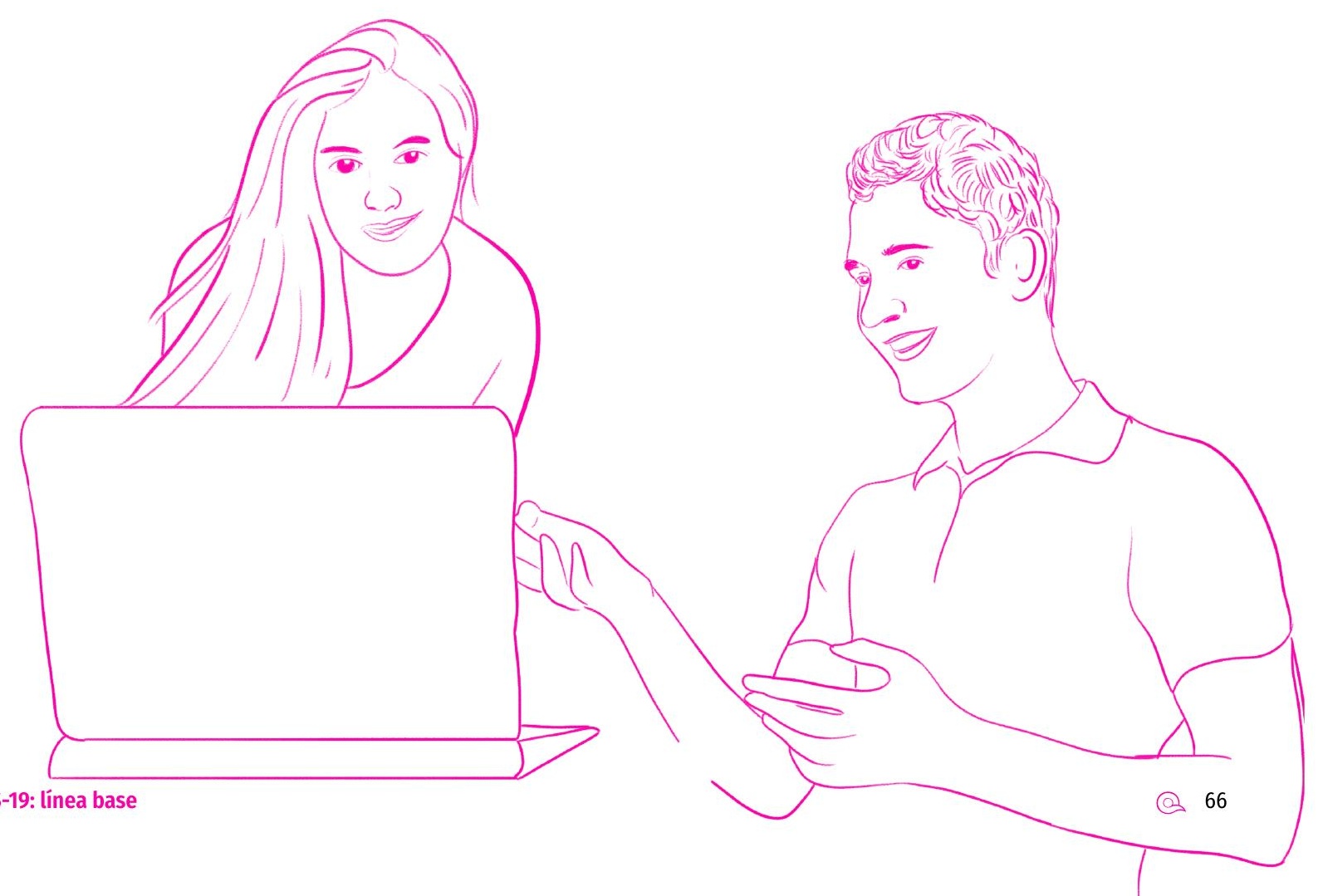




\section{Resumen de los hallazgos}

Los hallazgos sobre la educación y el aprendizaje ilustran uno de los desafíos más serios que enfrentan adolescentes y jóvenes en México. En primer lugar, es importante reconocer que las estrategias de selección y difusión de la encuesta para VOCES-19 limitaron nuestra capacidad de recopilar información sobre personas no escolarizadas. Sin embargo, en el caso de las y los adolescentes que no estaban inscritos en la escuela en el momento de la encuesta, encontramos que la pandemia era la razón más comúnmente citada para haber dejado la escuela. Era más probable que la pandemia se citara como motivo principal del abandono escolar para las personas más favorecidas: las y los participantes que no son I/AD y las personas de mayores ingresos fueron más propensas a haber dejado la escuela debido a la pandemia que sus pares I/AD no escolarizados y de bajos ingresos. Las y los adolescentes de estos grupos en mayor situación de marginación eran más propensos a declarar que habían dejado la escuela porque no podían costear continuar sus estudios. No está claro hasta qué punto esta incapacidad financiera puede haber estado ligada a las consecuencias económicas de las medidas de cierre de la pandemia.

Las personas participantes de VOCES-19 que aún estaban inscritas en la escuela en el momento de la encuesta han recibido casi todas sus clases en línea y sólo un pequeño porcentaje considera que ha aprendido más en este tiempo que cuando sus clases y lecciones eran presenciales. Además, como muestran estos resultados, las repercusiones negativas del paso a la enseñanza en línea han afectado y seguirán afectando de forma desproporcionada a estudiantes de grupos en mayor situación de marginación. Las y los adolescentes y jóvenes que se identifican como indígenas y/o afrodescendientes y los que tienen un estatus socioeconómico más bajo han tenido dificultades para acceder a sus deberes y tareas y entregarlos de forma constante durante toda la pandemia. Preocupantemente, estas grandes desigualdades se encontraron entre un grupo de encuestados que sabemos que es probable que hayan tenido al menos un acceso algo constante a Internet durante la pandemia, dado que pudieron acceder y completar la encuesta en línea. En realidad, sabemos muy poco sobre las dificultades a las que se enfrenta la dimensión de la educación entre aquellas poblaciones en mayor situación de vulnerabilidad que no están bien conectadas a Internet. Dados los niveles de desigualdad encontrados aquí, sólo se puede imaginar la magnitud de las desigualdades reales presentes en el país con respecto al acceso educativo y las experiencias de aprendizaje. Por ello, los esfuerzos de recuperación educativa en México deben centrarse en este sector de la población.

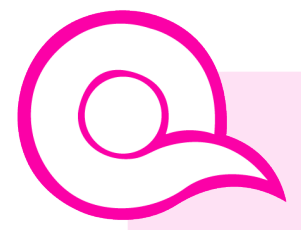

Voy muy bien en la escuela y ahora disfruto más el tiempo con mi familia, a pesar de todo la pandemia me ha traído muy buenas cosas.

Mujer 15 años, San Luis Potosí. 


\section{Empleo e ingresos}

\section{Puntos destacados}

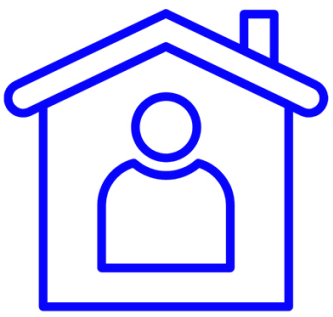

$62 \%$

de los adolescentes

$75 \%$

de los jóvenes reportaron que es algo probable o muy probable que su hogar obtenga ingresos menores en el año en curso, en comparación con el año anterior.

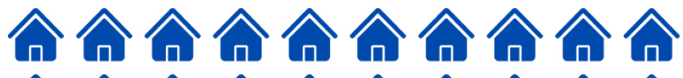
तิ

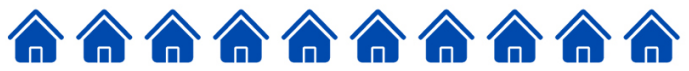

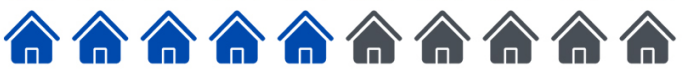

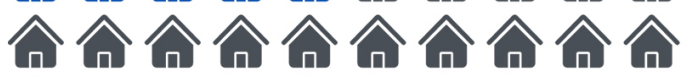

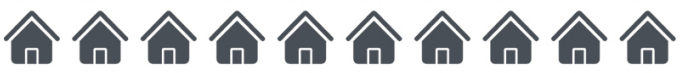

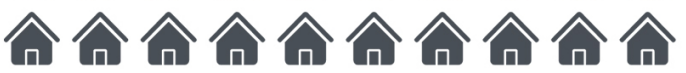

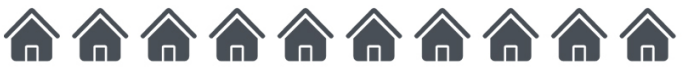

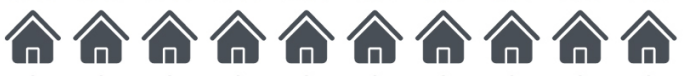
तิ

\section{El $35 \%$ de las y los adolescentes y $\mathbf{4 1 \%}$ de las y los jóvenes}

reportaron que, debido a la pandemia, al menos un miembro de su hogar perdió su principal fuente de ingresos en el mes anterior a la encuesta.

Los resultados muestran grandes brechas en los indicadores relacionados con los ingresos y las capacidades financieras de los hogares, favoreciendo de forma abrumadora a participantes de los hogares más acomodados dentro de ambos grupos de edad.

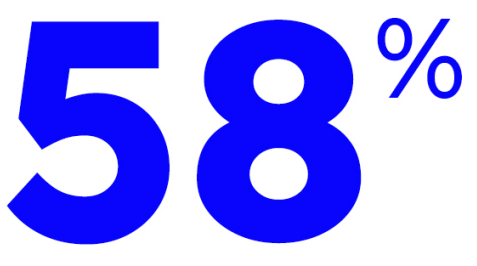

de las personas participantes del nivel socioeconómico más bajo informaron que al menos un miembro de su hogar había perdido su trabajo o cerrado su negocio debido a las medidas de mitigación asociadas a la pandemia de COVID-19 en el mes anterior a la realización de la encuesta, frente al $22 \%$ del nivel socioeconómico más alto.

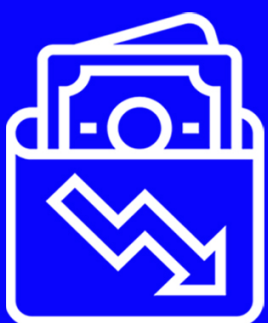

El $16 \%$ de las personas encuestados del nivel socioeconómico más bajo (NSE) declaró que su hogar casi nunca o nunca pudo pagar facturas importantes como la renta durante la pandemia, en comparación con sólo el 3\% del NSE más alto. 
La Organización Internacional del Trabajo (OIT) prevé que la pandemia de COVID-19 tendrá un impacto amplio y devastador sobre el empleo y la generación de ingresos en todo el mundo (International Labour Organization, 2021). Según el informe más reciente de la organización, de enero de 2021, alrededor del 93\% de las y los trabajadores de todo el mundo vivían en países con algún tipo de medidas de distanciamiento social en su lugar de trabajo todavía en vigor al momento de redactar este informe. Se estima que, como resultado de estas medidas de contención, en 2020 se perdieron alrededor de $8.8 \%$ de las horas de trabajo en el mundo, el equivalente a 255 millones de empleos a tiempo completo, en comparación con el cuarto trimestre de 2019.

Desagregado por regiones del mundo, América Latina y el Caribe registraron las mayores pérdidas de horas de trabajo. En México, se estimó un exceso de horas de trabajo perdidas del 12.5\% en 2020, respecto a finales de 2019. Las Américas también experimentaron las mayores pérdidas de ingresos laborales en 2020, con un descenso estimado del 10.3\%. En junio de 2020, la tasa de desempleo en México se elevó al 5.5\% y se espera que haya aumentado a más del 10\% en 2021 (International Labour Organization, 2020). Al igual que otros indicadores que hemos analizado, los datos muestran que existen grandes desigualdades en los impactos de la pandemia sobre el empleo y los ingresos (International Labour Organization, 2021). Las pérdidas de ingresos laborales fueron mayores para las personas trabajadores jóvenes, las mujeres, las personas autoempeladas y personas trabajadoras de baja y media cualificación, mientras que la reducción de puestos de trabajo afectó de forma desproporcionada a los empleos poco remunerados y de baja cualificación. Esta realidad señala la necesidad de centrarse en la recuperación económica de las personas en mayor situación de vulnerabilidad para minimizar el continuo agravamiento de las desigualdades en los próximos años.

VOCES-19 busca examinar las situaciones económicas y las dificultades experimentadas por adolescentes y jóvenes, y sus familias, desde el inicio de la pandemia. El análisis también pretende identificar las diferencias por género, etnicidad y nivel socioeconómico. Todos los resultados se presentan por separado por grupo de edad.

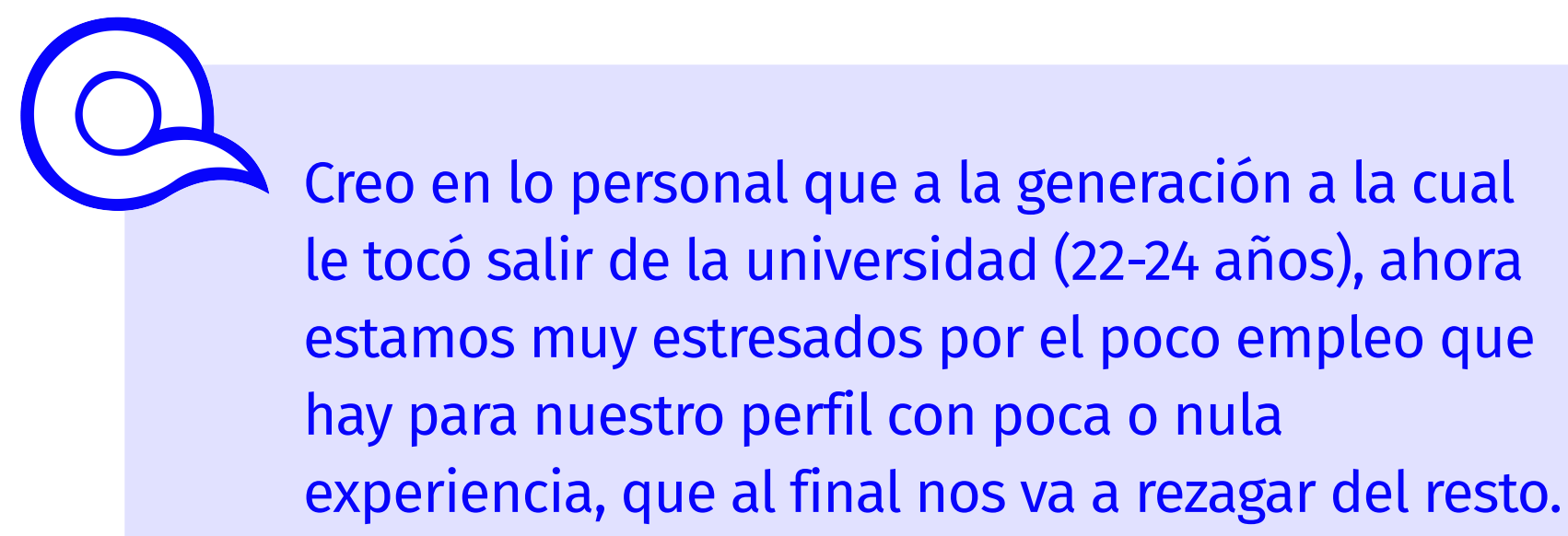

Hombre, 22 años, Ciudad de México. 


\section{¿Cuál era el estatus laboral de las personas participantes de VOCES-19 a 8 meses de iniciar la pandemia?}

\section{Adolescentes}

Del total de adolescentes que participaron en VOCES-19, $23 \%$ tenía un trabajo o un negocio en el momento de la encuesta. Sin embargo, $43 \%$ de las personas que tenían un trabajo o negocio declararon que no habían trabajado en la última semana por una razón relacionada con la pandemia. El 38\% de las y los adolescentes desempleados también mencionaron las medidas de contingencia para COVID-19 como la razón principal para no buscar trabajo en la semana anterior a la realización de la encuesta.

Las mujeres adolescentes tenían menos probabilidades de estar empleadas en el momento de la encuesta en comparación con los hombres adolescentes ( $18 \%$ frente a $27 \%$ ), pero también tenían menos probabilidades de mencionar las medidas de mitigación de COVID-19 como una razón para no buscar trabajo en la semana anterior a la encuesta (35\% frente a 43\%). Las personas participantes indígenas y/o afrodescendientes (I/AD) y de hogares de bajos ingresos tenían más probabilidades de estar trabajando en el momento de la encuesta, en comparación con las personas participantes no I/AD y de hogares de altos ingresos, respectivamente (28\% de participantes I/AD frente al $20 \%$ de participantes no I/AD y $27 \%$ de adolescentes de bajos ingresos frente al $21 \%$ de adolescentes de altos ingresos). Las personas adolescentes empleadas de hogares de bajos ingresos, en comparación con sus pares de hogares de altos ingresos, también fueron más propensas a informar que no habían trabajado en la última semana por razones relacionadas con la pandemia (60\% frente al $33 \%)$. Además, las y los adolescentes desempleados de hogares de bajos ingresos declararon con mayor frecuencia que las medidas de contingencia de la COVID-19 eran la razón principal para no haber buscado trabajo en la semana anterior a la realización de la encuesta, en comparación con los adolescentes de hogares de altos ingresos (43\% frente al $32 \%$ ).

\section{Personas jóvenes}

Cuatro de cada diez jóvenes que participaron en VOCES-19 estaban trabajando en el momento de la encuesta. Entre las personas jóvenes empleadas, $46 \%$ no trabajó en la semana anterior a la encuesta por una razón relacionada con la pandemia. Entre las y los jóvenes desempleados, 51\% declaró las medidas de contingencia del COVID-19 como la razón principal para no haber buscado trabajo en la semana anterior a la pandemia.

En este grupo de edad, las mujeres también tenían menos probabilidades de estar empleadas en el momento de la encuesta, en comparación con los hombres jóvenes ( $41 \%$ frente al $48 \%$ ), pero también era menos probable que declararan que la pandemia de COVID-19 era la razón principal por la que, aun estando empleados, no habían trabajado en la semana anterior a la pandemia (39\% frente al 52\%). Las personas jóvenes I/AD tenían más probabilidades de estar trabajando en el momento de la encuesta, en comparación con las personas no I/AD ( $47 \%$ frente al $43 \%$ ). No se encontraron diferencias significativas en cuanto a la situación laboral entre jóvenes de hogares con ingresos bajos en comparación con los de ingresos altos. Sin embargo, las personas jóvenes empleadas de hogares de bajos ingresos, en comparación con jóvenes de 
hogares de altos ingresos, fueron más propensas a declarar la pandemia de COVID-19 como la razón por la que no trabajaron la semana anterior a la encuesta (55\% vs. 33\%), y las personas jóvenes desempleadas en el NSE más bajo también fueron más propensas a declarar la pandemia de COVID-19 como la razón principal de no haber buscado trabajo en la semana anterior a la encuesta, en comparación con sus pares en el NSE más alto (60\% vs. 47\%).

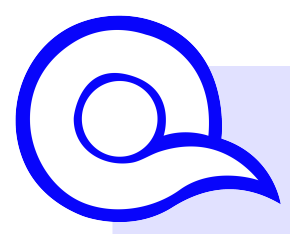

En mi caso personal, porque no he tenido ingresos (cambié de trabajo) hasta el 16 de diciembre (que será mi primera quincena), sí he visto dificultad para adquirir alimentos y medicinas sin sentir que me estoy endeudando. Mi familia también me trae comida y me apoya con los gastos de renta y servicios mientras tanto. También fue la primera vez que pedí un crédito... Algo que me dió alivio, pero genera tensión. Considero que mi factor principal de estrés en este momento es el dinero, aunque también me incomoda no salir tanto como quisiera. Creo que mi tensión se reducirá a partir de mi primer ingreso, ya que dejaré de pensar en mis deudas y podré retomar mi terapia psicológica.

Mujer, 24 años, Jalisco.

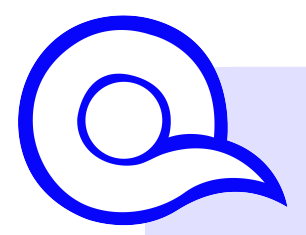

En los últimos meses todo ha cambiado en mi familia ya que fallecieron mis abuelitos. Casi todos mis tíos se contagiaron de COVID y por esa razón los descansaron de su trabajo, por lo cual estamos muy mal económicamente. Yo trabajaba con uno de mis tíos en su negocio familiar, pero lo cerró por un tiempo. Ahora solo trabaja mi mamá pero está en riesgo de que la descansen un tiempo ya que su patrón contrajo COVID-19, por eso mismo nuestro estado de ánimo cambió... a algo más negativo. Sin embargo, estamos haciendo todo lo posible por salir adelante.

Mujer, 19 años, Guanajuato. 


\title{
¿Cómo ha impactado la pandemia las condiciones de empleo e ingresos en los hogares de las personas participantes de VOCES-19?
}

\author{
Adolescentes
}

VOCES-19 muestra que las personas adolescentes mexicanas están sintiendo los impactos negativos de la pandemia en las condiciones de empleo e ingresos tanto familiares como personales. Por ejemplo, 36\% indicó que al menos un miembro de su hogar perdió su trabajo o cerró su negocio debido a la pandemia en el mes anterior a la encuesta, 34\% consideró que él/ella u otro miembro de su hogar perdería ingresos en los próximos meses debido a la pandemia, y 63\% declaró que es algo probable o muy probable que su hogar obtenga menores ingresos en 2020, en comparación con 2019. También preguntamos a las y los adolescentes si desde el comienzo de la pandemia, sus hogares nunca, o rara vez, habían podido comprar suficientes alimentos, pagar facturas importantes (por ejemplo, la renta), y/o comprar medicamentos necesarios. El 3\% declaró esto último para los alimentos, y el 7\% para las facturas y/o los medicamentos necesarios.

Al analizar estas variables por género, etnicidad y NSE, las diferencias más importantes se encontraron entre las personas adolescentes de hogares de bajos ingresos en comparación con los de altos ingresos. Las y los adolescentes del NSE más bajo, en comparación con sus pares del NSE más alto, fueron más propensos a considerar una pérdida de ingresos en los próximos meses (48\% vs. 22\%), más propensos a percibir que su hogar ganaba menos ingresos en 2020 que en 2019 (69\% vs. 53\%), y más propensos a informar que al menos un miembro de la familia había perdido su principal fuente de

Figura 12. Diferencia en puntos porcentuales en el impacto financiero de las medidas de mitigación de COVID-19 entre adolescentes, por NSE. VOCES-19. México.

- Hogares de ingresos más bajos (primer quintil) - Hogares de ingresos más altos (quinto quintil)
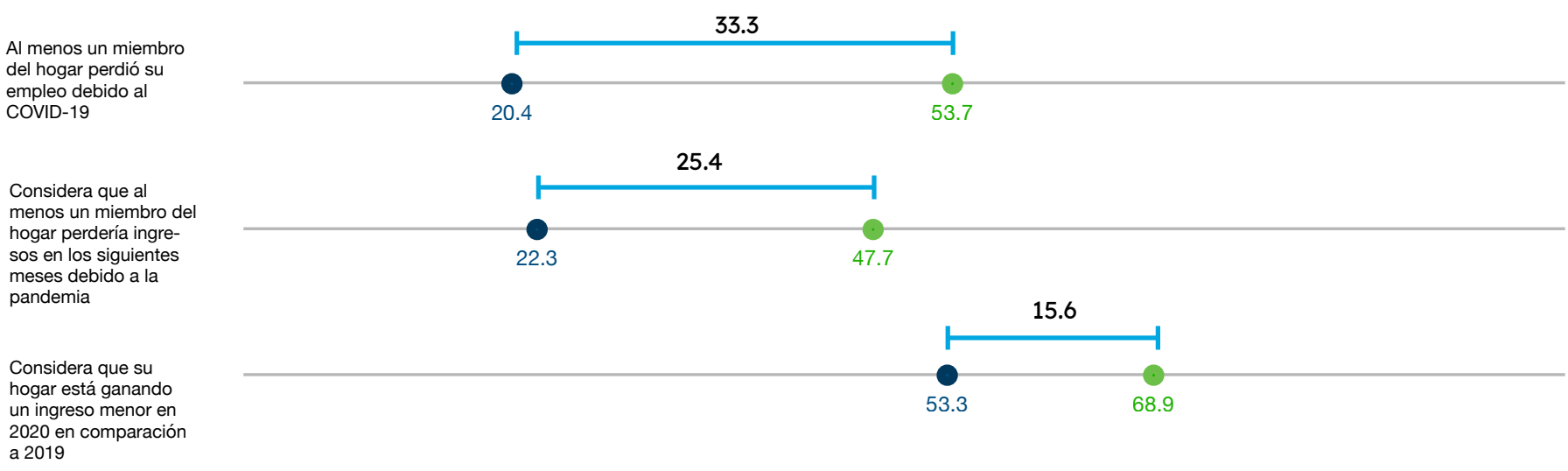

0

20

40

60

80

100 
ingresos debido al COVID-19 (54\% vs. 20\%) (ver Figura 12). También informaron con mayor frecuencia que, desde el comienzo de la pandemia, sus hogares rara vez o nunca han podido comprar suficientes alimentos (6\% frente a $1 \%$ ), pagar facturas importantes (15\% frente a $3 \%$ ), y/o comprar los medicamentos necesarios ( $13 \%$ frente a $3 \%$ ).

\section{Los hogares de las personas adolescentes I/AD también resultaron ser más vulnerables} económicamente que los de las personas adolescentes no I/AD. Las y los adolescentes I/AD fueron más propensos que sus pares no I/AD a esperar una pérdida de ingresos en los próximos meses (40\% vs. $31 \%$ ), más propensos a percibir que su hogar tendría menos ingresos en 2020 que en 2019 (67\% vs. 61\%), y más propensos a informar que al menos un miembro de la familia había perdido su principal fuente de ingresos debido al COVID-19 (41\% vs. 33\%) (ver Figura 13). Además, un mayor porcentaje de adolescentes I/AD frente a sus pares no I/AD percibió que desde el inicio de la pandemia sus hogares rara vez o nunca pudieron comprar suficientes alimentos (3\% frente a $2 \%$ ), pagar facturas importantes (10\% frente a $6 \%$ ), y/o comprar los medicamentos necesarios ( $9 \%$ frente a $6 \%$ ).

Figura 13. Diferencias en puntos porcentuales en el impacto financiero de las medidas de mitigación de COVID-19 entre adolescentes, por origen étnico. VOCES-19. México.

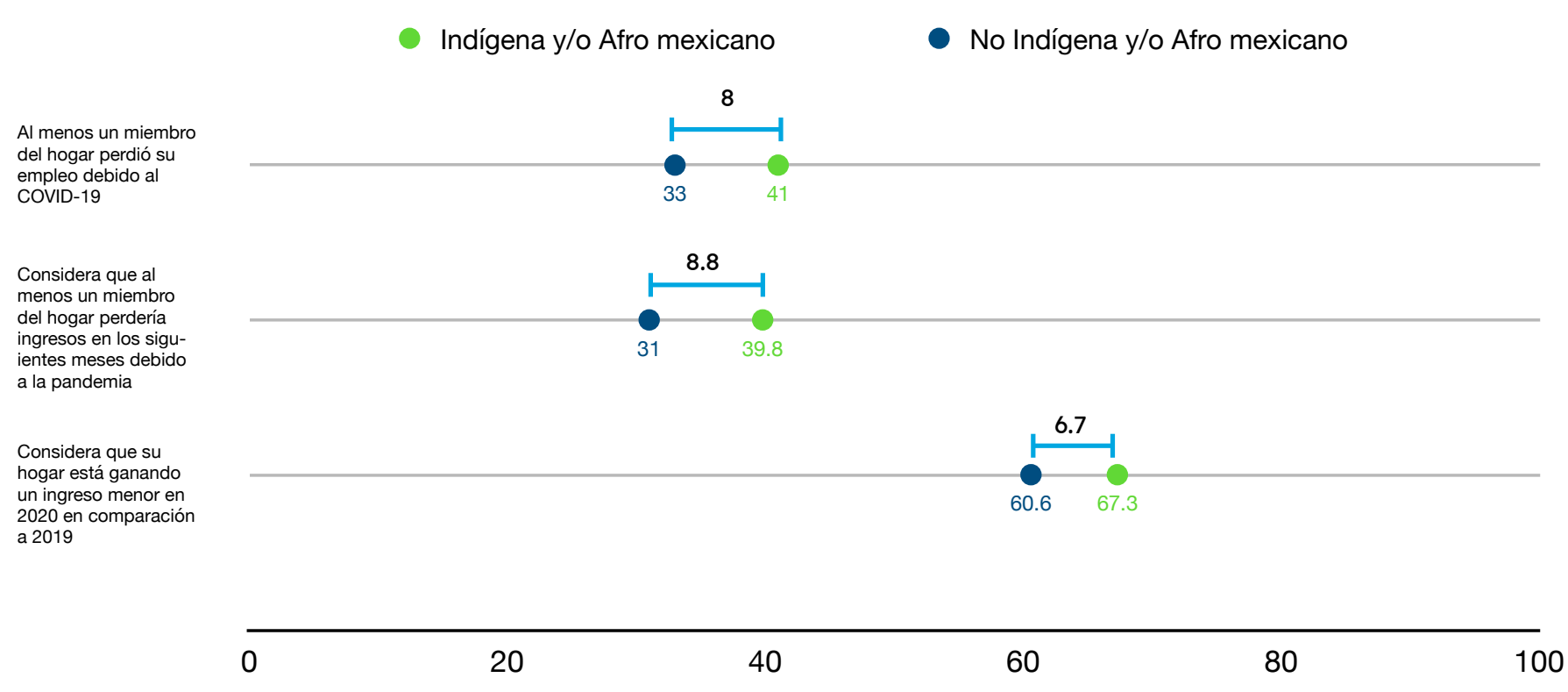

Por último, también identificamos diferencias por género, donde las mujeres adolescentes en comparación con los hombres adolescentes fueron más propensas a percibir impactos económicos negativos. Un mayor porcentaje de mujeres en comparación con los hombres esperaban una pérdida de ingresos en los próximos meses (37\% frente a 30\%), percibieron que su hogar estaba ganando un menor ingreso en 2020 que en 2019 (64\% frente a 62\%), y reportaron que al menos un miembro de la familia había perdido su principal fuente de ingresos debido al COVID-19 (40\% frente a $31 \%$ ). 


\section{Personas jóvenes}

Cuatro de cada diez personas jóvenes que participaron en VOCES-19 percibieron un impacto de la pandemia en las condiciones de empleo e ingresos de su hogar. El $41 \%$

consideró que ellos/ellas u otro miembro de la familia en su hogar perdería ingresos en los próximos meses debido a la pandemia. Además, $75 \%$ percibió que era algo o muy probable que su hogar recibiera menos ingresos en 2020 en comparación con 2019 y $41 \%$ informó que al menos un miembro de su hogar perdió su principal fuente de ingresos debido a la pandemia en el mes anterior a la encuesta. Además, $4 \%$ de las personas jóvenes declaró que desde el comienzo de la pandemia su hogar rara vez o nunca pudo comprar suficientes alimentos, y el $8 \%$ pagar facturas importantes y/o comprar los medicamentos necesarios.
Las mayores diferencias se encontraron entre las personas jóvenes de hogares de bajos ingresos en comparación con los de altos ingresos. Por ejemplo, encontramos una diferencia de 33 puntos porcentuales entre jóvenes del NSE más bajo y del NSE más alto que consideraron una pérdida de ingresos en los próximos meses, de 19 puntos porcentuales entre jóvenes de hogares de bajos ingresos y los de hogares de altos ingresos que percibieron que su hogar estaba ganando un ingreso menor en 2020 en comparación con 2019, y de 40 puntos porcentuales entre jóvenes del NSE más bajo y del NSE más alto que informaron que al menos un miembro de la familia había perdido su principal fuente de ingresos debido al COVID-19 (ver Figura 14). También fueron más propensas a informar que, desde el comienzo de la pandemia, su hogar rara vez o nunca había podido comprar suficientes alimentos, pagar facturas importantes y/o comprar los medicamentos necesarios.

Figura 14. Diferencias en puntos porcentuales en el impacto financiero de las medidas de mitigación del COVID-19 entre jóvenes, por NSE. VOCES-19. México.

Al menos un miembro del hogar perdió su empleo debido al COVID-19

Hogares de ingresos más bajos (primer quintil)

37.9

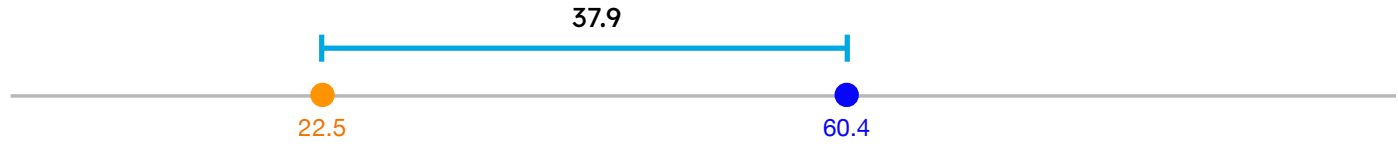

Considera que al menos un miembro del hogar perdería ingresos en los siguientes meses debido a la pandemia
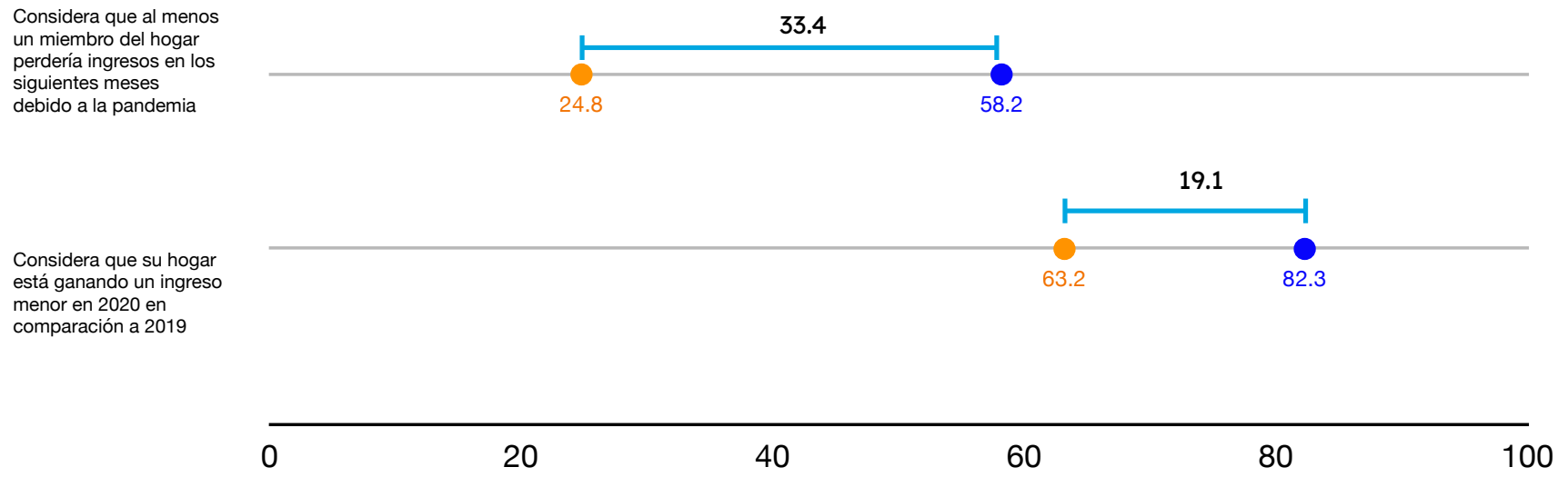
Las personas jóvenes I/AD, en comparación con jóvenes no I/AD, también fueron más propensas a anticipar una pérdida de ingresos en los próximos meses (49\% frente al 38\%), más propensas a percibir que su hogar estaba ganando un menor ingreso en 2020 que en 2019 (80\% frente al 73\%), y más propensas a informar que al menos un miembro de la familia había perdido su principal fuente de ingresos debido al COVID-19 (50\% frente al 37\%) (ver Figura 15). Las personas jóvenes I/AD también fueron más propensas a informar que desde el inicio de la pandemia su hogar rara vez o nunca había podido comprar suficiente comida, pagar facturas importantes y/o comprar medicamentos necesarios, en comparación con jóvenes no I/AD.

Figura 15. Diferencias en puntos porcentuales en el impacto financiero de las medidas de mitigación de COVID-19 entre jóvenes, por origen étnico. VOCES-19. México.

Al menos un miembro del hogar perdió su

empleo debido al

COVID-19

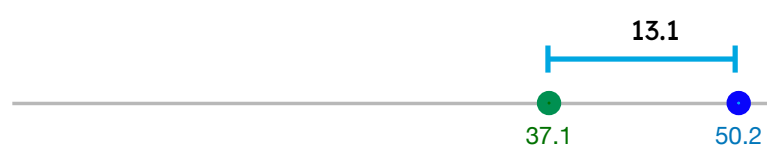

Considera que al menos un miembro del hogar perdería ingresos en los siguientes meses debido a la pandemia

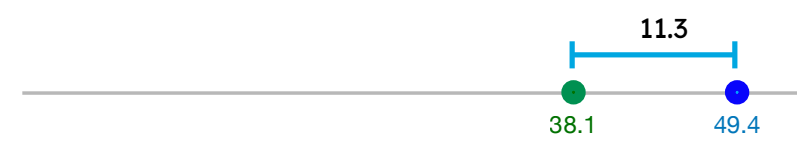

a 2019

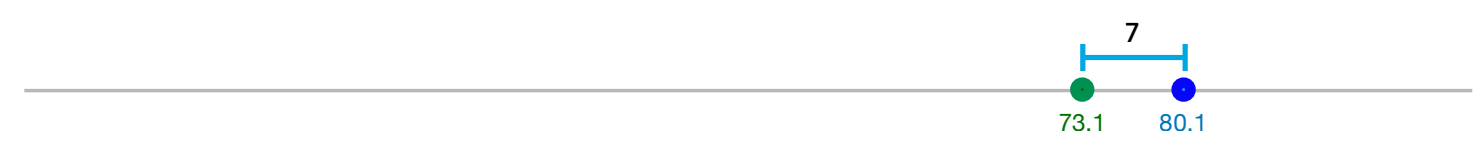

0

20

40

60

80

Para este grupo de edad, las mujeres fueron más propensas que los hombres a prever una pérdida de ingresos en los próximos meses ( $43 \%$ frente a 39\%) y declararon en mayor proporción que al menos un miembro de la familia había perdido su principal fuente de ingresos debido a la COVID-19 (45\% frente a $37 \%$ ). No se encontraron otras diferencias significativas para estas variables al comparar los resultados por género.

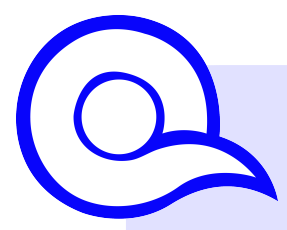

Cabe decir que desde que empezó la pandemia del COVID. Muchos jóvenes recién egresados de la universidad (como es mi caso) nos enfrentamos en un campo de desempleo y me gustaría que formulen políticas públicas por parte del gobierno para apoyar a los jóvenes profesionistas. Gracias.

Hombre, 24 años, Quintana Roo. 


\section{¿Cómo lidiaron los hogares de las personas participantes con los impactos financieros de la pandemia de COVID-19?}

\section{Adolescentes}

Los resultados muestran que los hogares de las personas adolescentes participantes aplicaron medidas financieras para contrarrestar los impactos de la pandemia, en particular los de los hogares de participantes I/AD y de bajos ingresos. El $44 \%$ de las y los adolescentes declaró que su familia había vendido artículos y/o pedido dinero prestado, entre otras medidas, para hacer frente a los impactos financieros de la pandemia, y el 16\% informó que sus familias empezaron a recibir ayuda de un programa gubernamental desde que empezó la pandemia. Un mayor porcentaje de participantes I/AD frente a participantes no I/AD (47\% frente a $42 \%$ ) y de adolescentes de hogares con ingresos bajos frente a participantes de ingresos altos (59\% frente a $29 \%$ ) declararon que su familia vendió artículos y/o pidió dinero prestado, entre otras medidas, para hacer frente a los impactos financieros de la pandemia. No se encontraron diferencias por género para estas dos variables.

\section{Personas jóvenes}

Los hogares de las personas jóvenes participantes también aplicaron medidas de contingencia para hacer frente a las consecuencias financieras de la pandemia. El 59\% de las personas jóvenes declaró que su familia vendió artículos y/o pidió dinero prestado, para poder hacer frente a los impactos financieros de la pandemia. Uno de cada diez jóvenes declaró que sus familias empezaron a recibir ayuda de un programa gubernamental desde que empezó la pandemia. Las personas I/AD y jóvenes de hogares con bajos ingresos declararon con mayor frecuencia que sus familias tuvieron que vender artículos y/o pedir dinero prestado, en comparación con las personas no I/AD (65\% frente a 56\%) y jóvenes de hogares con altos ingresos (78\% frente a 39\%). Al comparar por género, vemos que son más los hombres que declararon que sus familias empezaron a recibir ayuda de un programa gubernamental desde que empezó la pandemia, en comparación con las mujeres (12\% frente a $9 \%)$.

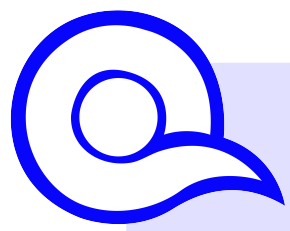

Tuve que dejar mis estudios universitarios para aportar recursos económicos a la familia. Tuve que vender mi computadora. Y actualmente no cuento con ningún trabajo, ya que por donde resido están cerrando todo de nuevo.

Hombre, 19 años, Puebla. 


\section{Resumen de los hallazgos}

Las personas participantes en VOCES-19 perciben fuertemente los impactos negativos de la pandemia en las condiciones de empleo e ingresos de sus hogares. Para casi todos los indicadores, estos impactos negativos fueron reportados en mayor proporción por las mujeres en comparación con los hombres, los participantes I/AD en comparación con los no I/AD, y las personas con menores ingresos en comparación con las de mayores ingresos. Por ejemplo, las personas participantes adolescentes y jóvenes pertenecientes a estos grupos eran significativamente más propensas que sus homólogas a informar que ellas u otro miembro de su hogar perdería ingresos en los próximos meses debido a la pandemia, que al menos un miembro del hogar había perdido su trabajo o había tenido que cerrar un negocio debido a las medidas de cierre de COVID-19 en el mes anterior a la realización de la encuesta, y que era probable que su hogar tuviera menos ingresos en el año en curso en comparación con el año anterior.

Las personas participantes del nivel socioeconómico más bajo también eran más propensas a afirmar que su hogar rara vez o nunca había podido comprar suficientes alimentos, pagar facturas importantes y comprar los medicamentos necesarios, en comparación con participantes del nivel socioeconómico más alto. Las desigualdades observadas en estos indicadores de empleo y salud financiera apoyan la evidencia reciente que ha mostrado cómo las mujeres jóvenes y los trabajadores con empleos poco remunerados se han visto desproporcionadamente afectados por la pandemia y señalan la necesidad de asegurar que los esfuerzos de recuperación económica en México se diseñen e implementen teniendo en cuenta las prioridades de los grupos en situación de mayor vulnerabilidad (UN Women, 2020).

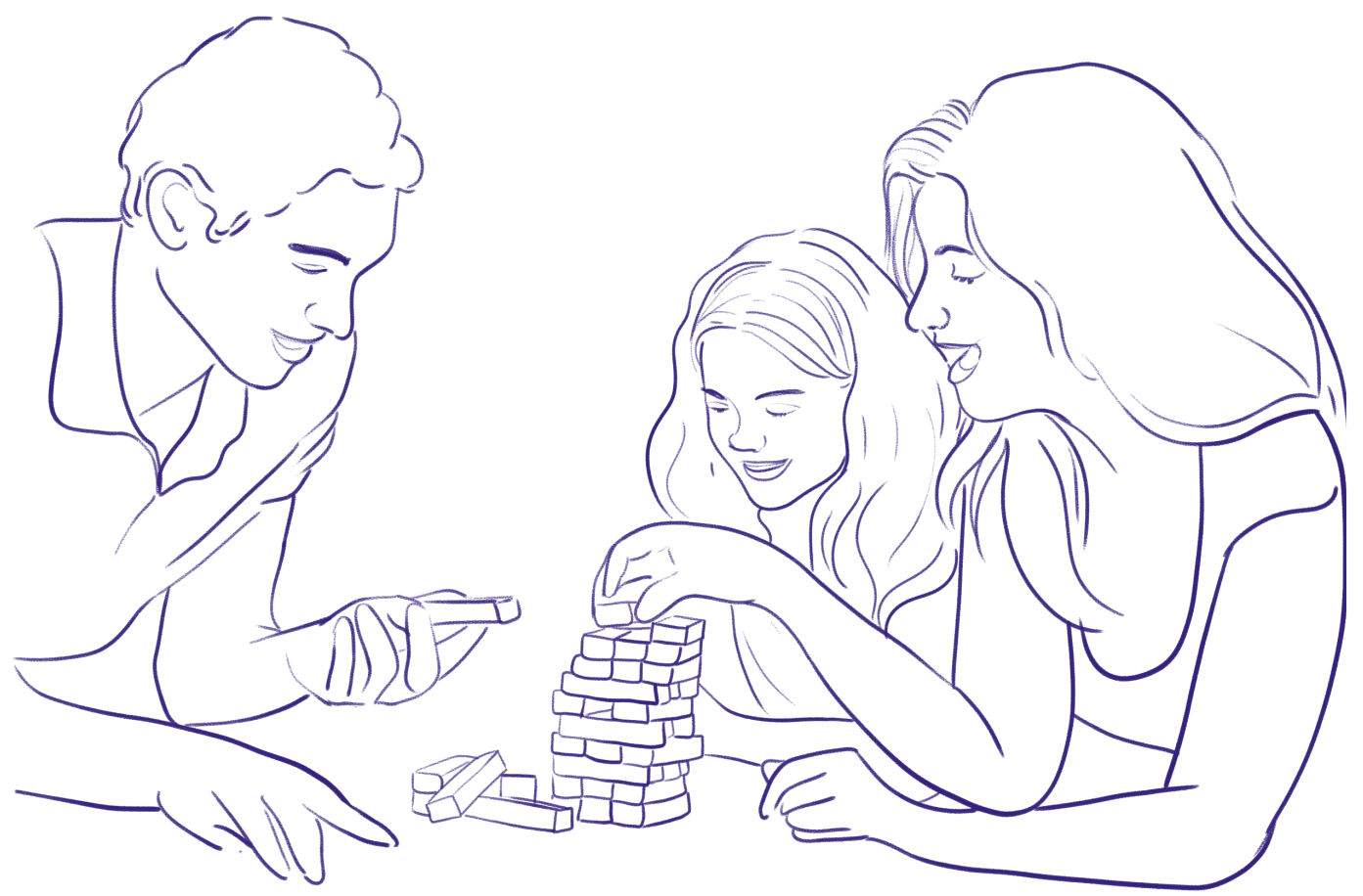

Crédito de la ilustración: Valeria García Trejo. Instagram grillolunar_vg. 


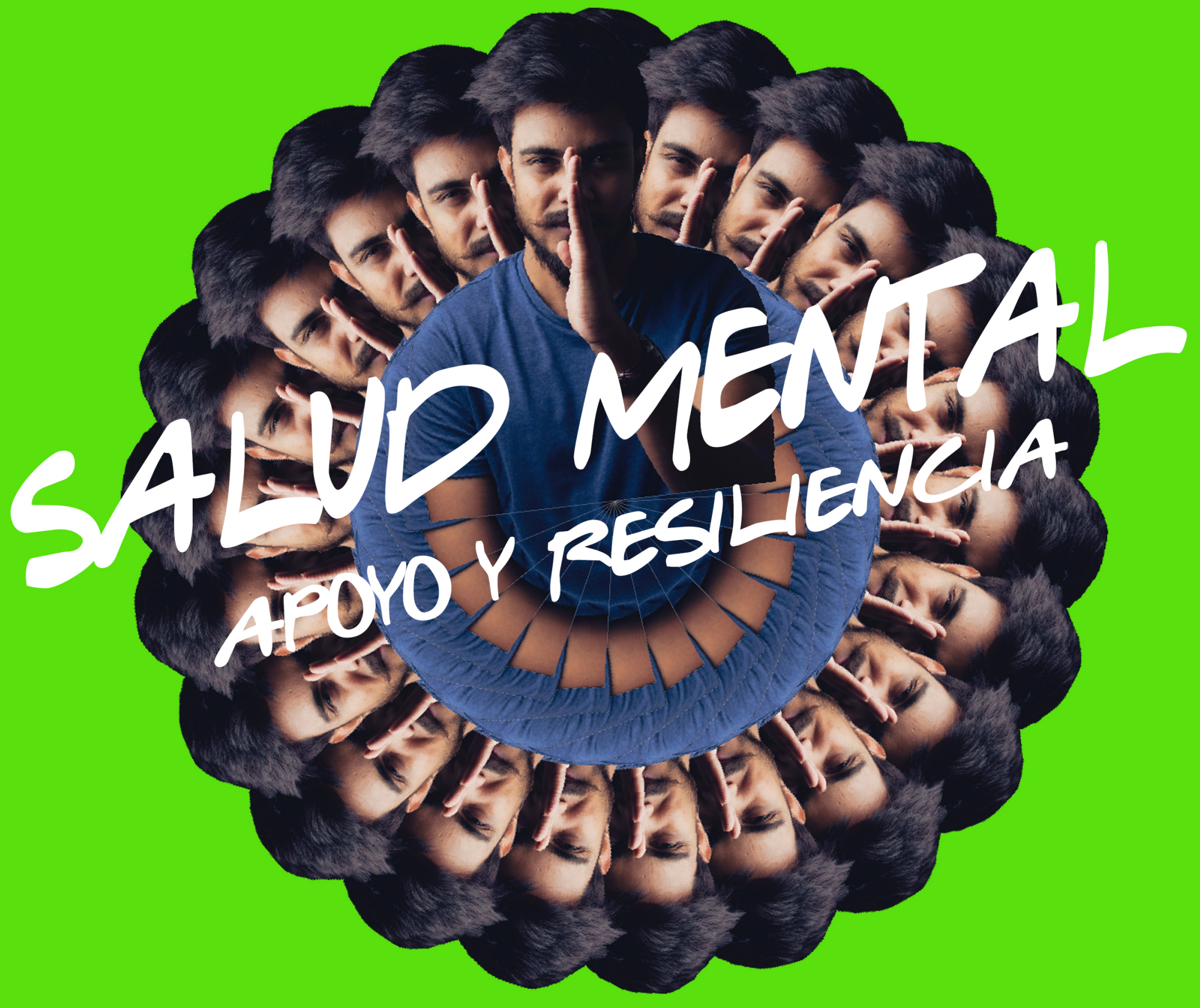




\section{Salud mental, apoyo y resiliencia}

Puntos destacados
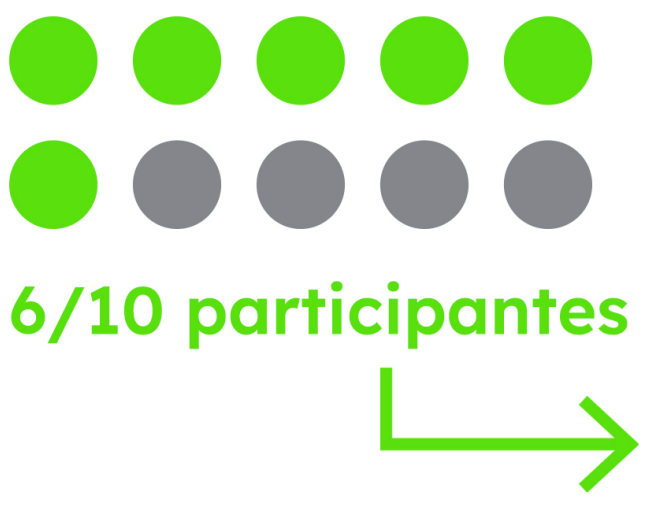

Casi seis de cada diez participantes en el estudio declararon que los sentimientos relacionados con los síntomas de ansiedad y depresión les han molestado más desde el comienzo de la pandemia, en comparación con antes.

La prevalencia de sintomas de depresión y de ansiedad fue significativamente mayor entre las mujeres y las personas no binarias que entre los hombres en ambos grupos de
Acceso a terapia para el quintil socioeconómico más alto VS el quintil socioeconómico más bajo
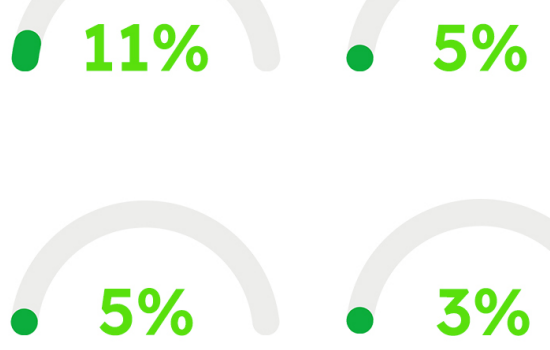

Los hallazgos ilustran algunas diferencias basadas en los ingresos en el uso de ciertas estrategias de afrontamiento para lidiar con los sentimientos preocupantes que jóvenes y adolescentes han sentido desde el comienzo de la pandemía.

Casi el $11 \%$ de las personas jóvenes y $5 \%$ de las y los adolescentes en los quintiles socioeconómicos más altos declararon haber recibido algún tipo de terapia por teléfono o a través de sesiones virtuales en algún momento desde el inicio de la pandemia, en comparación con $5 \%$ de jóvenes y $3 \%$ de adolescentes en el quintil socioeconómico más bajo.

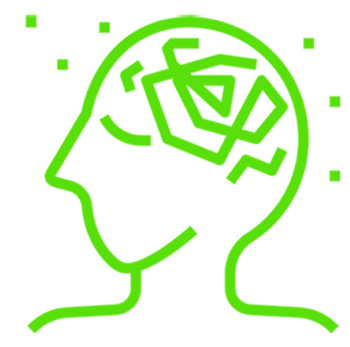

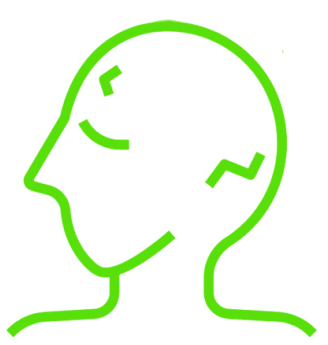


La Asociación Americana de Psicología define la resiliencia mental como "el proceso de adaptarse bien ante la adversidad, el trauma, la tragedia, las amenazas o incluso fuentes significativas de estrés" (American Psychological Association, 2012). Esta capacidad de adaptarse bien y superar estos sucesos de la vida estresantes ha tenido relevancia durante la pandemia del COVID-19, durante la cual adolescentes y jóvenes se han enfrentado a una incertidumbre extrema y a la pérdida de control, y en consecuencia han experimentado un aumento de las tasas de ansiedad, depresión y estrés (Shanahan, et al., 2020).

Mientras que las personas más jóvenes se enfrentan a un menor riesgo de complicaciones de salud graves relacionadas con el COVID-19, las fuentes de esta incertidumbre pueden ir desde el miedo a perder a los miembros de la familia, la paralización social asociada a las medidas de cierre y las dificultades económicas. Los estudios realizados durante la pandemia han demostrado que las estrategias de afrontamiento específicas, como el mantenimiento de una rutina diaria, la práctica constante de ejercicio y el mantenimiento del contacto con los amigos y la familia, están asociadas a la reducción del estrés (Shanahan, et al., 2020).

Con VOCES-19, nos interesaba explorar las experiencias de personas jóvenes y adolescentes mexicanas con la ansiedad y la depresión a lo largo de la pandemia de COVID-19 y conocer cómo han estado afrontado los factores de estrés provocados por las medidas de mitigación de la pandemia, así como la pandemia misma. Al igual que en las secciones anteriores, presentamos todos los resultados por separado según el grupo de edad, y destacamos las diferencias en cada dimensión entre participantes según el género, la etnicidad y el nivel socioeconómico.

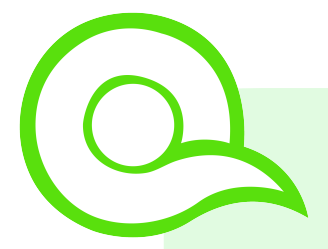

La salud mental de todos los jóvenes se ha venido abajo no solo por el cambio de la escuela en casa, si no que se pierde la relación humana, nos sentimos inseguros de no aprender y de no saber qué hacer después con nuestro futuro. La pérdida de un ser querido en estas condiciones a la larga puede ser muy fuerte, y no tenemos lo medios para poder tomar terapia

Mujer, 22 años, Ciudad de México. 


\section{¿Cuál es el estado de la salud mental entre adolescentes y jóvenes?}

\section{Adolescentes}

Las personas participantes adolescentes mostraron una alta prevalencia de síntomas tanto de ansiedad como de depresión en las dos semanas anteriores a la realización de la encuesta. Según los criterios de puntuación de las escalas PHQ-9 y GAD-7, la prevalencia de síntomas depresivos de leves a graves entre las y los adolescentes del estudio fue del 64\%, mientras que la prevalencia de síntomas de ansiedad de leves a graves fue del $57 \%$.

Encontramos diferencias significativas tanto para la depresión como para la ansiedad al comparar entre mujeres y hombres adolescentes, y adolescentes no binarios y binarios. Por ejemplo, el $71 \%$ y el 65\% de las mujeres adolescentes mostraron síntomas de depresión y ansiedad, respectivamente, en comparación con el $56 \%$ y el $49 \%$ de los hombres adolescentes. La prevalencia entre los adolescentes no binarios fue significativamente mayor que entre los adolescentes binarios (89\% frente a $63 \%$ para la depresión y $83 \%$ frente a $57 \%$ para la ansiedad) (ver Figura 16). También hubo diferencias significativas en función del NSE, ya que las personas adolescentes de hogares con ingresos allos tenían más probabilidades que las personas de hogares con ingresos bajos de haber experimentado síntomas depresivos en las dos semanas anteriores a la encuesta (67\% frente a $62 \%$ ).

Figura 16. Porcentaje de adolescentes con síntomas depresivos y de ansiedad, por género. VOCES-19. México.

- Mujeres adolescentes $\bullet$ Hombres adolescentes Adolescentes no binarios

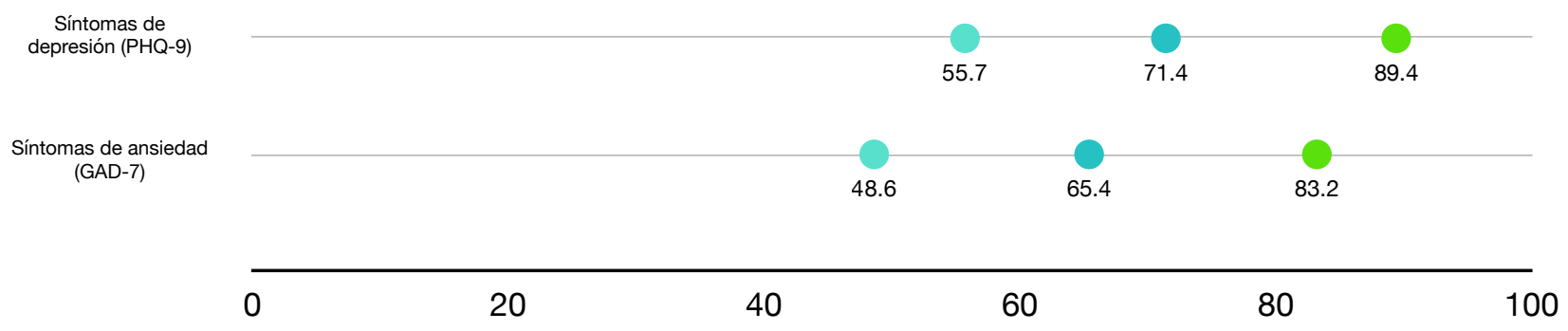

Un indicador que ilustra la gravedad de la situación para las y los adolescentes a lo largo de la pandemia es el ítem de la escala PHQ-9 que pregunta a los participantes con qué frecuencia habían considerado lastimarse de alguna manera o habían experimentado pensamientos sobre que estarían mejor muertos/ as. El $26 \%$ de todas las personas adolescentes que completaron la encuesta informaron de que habían experimentado estos pensamientos al menos algunos días en las dos semanas anteriores a la encuesta. Un mayor porcentaje de mujeres adolescentes (30\%) en comparación con los hombres adolescentes (21\%), y adolescentes no binarios (61\%) frente a binarios (25\%) declararon haber experimentado estos pensamientos. 


\section{Personas jóvenes}

Las tasas de prevalencia de depresión y ansiedad también fueron elevadas para las personas jóvenes: $71 \%$ para los síntomas depresivos y $64 \%$ para los síntomas de ansiedad. Se encontraron diferencias de género en las tasas de prevalencia de los indicadores de depresión y ansiedad. En este grupo de edad, $76 \%$ de las mujeres, $64 \%$ de los hombres y $94 \%$ de las personas no binarias presentaban síntomas de depresión (ver Figura 17). Las tasas de prevalencia de los síntomas de ansiedad fueron del $71 \%$ para las mujeres, del $57 \%$ para los hombres y del $78 \%$ para las personas no binarias. No se encontraron diferencias en las tasas de prevalencia según la etnicidad o el NSE.

\section{Figura 17. Porcentaje de jóvenes con síntomas depresivos y de ansiedad, por género. VOCES-19. México.}

Mujeres jóvenes Hombres jóvenes Jóvenes no-binarios

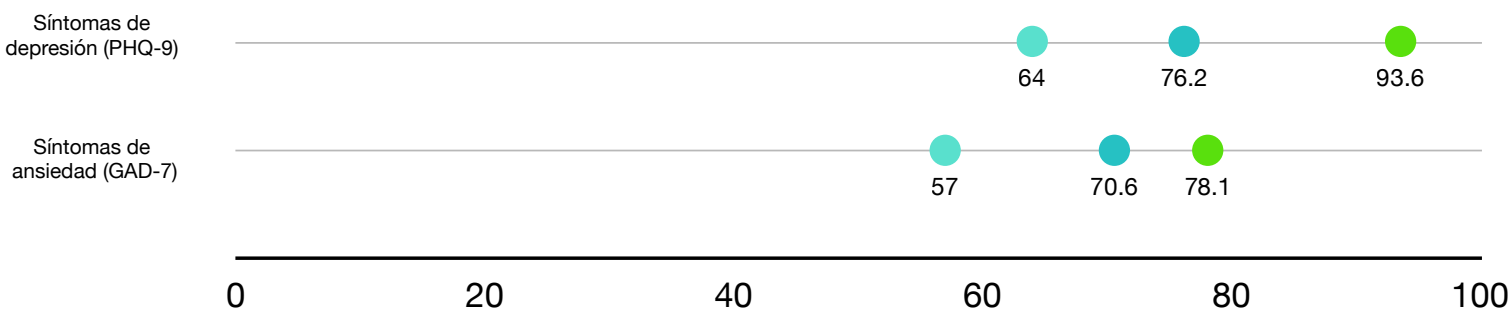

Casi 3 de cada 10 jóvenes declararon haber tenido pensamientos sobre que estarían mejor muertos/as o pensamientos de lastimarse de alguna manera en las dos semanas anteriores a la encuesta. Las mujeres jóvenes tenían más probabilidades de haber experimentado estos pensamientos en comparación con los hombres ( $29 \%$ frente al $26 \%$ ), al igual que las personas no binarias en comparación con las personas binarias ( $62 \%$ frente al $28 \%$ ).

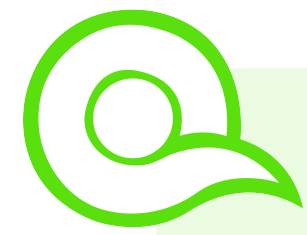

La salud mental está jugando un papel sumamente importante en la vida de la sociedad ya que el confinamiento está dejando una pandemia mental.

Mujer, 22 años, México. 


\section{¿La pandemia ha impactado en la salud mental de adolescentes y jóvenes?}

Adolescentes

Cinco de cada diez adolescentes declararon que los sentimientos problemáticos les habian molestado más desde el comienzo de la pandemia, en comparación con antes. En particular, las mujeres adolescentes tenían alrededor de 17 puntos porcentuales más de probabilidades que los hombres adolescentes de declarar un aumento en estos síntomas (59\% frente a $42 \%$ ).

Las personas de los grupos étnicos y socioeconómicos en menor situación de marginación fueron más propensas que sus pares en mayor situación de marginación a informar que los sentimientos problemáticos aumentaron tras el inicio de la pandemia. Las personas adolescentes no I/AD fueron unos cuatro puntos porcentuales más propensas que sus pares I/AD a informar de este impacto (52\% frente al $48 \%$ ), mientras que las personas del quintil socioeconómico más alto también fueron cuatro puntos porcentuales más propensas a reportar esto que las del quintil más bajo (54\% frente al 50\%).

\section{Personas jóvenes}

Entre la población joven, casi seis de cada diez participantes declararon que la ansiedad y los síntomas depresivos les han molestado más desde el comienzo de la pandemia, en comparación con antes. Al igual que en el caso de las y los adolescentes, las mujeres jóvenes fueron más propensas a haber experimentado este aumento en comparación con los hombres jóvenes (66\% frente al 52\%).

En este grupo de edad, las personas participantes no I/AD y las que proceden de hogares con altos ingresos también informaron de un aumento de estos sentimientos con mayor frecuencia. El 61\% de las personas jóvenes no I/AD informaron de este aumento, en comparación con el $55 \%$ de jóvenes I/AD, y el 64\% de jóvenes en el NSE más alto lo hicieron, en comparación con el $56 \%$ en el NSE más bajo.

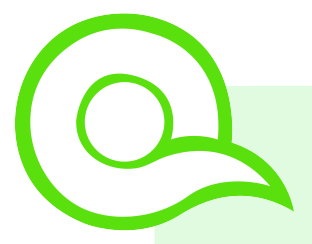

La pandemia está afectando fuertemente la salud mental de los jóvenes ya que nosotros estamos en una etapa de crecimiento la cual necesita de una mayor conciencia social, esto ¿cómo podría solucionarse?

Hombre, 17 años, Ciudad de México. 


\section{¿Cuáles fueron las principales preocupaciones de los participantes sobre el futuro tras el inicio de la pandemia?}

\section{Adolescentes}

Además de preguntarles sobre su experiencia con los síntomas de ansiedad y depresión, también se les pidió que indicaran sus tres principales preocupaciones sobre su futuro desde el comienzo de la pandemia. La preocupación más citada entre las personas adolescentes fue la pérdida de un familiar o a migo: 44\% de adolescentes incluyó esta respuesta entre sus tres principales preocupaciones. Otras preocupaciones comúnmente mencionadas fueron su situación económica personal (29\% de las mujeres adolescentes, $34 \%$ de los hombres adolescentes y $41 \%$ de adolescentes no binarios citaron esto), y la situación económica de su familia (38\% de las mujeres adolescentes, $34 \%$ de los hombres adolescentes y $35 \%$ de adolescentes no binarios).

\section{La preocupación por la situación económica} personal y familiar es mayor entre adolescentes I/AD que entre participantes que no son I/AD. Entre adolescentes I/AD, 33\% citó su situación económica personal y $38 \%$ la situación económica de su familia como una de sus principales preocupaciones en su vida. Entre adolescentes no I/AD, 31\% citó su situación económica personal y $35 \%$ la situación económica de su familia como una de sus principales preocupaciones en la vida. Se encontraron resultados similares cuando se compararon las respuestas según el NSE: las y los adolescentes de hogares con bajos ingresos fueron 9 puntos porcentuales más propensos que los de hogares con altos ingresos a citar la situación económica de su familia como una de sus principales preocupaciones (38\% frente al $29 \%)$.

\section{Personas jóvenes}

La preocupación más citada sobre el futuro entre jóvenes fue su situación económica personall (59\%). Los hombres jóvenes informaron de ello en mayor medida que las mujeres jóvenes (61\% frente al 56\%), mientras que las mujeres jóvenes fueron más propensas que los hombres jóvenes a citar la preocupación por la pérdida de un familiar o un amigo (54\% frente al 44\%) y la situación económica de su familia (53\% frente al $47 \%$ ).

Las personas jóvenes no I/AD fueron más propensas a informar de la pérdida de un familiar o un amigo como preocupación principal, en comparación con las personas jóvenes I/AD (52\% frente al 43\%). En cuanto al NSE, las personas jóvenes de hogares con altos ingresos fueron más propensas a citar la pérdida de un familiar o amigo (58\% frente al $41 \%$ ), y su propia situación económica (62\% frente al 54\%), mientras que las personas jóvenes de hogares con bajos ingresos fueron más propensas a citar la situación económica de su familia (57\% frente al $42 \%$ ). 


\section{¿Cómo impactó la pandemia el uso de redes sociales, las prácticas de socialización y el uso de servicios de apoyo entre adolescentes y jóvenes?}

\section{Adolescentes}

Se preguntó a las personas participantes sobre el uso de redes sociales y la comunicación con amistades, así como si habían utilizado algún servicio de apoyo desde el inicio de la pandemia. Los resultados de VOCES-19 sugieren que el tiempo que las personas adolescentes pasan en redes sociales aumentó tras el inicio de la pandemia. El $52 \%$ de las y los adolescentes informó que percibió un aumento en su uso de redes sociales, en comparación con el $14 \%$ que dijo que había disminuido, y el $30 \%$ que dijo que se había mantenido igual. Además, cinco de cada diez adolescentes estaban menos en contacto con sus amistades desde que empezó la pandemia, en comparación con antes.

Las personas no indígenas $\mathrm{y} / \mathrm{O}$ afrodescendientes (no I/AD) y las procedentes de hogares con altos ingresos fueron más propensas a declarar que pasaban más tiempo en redes sociales durante la pandemia que sus pares de grupos más excluidos social y económicamente. Las personas adolescentes no I/AD fueron 6 puntos porcentuales más propensas que las personas I/AD a afirmar que su uso de las redes sociales había aumentado ( $54 \%$ frente a $48 \%$ ), mientras que las y los adolescentes del nivel socioeconómico (NSE) más alto fueron 20 puntos porcentuales más propensos que sus pares del NSE más bajo a informar de ello (61\% frente a $41 \%$ ).

Además, las mujeres adolescentes perciben la pérdida de contacto con sus amigos con mayor frecuencia que los hombres adolescentes (57\% frente al 44\%), así como las personas adolescentes de hogares con bajos ingresos frente a las de altos ingresos (54\% frente al 48\%).

Para profundizar en el conocimiento de las redes de apoyo social, también preguntamos a las y los adolescentes si, desde el inicio de la pandemia, habían utilizado algún servicio de apoyo gubernamental relacionado con la salud mental, la violencia, el apoyo social y otros. El 69\% de las personas adolescentes declaró haber utilizado al menos uno de los servicios mencionados desde el inicio de la pandemia.

El uso de estos servicios fue más común entre las mujeres que entre los hombres (71\% frente a $67 \%)$, entre participantes no I/AD que participantes I/AD (70\% frente a 68\%), y entre las personas que procedían de hogares con ingresos altos frente a las de ingresos bajos (71\% frente a 64\%).

\section{Personas jóvenes}

El 57\% de las personas jóvenes percibió que su uso de redes sociales había aumentado desde el inicio de la pandemia, mientras que casi seis de cada diez declararon estar en contacto con sus amistades con menos frecuencia que antes. Las mujeres fueron más propensas que los hombres a declarar tanto un mayor uso de redes sociales (59\% frente al 55\%), como un contacto menos frecuente con su red social ( $54 \%$ frente al $47 \%$ ). 
También se observaron diferencias en el aumento del uso de redes sociales según la ełnicidad y el nivel socioeconómico de las personas participantes. La percepción de este aumento fue más común entre las y los jóvenes no I/AD (60\%), y jóvenes de hogares con altos ingresos (67\%), que entre jóvenes I/AD (50\%), y jóvenes de hogares con bajos ingresos (44\%), respectivamente.

Cuando se les preguntó por el uso de los servicios de apoyo gubernamentales desde el comienzo de la pandemia, $48 \%$ de las y los jóvenes declararon haber utilizado al menos un servicio. Un mayor número de participantes I/AD (53\%) y de jóvenes de hogares con bajos ingresos (50\%) utilizaron al menos un servicio desde el comienzo de la pandemia, en comparación con participantes no I/AD (46\%) y jóvenes de hogares con altos ingresos (39\%), respectivamente.

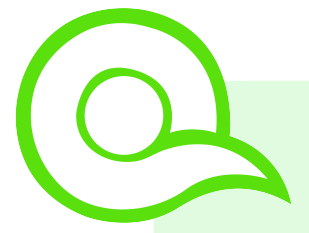

\section{La adicción a las redes sociales y el tiempo que las personas pasan consumiendo contenido de YouTube por ejemplo está afectando la salud mental de mis conocidos.}

Hombre, 21 años. Aguascalientes.

Crédito de la ilustración: Valeria García Trejo. Instagram grillolunar_vg. 


\section{¿Qué estrategias han implementado las personas adolescentes y jóvenes para lidiar con sentimientos problemáticos experimentados como resultado de la pandemia?}

\section{Adolescentes}

Se pidió a las personas participantes que seleccionaran una lista de estrategias que habían utilizado a lo largo de la pandemia para hacer frente a cualquier sentimiento problemático derivado de la misma. La estrategia que los adolescentes dijeron haber utilizado más fue hablar con sus amistades sobre los problemas que les preocupaban (34\%), seguida de hablar con un familiar (26\%) y hacer más ejercicio (25\%).

Hubo diferencias significativas por género en el uso de ciertas estrategias de afrontamiento, tanto entre hombres y mujeres, como entre personas binarias y no binarias. En el caso de las estrategias en las que se encontraron diferencias significativas entre hombres y mujeres, las mujeres fueron más propensas que los hombres de haberlas utilizado. Entre ellas se encuentran hablar con amistades sobre estos temas (36\% frente al 33\%), hablar con un miembro de la familia sobre estos temas (28\% frente al $25 \%$ ), buscar en Internet estrategias de afrontamiento (14\% frente al 10\%), recibir terapia (4.1\% frente al $2.7 \%$ ), tomar medicamentos recetados para la ansiedad o la depresión (1.9\% frente al $1.3 \%$ ) y empezar a tomar clases de yoga y/o meditación (3.5\% frente al 1.6\%).

Las personas no binarias reportaron un menor porcentaje de hablar con la familia sobre sus sentimientos problemáticos (14\% frente al $27 \%$ de las binarias), y en mayor porcentaje buscar estrategias de afrontamiento en Internet (24\% frente al $12 \%$ ), de tomar medicación para la ansiedad o la depresión (10\% frente al 1.6\%) y de acudir a terapia (7.3\% frente al 3.4\%) (ver Figura 18 ).

Figura 18. Estrategias de afrontamiento usadas entre adolescentes, por género. Porcentajes. VOCES-19. México.

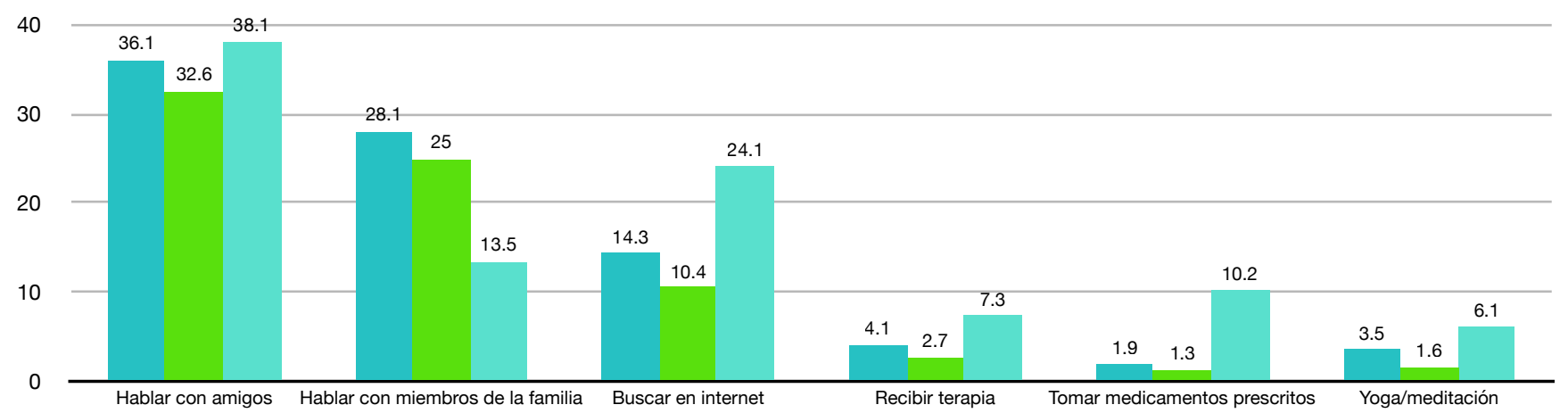


Los resultados también ilustran algunas diferencias notables entre personas adolescentes más y menos favorecidas en cuanto al uso de diferentes estrategias de afrontamiento para tratar los sentimientos preocupantes que han sentido desde el comienzo de la pandemia. Las y los adolescentes del quintil superior del NSE, por ejemplo, fueron unos siete puntos porcentuales más propensos que los del quintil inferior del NSE a declarar que hablaban con sus amistades sobre sus sentimientos preocupantes (38\% frente a 31\%). Las personas de los hogares con mayores ingresos también declararon recibir terapia (psicológica o de otro tipo) en mayor proporción que las de los hogares con menores ingresos (5.4\% frente a $2.6 \%$ ). Otras estrategias de afrontamiento utilizadas en mayor proporción por adolescentes del quintil superior frente a las y los del quintil inferior incluyen hacer más ejercicio (29\% frente a $21 \%$ ), buscar en Internet estrategias de afrontamiento ( $16 \%$ frente a $11 \%$ ), empezar a tomar clases de yoga y meditación (3.9\% frente a $1.7 \%$ ) y tomar medicamentos recetados para la ansiedad o la depresión (2.5\% frente a 1.2\%) (ver Figura 19).

Figura 19. Diferencias en puntos porcentuales en las estrategias de afrontamiento usadas entre adolescentes, por NSE. VOCES-19. México.

- Hogares de ingresos más bajos (primer quintil)

- Hogares de ingresos más altos (quinto quintil)

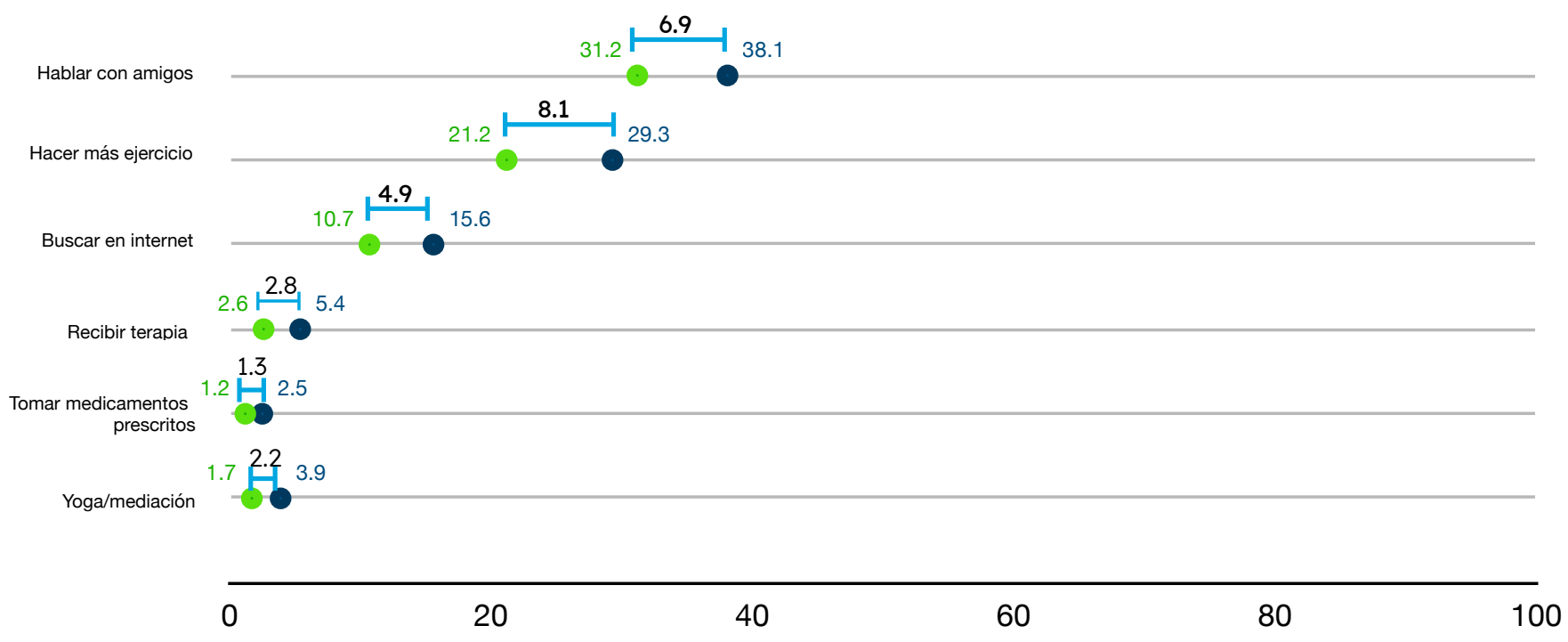

\section{Personas jóvenes}

Las tres estrategias que las personas jóvenes declararon haber puesto en práctica en mayor medida para hacer frente a los sentimientos problemáticos desde el comienzo de la pandemia fueron hablar con sus amistades (37\%), hablar con un familiar (33\%) y hacer más ejercicio (30\%). Al igual que las y los adolescentes, los hombres de este grupo de edad fueron menos propensos a informar que habían adoptado una de las estrategias de afrontamiento mencionadas en la encuesta para lidiar con los sentimientos problemáticos provocados por la pandemia. En concreto, fueron menos propensos a afirmar que hablaban con la familia sobre sus problemas (31\% frente al 35\%), que buscaban en Internet estrategias de afrontamiento (17\% frente al $21 \%$ ), que tomaban terapia (7.2\% frente al 10\%) y que practicaban yoga y/o meditación (3.6\% frente al 7.2\%) (ver Figura 20). 
Figura 20. Estrategias de afrontamiento usadas entre jóvenes, por género. Porcentajes. VOCES-19. México.

60

50

40

46.8

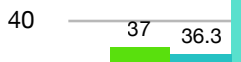

30

10
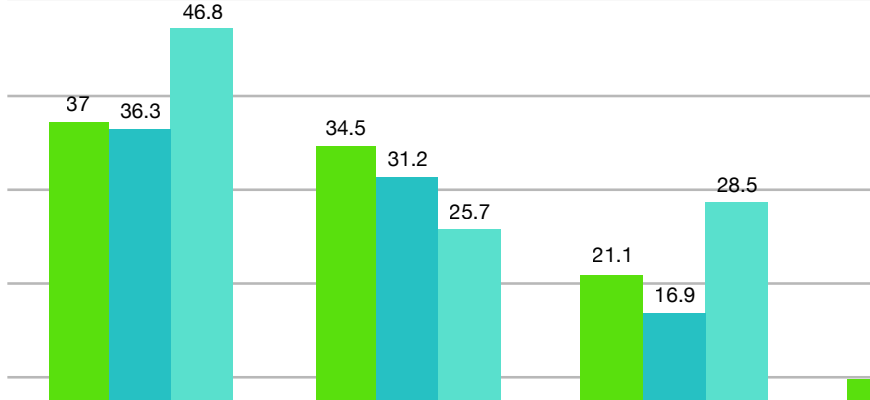

Hablar con amigos Hablar con miembros de la familia Buscar en internet

10

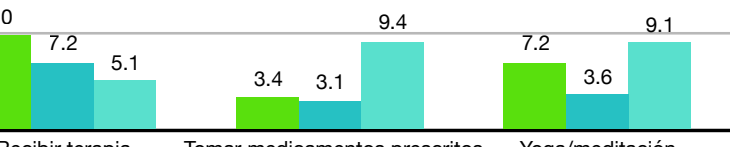

Los hallazgos también muestran que las personas jóvenes no I/AD fueron más propensas que las personas jóvenes I/AD a empezar a hacer más ejercicio (31\% frente al $27 \%$ ), a recibir terapia ( $9.3 \%$ frente al $7 \%$ ) y a empezar a tomar clases de yoga o meditación (5.9\% frente al 4.4\%).

Por último, las personas jóvenes con mayores ingresos declararon utilizar diferentes estrategias de afrontamiento en mayor medida que sus pares de hogares con bajos ingresos. El 45\% dijo que hablaba con amistades sobre sus problemas (frente al 32\%), $12 \%$ dijo que recibía terapia (frente al 5,4\%), $23 \%$ dijo que buscaba estrategias en Internet (frente al 17\%), 36\% dijo que hacía más ejercicio (frente al 22\%) y $10 \%$ dijo que había empezado a tomar clases de yoga o meditación (frente al 2.9\%) (ver Figura 21).

Figura 21. Diferencia en puntos porcentuales en las estrategias de afrontamiento usadas entre jóvenes, por NSE. VOCES-19. México.

Hogares de ingresos más bajos (primer quintil) Hogares de ingresos más altos (quinto quintil)

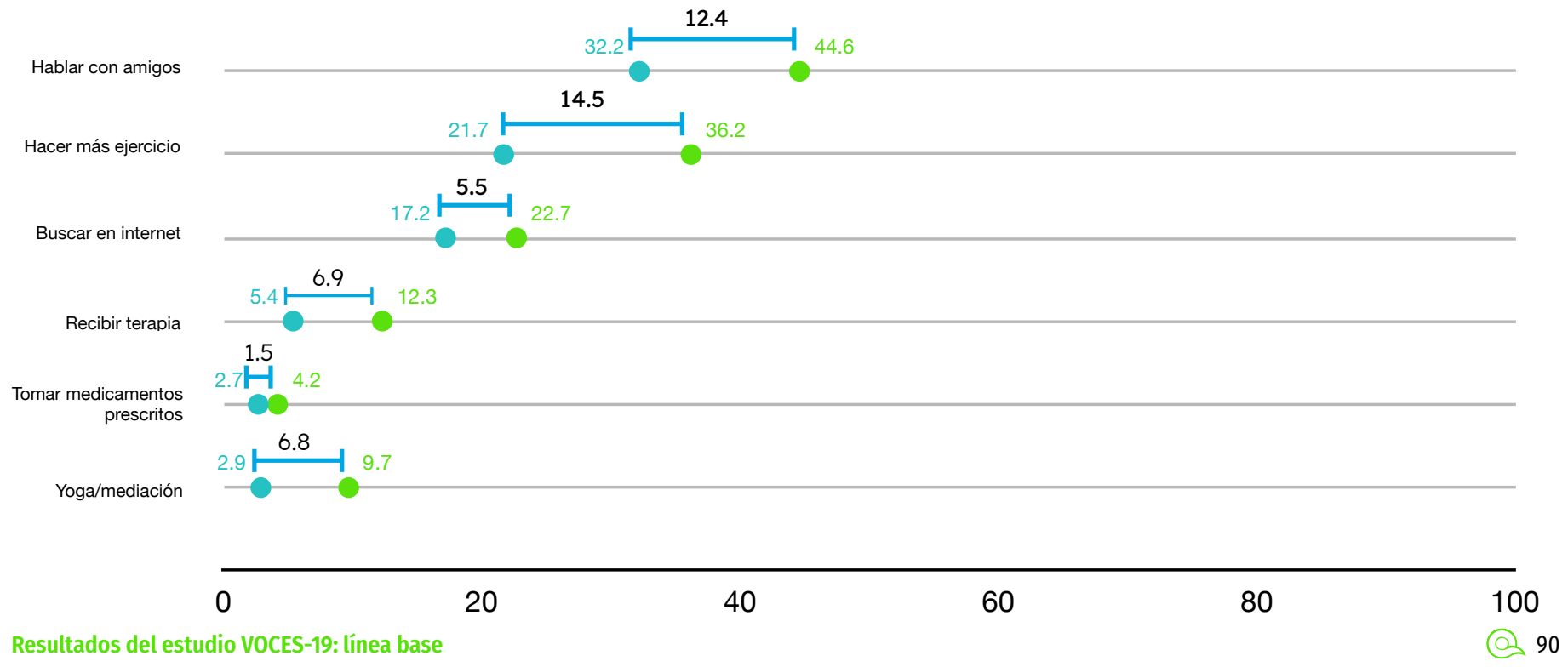




\section{Resumen de los hallazgos}

La prevalencia de síntomas de depresión y ansiedad fue preocupantemente alta en toda la población de participantes de VOCES-19, con tasas particularmente abrumadoras entre las personas no binarias y las mujeres. Estos últimos hallazgos coinciden con evidencia reciente de todo el mundo de que la salud mental de las mujeres jóvenes se ha visto más impactada por la pandemia (Williams, Davis, Figueira, \& Vizard, 2021).

Dados los graves impactos en la salud mental observados entre adolescentes y jóvenes en México, será de vital importancia considerar las estrategias utilizadas por estas personas para hacer frente a los sentimientos problemáticos provocados por el aislamiento social, el cierre de las escuelas, entre otros factores. Los hallazgos de este informe muestran que las juventudes han experimentado un aumento en la cantidad de tiempo que han pasado en redes sociales, mientras que cerca de la mitad de todas las personas participantes declararon que han permanecido en contacto con sus amistades menos que antes del comienzo de la pandemia. También muestran que las personas participantes I/AD y jóvenes de hogares con bajos ingresos pusieron en práctica estrategias de afrontamiento con menos frecuencia para lidiar con los sentimientos problemáticos experimentados como resultado de la pandemia.

Teniendo en cuenta las pruebas recientes que demuestran que estrategias como hacer ejercicio de forma constante y mantenerse en contacto con las amistades se han asociado a una reducción del estrés durante la pandemia, en el futuro será importante involucrar a adolescentes y jóvenes en actividades que reduzcan los sentimientos de estrés, impotencia y soledad (Shanahan, et al., 2020). Seguirá siendo importante analizar la aceptación diferenciada de estas actividades entre los distintos grupos, con el fin de aplicar estrategias que aumenten el acceso a apoyos esenciales como la terapia y los grupos de apoyo mutuo para cualquiera que pueda necesitarlos. Es igualmente importante comprender mejor si la menor aceptación de estas estrategias por parte de las y los participantes de hogares con bajos ingresos, en comparación con participantes de hogares con altos ingresos, está relacionada con su capacidad para pagar el acceso a estas actividades.

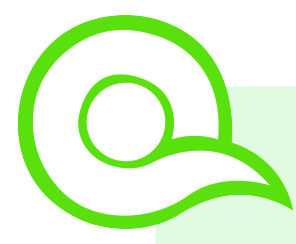

Creo que tengo depresión y ansiedad, pero no sé dónde me puedan dar terapia gratuita ya que mis papás no pueden pagarme una, aparte tampoco se como decirles.

Mujer, 15 años, Ciudad de México. 

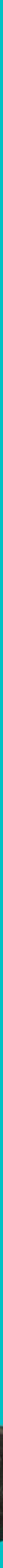


\section{Acceso a la salud y uso de sustancias}

\section{Puntos destacados}

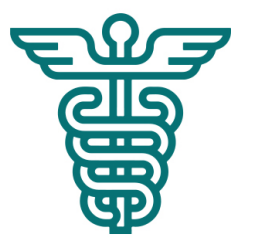

Las juventudes reportan que la pandemia afectó a su acceso a los servicios de salud y su consumo de sustancias.

Las barreras en el acceso a los servicios de salud fueron percibidas por el $53 \%$ de las y los adolescentes y el $75 \%$ de las personas jóvenes que intentaron acceder a estos servicios.

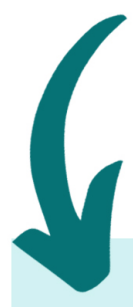

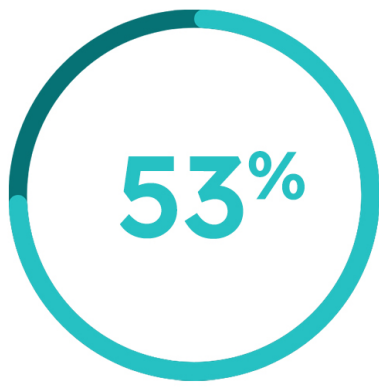

Adolescentes

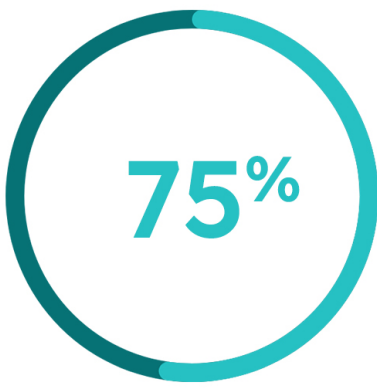

Personas jóvenes

En ambos grupos de edad, más mujeres que hombres, y participantes de hogares con bajos ingresos frente a hogares con altos ingresos, percibieron un acceso deteriorado a los servicios de salud durante la pandemia.

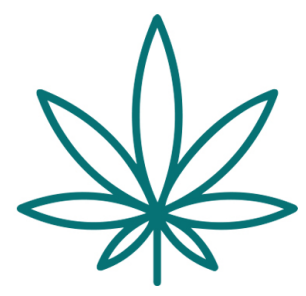

En cuanto al consumo de sustancias durante la pandemia, los opiáceos y otras drogas duras fueron las sustancias cuyo aumento fue el más común desde el inicio de la pandemia entre las y los adolescentes (18\%). Una mayor proporción de jóvenes informó un aumento en el consumo de cannabis (21\%).

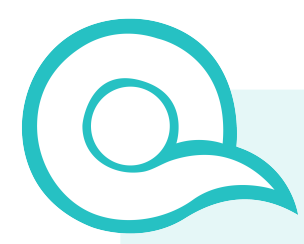

Es más fácil conseguir drogas ahora, que antes de la pandemia.

Hombre, 18 años, Ciudad de México. 
En todo el mundo, las estrategias de mitigación de COVID-19, junto con la redistribución de los recursos sanitarios para responder a la pandemia, redujeron el acceso a los servicios de salud, incluido el acceso a los servicios de salud mental, relacionados con la violencia y de salud sexual y reproductiva (SSR) (Ahmed, et al., 2020). El deterioro del acceso a los servicios sanitarios tendrá profundas consecuencias en la salud de adolescentes y jóvenes. Además, como se analiza en la sección sobre los resultados en materia de salud mental, las juventudes han tenido dificultades para procesar las circunstancias que rodean a la pandemia. La relación entre el consumo de sustancias y la salud mental se percibe como multidireccional, en la que un aumento en el consumo de sustancias contribuye a una pobre salud mental, pero el peso de la pandemia en la salud mental de las juventudes también, a su vez, aumenta el riesgo de abuso de sustancias durante este periodo (Bhatia, Chatterjee, \& Dhawan, 2021).

Basándose en estas evidencias, VOCES-19 busca identificar cómo la pandemia ha afectado a las percepciones de las personas participantes con respecto al acceso a la atención a la salud y al consumo de sustancias por género, etnicidad y nivel socioeconómico. Todos los resultados se presentan por separado según el grupo de edad.

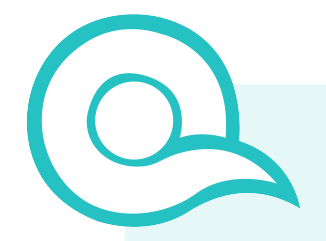

La calidad de los servicios de salud mental es algo importante para evaluar. En cuanto a mi experiencia puedo decir que, al menos el departamento de psiquiatría y salud mental de la Facultad de medicina de la UNAM, se encuentran saturados y esto provoca que la atención que ofrece no sea buena, pues el centro no da citas de seguimiento posteriores a una consulta de primera vez (que por cierto es sumamente breve) a pesar de que se pidan en repetidas ocasiones (esto como experiencia propia y compartida por amigos). Por esta razón creo que es importante realizar una revisión de los servicios como el anterior para que estos sean eficaces y no queden solo en la oferta sin ofrecer ayuda real.

Hombre, 21 años, México. 


\title{
¿Cuáles son las percepciones de adolescentes y jóvenes sobre el impacto de la pandemia en el acceso a servicios de salud?
}

\author{
Adolescentes
}

El acceso a los servicios de salud generales, así como a los servicios de salud sexual y reproductiva (SSR) fue limitado durante la pandemia para las y los adolescentes que los buscaron. El 70\% de todas las personas adolescentes participantes de VOCES-19 $(n=44,955)$ informaron que durante la pandemia, ellos/as o un miembro de su familia intentaron acceder a un servicio de salud general y $4 \%$ informaron que intentaron acceder a un servicio de SSR. Cuando se les preguntó si percibían que la pandemia había afectado de algún modo a su acceso a los mismos, 53\% informó de una interrupción en el acceso a los servicios sanitarios generales y $20 \%$ informó de una interrupción en el acceso a los servicios de SSR.

Se encontraron diferencias significativas en función del género y el nivel socioeconómico (NSE), siendo las mujeres y las personas no binarias, así como las que procedían de hogares con bajos ingresos, quienes informaron de mayores tasas de interrupción de los servicios. Por ejemplo, más mujeres adolescentes que hombres (57\% frente a $49 \%$ ) y adolescentes no binarios en comparación con adolescentes binarios (73\% frente a 53\%) percibieron que su acceso o el de su familia a los servicios de salud generales se había visto interrumpido de alguna manera por la pandemia. Del mismo modo, más adolescentes de hogares con bajos ingresos percibieron una interrupción en el acceso tanto a los servicios de salud general como a los de SSR, en comparación con sus pares de hogares con altos ingresos (58\% frente a $51 \%$ para los servicios de salud general y $26 \%$ frente a $15 \%$ para los servicios de SSR) (ver Figura 22). No se encontraron diferencias significativas entre adolescentes I/AD y no I/AD en cuanto a la percepción de interrupción del acceso a los servicios generales o de SSR durante la pandemia.

Figura 22. Diferencias en puntos porcentuales en la percepción de adolescentes sobre el acceso deficiente a los servicios de salud desde el inicio de la pandemia, por NSE. VOCES-19. México.

- Hogares de ingresos más bajos (primer quintil) • Hogares de ingresos más altos (quinto quintil)

Impacto en el acceso a los servicios de salud en general

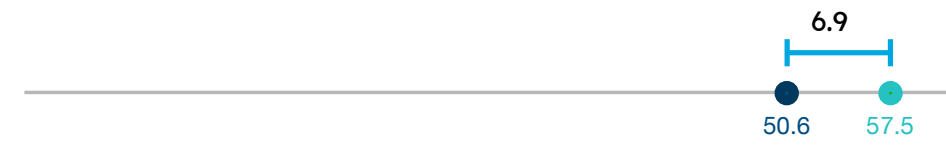

Impacto en el acceso a

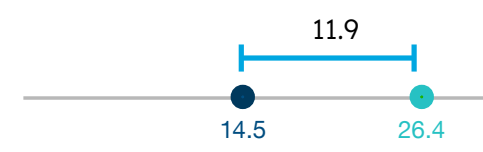




\section{Personas jóvenes}

El acceso de las personas jóvenes a la atención a la salud también se vio afectado durante la pandemia. Del total de jóvenes que participaron en el estudio ( $n=10,737$ ), el $75 \%$ informó que ellos/as o un miembro de su familia intentaron acceder a un servicio de salud general, mientras que $13 \%$ informó de que intentó acceder a un servicio de SSR durante la pandemia. El 71\% de las personas jóvenes que intentaron acceder a un servicio de salud general informaron que el acceso se había visto interrumpido de alguna manera por la pandemia, así como 4 de cada 10 jóvenes que intentaron acceder a un servicio de SSR.

Los resultados muestran que el acceso se vio interrumpido para las mujeres más que para los hombres, y para las personas jóvenes de bajos ingresos mas que para sus pares de allos ingresos. Un mayor porcentaje de mujeres, en comparación con los hombres, percibió que su acceso a los servicios de salud generales se vio interrumpido de alguna manera por la pandemia (79\% frente al 71\%). Asimismo, más jóvenes de hogares con bajos ingresos percibieron que su acceso a los servicios de salud general y a los servicios de salud sexual y reproductiva se vio interrumpido, en comparación con jóvenes de hogares con altos ingresos (79\% frente a $72 \%$ para los servicios de salud general y $48 \%$ frente a $29 \%$ para los servicios de salud reproductiva) (ver Figura 23). No encontramos diferencias significativas entre jóvenes I/ AD y no I/AD en cuanto a la percepción de la interrupción del acceso a los servicios generales o de SSR durante la pandemia.

Figura 23. Diferencias en puntos porcentuales en la percepción de las personas jóvenes sobre el acceso deficiente a los servicios de salud desde el inicio de la pandemia, por NSE. VOCES-19. México.

Hogares de ingresos más bajos (primer quintil) Hogares de ingresos más altos (quinto quintil)

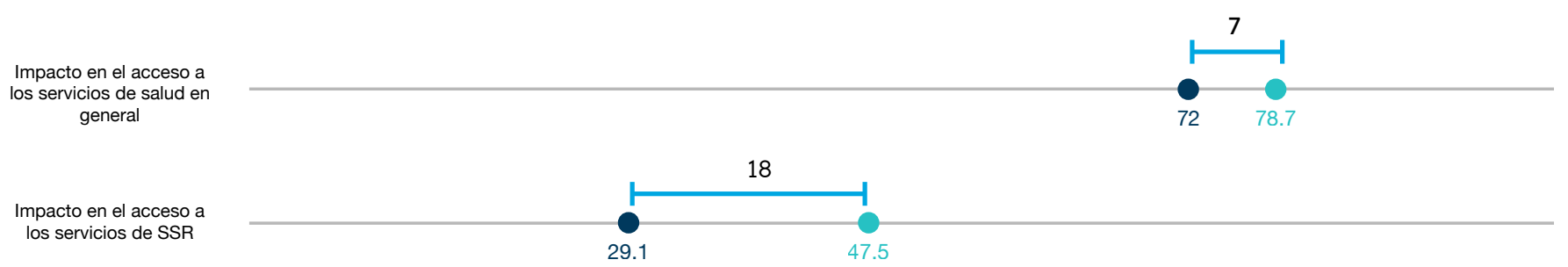

0

20

40

60

80

100

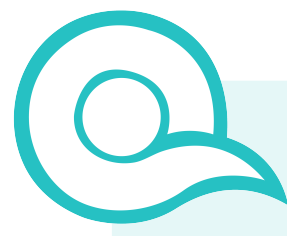

Los servicios hospitalarios dieron prioridad a los enfermos por COVID y uno de mis hermanos necesitaba tratamientos oncológicos que se aplazaron demasiado. Al final falleció.

Hombre, 23 años, Ciudad de México. 


\section{¿Las personas adolescentes y jóvenes percibieron que su consumo de sustancias ha cambiado desde el inicio de la pandemia?}

\section{Adolescentes}

A las personas participantes de VOCES-19 se les preguntó con qué frecuencia consumían alcohol, marihuana y otras drogas, en una escala de rara vez a más de una vez al día. Del total de adolescentes que participaron en la encuesta, el 25\% informó de al menos algún consumo de alcohol, 3\% de consumo de marihuana y $0.9 \%$ de consumo de opiáceos y otras drogas duras (heroína, cocaína, crack y/o anfetaminas).

Los resultados del estudio muestran que la tasa más alta de aumento del consumo de sustancias desde el inicio de la pandemia se dio en el caso de los opiáceos y otras drogas duras: el $18 \%$ de las personas que consumían estas sustancias declararon un aumento de su consumo. Le siguieron el aumento en el consumo de cannabis (17\%) y alcohol (14\%) (ver Figura 24 ).

Figura 24. Aumento del consumo de sustancias desde el inicio de la pandemia entre adolescentes. Porcentajes. VOCES-19. México.

100

80

60

40

20

18.3 16.6

14

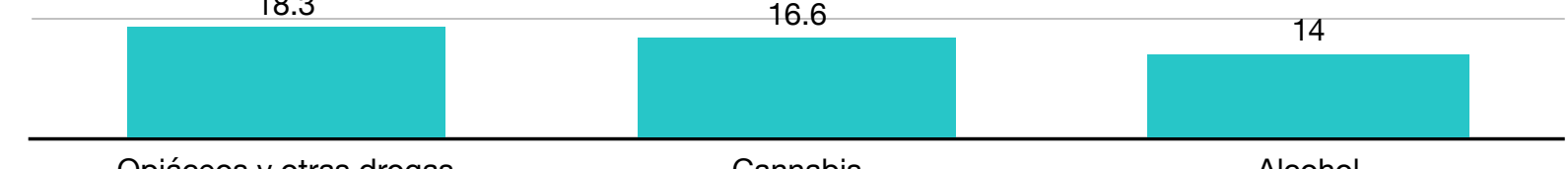

Opiáceos y otras drogas

Cannabis

Alcohol

Al comparar el aumento en el consumo de alcohol por género, etnicidad y NSE en este grupo de edad, la única diferencia encontrada fue para el consumo de alcohol, donde un mayor porcentaje de adolescentes en el quintil superior del NSE informó de un aumento en comparación con sus pares en el quintil inferior del NSE (16\% frente al $12 \%)$. 


\section{Personas jóvenes}

El 53\% de las personas jóvenes declaró algún nivel de consumo de alcohol, $8 \%$ declaró consumir marihuana y $1.2 \%$ reportó consumir opiáceos y otras drogas duras. Para todas las sustancias, los hombres las consumen con una frecuencia significativamente mayor que las mujeres. En jóvenes, un mayor porcentaje de personas binarias frente a las no binarias consumió heroína y otras drogas duras (1.2\% frente a $0.1 \%)$.

La sustancia cuyo consumo aumentó más entre jóvenes durante la pandemia fue el cannabis (21\%), seguido del alcohol (14\%) y los opiáceos y otras drogas duras (13\%) (ver Figura 25). No se encontraron diferencias por género, etnicidad o NSE entre jóvenes en cuanto al aumento del consumo de sustancias desde el inicio de la pandemia.

Figura 25. Aumento del consumo de sustancias desde el inicio de la pandemia entre las personas jóvenes. Porcentajes. VOCES-19. México.

100

80

60

40

20

0

20.8

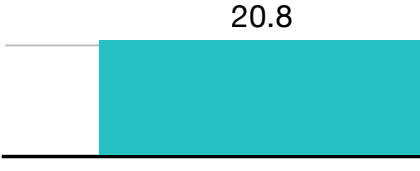

Cannabis
14.3

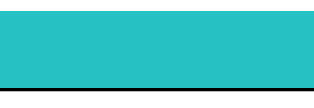

Alcohol
13.4

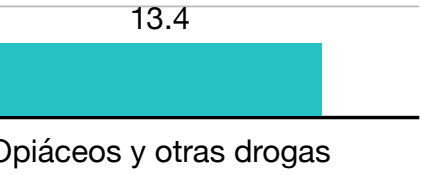

Opiáceos y otras drogas

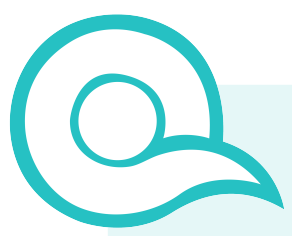

Mis amigos se han enfermado por tanto estrés algunos ya no quieren estudiar están desmotivados y su consumo de drogas y alcohol aumentó.

Mujer, 15 años, Ciudad de México. 


\section{Resumen de los hallazgos}

Los resultados de VOCES-19 ponen de manifiesto las desigualdades de género y de ingresos en cuanto al acceso a la atención a la salud y SSR, principalmente en lo que se refiere a los servicios de salud generales, donde un mayor porcentaje de mujeres, personas no binarias y participantes de hogares con menores ingresos informaron que el acceso a estos servicios se había visto afectado por la pandemia en comparación con los hombres, personas binarias y sus pares de hogares con mayores ingresos.

Además, los resultados más preocupantes en cuanto al aumento del consumo de sustancias durante la pandemia entre adolescentes, fue el aumento autodeclarado del consumo de opioides y otras drogas duras. La falta de diferencias significativas para estas variables al comparar por género, etnicidad y nivel socioeconómico podría estar relacionada con el bajo número de participantes que autodeclararon consumir sustancias.

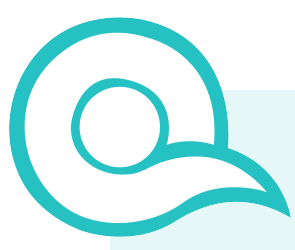

En cuanto a los servicios de salud, para acceder a mi tratamiento "integral" para VIH, pasé por varias situaciones, por ejemplo el IMSS me atendió 5 meses después de mi diagnóstico, pues la clínica que me toca era $100 \%$ para atención a casos de COVID. Sin embargo, durante esos meses tuve consulta de inicio y los estudios iniciales, en la clínica "Condesa" de la CDMX, así como el surtimiento gratuito de antiretrovirales, aunque las consultas de seguimiento seguían suspendidas.

Hombre, 21 años, México. 
CONCLUSIONES Y RECOMENDACIONES 


\section{CONCLUSIONES}

Al momento de redactar este informe, México se encontraba en medio de la tercera ola de la pandemia, con una carga diaria de nuevos casos superior a los picos anteriores, pero con menor letalidad (debido a la cobertura de vacunación). Sin embargo, esta tercera ola está afectando directamente a las poblaciones más jóvenes, aumentando los casos sintomáticos entre niñas, niños, adolescentes y personas jóvenes.

Los hallazgos de este reporte revelan cómo la pandemia de COVID-19 y las medidas de mitigación que la acompañan han tenido grandes impactos en varias dimensiones de la vida de adolescentes y jóvenes en México. Los hallazgos también revelan hasta qué punto la pandemia ha puesto al descubierto y ha exacerbado las desigualdades preexistentes entre esta población, especialmente en función del género, la etnicidad y el nivel socioeconómica. Por ejemplo, las mujeres del estudio fueron más propensas que los hombres a percibir impactos negativos en el empleo y los ingresos, a mostrar síntomas de ansiedad y depresión, y a informar de que se sentían menos seguras en sus comunidades desde el comienzo de la pandemia. Además, las personas participantes no indígenas y/o afrodescendientes y las de hogares más acomodados tenían menos probabilidades de ver interrumpido su acceso a los servicios de atención a la salud, de experimentar un aumento de la exposición a la violencia en sus hogares y de percibir impactos negativos de la pandemia en el empleo y la educación, en comparación con sus pares de grupos en mayor situación de marginación.

Las repercusiones del COVID-19 y las medidas de mitigación para las juventudes mexicanas y sus familias van mucho más allá de sus experiencias directas con la enfermedad. Uno de los principales intereses del estudio VOCES-19 era conocer más sobre cómo adolescentes y jóvenes del país estaban experimentando y percibiendo la violencia en sus hogares y comunidades desde el inicio de la pandemia, cuando las escuelas y los negocios cerraron y las familias se vieron obligadas a aislarse. Los resultados muestran que las personas adolescentes y jóvenes I/AD, en comparación con no I/AD, y las de nivel socioeconómico más bajo, en comparación con sus pares con mayores ingresos, eran más propensas a informar que su primera experiencia de violencia en el hogar se produjo después del inicio de la pandemia. También eran más propensas a informar de un aumento en la frecuencia o la gravedad de los actos violentos en sus hogares. Las personas jóvenes I/AD y de hogares con menores ingresos también informaron que se sentían menos seguras en sus barrios y percibían un mayor aumento de la delincuencia y la violencia en sus comunidades, en comparación con personas no I/AD y personas con mayores ingresos, respectivamente. Todos estos hallazgos pueden estar asociados a las dificultades y los factores de estrés económico a los que se enfrentaron especialmente las familias y las comunidades de menores ingresos durante la pandemia, lo que podría haber llevado a un aumento de las actitudes violentas contra adolescentes y jóvenes dentro de los hogares y en las comunidades.

El cierre de las instalaciones escolares tras las órdenes de encierro y distanciamiento social es otro de los graves retos a los que todavía se enfrentan adolescentes y jóvenes del país. Los resultados de VOCES-19 muestran que, desde el comienzo de la pandemia, las personas participantes inscritas en la escuela han recibido casi todas sus clases en línea, aunque sólo un pequeño porcentaje cree que ha aprendido más a través de la escolarización a distancia que cuando su escuela era presencial. Además, las personas de menor nivel socioeconómico han tenido dificultades para acceder a sus deberes y tareas y entregarlos de 
forma constante durante la pandemia. Estos resultados son preocupantes: es probable que el acceso desigual a la conectividad a Internet y a recursos como laptops y otros dispositivos para completar las tareas escolares amplie en gran medida la brecha de rendimiento educativo en el país (Saavedra \& Di Gropello, 2021). Las desigualdades analizadas en este informe ponen de manifiesto la urgente necesidad de garantizar la recuperación educativa de las y los estudiantes en mayor situación de vulnerabilidad del país.

Las personas participantes en el estudio también perciben fuertemente los impactos negativos que la pandemia ha tenido en las condiciones de empleo e ingresos de sus hogares, siendo las mujeres y participantes de los hogares con menores ingresos las más propensas a percibirlos. Por ejemplo, las personas de estos dos grupos eran significativamente más propensas a informar que ellas u otro miembro de su hogar perderían ingresos en los próximos meses debido a la pandemia y que al menos un miembro del hogar había perdido un trabajo o había tenido que cerrar un negocio debido a las medidas de encierro de COVID-19 en el mes anterior a que realizaran la encuesta. Las diferencias de género y socioeconómicas que se observan aquí apoyan la evidencia reciente que muestra cómo las mujeres jóvenes y las personas trabajadoras con empleos poco remunerados se han visto afectados de manera desproporcionada por la pandemia y apuntan a la necesidad de garantizar que los esfuerzos de recuperación económica en México se diseñen e implementen teniendo en cuenta las prioridades de los grupos en mayor situación de vulnerabilidad (UN Women, 2020).

No es de extrañar que las personas encuestadas también informaran que la pandemia ha tenido un impacto negativo en varios aspectos de sus vidas relacionados con la salud, como su capacidad para acceder a los servicios de atención a la salud, su salud mental y sus niveles de consumo de sustancias. Una vez más, observamos grandes desigualdades en estas dimensiones. Por ejemplo, un mayor porcentaje de adolescentes y jóvenes de hogares con bajos ingresos informó de que su acceso a los servicios de salud generales y a los servicios de salud sexual y reproductiva se había visto afectado por la pandemia en comparación con sus pares de hogares con mayores ingresos. En cuanto a la salud mental, las desigualdades más impactantes observadas estaban relacionadas con el género. Aunque la prevalencia de los síntomas de depresión era preocupantemente alta en toda la población, las tasas eran especialmente abrumadoras entre las personas no binarias y las mujeres en comparación con los hombres. Estos últimos hallazgos coinciden con evidencias recientes de todo el mundo que indican que las mujeres jóvenes se han llevado la peor parte de los impactos de la pandemia en la salud mental (Williams, Davis, Figueira, \& Vizard, 2021). En general, los impactos relacionados con la salud que se destacan en este reporte revelan la necesidad urgente de restablecer el acceso a la atención a la salud para las poblaciones en mayor situación de vulnerabilidad, con esfuerzos centrados en apoyar la salud mental y el bienestar de las mujeres jóvenes y las poblaciones no binarias.

Por último, dados los graves impactos en la salud mental observados entre adolescentes y jóvenes en México, también es importante considerar las estrategias utilizadas por estas personas para hacer frente a las emociones y situaciones difíciles a lo largo de la pandemia. Los hallazgos de este informe muestran que a las y los jóvenes en México les ha costado mucho afrontar la situación: más de la mitad de las personas participantes declararon que los pensamientos y sentimientos problemáticos les habían molestado más desde el inicio de la pandemia. También informaron que, durante este tiempo, su uso de las redes sociales aumentó y mantuvieron menos contacto con sus amistades en comparación con antes. 
Teniendo en cuenta las evidencias recientes que demuestran que estrategias como hacer ejercicio de forma constante y mantenerse en contacto con los amigos se han asociado a la reducción del estrés durante la pandemia, en el futuro será importante involucrar a adolescentes y jóvenes en actividades que reduzcan los sentimientos de estrés, impotencia y soledad.

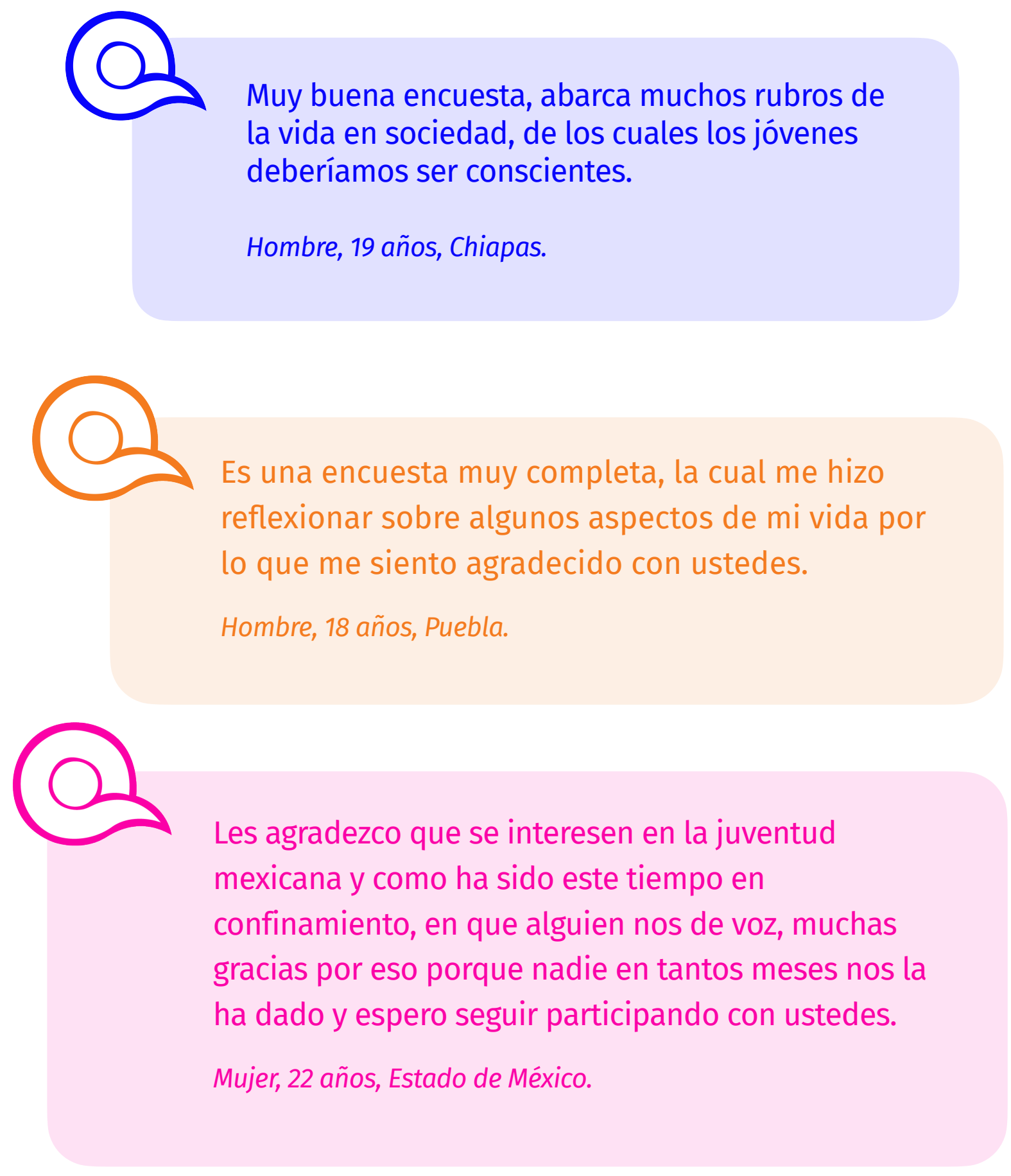




\section{RECOMENDACIONES}

\section{Programas de apoyo a las juventudes}

relacionados a la violencia

Según los resultados de VOCES-19, un alto porcentaje de jóvenes que participaron en la encuesta ha sufrido algún tipo de violencia en sus hogares. Los datos de las llamadas al 911 también mostraron un aumento de la violencia contra las mujeres desde el comienzo de la pandemia. Esta violencia parece aumentar a medida que avanza la pandemia. En México, la información y los servicios relacionados con la violencia se han dirigido principalmente a las mujeres adultas, pero han dejado de lado a las personas jóvenes no binarias, a adolescentes y a hombres jóvenes. Dado que las personas que han experimentado violencia en su infancia y juventud son más propensas a experimentar o perpetrar violencia como personas adultas, la prevención relacionada con la violencia y la atención oportuna son clave para romper este ciclo y ofrecer a las personas asesoramiento y apoyo oportuno. Aunque entendemos la importancia de contar con estrategias de prevención y asistencia directa dirigidas a mujeres y niñas, también creemos en la importancia de aplicar estrategias más amplias para todas las juventudes, incluidos los hombres y las personas no binarias.

En cuanto al acoso virtual, en los últimos años México ha tenido avances en la implementación de estrategias preventivas y de atención para enfrentar el ciberacoso y el hostigamiento en línea (la Ley Olimpia, por ejemplo). Sin embargo, VOCES-19 mostró que durante la pandemia hubo un incremento en las experiencias de este tipo de violencia. Como las estrategias en línea en los sectores de la educación y el empleo seguramente perdurarán en el futuro, se necesitan nuevas y mejores intervenciones para prevenir y atender oportunamente estos tipos de violencia. El aumento de la información sobre cómo identificar, prevenir y evitar el ciberacoso y el hostigamiento en línea, así como la forma de proteger sus datos personales, debe tenerse en cuenta para las futuras políticas sobre este tema.

Por último, la creación de colaboraciones entre el Gobierno, organizaciones no gubernamentales y las organizaciones lideradas por jóvenes, y la inclusión de las experiencias y contribuciones de las juventudes en el diseño de programas para prevenir y atender la violencia, así como el aumento de la oferta, la diversidad y la difusión de programas, dirigiéndolos a diferentes poblaciones, podrían ser caminos a seguir en el futuro para reducir las experiencias de violencia entre esta población.

\section{Estrategias para la recuperación}

educativa

Las estrategias educativas deben estar diseñadas para satisfacer las necesidades de las y los estudiantes en mayor situación de vulnerabilidad y dirigidas a minimizar los impactos negativos a largo plazo asociados a la pérdida de más de un año de educación de calidad. A medida que las escuelas comiencen a reabrir, será necesario dedicar recursos para reincorporar a los estudiantes que puedan haber abandonado los estudios debido a la pandemia, y para identificar y volver a involucrar a los estudiantes con alto riesgo de deserción. Además, las escuelas tendrán que dar prioridad al diagnóstico de las brechas de aprendizaje para comprender el alcance del daño causado por el acceso desigual a los 
recursos educativos mientras las escuelas estaban cerradas. Identificar con precisión las necesidades de las y los alumnos en mayor situación de vulnerabilidad permitirá aplicar estrategias de recuperación más específicas y eficaces.

La pandemia de COVID-19 también nos mostró que es posible implementar estrategias de educación a distancia. Sin embargo, al implementar estas estrategias, es fundamental tener en cuenta las desigualdades previas presentes en el país y la falta de acceso a Internet y a las tecnologías de la información por parte de algunos grupos de población. Como se muestra en VOCES-19, el acceso a Internet y a las tecnologías de la información no es universal en México. Esta falta de acceso tendrá repercusiones educativas desiguales para las juventudes de menor nivel socioeconómico y aumentará el rezago educativo preexistente. Un aumento en el acceso a puntos gratuitos de Internet y la implementación de estrategias alternativas a la educación a distancia en comunidades rurales y de difícil acceso podría ser un camino para reducir esta brecha.

\section{Apoyo a la economía de las mujeres y} familias de bajos ingresos

Los resultados de VOCES-19 muestran que, aun cuando todas las personas participantes percibieron un impacto significativo de la pandemia en los aspectos laborales y/o en la economía familiar, las mujeres y participantes pertenecientes a hogares con menores ingresos percibieron un mayor impacto en comparación con los hombres y participantes de hogares con mayores ingresos.

Esta realidad indica la necesidad de centrarse en la recuperación económica de las juventudes en mayor situación de vulnerabilidad para minimizar el empeoramiento de las desigualdades en los próximos años. Ampliar las intervenciones que apoyan directamente a las personas jóvenes con recursos económicos puede ser un camino a seguir. Sin embargo, el apoyo directo a los ingresos puede no ser suficiente. Por ello, es imprescindible mejorar también los determinantes estructurales del sector laboral.

Incrementar el acceso a la salud para las comunidades de bajos recursos e implementar intervenciones dirigidas a la salud mental para jóvenes, mujeres y poblaciones no binarias

Aunque existen probables sesgos en la información por no provenir de una muestra representativa, los resultados de la encuesta son consistentes con los reportados en otros estudios, así como con las predicciones hechas por la Organización Mundial de la Salud sobre el impacto de la pandemia en el acceso a los servicios y, particularmente, en los servicios de salud mental y salud sexual y reproductiva. Aunque el impacto de la pandemia en el acceso a los servicios y la salud de adolescentes y jóvenes ha sido generalizado, el grado de afectación no es igual, afectando en mayor medida a los grupos con mayor desventaja socioeconómica y a la población que se autoidentificó como no binaria.

El impacto de la pandemia en la salud mental tendrá un efecto duradero. La atención a la salud mental de las juventudes debe ser una prioridad para las autoridades gubernamentales. Es necesario difundir ampliamente información a los diferentes sectores de la sociedad y a las autoridades competentes sobre los diferentes retos a los que se enfrentan adolescentes y jóvenes. Asimismo, para reducir las disparidades en la oferta y la demanda de estos servicios, es 
importante ampliar la evidencia sobre la percepción y el conocimiento de la salud mental y cuáles serían los medios más adecuados para acercar los servicios de salud a las diferentes poblaciones, considerando las necesidades diferenciadas desde una perspectiva de género.

En cuanto al acceso a la salud sexual y reproductiva, el asesoramiento y acceso a una amplia gama de métodos anticonceptivos son fundamentales ahora más que nunca. El acceso debe incluir no sólo métodos anticonceptivos, sino también servicios de asesoramiento para que las juventudes puedan elegir el mejor método anticonceptivo para ellas. La información y el asesoramiento en materia de salud sexual y reproductiva pueden proporcionarse a través de distintas estrategias, incluidos los servicios de telemedicina y las estrategias basadas en la comunidad. Además, es recomendable crear alianzas entre el gobierno, las juventudes y las organizaciones de la sociedad civil que trabajan con las juventudes, para tomar en cuenta las voces de las y los jóvenes y lograr un mayor impacto con estas estrategias. 


\section{PRÓXIMOS PASOS}

VOCES-19 pretende ser un centro de datos y evidencias para la toma de decisiones de políticas diseñadas para las juventudes en México. El sitio web del proyecto (https://vocescontralaviolencia.org), permite el acceso a un tablero interactivo que permitirá a las juventudes, organizaciones, actores clave y responsables de la toma de decisiones profundizar en los datos recogidos. La información para identificar las desigualdades de género, de ingresos y étnicas también estará disponible a través de este tablero. A finales de 2021, la base de datos de VOCES-19 será de libre acceso a través del sitio web. El equipo de investigación de VOCES-19 publicará continuamente informes, artículos y resúmenes sobre los principales hallazgos del proyecto. Dado que el enfoque principal de VOCES-19 fue la violencia, el equipo de investigación está trabajando en un análisis para identificar qué juventudes están experimentando los mayores índices de violencia y cómo la violencia está relacionada con los determinantes relacionados con la familia y la comunidad.

También impulsaremos que VOCES-19 sea una plataforma para los defensores de la juventud y un centro de recursos para las juventudes. Actualizaremos continuamente la información del sitio web sobre los recursos y las oportunidades para las y los jóvenes, de modo que toda la información pertinente sobre los programas y las oportunidades para ellos sea de fácil acceso.

La próxima ronda de VOCES-19 se llevará a cabo en noviembre de 2021. El seguimiento de las personas participantes de la primera ronda nos permitirá aprender más y profundizar en los impactos de la pandemia en la juventud mexicana.

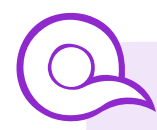

Muchas gracias por darnos a

todos nosotros, los jóvenes, la oportunidad de expresar nuestros sentimientos y compartir nuestras experiencias (tanto antes como después de la pandemia) a través de este medio. En serio, muchísimas gracias. Hombre, 19 años, CDMX.

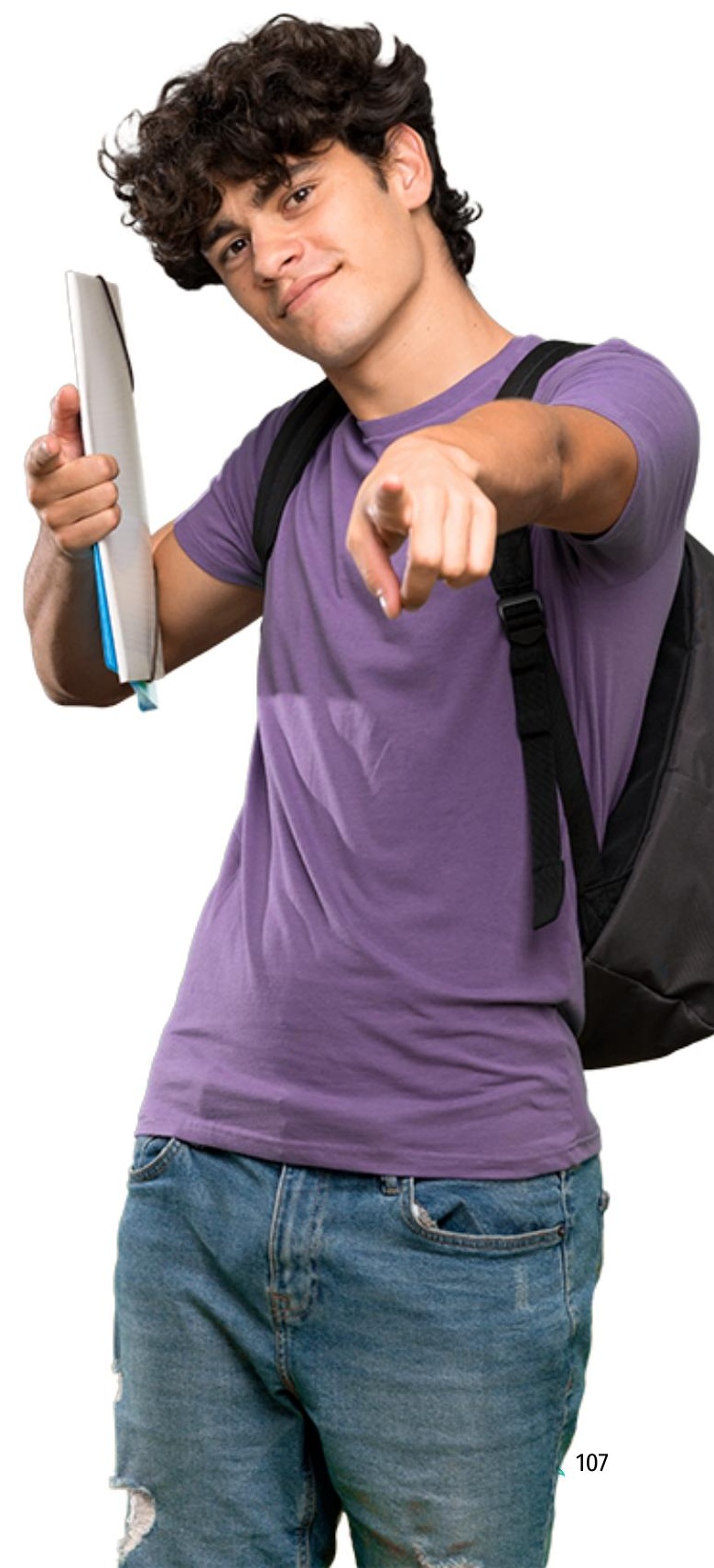


REFERENCIAS 
Institute of Health Metrics and Evaluation. (2021, October 13). COVID-19 Projections Mexico. Retrieved from COVID-19 Projections: https://covid19.healthdata.org/mexico?view=cumulative-deaths\&tab=trend

Secretaría de Educación Pública. (2021, Agosto 20). Diario Oficial de la Federación. Retrieved from ACUERDO número 23/08/21 por el que se establecen diversas disposiciones para el desarrollo del ciclo escolar 2021-2022 y reanudar las actividades del servicio público educativo de forma presencial, responsable y ordenada, y dar cumplimiento a los planes y: https://www.dof.gob.mx/nota_detalle.php?codigo $=5627244 \&$ fecha $=20 / 08 / 2021$

Gutierrez, J., Sucilla-Perez, H., Conde-Gonzalez, C., Izazola, J., Romero-Martinez, M., \& Hernandez-Avila, M. (2014). Seroprevalencia de VIH en población mexicana de entre 15 y 49 años: resultados de la Ensanut 2012. Salud pública de México, 56(4), 323-332.

Moral de la Rubia, J. (2011). Orientación sexual en adolescentes y jóvenes mexicanos de 12 a 29 años de edad. Psicología desde el Caribe, 27, 112-135.

Dirección General de Epidemiología. (2021, October 13). Datos Abiertos Dirección General de Epidemiología. Retrieved from Datos Abiertos Dirección General de Epidemiología: https://www.gob.mx/ salud/documentos/datos-abiertos-152127

UNESCO. (2021, March 19). One year into COVID-19 education disruption: Where do we stand? Retrieved from https://en.unesco.org/news/one-year-covid-19-education-disruption-where-do-we-stand

UNESCO. (2021, February 22). COVID-19: Two-thirds of poorer countries are cutting their education budgets at a time when they can least afford to. Retrieved from https://en.unesco.org/news/covid-19two-thirds-poorer-countries-are-cutting-their-education-budgets-time-when-they-can

Instituto Nacional de Estadística y Geografía. (2020). Encuesta para la Medición del Impacto COVID-19 en la Educación (ECOVID-ED) 2020. Retrieved from https://www.inegi.org.mx/contenidos/investigacion/ ecovided/2020/doc/ecovid_ed_2020_nota_tecnica.pdf

Instituto Nacional de Estadística y Geografía. (2021, March 23). INEGI presenta resultados de la Encuesta para la Medición del Impacto COVID-19 en la Educación (ECOVID-ED) 2020. Retrieved from https:// www.inegi.org.mx/contenidos/saladeprensa/boletines/2021/OtrTemEcon/ECOVID-ED_2021_03.pdf

International Labour Organization. (2021). ILO Monitor: COVID-19 and the world of work. Seventh edition. Updated estimates and analysis. ILO. Geneva: ILO.

International Labour Organization. (2020). México y la crisis de la COVID-19 en el mundo del trabajo: respuestas y desafíos. Mexico City: ILO.

Secretaría de Salud. (2021). Datos Abiertos Dirección General de Epidemiología. Retrieved July 08, 2021, from https://www.gob.mx/salud/documentos/datos-abiertos-152127

Secretaría de Salud. (2020). Jornada Nacional de Sana Distancia. Retrieved July 08, 2021, from https:// www.gob.mx/salud/hospitalgea/documentos/jornada-nacional-de-sana-distancia

Instituto Nacional de Estadística y Geografía. (2020). Encuesta para la Medición del Impacto COVID-19 en la Educación (ECOVID-ED) 2020. Retrieved July 08, 2021, from https://www.inegi.org.mx/investigacion/ecovided/2020/

OECD. (2021). Income inequality. Retrieved July 08, 2021, from https://data.oecd.org/inequality/incomeinequality.htm

Consejo Nacional de Evaluación de la Política de Desarrollo Social. (2021). Informe de Evaluación de la Política de Desarrollo Social 2020. Ciudad de México.

Instituto Nacional de Estadística y Geografía. (2020). Características educativas de la población. Retrieved July 08, 2021, from https://www.inegi.org.mx/temas/educacion/\#Tabulados 
Instituto Nacional de Estadística y Geografía. (2021). Empleo y Ocupación. Retrieved July 08, 2021, from https://www.inegi.org.mx/temas/empleo/

UNICEF México. (2020). Encuesta de Seguimiento de los Efectos del COVID-19 en el Bienestar de los Hogares en la Ciudad de México - ENCOVID-CDMX. Ciudad de México.

Peterman, A., O'Donnell, M., \& Palermo, T. (2020, June 01). COVID-19 and Violence against Women and Children What Have We Learned So Far? Retrieved from Center for Global Development: https:// www.cgdev.org/sites/default/files/covid-and-violence-against-women-and-children-what-we-havelearned.pdf

Fernández-Nieto, B. (2020, May 03). Violencia Doméstica en México durante el confinamiento por la pandemia COVID-19. Retrieved July 08, 2021, from https://datapopalliance.org/violencia-domesticaen-mexico-durante-el-confinamiento-por-la-pandemia-covid-19/

UNFPA. (2020). Repercusión de la pandemia de COVID-19 en la planificación familiar y la eliminación de la violencia de género, la mutilación genital femenina y el matrimonio infantil.

Cousins, S. (2020). COVID-19 has "devastating" effect on women and girls. Lancet, 396(10247), 301-302.

World Health Organization. (2020). Mental health and COVID-19. Retrieved July 08, 2021, from https:// www.euro.who.int/en/health-topics/health-emergencies/coronavirus-covid-19/publications-andtechnical-guidance/noncommunicable-diseases/mental-health-and-covid-19

World Health Organization. (2020). The impact of COVID-19 on mental, neurological and substance use services: results of a rapid assessment. Geneva.

ECLAC-UNESCO. (2020). Education in the time of COVID-19. Santiago.

Blundell, R., Costa-Dias, M., Joyce, R., \& Xu, X. (2020). COVID-19 and Inequalities. Fiscal Studies, 41(2), 1-29.

Instituto Nacional de Estadística y Geografía. (2020, May 14). Estadística a propósito del Día Mundial del Internet (17 de mayo). Datos Nacionales. Retrieved July 08, 2021, from https://www.inegi.org.mx/ contenidos/saladeprensa/aproposito/2020/eap_internet20.pdf

World Health Organization. (2021). COVID-19 Strategic Preparedness and Response Plan. Operational Planning Guideline. Geneva.

Secretaría de Salud. (2020). Sana Distancia COVID-19. Retrieved July 08, 2021, from https://www.gob.mx/ salud/documentos/sana-distancia

Gobierno de México. (2020). Entidades Federativas. Medidas Económicas. Retrieved July 08, 2021, from https://www.gob.mx/covid19medidaseconomicas?tab=EntidadesFederativas

El Economista. (2021, March 01). Cronología de la pandemia en México. El Economista.

Vieitez-Martínez, I., Larrea, S., Romero, F., \& Cicolella, L. (2020). Conocimientos, actitudes y prácticas relacionadas a la pandemia del COVID-19 en comunidades indígenas de Yucatán y Chiapas. Ciudad de México: Population Council.

BBC. (2020, February 18). How dangerous is Mexico? . BBC.

Statista. (2020). Ranking the most dangerous cities in the world in 2020, by murder rate per 100,000 inhabitants. Retrieved July 08, 2021, from https://www.statista.com/statistics/243797/ranking-of-themost-dangerous-cities-in-the-world-by-murder-rate-per-capita/

Instituto Nacional de Estadística y Geografía. (2019). Encuesta Nacional de Victimización y Percepción sobre Seguridad Pública (ENVIPE) 2019. Retrieved July 20, 2021, from https://www.inegi.org.mx/programas/envipe/2019/ 
Instituto Nacional de Estadística y Geografía. (2016). Encuesta Nacional sobre la Dinámica de las Relaciones en los Hogares 2016. Retrieved July 08, 2021, from https://www.inegi.org.mx/programas/endireh/ 2016/

UNICEF; Instituto Nacional de Salud Pública. (2015). Encuesta Nacional de Niños, Niñas y Mujeres 2015. Ciudad de México.

ECLAC-UNICEF. (2020). Violence against children and adolescents in the time of COVID-19.

Un Women. (2020, September 16). COVID-19 and its economic toll on women: The story behind the numbers. Retrieved July 18, 2021, from https://www.unwomen.org/en/news/stories/2020/9/featurecovid-19-economic-impacts-on-women

Ahmed, S., Ajisola, M., Azeem, K., Bakibinga, P., Chen, Y.-F., Choudhury, N., . . Sartori, J. (2020). Impact of the societal response to COVID-19 on access to healthcare for non-COVID-19 health issues in slum communities of Bangladesh, Kenya, Nigeria and Pakistan: results of pre-COVID and COVID-19 lockdown stakeholder engagements. British Medical Journal Global Health, 5, e003042.

Jones, E., Mitra, A. K., \& R, B. A. (2021). Impact of COVID-19 on mental health in adolescents: A systematic review. International Journal of Environmental Research and Public Health, 18(5), 2470.

Bhatia, G., Chatterjee, B., \& Dhawan, A. (2021). Adolescents, Drugs, and COVID-19: Special Challenges During the Pandemic. Indian Journal of Psychological Medicine, 43(2).

American Psychological Association. (2012). Building your resilience. Retrieved from https://www.apa.org/ topics/resilience

Shanahan, L., Steinhoff, A., Bechtiger, L., Murray, A. L., Hepp, U., Ribeaud, D., \& Eisner, M. (2020). Emotional distress in young adults during the COVID-19 pandemic: evidence of risk and resilience from a longitudinal cohort study. Psychological Medicine, 1-10.

Saavedra, J., \& Di Gropello, E. (2021, March 17). COVID-19 and the Learning Crisis in Latin America and the Caribbean: How Can We Prevent a Tragedy? Retrieved July 18, 2021, from https://blogs.worldbank.org/education/covid-19-and-learning-crisis-latin-america-and-caribbean-how-can-we-prevent-tragedy

Williams, T., Davis, J., Figueira, C., \& Vizard, T. (2021, May 5). Coronavirus and depression in adults, Great Britian: January to March 2021. Retrieved July 18, 2021, from https://www.ons.gov.uk/peoplepopulationandcommunity/wellbeing/articles/coronavirusanddepressioninadultsgreatbritain/januarytomarch2021 
TABLAS 
A. CARACTERISTICAS DE L AS PERSONAS PARTICIPANTES 
TABLA 2 Características de las personas participantes en VOCES-19

\begin{tabular}{|c|c|c|c|c|c|c|c|c|c|c|c|c|c|c|c|}
\hline \multirow{3}{*}{ Variable } & \multicolumn{5}{|c|}{ 15-17 años } & \multicolumn{5}{|c|}{ 18-24 años } & \multicolumn{5}{|c|}{ Total } \\
\hline & Mujeres & Hombres & Binarias & No binarias & Total & Mujeres & Hombres & Binarias & No binarias & Total & Mujeres & Hombres & Binarias & No binarias & Total \\
\hline & $\mathrm{n}=27,112$ & $\mathrm{n}=16,548$ & $\mathrm{n}=43,660$ & $\mathrm{n}=501$ & $\mathrm{n}=44,955$ & $\mathrm{n}=6,367$ & $\mathrm{n}=4,107$ & $\mathrm{n}=10,474$ & $\mathrm{n}=137$ & $\mathrm{n}=10,737$ & $\mathrm{n}=33,479$ & $\mathrm{n}=20,655$ & $\mathrm{n}=54,134$ & $\mathrm{n}=638$ & $\mathrm{~N}=55,692$ \\
\hline $\begin{array}{l}\text { Edad promedio (95\% Cl) } \\
\text { Grupo de edad \% (95\% Cl) }\end{array}$ & $\begin{array}{c}16.0 \\
(16.0,16.0)\end{array}$ & $\begin{array}{c}16.0^{*} \\
(15.9,16.0)\end{array}$ & $\begin{array}{c}16.0 \\
(16.0,16.0)\end{array}$ & $\begin{array}{c}15.9 \\
(15.8,16.0) \\
-\end{array}$ & $\begin{array}{c}16.0 \\
(16.0 .16 .0) \\
31.4 \\
(30.62 .11\end{array}$ & $\begin{array}{c}20.7 \\
(20.7,20.8)\end{array}$ & $\begin{array}{c}20.6 \\
(20.5,20.7)\end{array}$ & $\begin{array}{c}20.7 \\
(20.6,20.7)\end{array}$ & $\begin{array}{c}20.6 \\
(20.1,21.2)\end{array}$ & $\begin{array}{c}20.7 \\
(20.6,2.7 .7) \\
68.5 \\
(67.869 .3)\end{array}$ & $\begin{array}{c}19.3 \\
(19.2,19.4)\end{array}$ & $\begin{array}{c}19.1^{*} \\
(19.0,19.2)\end{array}$ & $\begin{array}{c}19.2 \\
(19.1,19.3)\end{array}$ & $\begin{array}{c}19.2 \\
(18.7,19.8)\end{array}$ & $\begin{array}{c}19.2 \\
(19.1,19.3)\end{array}$ \\
\hline Género \% (95\% Cl) & $\begin{array}{c}49.0 \\
(48.2,49.9)\end{array}$ & $\begin{array}{c}49.6 \\
(48.7,50.5)\end{array}$ & $\begin{array}{c}98.7 \\
(98.5,98.9)\end{array}$ & $\begin{array}{c}1.2 \\
(1.0,1.4)\end{array}$ & - & $\begin{array}{c}51.4 \\
(49.8,52.9)\end{array}$ & $\begin{array}{c}47.2 \\
(45.6,48.7)\end{array}$ & $\begin{array}{c}98.6 \\
(98.1,98.9)\end{array}$ & $\begin{array}{c}1.3 \\
(1.0,1.8)\end{array}$ & - & $\begin{array}{c}50.6 \\
(49.5,51.7)\end{array}$ & $\begin{array}{c}47.9 \\
(46.8,49.0)\end{array}$ & $\begin{array}{c}98.6 \\
(98.3,98.9)\end{array}$ & $\begin{array}{c}1.3 \\
(1.0,1.6)\end{array}$ & - \\
\hline \multicolumn{16}{|c|}{ Orientación sexual \% (95\% Cl) } \\
\hline Heterosexual & $\begin{array}{c}82.0 \\
(81.2,82.9)\end{array}$ & $\begin{array}{c}89.9^{*} \\
(88.9,90.8)\end{array}$ & $\begin{array}{c}86.0 \\
(85.486 .6)\end{array}$ & $\begin{array}{c}14.9^{+} \\
(10.2,21.1)\end{array}$ & $\begin{array}{l}84.7 \\
(84.0,85.3)\end{array}$ & $\begin{array}{c}83.4 \\
(81.884 .9)\end{array}$ & $\begin{array}{c}82.1 \\
(80.0,84.11\end{array}$ & $\begin{array}{c}82.8 \\
(81.5,84.0)\end{array}$ & $\begin{array}{l}5.9^{t} \\
(3.0,11.2)\end{array}$ & $\begin{array}{c}81.5 \\
(80.1,82.8)\end{array}$ & $\begin{array}{c}83.0 \\
(81.9,84.1)\end{array}$ & $\begin{array}{c}84.5 \\
(83.0,85.9)\end{array}$ & $\begin{array}{c}83.8 \\
(82.88,84.7)\end{array}$ & $\begin{array}{l}8.4^{4} \\
(55.6,12.4)\end{array}$ & $\begin{array}{c}82.4 \\
(81.583 .4)\end{array}$ \\
\hline $\begin{array}{l}\text { Homosexual, lesbiana o } \\
\text { gay }\end{array}$ & $\begin{array}{c}0.9 \\
(0.7,1.0)\end{array}$ & $\begin{array}{c}2.5^{*} \\
(2.1,3.1)\end{array}$ & $\begin{array}{c}17.6 \\
(15.0,20.6)\end{array}$ & $\begin{array}{c}14.5^{+} \\
(9.8,21.1)\end{array}$ & $\begin{array}{c}1.9 \\
(1.7,2.2)\end{array}$ & $\begin{array}{c}2.1 \\
(1.5,3.0)\end{array}$ & $\begin{array}{c}8.8^{*} \\
(7.3,10.5)\end{array}$ & $\begin{array}{c}5.3 \\
(4.5,6.3)\end{array}$ & $\begin{array}{c}21.5^{\dagger} \\
(13.0,33.4)\end{array}$ & $\begin{array}{c}5.6 \\
(4.8 .6 .6)\end{array}$ & $\begin{array}{c}1.8 \\
(1.3,2.4)\end{array}$ & $\begin{array}{c}6.8^{*} \\
(5.8,8.1)\end{array}$ & $\begin{array}{c}4.3 \\
(3.7,4.9)\end{array}$ & $\begin{array}{c}19.6^{+} \\
(13.2,28.0)\end{array}$ & $\begin{array}{c}4.5 \\
(3.0,5.2)\end{array}$ \\
\hline Bisexual & $\begin{array}{c}14.2 \\
(13.5,15.0)\end{array}$ & $\begin{array}{c}4.0^{*} \\
(3.5,4.7)\end{array}$ & $\begin{array}{c}9.0 \\
(8.6,9.5)\end{array}$ & $\begin{array}{c}54.6^{+} \\
(46.7,62.2)\end{array}$ & $\begin{array}{c}10.0 \\
(9.5,10.5)\end{array}$ & $\begin{array}{c}12.0 \\
(10.8,13.5)\end{array}$ & $\begin{array}{c}7.1^{*} \\
(5.8,8.6)\end{array}$ & $\begin{array}{c}9.7 \\
(8.7,70.7)\end{array}$ & $\begin{array}{c}50.1^{+} \\
(36.2,640.0)\end{array}$ & $\begin{array}{c}10.4 \\
(9.4,41.4)\end{array}$ & $\begin{array}{c}12.7 \\
(11.7,13.7)\end{array}$ & $\begin{array}{c}6.1^{*} \\
(5.2,7.2)\end{array}$ & $\begin{array}{c}9.5 \\
(8.8,10.2)\end{array}$ & $\begin{array}{c}51.3^{+} \\
(411.0,61.1)\end{array}$ & $\begin{array}{c}10.2 \\
(9.6,11.0)\end{array}$ \\
\hline Otra & $\begin{array}{c}2.7 \\
(2.3,3,11\end{array}$ & $\begin{array}{c}3.3^{*} \\
(2.9,3.9)\end{array}$ & $\begin{array}{c}3.0 \\
(2.7,3.4)\end{array}$ & $\begin{array}{c}15.8^{+} \\
(11.6,21.1)\end{array}$ & $\begin{array}{c}3.2 \\
(2.9,3.6)\end{array}$ & $\begin{array}{c}2.2 \\
(1.6,2.9)\end{array}$ & $\begin{array}{c}1.8 \\
(1.3,2.6)\end{array}$ & $\begin{array}{c}2.0 \\
(1.6,2.5)\end{array}$ & $\begin{array}{c}22.4^{+} \\
(12.7,36.2)\end{array}$ & $\begin{array}{c}2.3 \\
(1.9,2.8)\end{array}$ & $\begin{array}{c}2.3 \\
(1.9,2.8)\end{array}$ & $\begin{array}{c}2.3 \\
(1.9,2.8)\end{array}$ & $\begin{array}{c}2.3 \\
(2.0,2.7)\end{array}$ & $\begin{array}{c}20.5^{+} \\
(13.2,30.4)\end{array}$ & $\begin{array}{c}2.6 \\
(2.3,3.0)\end{array}$ \\
\hline $\begin{array}{l}\text { Se auto-identifica como } \\
\text { Indigena y/o } \\
\text { Afromexicano/a (I/AM) } \\
\% \text { (IQR) }\end{array}$ & $\begin{array}{c}30.0 \\
(29.1,31.0)\end{array}$ & $\begin{array}{c}33.8^{*} \\
(32.4,35.2)\end{array}$ & $\begin{array}{c}31.9 \\
(31.132 .7)\end{array}$ & $\begin{array}{c}28.8 \\
(22.436 .1)\end{array}$ & $\begin{array}{c}31.9 \\
(31.032 .7)\end{array}$ & $\begin{array}{c}26.9 \\
(25.3,28.7)\end{array}$ & $\begin{array}{c}30.6^{*} \\
(28.4,32.8)\end{array}$ & $\begin{array}{l}28.7 \\
(27.3,30.1)\end{array}$ & $\begin{array}{c}15.7^{+} \\
(88.8,26.2)\end{array}$ & $\begin{array}{l}28.5 \\
(27.2,29.9)\end{array}$ & $\begin{array}{c}27.9 \\
(26.7,29.1)\end{array}$ & $\begin{array}{c}31.6 * \\
(30.1,33.2)\end{array}$ & $\begin{array}{c}29.7 \\
(28.7,30.7)\end{array}$ & $\begin{array}{c}19.5^{+} \\
(13.7,26.9)\end{array}$ & $\begin{array}{l}29.5 \\
(28.6,30.5)\end{array}$ \\
\hline \multicolumn{16}{|c|}{ Nivel Socioeconómico \% (95\% Cl) } \\
\hline $1^{\text {th }}$ Quintil & $\begin{array}{c}20.7 \\
(19.8,21.6)\end{array}$ & $\begin{array}{c}17.41^{*} \\
(16.3,18.4)\end{array}$ & $\begin{array}{c}19.0 \\
(18.3,19.7)\end{array}$ & $\begin{array}{c}17.3 \\
(12.5,23.5)\end{array}$ & $\begin{array}{c}19.1 \\
(18.4,19.8)\end{array}$ & $\begin{array}{c}21.9 \\
(20.4,23.5)\end{array}$ & $\begin{array}{c}18.22^{*} \\
(16.5,20.0)\end{array}$ & $\begin{array}{c}20.2 \\
(19.1,21.4)\end{array}$ & $\begin{array}{l}10.91^{+} \\
(5.6,20.0)\end{array}$ & $\begin{array}{c}20.3 \\
(19.2,21.5)\end{array}$ & $\begin{array}{c}21.51 \\
(20.5,22.7)\end{array}$ & $\begin{array}{c}17.91^{*} \\
(16.7,19.2)\end{array}$ & $\begin{array}{c}19.8 \\
(19.0,20.7)\end{array}$ & $\begin{array}{l}12.81^{+} \\
(8.3,19.0)\end{array}$ & $\begin{array}{c}19.9 \\
(19.1,20.8)\end{array}$ \\
\hline $2^{\text {nd }}$ Quintil & $\begin{array}{c}21.2 \\
(20.4,22.1)\end{array}$ & $\begin{array}{c}17.61^{*} \\
(16.5,18.7)\end{array}$ & $\begin{array}{c}19.4 \\
(18.8,20.1)\end{array}$ & $\begin{array}{c}11.21^{+} \\
(8.1,15.1)\end{array}$ & $\begin{array}{c}19.4 \\
(18.7,20.0)\end{array}$ & $\begin{array}{c}19.7 \\
(18.2,21.2)\end{array}$ & $\begin{array}{c}18.2 \\
(16.5,20.0)\end{array}$ & $\begin{array}{c}19.0 \\
(17.9,20.2)\end{array}$ & $\begin{array}{c}13.7 \\
(7.3,24.0)\end{array}$ & $\begin{array}{c}19.0 \\
(17.8,20.1)\end{array}$ & $\begin{array}{c}20.1 \\
(19.1,21.3)\end{array}$ & $\begin{array}{c}18.01 * \\
(16.8,19.3)\end{array}$ & $\begin{array}{c}19.2 \\
(18.3,20.0)\end{array}$ & $\begin{array}{l}12.91^{+} \\
(8.1,20.0)\end{array}$ & $\begin{array}{c}19.1 \\
(18.3,19.9)\end{array}$ \\
\hline $3^{\text {td Quintil }}$ & $\begin{array}{c}20.1 \\
(19.3,20.9)\end{array}$ & $\begin{array}{c}18.6 \\
(17.6,69.7)\end{array}$ & $\begin{array}{c}19.5 \\
(18.8,20.1)\end{array}$ & $\begin{array}{c}17.4 \\
(12.5,23.6)\end{array}$ & $\begin{array}{c}19.5 \\
(18.8,20.2)\end{array}$ & $\begin{array}{c}17.0 \\
(15.6,18.5)\end{array}$ & $\begin{array}{c}17.7 \\
(16.0,19.5)\end{array}$ & $\begin{array}{c}17.2 \\
(16.2,18.4)\end{array}$ & $\begin{array}{c}21.5 \\
(11.6,36.2)\end{array}$ & $\begin{array}{c}17.3 \\
(16.2,18.4)\end{array}$ & $\begin{array}{c}17.9 \\
(16.9,19.0)\end{array}$ & $\begin{array}{c}18.0 \\
(16.8,19.2)\end{array}$ & $\begin{array}{c}17.9 \\
(17.1,18.8)\end{array}$ & $\begin{array}{c}20.3 \\
(12.8,20.6)\end{array}$ & $\begin{array}{c}18.0 \\
(17.2,18.8)\end{array}$ \\
\hline $4^{\text {th }}$ Quintil & $\begin{array}{c}19.1 \\
(18.3,20.0)\end{array}$ & $\begin{array}{c}22.6^{*} \\
(21.5,23.8)\end{array}$ & $\begin{array}{c}20.9 \\
(20.2,21.7)\end{array}$ & $\begin{array}{c}20.8 \\
(15.9,26.7)\end{array}$ & $\begin{array}{c}20.9 \\
(20.1,21.6)\end{array}$ & $\begin{array}{c}16.9 \\
(15.5,18.4)\end{array}$ & $\begin{array}{c}18.1 \\
(16.3,19.9)\end{array}$ & $\begin{array}{c}17.6 \\
(16.4,18.8)\end{array}$ & $\begin{array}{c}12.8 \\
(5.2,27.8)\end{array}$ & $\begin{array}{c}17.5 \\
(16.4,18.7)\end{array}$ & $\begin{array}{c}17.6 \\
(16.6,18.7)\end{array}$ & $\begin{array}{c}19.51^{*} \\
(18.3,20.9)\end{array}$ & $\begin{array}{c}18.6 \\
(17.8,19.5)\end{array}$ & $\begin{array}{c}15.1 \\
(8.9,24.5)\end{array}$ & $\begin{array}{c}18.5 \\
(177.7,19.4)\end{array}$ \\
\hline $5 \mathrm{t}^{\mathrm{h}}$ Quintil & $\begin{array}{c}18.6 \\
(17.9,19.4)\end{array}$ & $\begin{array}{c}23.6^{*} \\
(22.5,24.8)\end{array}$ & $\begin{array}{c}20.9 \\
(20.3,21.7)\end{array}$ & $\begin{array}{c}33.1^{+} \\
(25.741 .6)\end{array}$ & $\begin{array}{c}20.9 \\
(20.3,21.6)\end{array}$ & $\begin{array}{c}24.3 \\
(22.5,26.2)\end{array}$ & $\begin{array}{c}27.6^{*} \\
(25.5,29.9)\end{array}$ & $\begin{array}{c}25.7 \\
(24.3,27.2)\end{array}$ & $\begin{array}{c}41.0^{+} \\
(28.3,55.1)\end{array}$ & $\begin{array}{c}25.7 \\
(24.3,27.1)\end{array}$ & $\begin{array}{c}22.6 \\
(21.3,23.9)\end{array}$ & $\begin{array}{c}26.3^{*} \\
(24.8,27.9)\end{array}$ & $\begin{array}{c}24.2 \\
(23.2,25.2)\end{array}$ & $\begin{array}{c}38.7^{+} \\
(29.3,49.0)\end{array}$ & $\begin{array}{c}24.2 \\
(23.2,25.2)\end{array}$ \\
\hline \multicolumn{16}{|c|}{ Estado Civil \% $(95 \% \mathrm{Cl})$} \\
\hline $\begin{array}{l}\text { Vive con parejals) } \\
\text { (matrimonio/unión libre) }\end{array}$ & $\begin{array}{c}0.8 \\
(0.6,1,0)\end{array}$ & $\begin{array}{c}0.7 \\
(0.5,1.0)\end{array}$ & $\begin{array}{c}0.7 \\
(0.6,0.9)\end{array}$ & $\begin{array}{c}0.5 \\
(0.1,1.8)\end{array}$ & $\begin{array}{c}0.7 \\
(0.6,0.9)\end{array}$ & $\begin{array}{c}10.8 \\
(9.5,12.3)\end{array}$ & $\begin{array}{c}7.0 * \\
(5.7 .8 .6)\end{array}$ & $\begin{array}{c}9.0 \\
(8.0,10.1)\end{array}$ & $\begin{array}{c}15.5 \\
(6.6,32.1)\end{array}$ & $\begin{array}{c}9.1 \\
(8.2,10.2)\end{array}$ & $\begin{array}{c}7.9 \\
(7.0,9.0)\end{array}$ & $\begin{array}{c}5.1 * \\
(4.1,6.2)\end{array}$ & $\begin{array}{c}6.6 \\
(5.9 .7,7.3)\end{array}$ & $\begin{array}{c}11.5 \\
(4.9,24.5)\end{array}$ & $\begin{array}{c}6.6 \\
(6.0,7.4)\end{array}$ \\
\hline $\begin{array}{l}\text { Tiene pareja pero no vive } \\
\text { con él/ /llla }\end{array}$ & $\begin{array}{c}21.0 \\
(20.2,21.9)\end{array}$ & $\begin{array}{c}18.8^{*} \\
(17.7,20.0)\end{array}$ & $\begin{array}{c}19.9 \\
(19.2,20.7)\end{array}$ & $\begin{array}{c}23.6 \\
(16.9,31.8)\end{array}$ & $\begin{array}{c}19.9 \\
(19.2,20.6)\end{array}$ & $\begin{array}{c}33.2 \\
(31.3,35.1)\end{array}$ & $\begin{array}{c}28.4 \\
(26.2,30.7)\end{array}$ & $\begin{array}{c}30.9 \\
(29.5,32.4)\end{array}$ & $\begin{array}{c}32.5^{+} \\
(20.6,47.1)\end{array}$ & $\begin{array}{c}30.9 \\
(29.5,32.3)\end{array}$ & $\begin{array}{c}29.7 \\
(28.3,31.1)\end{array}$ & $\begin{array}{c}25.5^{*} \\
(23.9,27.1)\end{array}$ & $\begin{array}{c}27.7 \\
(26.6,28.7)\end{array}$ & $\begin{array}{c}30.1 \\
(21.0,41.1)\end{array}$ & $\begin{array}{c}27.6 \\
(26.6,28.7)\end{array}$ \\
\hline Soltera/o & $\begin{array}{c}68.5 \\
(67.5,69.6)\end{array}$ & $\begin{array}{c}69.4 \\
(68.1,70.8)\end{array}$ & $\begin{array}{c}69.0 \\
(68.1,1,69.8)\end{array}$ & $\begin{array}{c}65.4 \\
(57.2,72.8)\end{array}$ & $\begin{array}{c}69.1 \\
(68.3,69.9)\end{array}$ & $\begin{array}{c}51.3 \\
(49.3 .53 .3)\end{array}$ & $\begin{array}{c}60.3^{*} \\
(57.9,62.7)\end{array}$ & $\begin{array}{c}55.6 \\
(54.0,57.1)\end{array}$ & $\begin{array}{c}46.4 \\
(33.1,60.2)\end{array}$ & $\begin{array}{c}55.3 \\
(53.856 .9)\end{array}$ & $\begin{array}{c}56.2 \\
(54.7,57.7)\end{array}$ & $\begin{array}{c}63.1^{*} \\
(61.3,64.8)\end{array}$ & $\begin{array}{c}59.5 \\
(58.4,60.7)\end{array}$ & $\begin{array}{c}51.5 \\
(40.9,61.9)\end{array}$ & $\begin{array}{c}59.4 \\
(58.3,60.5)\end{array}$ \\
\hline $\begin{array}{l}\text { Otro (separada/o, } \\
\text { divorcidada/o viuda/o) }\end{array}$ & $\begin{array}{c}0.2 \\
(0.1,0.3)\end{array}$ & $\begin{array}{c}0.8^{*} \\
(0.6,1.1)\end{array}$ & $\begin{array}{c}0.5 \\
(0.4,0.6)\end{array}$ & $\begin{array}{c}0.03^{+} \\
(0.004,0.2)\end{array}$ & $\begin{array}{c}0.5 \\
(0.4,0.6)\end{array}$ & $\begin{array}{c}0.7 \\
(0.5,1.1)\end{array}$ & $\begin{array}{c}0.4 \\
(0.2,0.8)\end{array}$ & $\begin{array}{c}0.6 \\
(0.4,0.8)\end{array}$ & $\begin{array}{c}1.7 \\
(0.2,11.3)\end{array}$ & $\begin{array}{c}0.6 \\
(0.4,0.8)\end{array}$ & $\begin{array}{c}0.6 \\
(0.4,0.9)\end{array}$ & $\begin{array}{c}0.5 \\
(0.3,0.7)\end{array}$ & $\begin{array}{c}0.5 \\
(0.4,0.7)\end{array}$ & $\begin{array}{c}1.2 \\
(0.1,8.4)\end{array}$ & $\begin{array}{c}0.6 \\
(0.4,0.7)\end{array}$ \\
\hline
\end{tabular}




\begin{tabular}{|c|c|c|c|c|c|c|c|c|c|c|c|c|c|c|c|}
\hline $\begin{array}{l}\text { Unión o matrimonio } \\
\text { temprano (antes de los } 18 \\
\text { años) }\end{array}$ & $\begin{array}{c}0.6 \\
(0.5,0.8) \\
\end{array}$ & $\begin{array}{c}0.6 \\
(0.4,0.8) \\
\end{array}$ & $\begin{array}{c}0.6 \\
(0.5,0.7) \\
\end{array}$ & $\begin{array}{c}0.4 \\
(0.1,1.6)\end{array}$ & $\begin{array}{c}0.6 \\
(0.5,0.7) \\
\end{array}$ & $\begin{array}{c}2.9 \\
(2.2,3.7)\end{array}$ & $\begin{array}{c}1.5^{*} \\
(0.9,2.3) \\
\end{array}$ & $\begin{array}{c}2.2 \\
(1.8,2.8) \\
\end{array}$ & $\begin{array}{c}2.2 \\
(0.4,9.8) \\
\end{array}$ & $\begin{array}{r}2.2 \\
(1.8,2.8) \\
\end{array}$ & $\begin{array}{c}2.2 \\
(1.7,2.8) \\
\end{array}$ & $\begin{array}{c}1.2^{*} \\
(0.8,1.7) \\
\end{array}$ & $\begin{array}{c}1.7 \\
(1.4,2.1) \\
\end{array}$ & $\begin{array}{c}1.7 \\
(0.4,6.8) \\
\end{array}$ & $\begin{array}{c}1.7 \\
(1.4,2.1)\end{array}$ \\
\hline $\begin{array}{l}\text { Embarazada al momento } \\
\text { del estudio (solo mujeres) }\end{array}$ & $\begin{array}{c}1.7 \\
(1.2,2.4)\end{array}$ & $\cdot$ & - & $\cdot$ & & $\begin{array}{c}1.7 \\
(1.1,2.6)\end{array}$ & $\cdot$ & - & $\cdot$ & & $\begin{array}{c}1.7 \\
(1.2,2.5)\end{array}$ & $\cdot$ & $\cdot$ & - & \\
\hline \multicolumn{16}{|c|}{ Características del hogar $\%(95 \% \mathrm{Cl})$} \\
\hline $\begin{array}{l}\text { Vive en un hogar con } \\
\text { hacinamiento }\end{array}$ & $\begin{array}{c}32.7 \\
(31.7,33.7)\end{array}$ & $\begin{array}{c}30.0^{*} \\
(28.7,31.3)\end{array}$ & $\begin{array}{c}31.3 \\
(30.5,32.2)\end{array}$ & $\begin{array}{c}28.9 \\
(22.7,36.0)\end{array}$ & $\begin{array}{c}31.4 \\
(30.6,32.2)\end{array}$ & $\begin{array}{c}27.4 \\
(25.7,29.1)\end{array}$ & $\begin{array}{c}24.9 \\
(23.0,27.0)\end{array}$ & $\begin{array}{c}26.2 \\
(24.9,27.5)\end{array}$ & $\begin{array}{c}25.3 \\
(14.9,39.6)\end{array}$ & $\begin{array}{c}26.3 \\
(25.1,27.7)\end{array}$ & $\begin{array}{c}29.0 \\
(27.8,30.2)\end{array}$ & $\begin{array}{c}26.6^{*} \\
(25.2,28.0)\end{array}$ & $\begin{array}{c}27.8 \\
(26.9,28.8)\end{array}$ & $\begin{array}{c}26.3 \\
(18.3,36.3)\end{array}$ & $\begin{array}{c}27.9 \\
(27.0,28.9)\end{array}$ \\
\hline Vive en un hogar familiar & $\begin{array}{c}99.6 \\
(99.5,99.7)\end{array}$ & $\begin{array}{c}99.6 \\
(99.5,99.7)\end{array}$ & $\begin{array}{c}99.6 \\
(99.5,99.7)\end{array}$ & $\begin{array}{c}99.8 \\
(98.6,99.9)\end{array}$ & $\begin{array}{c}99.6 \\
(99.5,99.7)\end{array}$ & $\begin{array}{c}99.5 \\
(99.0,99.7)\end{array}$ & $\begin{array}{c}99.7 \\
(99.4,99.8)\end{array}$ & $\begin{array}{c}99.6 \\
(99.3,99.7)\end{array}$ & $\begin{array}{c}94.4 \\
(72.7,99.1)\end{array}$ & $\begin{array}{c}99.5 \\
(99.2,99.7)\end{array}$ & $\begin{array}{c}99.5 \\
(99.2,99.7)\end{array}$ & $\begin{array}{c}99.7 \\
(99.5,99.8)\end{array}$ & $\begin{array}{c}99.6 \\
(99.4,99.7)\end{array}$ & $\begin{array}{c}96.0 \\
(79.6,99.3)\end{array}$ & $\begin{array}{c}99.5 \\
(99.3,99.7)\end{array}$ \\
\hline $\begin{array}{l}\text { Vive en un hogar con jefa } \\
\text { del hogar mujer }\end{array}$ & $\begin{array}{c}41.0 \\
(40.0,02.0)\end{array}$ & $\begin{array}{c}39.0^{*} \\
(37.7,40.4)\end{array}$ & $\begin{array}{c}40.0 \\
(39.1,40.9)\end{array}$ & $\begin{array}{c}47.1 \\
(39.4,54.8)\end{array}$ & $\begin{array}{c}40.1 \\
(39.3,41.0)\end{array}$ & $\begin{array}{c}38.7 \\
(36.8,40.6)\end{array}$ & $\begin{array}{c}33.5^{*} \\
(31.3,35.8)\end{array}$ & $\begin{array}{c}36.2 \\
(34.8,37.7)\end{array}$ & $\begin{array}{c}28.7 \\
(18.4,41.8)\end{array}$ & $\begin{array}{c}36.2 \\
(34.7,37.6)\end{array}$ & $\begin{array}{c}39.4 \\
(38.0,40.7)\end{array}$ & $\begin{array}{c}35.3^{*} \\
(33.7,36.9)\end{array}$ & $\begin{array}{c}37.4 \\
(36.3,38.4)\end{array}$ & $\begin{array}{c}34.0 \\
(25.6,43.4)\end{array}$ & $\begin{array}{c}37.4 \\
(36.4,38.4)\end{array}$ \\
\hline $\begin{array}{l}\text { Tiene acceso a internet } \\
\text { privado (Wifi) en el hogar }\end{array}$ & $\begin{array}{c}80.2 \\
(79.3,81.1) \\
\end{array}$ & $\begin{array}{c}83.1^{*} \\
(82.0,84.1) \\
\end{array}$ & $\begin{array}{c}81.7 \\
(81.0,82.3)\end{array}$ & $\begin{array}{c}86.0 \\
(78.9,91.0)\end{array}$ & $\begin{array}{c}81.6 \\
(80.9,82.3) \\
\end{array}$ & $\begin{array}{c}75.3 \\
(73.5,76.9) \\
\end{array}$ & $\begin{array}{c}79.8^{*} \\
(77.8181 .6)\end{array}$ & $\begin{array}{c}77.4 \\
(76.1,78.7) \\
\end{array}$ & $\begin{array}{c}90.9^{+} \\
(80.7,96.0)\end{array}$ & $\begin{array}{c}77.4 \\
(76.1,78.6) \\
\end{array}$ & $\begin{array}{c}76.8 \\
(75.5,77.9) \\
\end{array}$ & $\begin{array}{l}80.8^{* * *} \\
(79.4,82.1)\end{array}$ & $\begin{array}{c}78.7 \\
(77.8,79.6)\end{array}$ & $\begin{array}{c}89.5^{\wedge} \\
(82.7,93.8)\end{array}$ & $\begin{array}{c}78.7 \\
(77.8,79.6)\end{array}$ \\
\hline \multicolumn{16}{|c|}{ Educación y Empleo \% (95\% Cl) } \\
\hline $\begin{array}{l}\text { Inscrita/o a la escuela al } \\
\text { momento de la encuesta }\end{array}$ & $\begin{array}{c}99.6 \\
(99.4,999.7)\end{array}$ & $99.5(99.3,99.7)$ & $99.5(99.4,99.6)$ & $96.7(90.6,102.8)$ & $99.5(99.3,99.6)$ & $\begin{array}{c}73.5 \\
(71.6,75.4)\end{array}$ & $\begin{array}{c}77.3 \\
(74.0,78.6)\end{array}$ & $\begin{array}{c}74.8 \\
(73.3 .76 .3)\end{array}$ & $\begin{array}{c}85.6 \\
(76.6,94.7)\end{array}$ & $\begin{array}{c}75.0 \\
(73.5,76.5)\end{array}$ & $\begin{array}{c}81.3 \\
(79.98 .7)\end{array}$ & $\begin{array}{c}83.8^{*} \\
(82.1,85.4)\end{array}$ & $82.5(81.4,83.6)$ & $88.8(82.1,95.4)$ & $\begin{array}{c}82.6 \\
(81.6,83.7)\end{array}$ \\
\hline $\begin{array}{l}\text { Trabajando el momento de } \\
\text { la encuesta }\end{array}$ & $18.3(17.5,19.2)$ & $\begin{array}{c}26.7^{*} \\
(25.5,27.9)\end{array}$ & $22.5(21.8,23.3)$ & $19.5(13.6,25.4)$ & $22.5(21.8,23.3)$ & $40.5(38.5,42.5)$ & $\begin{array}{c}48.3^{*} \\
(45.9,50.8)\end{array}$ & $44.2(42.6,45.8)$ & $40.7(26.2,55.1)$ & $44.1(42.5,45.6)$ & $34.0(32.5,35.4)$ & $\begin{array}{c}41.4^{*} \\
(39.7,43.2)\end{array}$ & $\begin{array}{c}37.6 \\
(36.4,38.7)\end{array}$ & $34.5(23.8,45.1)$ & $37.5(36.3,38.6)$ \\
\hline $\begin{array}{l}\text { Recibió apoyo del gobierno } \\
\text { desdde el inicio de la } \\
\text { pandemia }\end{array}$ & $\begin{array}{c}70.6 \\
(69.7,71.6)\end{array}$ & $\begin{array}{c}67.2^{*} \\
(65.7,68.6)\end{array}$ & $\begin{array}{c}68.9 \\
(68.0,99.7)\end{array}$ & $\begin{array}{c}73.4 \\
(65.1,80.3)\end{array}$ & $\begin{array}{c}68.9 \\
(68.1,69.8)\end{array}$ & $\begin{array}{c}46.6 \\
(44.7,48.6)\end{array}$ & $\begin{array}{c}48.7 \\
(46.3,51.1)\end{array}$ & $\begin{array}{c}47.6 \\
(46.1,49.2)\end{array}$ & $\begin{array}{c}48.5 \\
(34.9,62.3)\end{array}$ & $\begin{array}{c}47.7 \\
(46.2,49.2)\end{array}$ & $\begin{array}{c}53.8 \\
(52.455 .3)\end{array}$ & $\begin{array}{c}54.6 \\
(52.9,56.4)\end{array}$ & $\begin{array}{c}54.2 \\
(53.1,5.3)\end{array}$ & $\begin{array}{c}55.8 \\
(45.2,65.9)\end{array}$ & $\begin{array}{c}54.3 \\
(53.2,55.4)\end{array}$ \\
\hline \multicolumn{16}{|c|}{ Dinámicas del hogar y de la familia \% $(95 \% \mathrm{Cl})$} \\
\hline $\begin{array}{l}\text { indice de división de } \\
\text { responsabilidaded del } \\
\text { hogar puntaje promedio } \\
( \pm \leq D)\end{array}$ & $\begin{array}{l}21.7 \\
(0.06)\end{array}$ & $\begin{array}{l}22.9^{*} \\
(0.06)\end{array}$ & $\begin{array}{l}22.3 \\
(0.04)\end{array}$ & $\begin{array}{l}21.1 \\
(0.75)\end{array}$ & $\begin{array}{l}22.3 \\
(0.04)\end{array}$ & $\begin{array}{l}21.0 \\
(0.13)\end{array}$ & $\begin{array}{l}23.3^{*} \\
(0.111\end{array}$ & $\begin{array}{l}22.0 \\
(0.09)\end{array}$ & $\begin{array}{l}20.7 \\
(0.96)\end{array}$ & $\begin{array}{l}22.0 \\
(0.09)\end{array}$ & $\begin{array}{l}21.2 \\
10.099\end{array}$ & $\begin{array}{l}23.1^{*} \\
(0.07)\end{array}$ & $\begin{array}{l}22.1 \\
(0.06)\end{array}$ & $\begin{array}{l}20.9 \\
(0.68)\end{array}$ & $\begin{array}{l}22.1 \\
(0.06)\end{array}$ \\
\hline $\begin{array}{l}\text { indice de división de la } \\
\text { responsabilidadd de la toma } \\
\text { de decisiones en el hogar } \\
\text { puntaje promedio ( }( \pm S D)\end{array}$ & $\begin{array}{c}8.2 \\
(0.02)\end{array}$ & $\begin{array}{l}8.2 \\
(0.02)\end{array}$ & $\begin{array}{c}8.2 \\
(0.01)\end{array}$ & $\begin{array}{c}8.2 \\
(0.15)\end{array}$ & $\begin{array}{c}8.2 \\
(0.01)\end{array}$ & $\begin{array}{c}7.8 \\
(0.03)\end{array}$ & $\begin{array}{l}8.0^{*} \\
(0.04)\end{array}$ & $\begin{array}{c}7.9 \\
(0.02)\end{array}$ & $\begin{array}{c}7.6 \\
(0.25)\end{array}$ & $\begin{array}{c}7.9 \\
(0.02)\end{array}$ & $\begin{array}{c}7.9 \\
10.021\end{array}$ & $\begin{array}{l}8.0^{*} \\
(0.03)\end{array}$ & $\begin{array}{l}8.0 \\
(0.02)\end{array}$ & $\begin{array}{l}7.8 \\
(1.2)\end{array}$ & $\begin{array}{c}8.0 \\
(0.02)\end{array}$ \\
\hline $\begin{array}{l}\text { Vive en un hogar donde las } \\
\text { mujeres manejan los } \\
\text { ingresos }\end{array}$ & $\begin{array}{c}12.0 \\
(11.3,12.7)\end{array}$ & $\begin{array}{c}13.8^{*} \\
(12.7,15.0)\end{array}$ & $\begin{array}{c}12.9 \\
(12.3,13.6)\end{array}$ & $\begin{array}{c}13.2 \\
(7.5,22.1)\end{array}$ & $\begin{array}{c}12.9 \\
(12.2,13.6)\end{array}$ & $\begin{array}{c}14.0 \\
(12.6,15.5)\end{array}$ & $\begin{array}{c}14.1 \\
(12.5,15.9)\end{array}$ & $\begin{array}{c}14.1 \\
(13.0,15.2)\end{array}$ & $\begin{array}{c}16.3 \\
(9.0,27.8)\end{array}$ & $\begin{array}{c}14.1 \\
(13.1,15.3)\end{array}$ & $\begin{array}{c}13.4 \\
(12.4,14.5)\end{array}$ & $\begin{array}{c}14.0 \\
(12.8,15.3)\end{array}$ & $\begin{array}{c}13.7 \\
(12.9,14.5)\end{array}$ & $\begin{array}{l}15.4 \\
(9.7,73.8)\end{array}$ & $\begin{array}{l}13.7 \\
(13.0,14.5)\end{array}$ \\
\hline $\begin{array}{l}\text { La madre o el padre } \\
\text { consume frecuentemente } \\
\text { alconolo o drogas (entre } \\
\text { aquellos que tienen un } \\
\text { miembrod de la familia que } \\
\text { consuma alcohol o drogas) }\end{array}$ & $\begin{array}{c}4.8 \\
(4.4,5.2)\end{array}$ & $\begin{array}{c}5.0 \\
(4.3 .5 .8)\end{array}$ & $\begin{array}{c}4.9 \\
(4.5 .5 .3)\end{array}$ & $\begin{array}{c}9.7^{+} \\
(6.2,14.8)\end{array}$ & $\begin{array}{c}4.9 \\
(4.5 .5 .3)\end{array}$ & $\begin{array}{c}5.6 \\
(4.7 .6 .6)\end{array}$ & $\begin{array}{c}6.4 \\
(5.2,7.7)\end{array}$ & $\begin{array}{c}6.0 \\
(5.2,6.8)\end{array}$ & $\begin{array}{c}7.6 \\
(3.8,14.6)\end{array}$ & $\begin{array}{c}6.0 \\
(5.2,6.8)\end{array}$ & $\begin{array}{c}5.3 \\
(4.7 .7 .6 .1)\end{array}$ & $\begin{array}{c}5.9 \\
(5.1,6.9)\end{array}$ & $\begin{array}{c}5.6 \\
(5.1,6.2)\end{array}$ & $\begin{array}{c}8.2 \\
(5.1,13.0)\end{array}$ & $\begin{array}{c}5.6 \\
(5.1,6.2)\end{array}$ \\
\hline $\begin{array}{l}\text { La madre oel padre tiene } \\
\text { depresión u otro problema } \\
\text { de salud mental (entre } \\
\text { aquellos quue tienen un } \\
\text { miembro de la familia con } \\
\text { depresión u trar } \\
\text { enfermedad mental) }\end{array}$ & $\begin{array}{c}3.6 \\
(3.2,4.1)\end{array}$ & $\begin{array}{c}2.0^{*} \\
(1.7,2.3)\end{array}$ & $\begin{array}{c}2.8 \\
(2.5,3.1)\end{array}$ & $\begin{array}{c}9.9 \\
(4.4,20.5)\end{array}$ & $\begin{array}{c}2.9 \\
(2.6,3.2)\end{array}$ & $\begin{array}{c}8.5 \\
(7.3,9.8)\end{array}$ & $\begin{array}{c}5.1^{*} \\
(4.0,6.64)\end{array}$ & $\begin{array}{c}6.8 \\
(6.0,7.7)\end{array}$ & $\begin{array}{c}23.5^{\dagger} \\
(11.9,40.9)\end{array}$ & $\begin{array}{c}7.1 \\
(6.2,8.0)\end{array}$ & $\begin{array}{c}7.1 \\
(6.2,8.0)\end{array}$ & $\begin{array}{c}4.1^{*} \\
(3.4,5.0)\end{array}$ & $\begin{array}{c}5.6 \\
(5.0,0.6 .2)\end{array}$ & $\begin{array}{c}19.7^{+} \\
(10.9,33.0)\end{array}$ & $\begin{array}{c}5.8 \\
(5.2,6.4)\end{array}$ \\
\hline
\end{tabular}




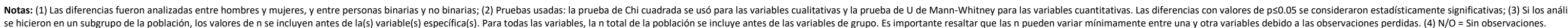

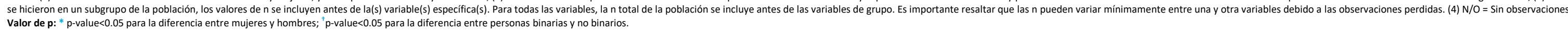


B. CUMPLIMIENTO DE LAS MEDIDAS DE MITIGACION DE COVID-19 
TABLA 3 Cumplimiento de las medidas de mitigación de COVID-19, por grupo de edad y género

\begin{tabular}{|c|c|c|c|c|c|c|c|c|c|c|c|c|c|c|c|}
\hline \multirow{3}{*}{ Variable } & \multicolumn{5}{|c|}{ 15-17 años } & \multicolumn{5}{|c|}{ 18-24 años } & \multicolumn{5}{|c|}{ Total } \\
\hline & Mujeres & Hombres & Binarias & No binarias & Total & Mujeres & Hombres & Binarias & No binarias & Total & Mujeres & Hombres & Binarias & No binarias & Total \\
\hline & $\mathrm{n}=27,112$ & $\mathrm{n}=16,548$ & $n=43,660$ & $n=501$ & $\mathrm{n}=44,955$ & $n=6,367$ & $\mathrm{n}=4,107$ & $\mathrm{n}=10,474$ & $\mathrm{n}=137$ & $n=10,737$ & $\mathrm{n}=33,479$ & $\mathrm{n}=20,655$ & $\mathrm{n}=54,134$ & $n=638$ & $\mathrm{~N}=55,692$ \\
\hline \multicolumn{16}{|c|}{ Cumplimiento de las medidas de mitigación \% (95\% Cl) } \\
\hline Lavado de manos & $\begin{array}{c}91.8 \\
(91.2,92.4)\end{array}$ & $\begin{array}{c}91.3 \\
(90.4,92.1)\end{array}$ & $\begin{array}{c}91.5 \\
(91.0,92.0)\end{array}$ & $\begin{array}{c}86.5 \\
(77.9,92.0)\end{array}$ & $\begin{array}{c}91.4 \\
(90.9,91.9)\end{array}$ & $\begin{array}{c}93.8 \\
(92.8,94.7)\end{array}$ & $\begin{array}{c}91.0 * \\
(89.6,92.3)\end{array}$ & $\begin{array}{c}92.5 \\
(91.6,93.3)\end{array}$ & $\begin{array}{c}76.2 \\
(58.4,87.9)\end{array}$ & $\begin{array}{c}92.2 \\
(91.3,93.0)\end{array}$ & $\begin{array}{c}93.2 \\
(92.5,93.9)\end{array}$ & $\begin{array}{c}91.1 * \\
(90.1,92.0)\end{array}$ & $\begin{array}{c}92.2 \\
(91.6,92.8)\end{array}$ & $\begin{array}{c}79.22^{\dagger} \\
(66.2,88.1)\end{array}$ & $\begin{array}{c}92.0 \\
(91.3,92.5)\end{array}$ \\
\hline Distanciamiento social & $\begin{array}{l}56.7 \\
(55.7,57.7)\end{array}$ & $\begin{array}{l}53.6^{*} \\
(52.255 .0)\end{array}$ & $\begin{array}{c}55.1 \\
(54.3,56.0)\end{array}$ & $\begin{array}{c}57.3 \\
(49.9,64.4)\end{array}$ & $\begin{array}{c}55.1 \\
(54.3,56.0)\end{array}$ & $\begin{array}{c}59.0 \\
(57.1,60.9)\end{array}$ & $\begin{array}{c}55.4^{*} \\
(53.1,57.8)\end{array}$ & $\begin{array}{c}57.3 \\
(55.8,58.8)\end{array}$ & $\begin{array}{c}63.9 \\
(50.4,75.6)\end{array}$ & $\begin{array}{c}57.3 \\
(55.8,58.8)\end{array}$ & $\begin{array}{c}58.3 \\
(56.9,59.7)\end{array}$ & $\begin{array}{c}54.8^{*} \\
(53.2,56.5)\end{array}$ & $\begin{array}{c}56.6 \\
(55.5,57.7)\end{array}$ & $\begin{array}{c}62.0 \\
(52.2,70.9)\end{array}$ & $\begin{array}{c}56.6 \\
(55.6,57.7)\end{array}$ \\
\hline Quedarse en casa & $\begin{array}{c}82.2 \\
(81.4,83.1)\end{array}$ & $\begin{array}{c}77.3^{*} \\
(76.0,78.5)\end{array}$ & $\begin{array}{c}79.7 \\
(79.0,80.5)\end{array}$ & $\begin{array}{c}74.9 \\
(66.1,82.1)\end{array}$ & $\begin{array}{c}79.6 \\
(78.9,80.4)\end{array}$ & $\begin{array}{c}83.0 \\
(81.4,84.4)\end{array}$ & $\begin{array}{c}79.3^{*} \\
(77.3,81.1)\end{array}$ & $\begin{array}{c}81.2 \\
(80.0,82.4)\end{array}$ & $\begin{array}{c}78.8 \\
(65.0,88.1)\end{array}$ & $\begin{array}{c}81.18 \\
(79.9,82.3)\end{array}$ & $\begin{array}{c}82.7 \\
(81.7,83.8)\end{array}$ & $\begin{array}{c}78.6^{*} \\
(77.3,80.0)\end{array}$ & $\begin{array}{c}80.7 \\
(79.9,81.6)\end{array}$ & $\begin{array}{c}77.6 \\
(68.0,85.0)\end{array}$ & $\begin{array}{c}80.7 \\
(79.8,81.5)\end{array}$ \\
\hline Uso de cubrebocas & $\begin{array}{c}97.4 \\
(97.0,97.8)\end{array}$ & $\begin{array}{c}94.2^{*} \\
(93.5,94.9)\end{array}$ & $\begin{array}{c}95.8 \\
(95.4,96.2)\end{array}$ & $\begin{array}{c}98.8^{\dagger} \\
(97.7,99.4)\end{array}$ & $\begin{array}{c}95.8 \\
(95.4-96.2)\end{array}$ & $\begin{array}{c}97.3 \\
(96.6,97.9)\end{array}$ & $\begin{array}{c}95.3^{*} \\
(94.2,96.2)\end{array}$ & $\begin{array}{c}96.3 \\
(95.7,96.9)\end{array}$ & $\begin{array}{c}95.3 \\
(86.7,98.5)\end{array}$ & $\begin{array}{c}96.3 \\
(95.7,96.8)\end{array}$ & $\begin{array}{c}97.3 \\
(96.8,97.8)\end{array}$ & $\begin{array}{c}95.0^{*} \\
(94.2,95.6)\end{array}$ & $\begin{array}{c}96.2 \\
(95.8,96.6)\end{array}$ & $\begin{array}{c}96.4 \\
(90.5,98.7)\end{array}$ & $\begin{array}{l}96.2 \\
(95.7,96.6)\end{array}$ \\
\hline $\begin{array}{l}\text { Uso de alcohol en gel para } \\
\text { manos }\end{array}$ & $\begin{array}{c}89.7 \\
(89.0,90.4)\end{array}$ & $\begin{array}{c}84.7 * \\
(83.7,85.7)\end{array}$ & $\begin{array}{c}87.2 \\
(86.6,87.8)\end{array}$ & $\begin{array}{c}88.2 \\
(83.0,91.9)\end{array}$ & $\begin{array}{c}87.2 \\
(86.6,87.7)\end{array}$ & $\begin{array}{c}89.9 \\
(88.6,91.0)\end{array}$ & $\begin{array}{c}85.7 * \\
(84.0,87.3)\end{array}$ & $\begin{array}{c}87.9 \\
(86.9,88.8)\end{array}$ & $\begin{array}{c}89.8 \\
(80.8,94.8)\end{array}$ & $\begin{array}{c}87.8 \\
(86.8,88.8)\end{array}$ & $\begin{array}{c}89.8 \\
(88.9,90.7)\end{array}$ & $\begin{array}{c}85.4^{*} \\
(84.2,86.5)\end{array}$ & $\begin{array}{c}87.7 \\
(86.9,88.4)\end{array}$ & $\begin{array}{c}89.3 \\
(83.3,93.3)\end{array}$ & $\begin{array}{c}87.6 \\
(86.9,88.3)\end{array}$ \\
\hline $\begin{array}{l}\text { Cumplimiento con todas las } \\
\text { medidas de mitigación }\end{array}$ & $\begin{array}{c}46.6 \\
(45.5,47.6)\end{array}$ & $\begin{array}{c}41.4^{*} \\
(40.0,42.8)\end{array}$ & $\begin{array}{c}44.0 \\
(43.1,44.8)\end{array}$ & $\begin{array}{c}38.6 \\
(31.8,45.9)\end{array}$ & $\begin{array}{c}43.8 \\
(43.0,44.7)\end{array}$ & $\begin{array}{c}48.5 \\
(46.5,50.5)\end{array}$ & $\begin{array}{c}42.77^{*} \\
(40.3,45.1)\end{array}$ & $\begin{array}{c}45.7 \\
(44.2,47.3)\end{array}$ & $\begin{array}{c}36.6 \\
(25.0,49.9)\end{array}$ & $\begin{array}{c}45.5 \\
(44.0,47.0)\end{array}$ & $\begin{array}{c}47.9 \\
(46.5,49.3)\end{array}$ & $\begin{array}{c}42.3^{*} \\
(40.6,43.9)\end{array}$ & $\begin{array}{c}45.2 \\
(44.1,46.3)\end{array}$ & $\begin{array}{l}37.2 \\
(28.5,46.8)\end{array}$ & $\begin{array}{l}45.0 \\
(43.9,46.1)\end{array}$ \\
\hline $\begin{array}{l}\text { No toma ninguna medida de } \\
\text { prevención }\end{array}$ & $\begin{array}{c}0.5 \\
(0.4,0.7)\end{array}$ & $\begin{array}{l}1.1^{\star} \\
(0.8,1.6)\end{array}$ & $\begin{array}{l}0.8 \\
(0.6,1.1)\end{array}$ & $\begin{array}{l}0.5 \\
(0.1,1.9)\end{array}$ & $\begin{array}{l}0.8 \\
(0.7,1.1)\end{array}$ & $\begin{array}{c}0.6 \\
(0.3,1.1)\end{array}$ & $\begin{array}{c}1.4^{*} \\
(0.9,2.2)\end{array}$ & $\begin{array}{l}1.0 \\
(0.7,1.4)\end{array}$ & $\begin{array}{c}0.9 \\
(0.1,4.9)\end{array}$ & $\begin{array}{c}1.0 \\
(0.7,1.4) \\
\end{array}$ & $\begin{array}{c}0.6 \\
(0.3,0.9)\end{array}$ & $\begin{array}{l}1.3^{*} \\
(0.9,1.8)\end{array}$ & $\begin{array}{l}0.9 \\
(0.7,1.2) \\
\end{array}$ & $\begin{array}{c}0.8 \\
(0.2,3.2)\end{array}$ & $\begin{array}{c}0.9 \\
(0.7,1.2)\end{array}$ \\
\hline $\begin{array}{l}\text { Sale de casa solo por razones } \\
\text { esenciales }\end{array}$ & $\begin{array}{c}56.3 \\
(55.2,57.4)\end{array}$ & $\begin{array}{c}52.0^{*} \\
(50.5,53.5)\end{array}$ & $\begin{array}{c}54.1 \\
(53.2,55.1)\end{array}$ & $\begin{array}{c}50.2 \\
(42.0,58.3)\end{array}$ & $\begin{array}{c}54.2 \\
(53.3,55.1)\end{array}$ & $\begin{array}{c}61.3 \\
(59.2,63.3)\end{array}$ & $\begin{array}{c}56.3^{*} \\
(53.8,58.8)\end{array}$ & $\begin{array}{c}58.9 \\
(57.3,60.5)\end{array}$ & $\begin{array}{c}41.9^{\dagger} \\
(29.2,55.8)\end{array}$ & $\begin{array}{c}58.7 \\
(57.1,60.2)\end{array}$ & $\begin{array}{c}59.8 \\
(58.3,61.3)\end{array}$ & $\begin{array}{c}55.0 * \\
(53.2,56.8)\end{array}$ & $\begin{array}{c}57.5 \\
(56.3,58.6)\end{array}$ & $\begin{array}{c}44.2^{\dagger} \\
(34.3,54.6)\end{array}$ & $\begin{array}{c}57.3 \\
(56.2,58.5)\end{array}$ \\
\hline $\begin{array}{l}\text { Sale de casa solo por razones } \\
\text { no esenciales }\end{array}$ & $\begin{array}{c}7.7 \\
(7.1,8.3)\end{array}$ & $\begin{array}{c}8.7 \\
(7.8,9.7)\end{array}$ & $\begin{array}{c}8.2 \\
(7.7,8.8)\end{array}$ & $\begin{array}{c}8.2 \\
(4.9,13.5)\end{array}$ & $\begin{array}{c}8.3 \\
(7.7,8.9)\end{array}$ & $\begin{array}{c}3.0 \\
(2.4,3.7)\end{array}$ & $\begin{array}{c}3.3 \\
(2.6,4.2)\end{array}$ & $\begin{array}{l}3.1 \\
(2.7,3.7)\end{array}$ & $\begin{array}{c}5.4 \\
(1.7,15.9)\end{array}$ & $\begin{array}{c}3.2 \\
(2.7,3.8)\end{array}$ & $\begin{array}{c}4.3 \\
(3.9,4.9)\end{array}$ & $\begin{array}{c}5.0 \\
(4.4,5.6)\end{array}$ & $\begin{array}{c}4.6 \\
(4.3,5.1)\end{array}$ & $\begin{array}{c}6.2 \\
(2.9,12.7)\end{array}$ & $\begin{array}{c}4.7 \\
(4.3,5.1)\end{array}$ \\
\hline
\end{tabular}


TABLA 4 Cumplimiento de las medidas de mitigación, por grupo de edad y origen étnico

\begin{tabular}{|c|c|c|c|c|c|c|c|c|c|}
\hline \multirow{3}{*}{ Variable } & \multicolumn{3}{|c|}{ 15-17 años } & \multicolumn{3}{|c|}{ 18-24 años } & \multicolumn{3}{|c|}{ Total } \\
\hline & $\begin{array}{l}\text { Participantes indigenas y/o } \\
\text { afrodescendientes }\end{array}$ & $\begin{array}{l}\text { Participantes no indigenas } \\
\text { y/o afrodescendientes }\end{array}$ & Total & $\begin{array}{l}\text { Participantes indigenas } y / 0 \\
\text { afrodescendientes }\end{array}$ & $\begin{array}{l}\text { Participantes no indigenas } \\
\text { y/o afrodescendientes }\end{array}$ & Total & $\begin{array}{l}\text { Participantes indigenas } y / 0 \\
\text { afrodescendientes }\end{array}$ & $\begin{array}{l}\text { Participantes no indigenas } \\
\text { y/o afrodescendientes }\end{array}$ & Total \\
\hline & $\mathrm{n}=12,843$ & $\mathrm{n}=32,112$ & $\mathrm{n}=44,955$ & $n=2,930$ & $n=7,807$ & $n=10,737$ & $\mathrm{n}=15,773$ & $\mathrm{n}=39,919$ & $\mathrm{n}=55,692$ \\
\hline Lavado de manos & $\begin{array}{c}91.5 \\
(90.5,92.4)\end{array}$ & $\begin{array}{c}91.4 \\
(90.7,92.0)\end{array}$ & $\begin{array}{c}91.4 \\
(90.9,91.9)\end{array}$ & $\begin{array}{c}93.9 \\
(92.6,95.0)\end{array}$ & $\begin{array}{c}91.5^{*} \\
(90.4,92.6)\end{array}$ & $\begin{array}{c}92.2 \\
(91.3,93.0)\end{array}$ & $\begin{array}{c}93.1 \\
(92.2,93.9)\end{array}$ & $\begin{array}{c}91.5^{*} \\
(90.7,92.2)\end{array}$ & $\begin{array}{c}92.0 \\
(91.3,92.5)\end{array}$ \\
\hline Distanciamiento social & $\begin{array}{c}54.3 \\
(52.7,55.9)\end{array}$ & $\begin{array}{c}55.5 \\
(54.5,56.5)\end{array}$ & $\begin{array}{c}55.1 \\
(54.3,56.0)\end{array}$ & $\begin{array}{c}60.4 \\
(57.7 .63 .1)\end{array}$ & $\begin{array}{c}56.1^{*} \\
(54.37,57.8)\end{array}$ & $\begin{array}{c}57.3 \\
(55.8,58.8)\end{array}$ & $\begin{array}{c}58.4 \\
(56.5,60.2)\end{array}$ & $\begin{array}{c}55.9 * \\
(54.6,57.2)\end{array}$ & $\begin{array}{c}56.6 \\
(55.6,57.7)\end{array}$ \\
\hline Quedarse en casa & $\begin{array}{c}79.7 \\
(78.2,81.0)\end{array}$ & $\begin{array}{c}79.6 \\
(78.7,80.5)\end{array}$ & $\begin{array}{c}79.6 \\
(78.9,80.4)\end{array}$ & $\begin{array}{c}83.5 \\
(81.4,85.5)\end{array}$ & $\begin{array}{c}80.2^{\star} \\
(78.7 .81 .6)\end{array}$ & $\begin{array}{c}81.18 \\
(79.9,82.3)\end{array}$ & $\begin{array}{c}82.2 \\
(80.8,83.6)\end{array}$ & $\begin{array}{c}80.0^{*} \\
(79.0,01.0)\end{array}$ & $\begin{array}{c}80.7 \\
(79.8,81.5)\end{array}$ \\
\hline Uso de cubrebocas & $\begin{array}{c}94.8 \\
(93.9 .95 .5)\end{array}$ & $\begin{array}{l}96.3^{*} \\
(95.9,96.8)\end{array}$ & $\begin{array}{c}95.8 \\
(95.4-96.2)\end{array}$ & $\begin{array}{c}95.0 \\
(93.7 .96 .1)\end{array}$ & $\begin{array}{c}96.8^{*} \\
(96.1,97.4)\end{array}$ & $\begin{array}{c}96.3 \\
(95.7,96.8)\end{array}$ & $\begin{array}{c}94.9 \\
(94.0,95.7)\end{array}$ & $\begin{array}{c}96.7^{\star} \\
(96.2,97.1)\end{array}$ & $\begin{array}{c}96.2 \\
(95.7,96.6)\end{array}$ \\
\hline Uso de alcohol en gel para manos & $\begin{array}{c}84.8 \\
(83.86,86.0)\end{array}$ & $\begin{array}{c}88.3^{*} \\
(87.6,88.9)\end{array}$ & $\begin{array}{c}87.2 \\
(86.6,87.7)\end{array}$ & $\begin{array}{c}84.4 \\
(82.3,86.4)\end{array}$ & $\begin{array}{c}89.2^{\star} \\
(88.1,90.3)\end{array}$ & $\begin{array}{c}87.8 \\
(86.8,88.8)\end{array}$ & $\begin{array}{c}84.6 \\
(83.1,85.9)\end{array}$ & $\begin{array}{c}88.9^{*} \\
(88.1,89.7)\end{array}$ & $\begin{array}{c}87.6 \\
(86.9,88.3)\end{array}$ \\
\hline Cumplimiento con todas las medidas de mitigación & $\begin{array}{c}43.4 \\
(41.8,45.0)\end{array}$ & $\begin{array}{c}44.0 \\
(43.0,45.0)\end{array}$ & $\begin{array}{c}28.3 \\
(27.5,29.1)\end{array}$ & $\begin{array}{c}47.9 \\
(45.2,50.7)\end{array}$ & $\begin{array}{c}44.6 * \\
(42.8,46.6)\end{array}$ & $\begin{array}{c}29.1 \\
(27.7,30.5)\end{array}$ & $\begin{array}{c}46.4 \\
(44.5,48.3)\end{array}$ & $\begin{array}{c}44.4 \\
(43.1,45.7)\end{array}$ & $\begin{array}{c}45.0 \\
(43.9,46.1)\end{array}$ \\
\hline No toma ninguna medida de prevención & $\begin{array}{c}1.2 \\
(0.8,1.9)\end{array}$ & $\begin{array}{c}0.7^{*} \\
(0.5,0.8)\end{array}$ & $\begin{array}{c}0.8 \\
(0.7,1.1)\end{array}$ & $\begin{array}{c}1.1 \\
(0.6,1.9)\end{array}$ & $\begin{array}{c}0.9 \\
(0.6,1.5)\end{array}$ & $\begin{array}{c}1.0 \\
(0.7,1.4)\end{array}$ & $\begin{array}{l}1.1 \\
(0.8,1.7)\end{array}$ & $\begin{array}{l}0.9 \\
(0.6,1.2)\end{array}$ & $\begin{array}{c}0.9 \\
(0.7,1.2)\end{array}$ \\
\hline Sale de casa solo por razones esenciales & $\begin{array}{c}58.6 \\
(56.9,60.3)\end{array}$ & $\begin{array}{c}52.1^{*} \\
(51.0,53.2)\end{array}$ & $\begin{array}{c}54.2 \\
(53.3,55.1)\end{array}$ & $\begin{array}{c}68.2 \\
(65.4,70.8)\end{array}$ & $\begin{array}{c}54.9^{*} \\
(53.1,56.8)\end{array}$ & $\begin{array}{c}58.7 \\
(57.1,60.2)\end{array}$ & $\begin{array}{c}65.1 \\
(63.1,67.0)\end{array}$ & $\begin{array}{c}54.1^{*} \\
(52.7,55.5)\end{array}$ & $\begin{array}{c}57.3 \\
(56.2,58.5)\end{array}$ \\
\hline 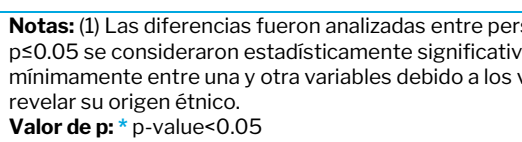 & $\begin{array}{l}\text { parte de r } \\
\text { alisis seh h } \\
\text { s; (4) Las }\end{array}$ & $\int \mathrm{de}$ & $\begin{array}{l}\text { inoría: } \\
\text { nse in } \\
\text { total d }\end{array}$ & sadas: la pruel & $\begin{array}{l}\text { adrada se usó pa } \\
\text { todas las variat } \\
\text { elos subgrupos }\end{array}$ & $\begin{array}{l}\text { itativas } \\
\text { oblació } \\
\text { que las }\end{array}$ & $\begin{array}{l}\text { J de Mann-Whitney } \\
\text { es de las variables de } \\
\text { ran obligatorias para }\end{array}$ & $\begin{array}{l}\text { riables cuantitativas. } \\
\text { simportante resaltar } \\
\text { nas participantes. Asi }\end{array}$ & $\begin{array}{l}\text { as con valores de } \\
\text { den variar } \\
\text { ue no hayan queric }\end{array}$ \\
\hline
\end{tabular}


TABLA 5 Cumplimiento de las medidas de mitigación de COVID-19, por grupo de edad y NSE

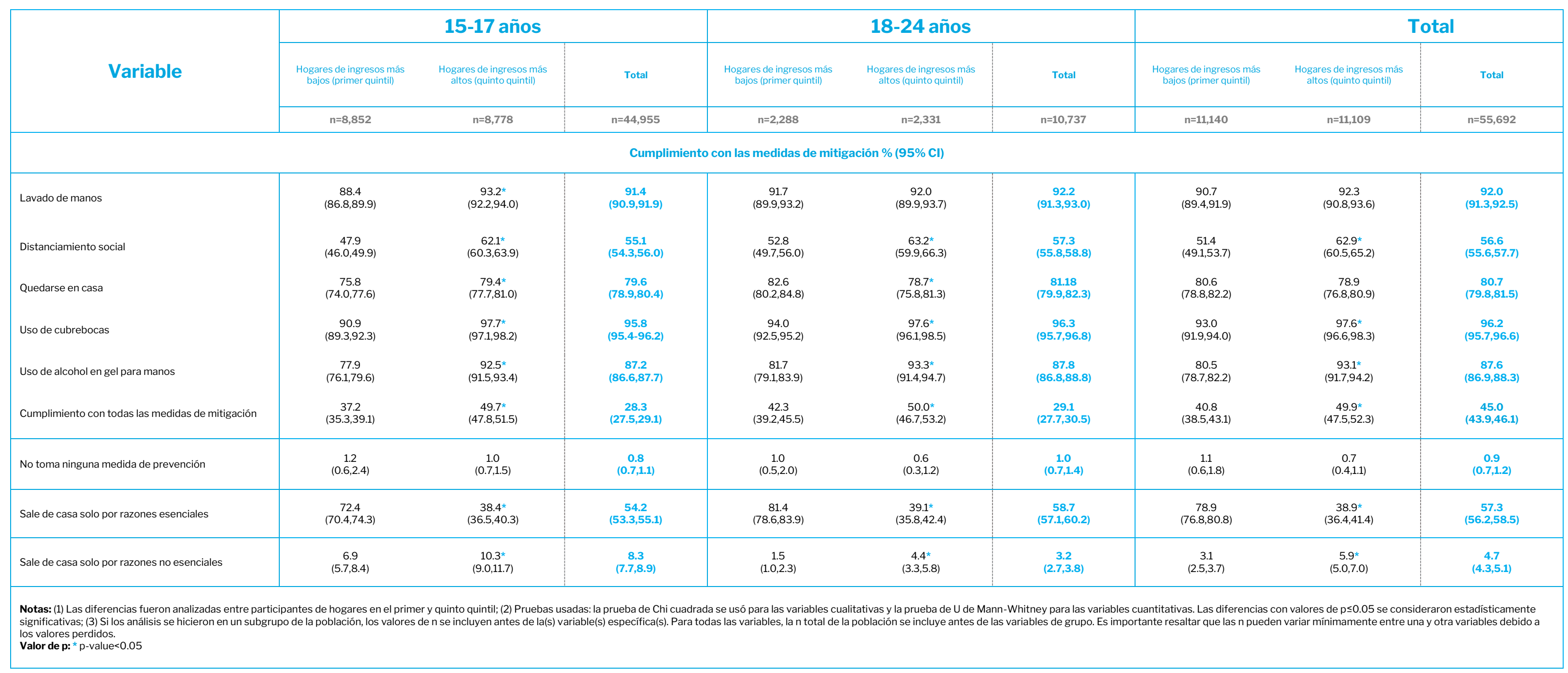


C. VIOLENCIA 
TABLA 6 Impacto de las medidas de mitigación de COVID-19 en la exposición a la violencia, por grupos de edad y género

\begin{tabular}{|c|c|c|c|c|c|c|c|c|c|c|c|c|c|c|c|}
\hline \multirow{3}{*}{ Variable } & \multicolumn{5}{|c|}{ 15-17 años } & \multicolumn{5}{|c|}{ 18-24 años } & \multicolumn{5}{|c|}{ Total } \\
\hline & Mujeres & Hombres & Binarias & No binarias & Total & Mujeres & Hombres & Binarias & No binarias & Total & Mujeres & Hombres & Binarias & No binarias & Total \\
\hline & $\mathrm{n}=27,112$ & $\mathrm{n}=16,548$ & $n=43,660$ & $\mathrm{n}=501$ & $\mathrm{n}=44,955$ & $\mathrm{n}=6,367$ & $\mathrm{n}=4,107$ & $\mathrm{n}=10,474$ & $\mathrm{n}=137$ & $\mathrm{n}=10,737$ & $\mathrm{n}=33,479$ & $\mathrm{n}=20,655$ & $n=54,134$ & $\mathrm{n}=638$ & $\mathrm{~N}=55,692$ \\
\hline
\end{tabular}

\begin{tabular}{|c|c|c|c|c|c|c|c|c|c|c|c|c|c|c|c|}
\hline $\begin{array}{l}\text { Exposición a cualquier tipo de } \\
\text { violencia en el hogar }\end{array}$ & $\begin{array}{c}38.6 \\
(37.5,39.6)\end{array}$ & $\begin{array}{c}33.8^{*} \\
(32.5,35.2)\end{array}$ & $\begin{array}{c}36.2 \\
(35.4,37.0)\end{array}$ & $\begin{array}{c}63.4+ \\
(55.8,70.5)\end{array}$ & $\begin{array}{c}36.5 \\
(35.7,37.4)\end{array}$ & $\begin{array}{c}49.2 \\
(47.2,51.2)\end{array}$ & $\begin{array}{c}41.9^{*} \\
(39.5,44.3)\end{array}$ & $\begin{array}{l}45.7 \\
(44.2,47.3)\end{array}$ & $\begin{array}{c}72.8^{\dagger} \\
(59.2,83.1)\end{array}$ & $\begin{array}{c}46.1 \\
(44.6,47.6)\end{array}$ & $\begin{array}{c}46.0 \\
(44.6,47.4)\end{array}$ & $\begin{array}{c}39.3^{*} \\
(37.6,41.0)\end{array}$ & $\begin{array}{c}42.7 \\
(41.6,43.8)\end{array}$ & $\begin{array}{c}70.0^{+} \\
(60.5,78.1)\end{array}$ & $\begin{array}{c}43.1 \\
(42.0,44.2)\end{array}$ \\
\hline $\begin{array}{l}\text { Exposición a violencia } \\
\text { psicológica en el hogar }\end{array}$ & $\begin{array}{c}38.9 \\
(37.8,40.0)\end{array}$ & $\begin{array}{c}30.4^{*} \\
(29.1,31.7)\end{array}$ & $\begin{array}{c}34.5 \\
(33.7,35.4)\end{array}$ & $\begin{array}{c}65.1^{\dagger} \\
(56.8,72.5)\end{array}$ & $\begin{array}{l}35.0 \\
(34.1,35.8)\end{array}$ & $\begin{array}{c}47.9 \\
(45.9,50.0)\end{array}$ & $\begin{array}{c}38.9 * \\
(36.6,41.4)\end{array}$ & $\begin{array}{c}43.6 \\
(42.0,45.2)\end{array}$ & $\begin{array}{c}74.0^{+} \\
(59.7 .84 .5)\end{array}$ & $\begin{array}{l}44.0 \\
(42.5,45.6)\end{array}$ & $\begin{array}{c}45.3 \\
(43.8,46.8)\end{array}$ & $\begin{array}{c}36.2^{\star} \\
(34.5,37.9)\end{array}$ & $\begin{array}{c}40.8 \\
(39.7,42.0)\end{array}$ & $\begin{array}{c}71.5^{\dagger} \\
(61.3,79.8)\end{array}$ & $\begin{array}{c}41.3 \\
(40.2,42.2)\end{array}$ \\
\hline $\begin{array}{l}\text { Exposición a violencia física en } \\
\text { el hogar }\end{array}$ & $\begin{array}{l}20.2 \\
(19.3,21.0)\end{array}$ & $\begin{array}{c}19.9 \\
(18.8,21.1)\end{array}$ & $\begin{array}{c}20.0 \\
(19.3,20.8)\end{array}$ & $\begin{array}{c}38.6^{+} \\
(30.87,47.0)\end{array}$ & $\begin{array}{c}20.3 \\
(19.6,21.0)\end{array}$ & $\begin{array}{c}25.0 \\
(23.2,26.8)\end{array}$ & $\begin{array}{l}24.1 \\
(22.1,26.3)\end{array}$ & $\begin{array}{c}24.6 \\
(23.2,26.0)\end{array}$ & $\begin{array}{c}33.2 \\
(22.0,46.7)\end{array}$ & $\begin{array}{c}24.7 \\
(23.4,26.1)\end{array}$ & $\begin{array}{c}23.6 \\
(22.3,24.9)\end{array}$ & $\begin{array}{c}22.8 \\
(21.3,24.3)\end{array}$ & $\begin{array}{l}23.2 \\
(22.2,24.2)\end{array}$ & $\begin{array}{c}34.77^{\dagger} \\
(26.1,44.5)\end{array}$ & $\begin{array}{c}23.3 \\
(22.4,24.3)\end{array}$ \\
\hline $\begin{array}{l}\text { Exposición a violencia sexual } \\
\text { en el hogar }\end{array}$ & $\begin{array}{c}3.6 \\
(3.3 .4 .1)\end{array}$ & $\begin{array}{c}1.1^{*} \\
(0.9,1.5)\end{array}$ & $\begin{array}{c}2.4 \\
(2.1,2.6)\end{array}$ & $\begin{array}{l}11.4^{+} \\
(6.1,20.2)\end{array}$ & $\begin{array}{c}2.6 \\
(2.3,2.8)\end{array}$ & $\begin{array}{c}5.1 \\
(4.3 .6 .1)\end{array}$ & $\begin{array}{c}3.3^{*} \\
(2.4,4.4)\end{array}$ & $\begin{array}{c}4.2 \\
(3.6,4.9)\end{array}$ & $\begin{array}{c}8.0 \\
(2.3,24.3)\end{array}$ & $\begin{array}{c}4.3 \\
(3.7,5.0)\end{array}$ & $\begin{array}{l}4.7 \\
(4.1,5.3)\end{array}$ & $\begin{array}{c}2.6^{*} \\
(2.0,3.3)\end{array}$ & $\begin{array}{c}3.6 \\
(3.2,4.1)\end{array}$ & $\begin{array}{c}8.9 \\
(3.9,19.0)\end{array}$ & $\begin{array}{c}3.7 \\
(3.3,4.2)\end{array}$ \\
\hline \multicolumn{16}{|c|}{ Atestiguar violencia en contra de un(a) hermano/a o pareja femenina del padre en el hogar, pepetrada por alguien viviendo en el mismo hogar \% $(95 \% \mathrm{Cl})$} \\
\hline $\begin{array}{l}\text { Alguna vez fue testigo de } \\
\text { cualquier tipo de violencia en el } \\
\text { hogar en contra de su } \\
\text { hermano/a }\end{array}$ & $\begin{array}{l}12.3 \\
(11.7,73.0)\end{array}$ & $\begin{array}{l}9.8^{*} \\
(9.0,10.6)\end{array}$ & $\begin{array}{l}11.0 \\
(10.5,11.6)\end{array}$ & $\begin{array}{c}23.3^{\dagger} \\
(18.0,29.5)\end{array}$ & $\begin{array}{l}11.2 \\
(10.7,11.8)\end{array}$ & $\begin{array}{l}20.0 \\
(18.4,21.8)\end{array}$ & $\begin{array}{c}13.1^{\star} \\
(11.6,14.8)\end{array}$ & $\begin{array}{l}16.7 \\
(15.6,17.9)\end{array}$ & $\begin{array}{l}31.9+ \\
(20.7,45.5)\end{array}$ & $\begin{array}{c}16.9 \\
(15.8,18.1)\end{array}$ & $\begin{array}{l}117.7 \\
(16.5,18.9)\end{array}$ & $\begin{array}{c}12.0^{*} \\
(11.0,13.2)\end{array}$ & $\begin{array}{c}14.9 \\
(14.1,15.8)\end{array}$ & $\begin{array}{c}29.3 \dagger \\
(21.1,39.2)\end{array}$ & $\begin{array}{l}15.1 \\
(14.3,15.9)\end{array}$ \\
\hline $\begin{array}{l}\text { Alguna vez fue testigo de } \\
\text { cualquier tipo de violencia en el } \\
\text { hogar en contra de una pareja } \\
\text { femenina del padre }\end{array}$ & $\begin{array}{l}10.3 \\
(9.7,10.9)\end{array}$ & $\left(\begin{array}{ll}7.3^{*} \\
(6.6,8.0)\end{array}\right.$ & $\begin{array}{c}8.8 \\
(8.3,9.2)\end{array}$ & $\begin{array}{c}24.44^{\dagger} \\
(17.9,32.4)\end{array}$ & $\begin{array}{l}9.0 \\
(8.6,9.5)\end{array}$ & $\begin{array}{ll}20.1 \\
(18.5,21.8)\end{array}$ & $\begin{array}{l}15.1^{*} \\
(13.4,17.0)\end{array}$ & $\begin{array}{ll}17.7 \\
(16.5,19.0)\end{array}$ & $\begin{array}{l}28.4 \\
(17.6,42.4)\end{array}$ & $\begin{array}{l}17.8 \\
(16.6,19.0)\end{array}$ & $\begin{array}{c}117.1 \\
(16.0,18.3)\end{array}$ & $\begin{array}{c}12.6^{*} \\
(11.4,13.9)\end{array}$ & $\begin{array}{c}14.9 \\
(14.1,15.8)\end{array}$ & $\begin{array}{l}27.2^{\dagger} \\
(19.1,77.2)\end{array}$ & $\begin{array}{l}15.0 \\
(4.3,14.2)\end{array}$ \\
\hline \multicolumn{16}{|c|}{ Exposición a acoso en línea en algún momento de sus vidas \% (95\% Cl) } \\
\hline $\begin{array}{l}\text { Exposición a cualquier tipo de } \\
\text { acoso en línea }\end{array}$ & $\begin{array}{c}43.5 \\
(42.5,44.6)\end{array}$ & $\begin{array}{c}24.3^{*} \\
(23.1,25.6)\end{array}$ & $\begin{array}{c}33.9 \\
(33.1,34.7)\end{array}$ & $\begin{array}{c}65.6^{+} \\
(58.2,72.3)\end{array}$ & $\begin{array}{c}34.4 \\
(33.6,35.3)\end{array}$ & $\begin{array}{c}56.6 \\
(54.6,58.5)\end{array}$ & $\begin{array}{c}37.7^{*} \\
(35.3,40.1)\end{array}$ & $\begin{array}{c}47.5 \\
(46.0,49.1)\end{array}$ & $\begin{array}{c}66.0^{+} \\
(51.9,77.8)\end{array}$ & $\begin{array}{l}47.7 \\
(46.2,49.2)\end{array}$ & $\begin{array}{c}52.6 \\
(51.2,54.0)\end{array}$ & $\begin{array}{c}33.4^{*} \\
(31.7,35.1)\end{array}$ & $\begin{array}{c}43.3 \\
(42.2,44.4)\end{array}$ & $\begin{array}{c}65.9^{\dagger} \\
(55.8,74.7)\end{array}$ & $\begin{array}{c}43.6 \\
(42.5,44.6)\end{array}$ \\
\hline Exposición a insultos ofensivos & $\begin{array}{c}17.2 \\
(16.4,18.1)\end{array}$ & $\begin{array}{c}12.6^{*} \\
(11.8,13.6)\end{array}$ & $\begin{array}{c}14.9 \\
(14.3,15.6)\end{array}$ & $\begin{array}{c}32.9^{\dagger} \\
(25.9,40.8)\end{array}$ & $\begin{array}{c}15.3 \\
(14.7,15.9)\end{array}$ & $\begin{array}{c}16.8 \\
(15.3,18.4)\end{array}$ & $\begin{array}{c}17.6 \\
(15.8,19.6)\end{array}$ & $\begin{array}{c}17.2 \\
(16.0,18.4)\end{array}$ & $\begin{array}{c}34.0^{+} \\
(22.4,48.0)\end{array}$ & $\begin{array}{l}17.4 \\
(16.2,18.6)\end{array}$ & $\begin{array}{c}16.9 \\
(15.8,18.0)\end{array}$ & $\begin{array}{c}16.0 \\
(14.7,17.4)\end{array}$ & $\begin{array}{c}16.5 \\
(15.6,17.4)\end{array}$ & $\begin{array}{c}33.7^{\dagger} \\
(24.9,43.7)\end{array}$ & $\begin{array}{c}16.7 \\
(15.9,17.6)\end{array}$ \\
\hline Exposición a difamación & $\begin{array}{ll}17.9 \\
(17.1,18.7)\end{array}$ & $\begin{array}{c}11.0^{*} \\
(10.2,11.9)\end{array}$ & $\begin{array}{c}14.4 \\
(13.9,15.0)\end{array}$ & $\begin{array}{c}36.4+ \\
(29.1,44.4)\end{array}$ & $\begin{array}{c}14.8 \\
(14.2,15.3)\end{array}$ & $\begin{array}{l}20.2 \\
(18.6,21.9)\end{array}$ & $\begin{array}{l}19.2 \\
(17.2,21.3)\end{array}$ & $\begin{array}{ll}19.7 \\
(18.5,21.1)\end{array}$ & $\begin{array}{c}34.5^{\dagger} \\
(22.9,48.2)\end{array}$ & $\begin{array}{c}19.9 \\
(18.6,21.2)\end{array}$ & $\begin{array}{c}19.5 \\
(18.4,20.7)\end{array}$ & $\begin{array}{c}16.5^{*} \\
(155.2,18.0)\end{array}$ & $\begin{array}{c}18.1 \\
(17.2,19.0)\end{array}$ & $\begin{array}{c}35.0^{\dagger} \\
(26.3,44.9)\end{array}$ & $\begin{array}{c}18.3 \\
(17.4,19.2)\end{array}$ \\
\hline $\begin{array}{l}\text { Exposición a ciber acoso } \\
\text { prolongado }\end{array}$ & $\begin{array}{c}3.9 \\
(3.5 .4 .3)\end{array}$ & $\begin{array}{c}1.7^{*} \\
(1.5,2.1)\end{array}$ & $\begin{array}{l}2.8 \\
(2.6,3,3.1)\end{array}$ & $\begin{array}{c}8.9{ }^{\dagger} \\
(5.9,13.0)\end{array}$ & $\begin{array}{c}2.9 \\
(2.6,3.1)\end{array}$ & $\begin{array}{c}7.4 \\
(6.3,8.6)\end{array}$ & $\begin{array}{c}4.1^{*} \\
(3.2,5.1)\end{array}$ & $\begin{array}{c}5.8 \\
(5.1,6.6)\end{array}$ & $\begin{array}{l}10.8 \\
(5.6,19.9)\end{array}$ & $\begin{array}{l}5.9 \\
(5.2,6.7)\end{array}$ & $\begin{array}{c}6.3 \\
(5.6,7.2)\end{array}$ & $\begin{array}{c}3.3^{*} \\
(2.7,4.0)\end{array}$ & $\begin{array}{c}4.9 \\
(4.4,5.4)\end{array}$ & $\begin{array}{c}10.3^{\dagger} \\
(6.2,16.4)\end{array}$ & $\begin{array}{c}5.0 \\
(4.5,5.5)\end{array}$ \\
\hline $\begin{array}{l}\text { Exposición a acecho en línea } \\
\text { (stalking) }\end{array}$ & $\begin{array}{c}8.8 \\
(8.2,9.5)\end{array}$ & $\begin{array}{c}2.8^{*} \\
(2.5,3.3)\end{array}$ & $\begin{array}{c}5.8 \\
(5.5,6.2)\end{array}$ & $\begin{array}{c}15.7^{\dagger} \\
(11.5,21.1)\end{array}$ & $\begin{array}{c}6.0 \\
(5.6,6.3)\end{array}$ & $\begin{array}{c}15.3 \\
(13.9,16.9)\end{array}$ & $\begin{array}{c}4.9^{*} \\
(4.0,6.0)\end{array}$ & $\begin{array}{c}10.3 \\
(9.4,11.3)\end{array}$ & $\begin{array}{c}21.22^{\dagger} \\
(12.6,33.5)\end{array}$ & $\begin{array}{c}10.4 \\
(9.5,11.4)\end{array}$ & $\begin{array}{c}13.3 \\
(12.3,14.5)\end{array}$ & $\begin{array}{c}4.2^{\star} \\
(3.6,5.0)\end{array}$ & $\begin{array}{c}8.9 \\
(8.3,9,6)\end{array}$ & $\begin{array}{c}19.6+ \\
(13.2,28.2)\end{array}$ & $\begin{array}{c}9.0 \\
(8.4,9.7)\end{array}$ \\
\hline
\end{tabular}




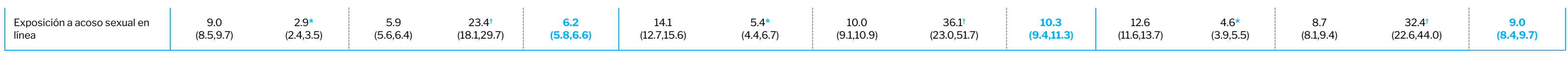

\begin{tabular}{|c|c|c|c|c|c|c|c|c|c|c|c|c|c|c|c|}
\hline \multicolumn{16}{|c|}{ Aumento de la violencia en casa desde el inicio de la pandemia (entre aquellas que informaron alguna experiencia con ese tipo de violencia en algún punto de su vida) $\%(95 \% \mathrm{CI})$} \\
\hline \multicolumn{16}{|c|}{ Violencia Psicolögica } \\
\hline & $\mathrm{n}=9,149$ & $\mathrm{n}=4,649$ & $\mathrm{n}=13,798$ & $\mathrm{n}=285$ & $\mathrm{n}=14,083$ & $\mathrm{n}=2,652$ & $\mathrm{n}=1,413$ & $\mathrm{n}=4,065$ & $\mathrm{n}=87$ & $\mathrm{n}=4,152$ & $\mathrm{n}=11,801$ & $\mathrm{n}=6,062$ & $\mathrm{n}=17,863$ & $\mathrm{n}=372$ & $\mathrm{n}=18,235$ \\
\hline $\begin{array}{l}\text { Solo experimentó violencia } \\
\text { psicologicac después del inicio } \\
\text { dicla la andemian no antes }\end{array}$ & $\begin{array}{c}5.8 \\
(5.0,6.7)\end{array}$ & $\begin{array}{l}5.7 \\
(4.4,6.9)\end{array}$ & $\begin{array}{l}5.7 \\
(5.0,6.5)\end{array}$ & $\begin{array}{c}2.8+ \\
(0.6,5.1)\end{array}$ & $\begin{array}{c}5.6 \\
(4.9,6.3)\end{array}$ & $\begin{array}{c}5.6 \\
(4.4,6.8)\end{array}$ & $\begin{array}{c}6.9 \\
(4.9,8.9)\end{array}$ & $\begin{array}{ccc}6.1 \\
(5.0,7.2)\end{array}$ & $\begin{aligned} 8.4 \\
(-0.1,17.0)\end{aligned}$ & $(5.2 .7 .3)$ & $\left(\begin{array}{c}5.6 .6 .6 \\
(4.6)\end{array}\right.$ & $\begin{array}{c}6.6 \\
(5,1,8.0)\end{array}$ & $\begin{array}{l}6.0 \\
(5.2,6.9)\end{array}$ & $\begin{array}{c}7.0 \\
(0.6,13.4)\end{array}$ & $\begin{array}{l}6.1 \\
(5.2,69)\end{array}$ \\
\hline 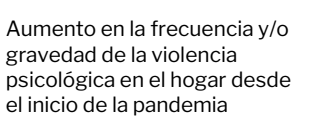 & $\begin{array}{l}28.9 \\
(27.230 .7)\end{array}$ & $\begin{array}{l}3.0 \\
(27.5,32.4)\end{array}$ & $\begin{array}{c}29.4 \\
(27.930 .9)\end{array}$ & $(19.1,35.7)$ & $\begin{array}{c}2.95 \\
(28.1,30.9)\end{array}$ & $\begin{array}{c}28.8 \\
(26.1,13.5)\end{array}$ & $\begin{array}{c}30.1 \\
(26.3,33.8)\end{array}$ & $\begin{array}{c}27.3 \\
(27.131 .6)\end{array}$ & $\begin{array}{l}33.7 \\
(18 ., 3.1 .1)\end{array}$ & $\begin{array}{l}227.4 .4 \\
(27.231 .6)\end{array}$ & $\begin{array}{c}28.8 \\
(26.8,30.9)\end{array}$ & $\begin{array}{c}30.0 \\
(27.2 .32 .9)\end{array}$ & $\begin{array}{l}292.4 .41 .1) \\
(27.731 .\end{array}$ & $\begin{array}{c}32.8 \\
(20.4,45.2)\end{array}$ & $\begin{array}{l}27.4 .4 \\
(27.83 .1 .1)\end{array}$ \\
\hline \multicolumn{16}{|c|}{ Violencia Fisica } \\
\hline & $\mathrm{n}=4,917$ & $\mathrm{n}=2,982$ & $\mathrm{n}=7,899$ & $n=180$ & $\mathrm{n}=8,079$ & $\mathrm{n}=1,448$ & $\mathrm{n}=878$ & $\mathrm{n}=2,326$ & $n=48$ & $n=2,374$ & $n=6,365$ & $n=3,860$ & $n=10,225$ & $\mathrm{n}=228$ & $n=10,453$ \\
\hline 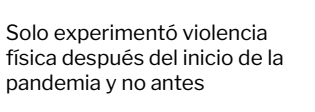 & $(3.4 .5 .1)$ & $\begin{array}{l}4.9 .9 \\
(2.47,4)\end{array}$ & $\begin{array}{c}4.6 \\
(3.3,5.9)\end{array}$ & $\begin{array}{c}2.0+ \\
(0.1,3.8)\end{array}$ & $\begin{array}{c}4.5 \\
(3.2,5.8)\end{array}$ & $(3.5 .7 .7 .6)$ & $\begin{array}{c}7.0 \\
(4.3,9.7)\end{array}$ & $\left(\begin{array}{c}6.3 .3 .9 \\
(4.7 .9)\end{array}\right.$ & $(-4,3,27.0)$ & $\begin{array}{l}6.4 .4 .0) \\
(44.8 .0)\end{array}$ & $\begin{array}{c}5.3 \\
(3.9,9.8)\end{array}$ & $\begin{array}{c}6.4 \\
(4.3 .8 .5)\end{array}$ & $\begin{array}{c}5.9 .9 \\
(4.6,7.1)\end{array}$ & $\begin{array}{c}8.3 .31 \\
(-2 ., 19.1)\end{array}$ & $\begin{array}{l}5.9 .9 .1) \\
(4.7 .7 .1)\end{array}$ \\
\hline $\begin{array}{l}\text { Aumento en la frecuencia y/o } \\
\text { gravedadd de laviolenciaitisisa } \\
\text { enel hogar desde linicio de la } \\
\text { pandemia }\end{array}$ & $\begin{array}{c}20.1 \\
(18.1,22.0)\end{array}$ & $\begin{array}{c}17.2 \\
(14.6,19.8)\end{array}$ & $\begin{array}{c}18.6 \\
(17.0,20.2)\end{array}$ & $\begin{array}{c}23.0 \\
(122.0,34.0)\end{array}$ & $\begin{array}{c}18.8 \\
(17.2,20.4)\end{array}$ & $\begin{array}{c}16.6 \\
(137,7,19.5)\end{array}$ & $\begin{array}{c}23.1^{\star} \\
(18.7,27.6)\end{array}$ & $\begin{array}{l}19.6 \\
(17.0,022.2)\end{array}$ & $\begin{array}{c}21.8 \\
(4.2,39.4)\end{array}$ & $\begin{array}{c}19.6 \\
(177,1,22.2)\end{array}$ & $\begin{array}{l}17.4 \\
(152.19 .7)\end{array}$ & $\begin{array}{c}21.55^{\star} \\
(18.2,24.8)\end{array}$ & $\begin{array}{l}19.4 \\
(177,4,21.3)\end{array}$ & $\begin{array}{l}2.22 \\
(9.83,34.6)\end{array}$ & $\begin{array}{c}19.4 \\
(177.5,21.3)\end{array}$ \\
\hline \multicolumn{16}{|c|}{ Violencia sexual } \\
\hline & $n=948$ & $\mathrm{n}=171$ & $\mathrm{n}=1,1,19$ & $n=39$ & $\mathrm{n}=1,158$ & $n=321$ & $n=95$ & $\mathrm{n}=416$ & $\mathrm{n}=12$ & $n=428$ & $\mathrm{n}=1,269$ & $\mathrm{n}=266$ & $\mathrm{n}=1,535$ & $n=51$ & $\mathrm{n}=1,586$ \\
\hline 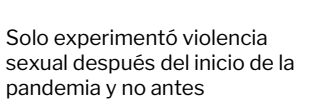 & $\begin{array}{c}7.0 \\
(2.4,11.7)\end{array}$ & $\begin{array}{c}9.0 \\
(1.6,16.5)\end{array}$ & $\begin{array}{c}7.5 \\
(7.5,11.5)\end{array}$ & $\begin{array}{l}0.0 \\
(0.0,0.0)\end{array}$ & $\begin{array}{c}7.1 \\
(3.4,10.7)\end{array}$ & $\begin{array}{c}3.1 \\
(0.1 .1,1)\end{array}$ & $\begin{array}{c}23.4 * \\
(8.6,38.3)\end{array}$ & $\begin{array}{c}10.6 \\
(4 ., 3,7.0)\end{array}$ & $\begin{array}{c}0.0 f \\
(0.0,0.0)\end{array}$ & $\begin{array}{c}10.3 \\
(4.1,16.5)\end{array}$ & $\begin{array}{c}4.0 \\
(1.5,6,6)\end{array}$ & $\begin{array}{c}21.3 * \\
(8 ., 34.2)\end{array}$ & $\begin{array}{c}10.0 \\
(4.8,15.2)\end{array}$ & $\begin{array}{l}0.0 . \\
(0.0,0.0)\end{array}$ & $\begin{array}{l}9.6 \\
(4.6,14.6)\end{array}$ \\
\hline
\end{tabular}




\begin{tabular}{|c|c|c|c|c|c|c|c|c|c|c|c|c|c|c|c|}
\hline $\begin{array}{l}\text { Aumento en la frecuencia y/o } \\
\text { gravedad de la violencia sexual } \\
\text { en el hogar desde el inicio de la } \\
\text { pandemia }\end{array}$ & $\begin{array}{c}9.9 \\
(6.8,13.0)\end{array}$ & $\begin{array}{c}25.6^{*} \\
(14.8,36.5)\end{array}$ & $\begin{array}{c}14.1 \\
(10.3,17.9)\end{array}$ & $\begin{array}{c}2.77^{\star} \\
(-0.7,6.2)\end{array}$ & $\begin{array}{c}13.2 \\
(9.7,16.8)\end{array}$ & $\begin{array}{c}10.2 \\
(5.4,15.0)\end{array}$ & $\begin{array}{c}36.6^{*} \\
(21.51 .5)\end{array}$ & $\begin{array}{c}20.5 \\
(13.5,27.5)\end{array}$ & $\begin{array}{c}0.0^{\dagger} \\
(0.0,0.0)\end{array}$ & $\begin{array}{c}20.0 \\
(13.3,26.8)\end{array}$ & $\begin{array}{c}10.2 \\
(6.4,13.9)\end{array}$ & $\begin{array}{c}35.0^{*} \\
(22.2,47.9)\end{array}$ & $\begin{array}{c}19.3 \\
(13.6,24.9)\end{array}$ & $\begin{array}{c}0.9{ }^{\dagger} \\
(-0.3,2.2)\end{array}$ & $\begin{array}{c}18.6 \\
(13.2,24.1)\end{array}$ \\
\hline \multicolumn{16}{|c|}{ Algún tipo de violencia } \\
\hline & $\mathrm{n}=10,075$ & $\mathrm{n}=5,454$ & $n=15,529$ & $\mathrm{n}=313$ & $\mathrm{n}=16,115$ & $\mathrm{n}=2,882$ & $\mathrm{n}=1,619$ & $\mathrm{n}=4,501$ & $\mathrm{n}=91$ & $\mathrm{n}=4,646$ & $\mathrm{n}=12,957$ & $n=7,073$ & $\mathrm{n}=20,030$ & $\mathrm{n}=404$ & $n=20,761$ \\
\hline $\begin{array}{l}\text { Experimentó algún tipo de } \\
\text { violencia en el hogar por } \\
\text { primera vez desde el Inicio de } \\
\text { la pandemia }\end{array}$ & $\begin{array}{c}4.2 \\
(3.6,5.0)\end{array}$ & $\begin{array}{c}4.6 \\
(3.4,6.2)\end{array}$ & $\begin{array}{l}4.4 \\
(3.7,5.2)\end{array}$ & $\begin{array}{c}2.2^{\star} \\
(0.9,5.3)\end{array}$ & $\begin{array}{c}4.3 \\
(3.6,5.1)\end{array}$ & $\begin{array}{c}4.0 \\
(3.0 .5 .2)\end{array}$ & $\begin{array}{c}5.9^{*} \\
(4.4 .8 .0)\end{array}$ & $\begin{array}{c}4.8 \\
(3.9 .5 .9)\end{array}$ & $\begin{array}{c}4.1 \\
(0.9,16.0)\end{array}$ & $\begin{array}{c}4.9 \\
(4.0,5.9)\end{array}$ & $\begin{array}{c}4.0 \\
(3.3 .4 .99)\end{array}$ & $\begin{array}{c}5.6^{*} \\
(4.4 .7 .1)\end{array}$ & $\begin{array}{c}4.7 \\
(4.0,5.5)\end{array}$ & $\begin{array}{c}3.6 \\
(1.0,11.6)\end{array}$ & $\begin{array}{c}4.7 \\
(4.0,5.5)\end{array}$ \\
\hline $\begin{array}{l}\text { Aumento en la frecuencia y/o } \\
\text { gravedad de actos violentos en } \\
\text { el hogar desde el inicio de la } \\
\text { pandemia }\end{array}$ & $\begin{array}{c}27.5 \\
(25.9,29.2)\end{array}$ & $\begin{array}{c}27.1 \\
(24.9,29.4)\end{array}$ & $\begin{array}{c}27.3 \\
(26.0,28 .)\end{array}$ & $\begin{array}{c}25.1 \\
(18.2,33.5)\end{array}$ & $\begin{array}{c}27.4 \\
(26.1,28.8)\end{array}$ & $\begin{array}{c}27.1 \\
(24.7,29.8)\end{array}$ & $\begin{array}{c}29.3 \\
(25.9,32.9)\end{array}$ & $\begin{array}{c}28.1 \\
(26.0,30.2)\end{array}$ & $\begin{array}{c}32.4 \\
(18.7,50.1)\end{array}$ & $\begin{array}{c}28.1 \\
(26.1,30.2)\end{array}$ & $\begin{array}{c}27.2 \\
(25.3,29.2)\end{array}$ & $\begin{array}{c}28.7 \\
(26.1,31.4)\end{array}$ & $\begin{array}{c}27.9 \\
(26.3,29.5)\end{array}$ & $\begin{array}{c}30.5 \\
(19.9,43.8)\end{array}$ & $\begin{array}{c}27.9 \\
(26.4,29.5)\end{array}$ \\
\hline \multicolumn{16}{|c|}{ Aumento del atestiguamiento de violencia y de la exposición a acoso virtual desde el inicio de la pandemia (entre las que declararon haber estado expuests a ese tipo de violencia a lo largo de su vida) \% (95\% Cl) } \\
\hline & $\mathrm{n}=4,597$ & $\mathrm{n}=2,174$ & $n=6,771$ & $\mathrm{n}=170$ & $n=7,065$ & $\mathrm{n}=1,556$ & $\mathrm{n}=767$ & $n=2,323$ & $n=56$ & $n=2,401$ & $n=6,153$ & $\mathrm{n}=2,941$ & $n=9,094$ & $n=226$ & $n=9,466$ \\
\hline & $\mathrm{n}=18,854$ & $\mathrm{n}=10,597$ & $\mathrm{n}=29,451$ & $\mathrm{n}=382$ & $\mathrm{n}=30,353$ & $\mathrm{n}=4,680$ & $\mathrm{n}=2,760$ & $\mathrm{n}=\mathbf{7 , 4 4 0}$ & $\mathrm{n}=107$ & $\mathrm{n}=7,630$ & $\mathrm{n}=23,534$ & $\mathrm{n}=13,357$ & $\mathrm{n}=36,891$ & $\mathrm{n}=489$ & $\mathrm{n}=37,983$ \\
\hline $\begin{array}{l}\text { Aumento de la frecuenciay y/o } \\
\text { gravedad del ciberbullying y del } \\
\text { acoso en linea desde e inicio } \\
\text { de la pandemia (entre las } \\
\text { personas que han declarado } \\
\text { estar expuestas a estos tipos } \\
\text { de violencia en sus vidas) }\end{array}$ & $\begin{array}{c}49.5 \\
(48.2,50.8)\end{array}$ & $\begin{array}{ll}44.8^{*} \\
(43.0,46.6)\end{array}$ & $\begin{array}{c}47.2 \\
(46.1,48.3)\end{array}$ & $\begin{array}{l}42.0 \\
(33.80,50.6)\end{array}$ & $\begin{array}{l}47.0 \\
(46.0,48.1)\end{array}$ & $\begin{array}{l}55.1 \\
(52.8,57.4)\end{array}$ & $\begin{array}{c}51.1^{*} \\
(48.2,54.0)\end{array}$ & $\begin{array}{c}53.3 \\
(51.455 .1)\end{array}$ & $\begin{array}{c}51.1 \\
(36.0,66.0)\end{array}$ & $\begin{array}{c}53.3 \\
(51.5,55.0)\end{array}$ & $\begin{array}{c}53.5 \\
(51.85 .52)\end{array}$ & $\begin{array}{c}49.2^{*} \\
(47.151 .2)\end{array}$ & $\begin{array}{l}51.5 \\
(50.2,52.8)\end{array}$ & $\begin{array}{c}48.5 \\
(37.3,59.9)\end{array}$ & $\begin{array}{c}51.4 \\
(50.1,52.7)\end{array}$ \\
\hline \multicolumn{16}{|c|}{ Uso de servicios gubernamentales relacionados a la violencia $\%(95 \% \mathrm{Cl})$} \\
\hline & $\mathrm{n}=10,075$ & $n=5,454$ & $\mathrm{n}=15,529$ & $\mathrm{n}=313$ & $n=16,115$ & $\mathrm{n}=2,882$ & $\mathrm{n}=1,619$ & $\mathrm{n}=4,501$ & $\mathrm{n}=91$ & $\mathrm{n}=4,646$ & $\mathrm{n}=12,957$ & $n=7,073$ & $\mathrm{n}=20,030$ & $n=404$ & $n=20,761$ \\
\hline
\end{tabular}




\begin{tabular}{|c|c|c|c|c|c|c|c|c|c|c|c|c|c|c|c|}
\hline $\begin{array}{l}\text { Ha utilizado el servicio } \\
\text { gubernamental 911 desde el } \\
\text { inicio de la pandemia }\end{array}$ & $\begin{array}{c}2.9 \\
(2.4,3.6)\end{array}$ & $\begin{array}{c}3.5 \\
(2.9,4.3)\end{array}$ & $\begin{array}{c}3.2 \\
(2.8,3.7)\end{array}$ & $\begin{array}{c}6.6 \\
(3.3,12.7)\end{array}$ & $\begin{array}{c}3.3 \\
(2.9,3.8)\end{array}$ & $\begin{array}{c}3.5 \\
(2.6,4.8)\end{array}$ & $\begin{array}{c}4.3 \\
(2.9,6.4)\end{array}$ & $\begin{array}{c}3.9 \\
(3.0,5.0)\end{array}$ & $\begin{array}{c}11.3 \\
(2.9,3.4)\end{array}$ & $\begin{array}{c}4.0 \\
(3.1,5.2)\end{array}$ & $\begin{array}{r}3.4 \\
(2.6,4.3)\end{array}$ & $\begin{array}{c}4.1 \\
(3.0,5.6)\end{array}$ & $\begin{array}{l}3.7 \\
(3.0,4.5)\end{array}$ & $\begin{array}{c}10.0 \\
(3.3,26.7)\end{array}$ & $\begin{array}{c}3.8 \\
(3.2,4.7)\end{array}$ \\
\hline $\begin{array}{l}\text { Ha utilizado el servicio } \\
\text { gubernamental "No estás sola" } \\
\text { desde el inicio de la pandemia }\end{array}$ & $\begin{array}{c}3.2 \\
(2.6,4.0)\end{array}$ & $\begin{array}{c}2.6 \\
(1.7,4.0)\end{array}$ & $\begin{array}{c}2.9 \\
(2.3,3.6)\end{array}$ & $\begin{array}{c}5.6 \\
(2.6,11.6)\end{array}$ & $\begin{array}{c}3.0 \\
(2.5,3.7)\end{array}$ & $\begin{array}{c}1.6 \\
(1.1,2.5)\end{array}$ & $\begin{array}{c}0.7^{*} \\
(0.3,1.5)\end{array}$ & $\begin{array}{c}1.2 \\
(0.8,1.8)\end{array}$ & $\begin{array}{c}9.7 \\
(2.3,32.9)\end{array}$ & $\begin{array}{c}1.4 \\
(1.0,2.1)\end{array}$ & $\begin{array}{c}2.0 \\
(1.5,2.7)\end{array}$ & $\begin{array}{c}1.2^{\star} \\
(0.8,1.9)\end{array}$ & $\begin{array}{c}1.7 \\
(1.3,2.1)\end{array}$ & $\begin{array}{c}8.7 \\
(2.6,25.2)\end{array}$ & $\begin{array}{c}1.8 \\
(1.5,2.3)\end{array}$ \\
\hline & $\mathrm{n}=27,112$ & $\mathrm{n}=16,548$ & $\mathrm{n}=43,660$ & $\mathrm{n}=501$ & $\mathrm{n}=44,955$ & $\mathrm{n}=6,367$ & $\mathrm{n}=4,107$ & $\mathrm{n}=10,474$ & $\mathrm{n}=137$ & $\mathrm{n}=10,737$ & $\mathrm{n}=33,479$ & $\mathrm{n}=20,655$ & $\mathrm{n}=54,134$ & $\mathrm{n}=638$ & $\mathrm{~N}=55,692$ \\
\hline $\begin{array}{l}\text { Se siente menos segura/o en } \\
\text { su hogar desde el comienzo de } \\
\text { la pandemia }\end{array}$ & $\begin{array}{c}6.5 \\
(6.0,7.1)\end{array}$ & $\begin{array}{l}7.6^{*} \\
(6.8,8.4)\end{array}$ & $\begin{array}{c}7.0 \\
(6.6,7.5)\end{array}$ & $\begin{array}{c}11.6 \\
(7.5,17.5)\end{array}$ & $\begin{array}{c}7.1 \\
(6.7,7.6)\end{array}$ & $\begin{array}{c}9.3 \\
(8.1,10.5)\end{array}$ & $\begin{array}{c}10.3 \\
(8.8,12.0)\end{array}$ & $\begin{array}{c}9.8 \\
(8.8,10.8)\end{array}$ & $\begin{array}{c}14.4 \\
(7.3,26.3)\end{array}$ & $\begin{array}{c}9.8 \\
(8.9,10.8)\end{array}$ & $\begin{array}{c}8.5 \\
(7.6,9.4)\end{array}$ & $\begin{array}{c}9.4 \\
(8.4,10.6)\end{array}$ & $\begin{array}{c}8.9 \\
(8.3,9.6)\end{array}$ & $\begin{array}{c}13.6 \\
(8.1,22.0)\end{array}$ & $\begin{array}{c}9.0 \\
(8.3,9.7)\end{array}$ \\
\hline $\begin{array}{l}\text { Se siente menos segura/o en } \\
\text { su vecindario desde el } \\
\text { comienzo de la pandemia }\end{array}$ & $\begin{array}{c}21.5 \\
(20.6,22.4)\end{array}$ & $\begin{array}{c}16.5^{*} \\
(15.4,17.5)\end{array}$ & $\begin{array}{c}18.9 \\
(18.3,19.6)\end{array}$ & $\begin{array}{c}30.3^{\dagger} \\
(24.1,37.4)\end{array}$ & $\begin{array}{c}19.2 \\
(18.5,19.9)\end{array}$ & $\begin{array}{c}29.0 \\
(27.2,30.9)\end{array}$ & $\begin{array}{c}23.1^{*} \\
(21.2,25.2)\end{array}$ & $\begin{array}{c}26.2 \\
(24.9,27.6)\end{array}$ & $\begin{array}{c}38.3 \\
(25.2,53.4)\end{array}$ & $\begin{array}{c}26.3 \\
(25.0,27.7)\end{array}$ & $\begin{array}{c}26.8 \\
(25.5,28.1)\end{array}$ & $\begin{array}{c}21.0^{*} \\
(19.6,22.5)\end{array}$ & $\begin{array}{c}24.0 \\
(23.0,25.0)\end{array}$ & $\begin{array}{c}36.1^{+} \\
(26.3,47.3)\end{array}$ & $\begin{array}{c}24.1 \\
(23.2,25.1)\end{array}$ \\
\hline $\begin{array}{l}\text { Percibe un aumento de la } \\
\text { delincuencia en su vecindario } \\
\text { desde el inicio de la pandemia }\end{array}$ & $\begin{array}{c}20.7 \\
(19.5,21.9)\end{array}$ & $\begin{array}{c}14.7^{*} \\
(13.6,15.8)\end{array}$ & $\begin{array}{c}17.5 \\
(16.7,18.3)\end{array}$ & $\begin{array}{c}17.8 \\
(12.2,25.2)\end{array}$ & $\begin{array}{c}17.5 \\
(16.7,78.3)\end{array}$ & $\begin{array}{c}28.4 \\
(26.3,30.6)\end{array}$ & $\begin{array}{c}22.3^{*} \\
(20.1,24.7)\end{array}$ & $\begin{array}{c}25.5 \\
(24.0,27.1)\end{array}$ & $\begin{array}{c}37.1 \\
(21.8,55.4)\end{array}$ & $\begin{array}{l}25.7 \\
(24.2,27.3)\end{array}$ & $\begin{array}{c}26.5 \\
(24.9,28.2)\end{array}$ & $\begin{array}{c}20.1^{*} \\
(18.5,21.8)\end{array}$ & $\begin{array}{c}23.3 \\
(22.2,24.5)\end{array}$ & $\begin{array}{c}32.3 \\
(20.5,47.0)\end{array}$ & $\begin{array}{c}23.5 \\
(22.3,24.7)\end{array}$ \\
\hline
\end{tabular}

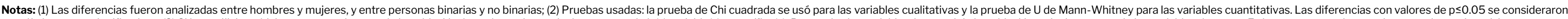

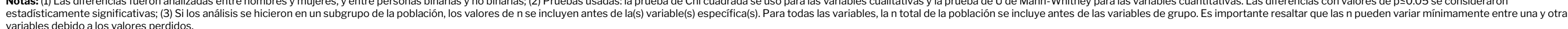
Valor de p: ${ }^{*}$-value $<0.05$ para la diferencia entre mujeres $\mathrm{y}$ hombres; ${ }^{\mathrm{p}} \mathrm{p}$-value $<0.05$ para la diferencia entre personas binarias $\mathrm{y}$ no binarias. 
TABLA 7 Impacto de las medidas de mitigación de COVID-19 en la exposición a la violencia, por grupo de edad y origen étnico

\begin{tabular}{|c|c|c|c|c|c|c|c|c|c|}
\hline \multirow{3}{*}{ Variable } & \multicolumn{3}{|c|}{ 15-17 años } & \multicolumn{3}{|c|}{ 18-24 años } & \multicolumn{3}{|c|}{ Total } \\
\hline & $\begin{array}{l}\text { Participantes indigenas } \\
\text { y/o afrodescendientes }\end{array}$ & $\begin{array}{l}\text { Participantes no } \\
\text { indigenas y/o } \\
\text { afrodescendientes }\end{array}$ & Total & $\begin{array}{c}\text { Participantes } \\
\text { indigenasy y/o } \\
\text { afrodescendientes }\end{array}$ & $\begin{array}{c}\text { Participantes no } \\
\text { indigenas y } / 0 \\
\text { afrodescendientes }\end{array}$ & Total & $\begin{array}{l}\text { Participantes indigenas } \\
\text { y/o a frodescendientes }\end{array}$ & $\begin{array}{l}\text { Participantes no } \\
\text { indigenasy y/o } \\
\text { afrodescendientes }\end{array}$ & Total \\
\hline & $\mathrm{n}=\mathbf{1 2 , 8 4 3}$ & $\mathrm{n}=32,112$ & $\mathrm{n}=44,955$ & $\mathrm{n}=\mathbf{2 , 9 3 0}$ & $\mathrm{n}=\mathbf{7 , 8 0 7}$ & $\mathrm{n}=10,737$ & $\mathrm{n}=15,773$ & $\mathrm{n}=39,919$ & $\mathrm{n}=55,692$ \\
\hline \multicolumn{10}{|c|}{ Aumento de la violencia en el hogar desde el inicio de la pandemia (entre las que declararon haber tenido alguna experiencia a lo largo de su vida con ese tipo de violencia) $\%(95 \% \mathrm{Cl})$} \\
\hline \multicolumn{10}{|c|}{ Violencia psicológica } \\
\hline & $\mathrm{n}=\mathbf{4 , 2 4 2}$ & $\mathrm{n}=\mathbf{1 0 , 0 8 6}$ & $\mathrm{n}=\mathbf{1 4 , 3 2 8}$ & $\mathrm{n}=\mathbf{1 , 1 2 9}$ & $\mathrm{n}=3,071$ & $n=4,200$ & $n=5,371$ & $\mathrm{n}=13,157$ & $\mathrm{n}=18,528$ \\
\hline $\begin{array}{l}\text { Sólo experimentaron violencia psicológica tras el } \\
\text { inicio de la pandemia y no antes }\end{array}$ & $\begin{array}{c}6.7 \\
(5.4,8.0)\end{array}$ & $\begin{array}{c}5.1^{\star} \\
(4.2,5.9)\end{array}$ & $\begin{array}{c}5.6 \\
(4.9,6.3)\end{array}$ & $\begin{array}{l}8.0 \\
(5.7,10.4)\end{array}$ & $\begin{array}{l}5.6 \\
(4.4,6.8)\end{array}$ & $\begin{array}{c}6.2 \\
(5.2,7.3)\end{array}$ & $\begin{array}{c}7.6 \\
(5.9,9.3)\end{array}$ & $\begin{array}{l}5.5^{*} \\
(4.5,6.4)\end{array}$ & $\begin{array}{c}6.1 \\
(5.2,6.9)\end{array}$ \\
\hline $\begin{array}{l}\text { Aumento de la frecuenciay/o gravedad de la } \\
\text { violencia psicológica en el hogar desde el inicio de la } \\
\text { pandemia }\end{array}$ & $\begin{array}{c}32.0 \\
(29.4,34.7)\end{array}$ & $\begin{array}{c}28.3^{*} \\
(26.6,30.0)\end{array}$ & $\begin{array}{c}29.5 \\
(28.1,30.9)\end{array}$ & $\begin{array}{c}38.6 \\
(34.1,43.0)\end{array}$ & $\begin{array}{c}26.1^{*} \\
(23.6,28.5)\end{array}$ & $\begin{array}{c}29.4 \\
(27.2,31.6)\end{array}$ & $\begin{array}{c}36.6 \\
(33.4,39.9)\end{array}$ & $\begin{array}{c}26.6^{*} \\
(24.7,28.5)\end{array}$ & $\begin{array}{c}29.4 \\
(27.8,31.1)\end{array}$ \\
\hline \multicolumn{10}{|c|}{ Violencia física } \\
\hline & $\mathrm{n}=2,516$ & $\mathrm{n}=5,693$ & $\mathrm{n}=8,209$ & $\mathrm{n}=667$ & $n=1,733$ & $\mathrm{n}=2,400$ & $n=3,183$ & $\mathrm{n}=7,426$ & $\mathrm{n}=10,609$ \\
\hline $\begin{array}{l}\text { Sólo experimentaron violencia física tras el inicio de } \\
\text { la pandemia y no antes }\end{array}$ & $\begin{array}{c}5.1 \\
(2.4,7.7)\end{array}$ & $\begin{array}{c}4.2 \\
(2.8,5.6)\end{array}$ & $\begin{array}{l}4.5 \\
(3.2,5.8)\end{array}$ & $\begin{array}{c}8.6 \\
(5.3,11.9)\end{array}$ & $\begin{array}{c}5.5 \\
(3.7,7.4)\end{array}$ & $\begin{array}{c}6.4 \\
(4.8,8.0)\end{array}$ & $\begin{array}{c}7.5 \\
(5.1,10.0)\end{array}$ & $\begin{array}{c}5.2 \\
(3.8,6.6)\end{array}$ & $\begin{array}{c}5.9 \\
(4.7,7.1)\end{array}$ \\
\hline \multicolumn{10}{|c|}{ Violencia sexual } \\
\hline & $\mathrm{n}=394$ & $\mathrm{n}=\mathbf{7 8 9}$ & $\mathrm{n}=1,183$ & $\mathrm{n}=148$ & $\mathrm{n}=284$ & $\mathrm{n}=432$ & $n=542$ & $n=1,073$ & $\mathrm{n}=1,615$ \\
\hline $\begin{array}{l}\text { Sólo experimentaron violencia sexual tras el inicio de } \\
\text { la pandemia y no antes }\end{array}$ & $\begin{array}{c}7.7 \\
(-0.2,15.6)\end{array}$ & $\begin{array}{c}6.7 \\
(3.4,9.9)\end{array}$ & $\begin{array}{c}7.1 \\
(3.4,10.7)\end{array}$ & $\begin{array}{c}12.6 \\
(2.2,22.9)\end{array}$ & $\begin{array}{c}9.0 \\
(1.2,16.7)\end{array}$ & $\begin{array}{c}10.3 \\
(4.1,16.5)\end{array}$ & $\begin{array}{c}11.5 \\
(3.2,19.8)\end{array}$ & $\begin{array}{c}8.5 \\
(2.3,14.7)\end{array}$ & $\begin{array}{c}9.6 \\
(4.6,14.6)\end{array}$ \\
\hline $\begin{array}{l}\text { Aumento de la frecuencia y/o gravedad de la } \\
\text { violencia sexual en el hogar desde el inicio de la } \\
\text { pandemia }\end{array}$ & $\begin{array}{l}17.8 \\
(11.2,24.4)\end{array}$ & $\begin{array}{l}10.4 \\
(6.4,14.5)\end{array}$ & $\begin{array}{l}13.2 \\
(9.7,16.8)\end{array}$ & $\begin{array}{c}22.6 \\
(10.5,34.7)\end{array}$ & $\begin{array}{c}18.6 \\
(10.5,26.7)\end{array}$ & $\begin{array}{c}20.0 \\
(13.3,26.8)\end{array}$ & $\begin{array}{c}21.6 \\
(11.9,31.2)\end{array}$ & $\begin{array}{c}17.0 \\
(10.5,23.5)\end{array}$ & $\begin{array}{c}18.6 \\
(13.2,24.1)\end{array}$ \\
\hline
\end{tabular}


Algún tipo de violencia

\begin{tabular}{|c|c|c|c|c|c|c|c|c|c|}
\hline \multicolumn{10}{|c|}{ Algún tipo de violencia } \\
\hline & $\mathrm{n}=4,811$ & $\mathrm{n}=11,304$ & $\mathrm{n}=16,115$ & $\mathrm{n}=1,266$ & $\mathrm{n}=3,380$ & $\mathrm{n}=\mathbf{1 0 , 5 8 6}$ & $\mathrm{n}=6,077$ & $\mathrm{n}=14,684$ & $\mathrm{n}=20,761$ \\
\hline $\begin{array}{l}\text { Sólo ha experimentado un tipo especiffico de } \\
\text { violencia en en hogar por primera vez desde el inicio } \\
\text { de la pandemia }\end{array}$ & $\begin{array}{l}5.6 \\
(4.1,7.4)\end{array}$ & $\begin{array}{l}3.7^{*} \\
(3.0,4.5)\end{array}$ & $\begin{array}{c}4.3 \\
(3.6,5.1)\end{array}$ & $\begin{array}{c}6.0 \\
(4.3,8.5)\end{array}$ & $\begin{array}{l}4.4 \\
(3.5,5.7)\end{array}$ & $\begin{array}{l}4.9 \\
(4.0,5.9)\end{array}$ & $\begin{array}{l}5.9 \\
(4.5,7.6)\end{array}$ & $\begin{array}{c}4.2 \\
(3.5,5.2)\end{array}$ & $\begin{array}{l}4.7 \\
(4.0,5.5)\end{array}$ \\
\hline $\begin{array}{l}\text { Aumento de la frecuencia y/o gravedad de los actos } \\
\text { violentos en el hogar desde el inicio de la pandemia } \\
\text { (entre las personas que han declarado haber estado } \\
\text { expuestas a cualquier tipo de violencia en sus vidas) }\end{array}$ & $\begin{array}{c}29.7 \\
(27.32,32.3)\end{array}$ & $\begin{array}{c}26.3^{*} \\
(24.7,27.9)\end{array}$ & $\begin{array}{l}27.4 \\
(26.1,28.8)\end{array}$ & $\begin{array}{c}36.4 \\
(32.3,40.7)\end{array}$ & $\begin{array}{c}25.0^{*} \\
(22.7,27.4)\end{array}$ & $\begin{array}{c}28.1 \\
(26.1,30.2)\end{array}$ & $\begin{array}{c}34.4 \\
(31.4,37.6)\end{array}$ & $\begin{array}{c}25.3^{*} \\
(23.5,27.2)\end{array}$ & $\begin{array}{l}27.9 \\
(26.4,29.5)\end{array}$ \\
\hline & $\mathrm{n}=\mathbf{2 , 2 5 3}$ & $\mathrm{n}=5,128$ & $\mathrm{n}=\mathbf{7 , 3 8 1}$ & $\mathrm{n}=695$ & $\mathrm{n}=1,780$ & $\mathrm{n}=2,475$ & $\mathrm{n}=2,948$ & $n=6,908$ & $\mathrm{n}=9,856$ \\
\hline $\begin{array}{l}\text { Aumento de la frecuencia y/o la gravedad de los } \\
\text { actos violentos contra un hermano/ a o la pareja } \\
\text { femenina de sus padres en el hogar desde el inicio de } \\
\text { la pandemia (entre las personas que han declarado } \\
\text { haber presenciado algun tipo de violencia en sus } \\
\text { vidas) }\end{array}$ & $\begin{array}{c}22.1 \\
(19.3,25.1)\end{array}$ & $\begin{array}{c}24.3 \\
(22.0,26.7)\end{array}$ & $\begin{array}{c}23.5 \\
(21.7,25.4)\end{array}$ & $\begin{array}{c}28.3 \\
(23.7,33.5)\end{array}$ & $\begin{array}{c}22.0 * \\
(19.2,25.2)\end{array}$ & $\begin{array}{c}23.9 \\
(21.4,26.5)\end{array}$ & $\begin{array}{c}26.8 \\
(23.2,30.7)\end{array}$ & $\begin{array}{c}22.5 \\
(20.1,25.0)\end{array}$ & $\begin{array}{c}23.8 \\
(21.8,25.9)\end{array}$ \\
\hline & $\mathrm{n}=8,878$ & $\mathrm{n}=21,475$ & $\mathrm{n}=30,353$ & $\mathrm{n}=2,131$ & $\mathrm{n}=5,499$ & $\mathrm{n}=7,630$ & $\mathrm{n}=11,009$ & $\mathrm{n}=26,974$ & $\mathrm{n}=37,983$ \\
\hline $\begin{array}{l}\text { Aumento de la frecuencia y/o gravedad del } \\
\text { ciberbulllying y del acoso en linea desde el inicio de la } \\
\text { pandemia (entre las personas que han declarado } \\
\text { haber estado expuestas a estos tipos de violencia en } \\
\text { sus vidas) }\end{array}$ & $\begin{array}{c}51.3 \\
(49.3,53.3)\end{array}$ & $\begin{array}{c}45.0^{*} \\
(43.7,46.3)\end{array}$ & $\begin{array}{l}47.0 \\
(46.0,48.1)\end{array}$ & $\begin{array}{c}59.3 \\
(56.2,62.4)\end{array}$ & $\begin{array}{c}50.8^{*} \\
(48.7,53.0)\end{array}$ & $\begin{array}{c}53.3 \\
(51.5,55.0)\end{array}$ & $\begin{array}{c}56.7 \\
(54.5,58.9)\end{array}$ & $\begin{array}{l}49.1^{*} \\
(47.6,50.7)\end{array}$ & $\begin{array}{l}51.4 \\
(50.1,52.7)\end{array}$ \\
\hline \multicolumn{10}{|c|}{ Uso de servicios gubernamentales relacionados a la violencia $\%(95 \% \mathrm{Cl})$} \\
\hline & $\mathrm{n}=4,811$ & $\mathrm{n}=11,304$ & $\mathrm{n}=16,115$ & $\mathrm{n}=1,266$ & $\mathrm{n}=3,380$ & $\mathrm{n}=10,586$ & $\mathrm{n}=6,077$ & $\mathrm{n}=14,684$ & $\mathrm{n}=\mathbf{2 0 , 7 6 1}$ \\
\hline $\begin{array}{l}\text { Ha utilizado el servicio gubernamental } 911 \text { desde el } \\
\text { inicio de la pandemia }\end{array}$ & $\begin{array}{l}3.2 \\
(2.7,3.7)\end{array}$ & $\begin{array}{c}2.3^{*} \\
(2.0,2.6)\end{array}$ & $\begin{array}{c}3.3 \\
(2.9,3.8)\end{array}$ & $\begin{array}{c}2.9 \\
(2.0,4.0)\end{array}$ & $\begin{array}{c}2.5 \\
(2.0,3.3)\end{array}$ & $\begin{array}{c}4.0 \\
(3.1,5.2)\end{array}$ & $\begin{array}{l}4.2 \\
(3.1,5.7)\end{array}$ & $\begin{array}{c}3.7 \\
(2.9 .4 .7)\end{array}$ & $\begin{array}{c}3.8 \\
(3.2,4.7)\end{array}$ \\
\hline $\begin{array}{l}\text { Ho utilizado e servicio gubernamental "No estás } \\
\text { sola" desde el inicio de la pandemia }\end{array}$ & $\begin{array}{l}2.5 \\
(2.2,3.0)\end{array}$ & $\begin{array}{c}2.2 \\
(1.8,2.7)\end{array}$ & $\begin{array}{c}3.0 \\
(2.5,3.7)\end{array}$ & $\begin{array}{l}0.6 \\
(0.4,1.0)\end{array}$ & $\begin{array}{c}1.3^{*} \\
(0.9,1.7)\end{array}$ & $\begin{array}{c}1.4 \\
(1.0,2.1)\end{array}$ & $\begin{array}{c}1.3 \\
(1.0,1.6)\end{array}$ & $\begin{array}{l}2.1^{*} \\
(1.6,2.8)\end{array}$ & $\begin{array}{l}1.8 \\
(1.5,2.3)\end{array}$ \\
\hline \multicolumn{10}{|c|}{ Percepción de la seguridad en el hogar y en la comunidad desde el comienzo de la pandemia en comparación con antes \% (95\% Cl) } \\
\hline & $\mathrm{n}=12,843$ & $\mathrm{n}=32,112$ & $\mathrm{n}=44,955$ & $\mathrm{n}=2,930$ & $\mathrm{n}=\mathbf{7 , 8 0 7}$ & $\mathrm{n}=\mathbf{1 0 , 7 3 7}$ & $\mathrm{n}=15,773$ & $\mathrm{n}=39,919$ & $\mathrm{n}=55,692$ \\
\hline $\begin{array}{l}\text { Se siente menos segura/o en su hogar desde el } \\
\text { comienzo de la pandemia }\end{array}$ & $\begin{array}{l}8.7 \\
(7.7,9.9)\end{array}$ & $\begin{array}{l}6.3^{*} \\
(5.9,6.8)\end{array}$ & $\begin{array}{l}7.1 \\
(6.7,7.6)\end{array}$ & $\begin{array}{c}11.1 \\
(9.3,13.2)\end{array}$ & $\begin{array}{c}9.3 \\
(8.2,10.5)\end{array}$ & $\begin{array}{l}9.8 \\
(8.9,10.8)\end{array}$ & $\begin{array}{l}10.3 \\
(9.1,11.7)\end{array}$ & $\begin{array}{c}8.4^{*} \\
(7.7,9.3)\end{array}$ & $\begin{array}{l}9.0 \\
(8.3,9.7)\end{array}$ \\
\hline
\end{tabular}




\begin{tabular}{|c|c|c|c|c|c|c|c|c|c|}
\hline $\begin{array}{l}\text { Se siente menos segura/o en su vecindario desde el } \\
\text { comienzo de la pandemia }\end{array}$ & $\begin{array}{c}19.7 \\
(18.4,21.1)\end{array}$ & $\begin{array}{c}18.9 \\
(18.2,19.7)\end{array}$ & $\begin{array}{c}19.2 \\
(18.5,19.9)\end{array}$ & $\begin{array}{c}27.8 \\
(25.3,30.4)\end{array}$ & $\begin{array}{c}25.7 \\
(24.2,27.3)\end{array}$ & $\begin{array}{c}26.3 \\
(25.0,27.7)\end{array}$ & $\begin{array}{c}25.1 \\
(23.3,26.9)\end{array}$ & $\begin{array}{c}23.7 \\
(22.6,24.9)\end{array}$ & $\begin{array}{c}24.1 \\
(23.2,25.1\end{array}$ \\
\hline $\begin{array}{l}\text { Percibe un aumento de la delincuencia en su } \\
\text { vecindario desde el inicio de la pandemia }\end{array}$ & $\begin{array}{c}18.1 \\
(16.6,19.6)\end{array}$ & $\begin{array}{c}17.1 \\
(16.2,18.1)\end{array}$ & $\begin{array}{c}17.5 \\
(16.7,18.3)\end{array}$ & $\begin{array}{c}28.4 \\
(25.6,31.5)\end{array}$ & $\begin{array}{c}24.6^{*} \\
(22.8,26.5)\end{array}$ & $\begin{array}{l}25.7 \\
(24.2,27.3)\end{array}$ & $\begin{array}{c}25.2 \\
(23.2,27.4)\end{array}$ & $\begin{array}{c}22.7 \\
(21.3,24.1)\end{array}$ & $\begin{array}{c}23.5 \\
(22.3,24.7\end{array}$ \\
\hline $\begin{array}{l}\text { Percibe un aumento de la violencia en su vecindario } \\
\text { desde el inicio de la pandemia }\end{array}$ & $\begin{array}{c}14.8 \\
(13.3,16.4)\end{array}$ & $\begin{array}{c}12.6^{*} \\
(11.9,13.4)\end{array}$ & $\begin{array}{c}13.4 \\
(12.7,14.1)\end{array}$ & $\begin{array}{c}24.6 \\
(21.9,27.5)\end{array}$ & $\begin{array}{c}21.0^{*} \\
(19.322 .8)\end{array}$ & $\begin{array}{c}22.0 \\
(20.6,23.6)\end{array}$ & $\begin{array}{c}21.6 \\
(19.6,23.6)\end{array}$ & $\begin{array}{c}18.8^{*} \\
(17.6,20.2)\end{array}$ & $\begin{array}{l}19.7 \\
(18.6,20.8\end{array}$ \\
\hline
\end{tabular}

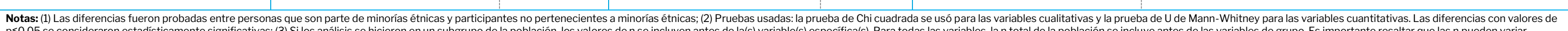

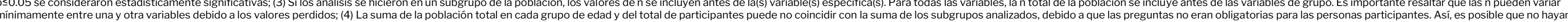

querido revelar su origen étr
Valor de $\mathrm{p}:{ }^{\mathrm{p}} \mathrm{p}$-value $<0.05$

TABLA 8 Impacto de las medidas de mitigación de COVID-19 en la exposición a la violencia, por grupos de edad y NSE

\begin{tabular}{|c|c|c|c|c|c|c|c|c|c|}
\hline \multirow{3}{*}{ Variable } & \multicolumn{3}{|c|}{ 15-17 años } & \multicolumn{3}{|c|}{ 18-24 años } & \multicolumn{3}{|c|}{ Total } \\
\hline & $\begin{array}{l}\text { Hogares de ingresosos más } \\
\text { bajos (primer quintili) }\end{array}$ & $\begin{array}{l}\text { Hogares de ingresos más } \\
\text { altos (quinto quintil) }\end{array}$ & Total & $\begin{array}{l}\text { Hogares de ingresosos más } \\
\text { bajos (primer quintil) }\end{array}$ & $\begin{array}{l}\text { Hogares de ingresos más } \\
\text { altos (quinto quinti) }\end{array}$ & Total & $\begin{array}{l}\text { Hogares de ingresos más } \\
\text { bajos (primer quintili) }\end{array}$ & $\begin{array}{l}\text { Hogares de ingresosos más } \\
\text { altos (quinto quintil) }\end{array}$ & Total \\
\hline & $\mathrm{n}=8,852$ & $\mathrm{n}=8,778$ & $\mathrm{n}=44,955$ & $\mathrm{n}=2,288$ & $\mathrm{n}=2,331$ & $\mathrm{n}=10,737$ & $\mathrm{n}=11,140$ & $\mathrm{n}=11,109$ & $\mathrm{n}=55,692$ \\
\hline \multicolumn{10}{|c|}{ Aumento de la violencia en el hogar desde el inicio de la pandemia (entre los que declararon haber tenido alguna experiencia en algún punto de la vida con ese tipo de violencia) \% (95\% Cl) } \\
\hline \multicolumn{10}{|c|}{ Violencia psicológica } \\
\hline & $\mathrm{n}=2,709$ & $\mathrm{n}=3,032$ & $\mathrm{n}=5,741$ & $\mathrm{n}=821$ & $\mathrm{n}=1,023$ & $\mathrm{n}=\mathbf{1}, \mathbf{8 4 4}$ & $\mathrm{n}=3,530$ & $\mathrm{n}=4,055$ & $\mathrm{n}=7,585$ \\
\hline $\begin{array}{l}\text { Sólo experimentaron violencia psicológica tras el } \\
\text { inicio de la pandemia y no antes }\end{array}$ & $\begin{array}{c}8.4 \\
(6.7,10.1)\end{array}$ & $\begin{array}{c}4.4^{*} \\
(2.7,6.1)\end{array}$ & $\begin{array}{c}5.6 \\
(4.9,6.3)\end{array}$ & $\begin{array}{l}10.0 \\
(6.8,13.3)\end{array}$ & $\begin{array}{c}4.5^{*} \\
(2.8,6.3)\end{array}$ & $\begin{array}{l}6.2 \\
(5.2,7.3)\end{array}$ & $\begin{array}{c}9.6 \\
(7.2,12.0)\end{array}$ & $\begin{array}{c}4.5^{*} \\
(3.1,6.0)\end{array}$ & $\begin{array}{c}6.1 \\
(5.2,6.9)\end{array}$ \\
\hline $\begin{array}{l}\text { Aumento de la frecuencia y/o gravedad de la } \\
\text { violencia psicolögica en el hogar desde el inicio de } \\
\text { la pandemia }\end{array}$ & $\begin{array}{c}37.0 \\
(33.6,40.3)\end{array}$ & $\begin{array}{c}25.6^{*} \\
(22.6,28.5)\end{array}$ & $29.5(28.1,30.9)$ & $\begin{array}{c}44.0 \\
(38.6,49.5)\end{array}$ & $\begin{array}{l}20.6^{*} \\
(17.0,24.2)\end{array}$ & $\begin{array}{c}29.4 \\
(27.2,31.6)\end{array}$ & $\begin{array}{c}42.2 \\
(38.1,46.4)\end{array}$ & $\begin{array}{c}21.6^{*} \\
(18.7,24.6)\end{array}$ & $\begin{array}{c}29.4 \\
(27.8,31.1)\end{array}$ \\
\hline \multicolumn{10}{|c|}{ Violencia física } \\
\hline & $\mathrm{n}=1,562$ & $\mathrm{n}=1,789$ & $\mathrm{n}=3,351$ & $n=483$ & $n=583$ & $\mathrm{n}=1,066$ & $\mathrm{n}=2,045$ & $\mathrm{n}=2,372$ & $\mathrm{n}=4,417$ \\
\hline $\begin{array}{l}\text { Sólo experimentaron violencia fisica tras el inicio } \\
\text { de la pandemia y no antes }\end{array}$ & $\begin{array}{c}6.1 \\
(4.1,8.1)\end{array}$ & $\begin{array}{c}2.2^{*} \\
(1.4,2.9)\end{array}$ & $\begin{array}{l}4.5 \\
(3.2,5.8)\end{array}$ & $\begin{array}{c}12.7 \\
(7.8,17.6)\end{array}$ & $\begin{array}{c}4.4^{*} \\
(1.6,7.2)\end{array}$ & $\begin{array}{c}6.4 \\
(4.8,8.0)\end{array}$ & $\begin{array}{c}11.1 \\
(7.3,14.8)\end{array}$ & $\begin{array}{c}3.9^{*} \\
(1.7,6.0)\end{array}$ & $\begin{array}{c}5.9 \\
(4.7,7.1)\end{array}$ \\
\hline $\begin{array}{l}\text { Aumento de la frecuencia y/o gravedad de la } \\
\text { violencia física en el hogar desde el inicio de la } \\
\text { pandemia }\end{array}$ & $\begin{array}{c}27.2 \\
(23.3,31.1)\end{array}$ & $\begin{array}{c}12.5^{*} \\
(10.2,14.9)\end{array}$ & $\begin{array}{c}18.8 \\
(17.2,20.4)\end{array}$ & $\begin{array}{c}37.9 \\
(30.5,45.2)\end{array}$ & $\begin{array}{c}12.1^{*} \\
(8.3,15.9)\end{array}$ & $\begin{array}{c}19.6 \\
(17.1,22.2)\end{array}$ & $\begin{array}{c}35.3 \\
(29.6,40.9)\end{array}$ & $\begin{array}{c}12.2^{\star} \\
(9.2,15.2)\end{array}$ & $\begin{array}{c}19.4 \\
(17.5,21.3)\end{array}$ \\
\hline
\end{tabular}




\begin{tabular}{|c|c|c|c|c|c|c|c|c|c|}
\hline $\begin{array}{l}\text { Sólo experimentaron violencia sexual tras el inicio } \\
\text { de la pandemia y no antes }\end{array}$ & $\begin{array}{c}9.5 \\
(0.8,18.3)\end{array}$ & $\begin{array}{c}4.0 \\
(0.8,7.1)\end{array}$ & $\begin{array}{c}7.1 \\
(3.4,10.7)\end{array}$ & $\begin{array}{c}15.0 \\
(2.0,28.0)\end{array}$ & $\begin{array}{c}3.8 \\
(-2.9,10.5)\end{array}$ & $\begin{array}{c}10.3 \\
(4.1,16.5)\end{array}$ & $\begin{array}{c}14.1 \\
(3.0,25.3)\end{array}$ & $\begin{array}{c}3.9 \\
(-1.6,9.3)\end{array}$ & $\begin{array}{c}9.6 \\
(4.6,14.6)\end{array}$ \\
\hline $\begin{array}{l}\text { Aumento de la frecuencia y/o gravedad de la } \\
\text { violencia sexual en el hogar desde el inicio de la } \\
\text { pandemia }\end{array}$ & $\begin{array}{c}26.4 \\
(14.5,38.2)\end{array}$ & $\begin{array}{c}8.7^{*} \\
(2.9,14.5)\end{array}$ & $\begin{array}{c}13.2 \\
(9.7,16.8)\end{array}$ & $\begin{array}{c}29.7 \\
(15.4 .44 .0)\end{array}$ & $\begin{array}{c}9.8^{*} \\
(0.2,19.3)\end{array}$ & $\begin{array}{l}20.0 \\
(13.3,26.8)\end{array}$ & $\begin{array}{c}29.2 \\
(16.9,41.6)\end{array}$ & $\begin{array}{c}9.5^{*} \\
(1.8,17.3)\end{array}$ & $\begin{array}{c}18.6 \\
(13.2,24.1)\end{array}$ \\
\hline \multicolumn{10}{|c|}{ Algún tipo de violencia } \\
\hline & $\mathrm{n}=3,044$ & $n=3,446$ & $n=16,115$ & $\mathrm{n}=919$ & $\mathrm{n}=1,119$ & $\mathrm{n}=10,586$ & $n=3,963$ & $\mathrm{n}=4,565$ & $\mathrm{n}=20,761$ \\
\hline $\begin{array}{l}\text { Sólo ha experimentado un tipo específico de } \\
\text { violencia en el hogar por primera vez desde el } \\
\text { inicio de la pandemia }\end{array}$ & $\begin{array}{c}5.6 \\
(4.4,7.0)\end{array}$ & $\begin{array}{c}3.2^{*} \\
(2.0,5.0)\end{array}$ & $\begin{array}{c}4.3 \\
(3.6,5.1)\end{array}$ & $\begin{array}{c}9.0 \\
(6.3,12.7)\end{array}$ & $\begin{array}{c}3.5^{*} \\
(2.2,5.5)\end{array}$ & $\begin{array}{l}4.9 \\
(4.0,5.9)\end{array}$ & $\begin{array}{c}8.1 \\
(6.0,10.8)\end{array}$ & $\begin{array}{c}3.4 * \\
(2.4,5.0)\end{array}$ & $\begin{array}{l}4.7 \\
(4.0,5.5)\end{array}$ \\
\hline $\begin{array}{l}\text { Aumento de la frecuenciay y/o gravedad de los } \\
\text { actos violentos en el hogar desde el inicio de la } \\
\text { pandemia (entre las personas que han declarado } \\
\text { haber estado expuestas a cualquier tipo de } \\
\text { violencia en sus vidas) }\end{array}$ & $\begin{array}{c}35.1 \\
(32.0,38.4)\end{array}$ & $\begin{array}{c}23.6^{*} \\
(21.0,26.5)\end{array}$ & $\begin{array}{l}27.4 \\
(26.1,28.8)\end{array}$ & $\begin{array}{c}42.4 \\
(37.37,87.8)\end{array}$ & $\begin{array}{c}20.0^{*} \\
(16.8,23.7)\end{array}$ & $\begin{array}{l}28.1 \\
(26.1,30.2)\end{array}$ & $\begin{array}{c}40.5 \\
(36.6,44.5)\end{array}$ & $\begin{array}{c}20.8^{*} \\
(18.1,23.7)\end{array}$ & $\begin{array}{l}27.9 \\
(26.4,29.5)\end{array}$ \\
\hline \multicolumn{10}{|c|}{ Aumento del atestiguamiento de violencia y de la exposición a acoso virtual desde el inicio de la pandemia (entre las que declararon haber estado expuests a ese tipo de violencia a lo largo de su vida) \% (95\% Cl) } \\
\hline & $\mathrm{n}=2,253$ & $n=5,128$ & $n=7,381$ & $\mathrm{n}=695$ & $\mathrm{n}=1,780$ & $n=2,475$ & $\mathrm{n}=2,948$ & $\mathrm{n}=6,908$ & $\mathrm{n}=9,856$ \\
\hline 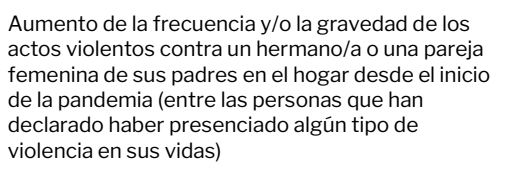 & $\begin{array}{c}27.6 \\
(23.4,32.2)\end{array}$ & $\begin{array}{c}24.2 \\
(19.5,29.6)\end{array}$ & $\begin{array}{c}23.5 \\
(21.7,25.4)\end{array}$ & $\begin{array}{c}34.1 \\
(28.2,40.6)\end{array}$ & $\begin{array}{c}17.5^{*} \\
(13.5,22.3)\end{array}$ & $\begin{array}{c}23.9 \\
(21.4,26.5)\end{array}$ & $\begin{array}{c}32.8 \\
(28.0,37.9)\end{array}$ & $\begin{array}{l}18.7 * \\
(15.3,22.7)\end{array}$ & $\begin{array}{c}23.8 \\
(21.8,25.9)\end{array}$ \\
\hline & $n=6,008$ & $n=5,948$ & $\mathrm{n}=30,353$ & $\mathrm{n}=1,571$ & $\mathrm{n}=1,659$ & $n=7,630$ & $\mathrm{n}=7,579$ & $n=7,607$ & $n=37,983$ \\
\hline $\begin{array}{l}\text { Aumento de la frecuencia y/o gravedad del } \\
\text { ciberbullying y del acoso en linea desdde el inicio de } \\
\text { la pandemia (entre las personas que hand declarado } \\
\text { haber estado oxpuestas a estos tipos de violencia } \\
\text { en sus vidas) }\end{array}$ & $\begin{array}{c}46.9 \\
(44.6,49.3)\end{array}$ & $\begin{array}{c}46.3 \\
(44.0,48.6)\end{array}$ & $\begin{array}{l}47.0 \\
(46.0,48.1)\end{array}$ & $\begin{array}{c}59.1 \\
(55.4,62.7)\end{array}$ & $\begin{array}{c}46.8^{*} \\
(42.9,50.6)\end{array}$ & $\begin{array}{c}53.3 \\
(51.5,55.0)\end{array}$ & $\begin{array}{c}55.5 \\
(52.8,58.2)\end{array}$ & $\begin{array}{c}46.6^{*} \\
(43.7,49.6)\end{array}$ & $\begin{array}{c}51.4 \\
(50.1,52.7)\end{array}$ \\
\hline \multicolumn{10}{|c|}{ Uso de servicios gubernamentales relacionados a la violencia $\%(95 \% \mathrm{Cl})$} \\
\hline & $n=3,044$ & $n=3,446$ & $n=16,115$ & $\mathrm{n}=919$ & $\mathrm{n}=1,119$ & $\mathrm{n}=10,586$ & $\mathrm{n}=3,963$ & $n=4,565$ & $n=20,761$ \\
\hline $\begin{array}{l}\text { Ha utilizado el servicio gubernamental } 911 \text { desde el } \\
\text { inicio de la pandemia }\end{array}$ & $\begin{array}{c}3.7 \\
(2.8,4.8)\end{array}$ & $\begin{array}{c}3.9 \\
(2.8,5.4)\end{array}$ & $\begin{array}{c}3.3 \\
(2.9,3.8)\end{array}$ & $\begin{array}{c}3.8 \\
(2.2,6.4)\end{array}$ & $\begin{array}{c}4.8 \\
(3.0,7.4)\end{array}$ & $\begin{array}{c}4.0 \\
(3.1,5.2)\end{array}$ & $\begin{array}{c}3.8 \\
(2.5,5.6)\end{array}$ & $\begin{array}{c}4.6 \\
(3.2,6.6)\end{array}$ & $\begin{array}{c}3.8 \\
(3.2,4.7)\end{array}$ \\
\hline
\end{tabular}




\begin{tabular}{|c|c|c|c|c|c|c|c|c|c|}
\hline $\begin{array}{l}\text { Ha utilizado el servicio gubernamental "No estás } \\
\text { sola" desde el inicio de la pandemia }\end{array}$ & $\begin{array}{c}3.0 \\
(2.2,4.1)\end{array}$ & $\begin{array}{c}3.2 \\
(2.3,4.4)\end{array}$ & $\begin{array}{l}3.0 \\
(2.5,3.7)\end{array}$ & $\begin{array}{c}1.8 \\
(0.8,3.8)\end{array}$ & $\begin{array}{c}2.6 \\
(0.7,3.7)\end{array}$ & $\begin{array}{l}1.4 \\
(1.0,2.1)\end{array}$ & $\begin{array}{c}2.1 \\
(1.2,3.4)\end{array}$ & $\begin{array}{c}2.0 \\
(1.1,3.4)\end{array}$ & $\begin{array}{c}1.8 \\
(1.5,2.3)\end{array}$ \\
\hline \multicolumn{10}{|c|}{ Percepción de la seguridad en el hogar y en la comunidad desde el comienzo de la pandemia en comparación con antes \% (95\% Cl) } \\
\hline $\begin{array}{l}\text { Se siente menos segura/o en su hogar desde el } \\
\text { comienzo de la pandemia }\end{array}$ & $\begin{array}{l}9.7 \\
(8.6,11.0)\end{array}$ & $\begin{array}{c}5.5^{*} \\
(4.7,6.3)\end{array}$ & $\begin{array}{l}7.1 \\
(6.7,7.6)\end{array}$ & $\begin{array}{c}12.3 \\
(10.1,14.9)\end{array}$ & $\begin{array}{c}8.4^{*} \\
(6.7,10.5)\end{array}$ & $\begin{array}{c}9.8 \\
(8.9,10.8)\end{array}$ & $\begin{array}{c}11.5 \\
(9.9,13.3)\end{array}$ & $\begin{array}{c}7.6^{*} \\
(6.3,9.2)\end{array}$ & $\begin{array}{l}9.0 \\
(8.3,9.7)\end{array}$ \\
\hline $\begin{array}{l}\text { Se siente menos segura/o en su vecindario desde } \\
\text { el comienzo de la pandemia }\end{array}$ & $\begin{array}{l}22.6 \\
(20.9,24.4)\end{array}$ & $\begin{array}{c}15.1^{*} \\
(14.0,16.3)\end{array}$ & $\begin{array}{l}19.2 \\
(18.5,19.9)\end{array}$ & $\begin{array}{c}32.1 \\
(29.1,35.3)\end{array}$ & $\begin{array}{c}21.3 * \\
(18.8,24.11\end{array}$ & $\begin{array}{c}26.3 \\
(25.0,27.7)\end{array}$ & $\begin{array}{c}29.3 \\
(27.1,31.6)\end{array}$ & ${ }_{(17.8,21.7)}^{19.7 *}$ & $\begin{array}{l}24.1 \\
(23.2,25.1)\end{array}$ \\
\hline $\begin{array}{l}\text { Percibe un aumento de la delincuencia en su } \\
\text { vecindario desde el inicio de la pandemia }\end{array}$ & $\begin{array}{c}22.0 \\
(20.1,24.0)\end{array}$ & $\begin{array}{c}13.8^{*} \\
(12.4,15.4)\end{array}$ & $\begin{array}{l}17.5 \\
(16.7,18.3)\end{array}$ & $\begin{array}{c}30.2 \\
(26.9,33.8)\end{array}$ & $\begin{array}{c}22.5^{*} \\
(19.5,25.8)\end{array}$ & $\begin{array}{l}25.7 \\
(24.2,27.3)\end{array}$ & $\begin{array}{c}28.1 \\
(25.6,30.8)\end{array}$ & $\begin{array}{c}20.4^{*} \\
(18.1,23.0)\end{array}$ & $\begin{array}{c}23.5 \\
(22.3,24.7)\end{array}$ \\
\hline $\begin{array}{l}\text { Percibe un aumento de la violencia en su } \\
\text { vecindario desde el inicio de la pandemia }\end{array}$ & $\begin{array}{c}16.9 \\
(15.2,18.7)\end{array}$ & $\begin{array}{l}9.9 * \\
(8.7,11.1)\end{array}$ & $\begin{array}{l}13.4 \\
(12.7,14.1)\end{array}$ & $\begin{array}{c}24.9 \\
(21.8,28.2)\end{array}$ & $\begin{array}{c}19.8^{*} \\
(16.9,23.0)\end{array}$ & $\begin{array}{l}22.0 \\
(20.6,23.6)\end{array}$ & $\begin{array}{c}22.8 \\
(20.5,25.3)\end{array}$ & $\begin{array}{c}17.3^{*} \\
(15.1,19.7)\end{array}$ & $\begin{array}{l}19.7 \\
(18.6,20.8)\end{array}$ \\
\hline
\end{tabular}




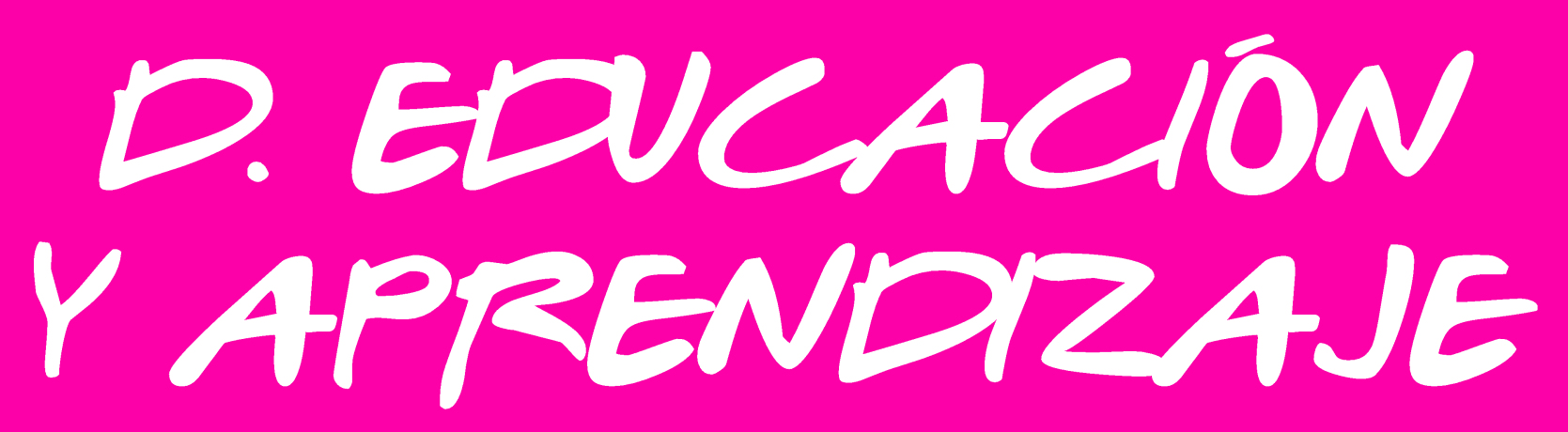


TABLE 9 Impacto de las medidas de mitigación de COVID-19 en las experiencias de educación y aprendizaje, por edad y género

\begin{tabular}{|c|c|c|c|c|c|c|c|c|c|c|c|c|c|c|c|}
\hline \multirow{2}{*}{ Variable } & \multicolumn{5}{|c|}{ 15-17 años } & \multicolumn{5}{|c|}{ 18-24 años } & \multicolumn{5}{|c|}{ Total } \\
\hline & Mujeres & Hombres & Binarias & No binarias & Total & Mujeres & Hombres & Binarias & No binarias & Total & Mujeres & Hombres & Binarias & No binarias & Total \\
\hline \multicolumn{16}{|c|}{ Deserción escolar y asistencia a clases $\%(95 \% \mathrm{Cl})$} \\
\hline & $\mathrm{n}=77$ & $n=76$ & $\mathrm{n}=153$ & $\mathrm{n}=2$ & $\mathrm{n}=155$ & $n=866$ & $\mathrm{n}=445$ & $\mathrm{n}=1,311$ & $n=16$ & $\mathrm{n}=1,327$ & $\mathrm{n}=943$ & $\mathrm{n}=521$ & $\mathrm{n}=1,464$ & $\mathrm{n}=18$ & $\mathrm{~N}=1,482$ \\
\hline $\begin{array}{l}\text { Dejól la escuela } \\
\text { especificamente debido a } \\
\text { la apandemia de CovID-19 } 19 \\
\text { (entre las personas que no } \\
\text { estân inscritas en la } \\
\text { escuela) }\end{array}$ & $\begin{array}{c}34.1 \\
(15.7,52.6)\end{array}$ & $\begin{array}{c}39.4 \\
(21.1,57.7)\end{array}$ & $\begin{array}{c}37.1 \\
(23.9,50.4)\end{array}$ & $\begin{array}{c}98.4^{\dagger} \\
(94.0,102.8)\end{array}$ & $\begin{array}{c}42.3 \\
(26.6,58.1)\end{array}$ & $9.1(6.4,11.7)$ & $\begin{array}{c}9.7 \\
(6.7,12.7)\end{array}$ & $\begin{array}{c}9.3 \\
(7.3,11.3)\end{array}$ & $\begin{array}{c}3.4 \\
(-2.4,9.1)\end{array}$ & $\begin{array}{c}9.2 \\
(7.3,11.2)\end{array}$ & $\begin{array}{c}9.2 \\
(6.6,11.8)\end{array}$ & $\begin{array}{c}10.0 \\
(7.0,13.0)\end{array}$ & $\begin{array}{c}9.6 \\
(7.6,11.5)\end{array}$ & $\begin{array}{c}11.3 \\
(-5.2,27.7)\end{array}$ & $\begin{array}{c}9.5 \\
(7.5,11.4)\end{array}$ \\
\hline & $\mathrm{n}=26,354$ & $\mathrm{n}=15,926$ & $\mathrm{n}=\mathbf{4 2 , 2 8 0}$ & $\mathrm{n}=483$ & $\mathrm{n}=43,479$ & $\mathrm{n}=5,360$ & $n=3,536$ & $\mathrm{n}=8,896$ & $\mathrm{n}=\mathbf{1 2 0}$ & $n=9,120$ & $\mathrm{n}=31,714$ & $\mathrm{n}=\mathbf{1 9 , 4 6 2}$ & $\mathrm{n}=51,176$ & $n=603$ & $\mathrm{~N}=52,599$ \\
\hline $\begin{array}{l}\text { Han asistido al menos al } \\
70 \% \text { de sus clases desde } \\
\text { que se cerraron las } \\
\text { instalaciones do su escuela } \\
\text { (entre las personas } \\
\text { actualmente inscritas en la } \\
\text { escuela) }\end{array}$ & $\begin{array}{c}92.8 \\
(92.2,93.4)\end{array}$ & $\begin{array}{c}90.8^{*} \\
(89.9,91.7)\end{array}$ & $\begin{array}{c}91.8 \\
(91.3,92.4)\end{array}$ & $\begin{array}{c}91.8 \\
(88.3,95.2)\end{array}$ & $\begin{array}{c}91.8 \\
(91.2,92.3)\end{array}$ & $\begin{array}{c}91.5 \\
(90.3,92.7)\end{array}$ & $\begin{array}{c}88.4 * \\
(86.7,90.1)\end{array}$ & $\begin{array}{c}90.0 \\
(89.0,91.0)\end{array}$ & $\begin{array}{c}78.1 \\
(64.4,91.9)\end{array}$ & $\begin{array}{c}89.8 \\
(88.7,90.8)\end{array}$ & $\begin{array}{c}92.0 \\
(91.2,92.8)\end{array}$ & $\begin{array}{c}89.3^{*} \\
(88.2,90.4)\end{array}$ & $\begin{array}{c}90.7 \\
(90.0,91.4)\end{array}$ & $\begin{array}{l}82.4 \\
(72.7,92.0)\end{array}$ & $\begin{array}{c}90.5 \\
(89.8,91.2)\end{array}$ \\
\hline \multicolumn{16}{|c|}{ Participantes que informan recibir clases a través de cada una de las siguientes modalidades (entre las personas actualmente inscritas en la escuela) \% $(95 \% \mathrm{Cl})$} \\
\hline & $\mathrm{n}=26,354$ & $\mathrm{n}=\mathbf{1 5 , 9 2 6}$ & $\mathrm{n}=\mathbf{4 2 , 2 8 0}$ & $\mathrm{n}=\mathbf{4 8 3}$ & $\mathrm{n}=43,479$ & $\mathrm{n}=5,360$ & $\mathrm{n}=\mathbf{3 , 5 3 6}$ & $\mathrm{n}=8,896$ & $\mathrm{n}=\mathbf{1 2 0}$ & $\mathrm{n}=9,120$ & $\mathrm{n}=31,714$ & $\mathrm{n}=\mathbf{1 9 , 4 6 2}$ & $\mathrm{n}=51,176$ & $\mathrm{n}=603$ & $\mathrm{~N}=\mathbf{5 2 , 5 9 9}$ \\
\hline En línea & $\begin{array}{c}99.2 \\
(99.0,99.4)\end{array}$ & $\begin{array}{c}98.8 \\
(98.4,99.2)\end{array}$ & $\begin{array}{c}99.0 \\
(98.7,99.2)\end{array}$ & $99.2(98.6,99.8)$ & $\begin{array}{c}99.0 \\
(98.8,99.2)\end{array}$ & $98.3(97.7,98.9)$ & $\begin{array}{c}98.5 \\
(97.8,99.3)\end{array}$ & $\begin{array}{c}98.4 \\
(97.9,98.9)\end{array}$ & $\begin{array}{c}100^{\dagger} \\
(100.0,100.0)\end{array}$ & $\begin{array}{c}98.4 \\
(98.0,98.9)\end{array}$ & $\begin{array}{c}98.6 \\
(98.2,99.0)\end{array}$ & $98.6(98.1,99.1)$ & $\begin{array}{c}98.6 \\
(98.3,98.9)\end{array}$ & $\begin{array}{c}99.7^{\dagger} \\
(99.5,100)\end{array}$ & $\begin{array}{c}98.6 \\
(98.3,98.9)\end{array}$ \\
\hline Televisión & $\begin{array}{c}2.7 \\
(2.3,3.1)\end{array}$ & $\begin{array}{c}2.7 \\
(2.1,3.3)\end{array}$ & $2.7(2.4,3.1)$ & $\begin{array}{c}2.8 \\
(0.5,5.1)\end{array}$ & $2.7(2.3,3.1)$ & $0.3(0.2,0.5)$ & $\begin{array}{c}0.8 \\
(0.3,1.3)\end{array}$ & $\begin{array}{c}0.6 \\
(0.3,0.8)\end{array}$ & $\begin{array}{c}0.0^{+} \\
(0.0,0.0)\end{array}$ & $\begin{array}{c}0.6 \\
(0.3,0.8)\end{array}$ & $\begin{array}{c}1.2 \\
(1.0,1.4)\end{array}$ & $\begin{array}{c}1.5 \\
(1.1,1.9)\end{array}$ & $\begin{array}{c}1.4 \\
(1.2,1.6)\end{array}$ & $\begin{array}{c}0.9 \\
(0.1,1.6)\end{array}$ & $\begin{array}{c}1.4 \\
(1.2,1.6)\end{array}$ \\
\hline Radio & $\begin{array}{c}0.1 \\
(0.0,0.1)\end{array}$ & $0.2^{\star}(0.1,0.3)$ & $0.1(0.1,0.2)$ & $\begin{array}{c}0.0 \\
(0.0,0.0)\end{array}$ & $0.1(0.1,0.2)$ & $\begin{array}{c}0.1 \\
(0.0,0.2)\end{array}$ & $\begin{array}{c}0.6 \\
(0.1,1.1)\end{array}$ & $\begin{array}{c}0.3 \\
(0.1,0.6)\end{array}$ & $\begin{array}{c}0.0 \\
(0.0,0.0)\end{array}$ & $\begin{array}{c}0.3 \\
(0.1,0.6)\end{array}$ & $\begin{array}{c}0.1 \\
(0.0,0.1)\end{array}$ & $\begin{array}{c}0.4^{*} \\
(0.1,0.7)\end{array}$ & $\begin{array}{c}0.3 \\
(0.1,0.4)\end{array}$ & $\begin{array}{c}0.0 \\
(0.0,0.0)\end{array}$ & $\begin{array}{c}0.2 \\
(0.1,0.4)\end{array}$ \\
\hline \multicolumn{16}{|c|}{ Percepciones de las personas participantes sobre el acceso y el aprendizaje (entre las personas actualmente inscritas en la escuela) $\%(95 \% \mathrm{CI})$} \\
\hline & $\mathrm{n}=26,354$ & $\mathrm{n}=15,926$ & $\mathrm{n}=\mathbf{4 2 , 2 8 0}$ & $\mathrm{n}=483$ & $\mathrm{n}=43,479$ & $n=5,360$ & $n=3,536$ & $\mathrm{n}=8,896$ & $\mathrm{n}=120$ & $\mathrm{n}=9,120$ & $\mathrm{n}=31,714$ & $\mathrm{n}=19,462$ & $\mathrm{n}=51,176$ & $\mathrm{n}=603$ & $\mathrm{~N}=52,599$ \\
\hline $\begin{array}{l}\text { Desde que se cerraron las } \\
\text { instalaciones escolares, ha } \\
\text { tenido los medios } \\
\text { necesarios para acceder a } \\
\text { las tareas y las asignaturas }\end{array}$ & $\begin{array}{c}60.3 \\
(59.3,61.4)\end{array}$ & $\begin{array}{c}59.8 \\
(58.3,61.2)\end{array}$ & $\begin{array}{c}60.1 \\
(59.2,61.0)\end{array}$ & $62.7(55.8,69.5)$ & $\begin{array}{c}60.0 \\
(59.1,60.9)\end{array}$ & $59.1(57.0,61.3)$ & $\begin{array}{c}56.9 \\
(54.3,59.5)\end{array}$ & $\begin{array}{c}58.1 \\
(56.4,59.7)\end{array}$ & $\begin{array}{c}77.3^{\dagger} \\
(65.9,88.7)\end{array}$ & $\begin{array}{c}58.2 \\
(56.5,59.8)\end{array}$ & $\begin{array}{c}59.6 \\
(58.1,61.0)\end{array}$ & $\begin{array}{c}58.0 \\
(56.3,59.7)\end{array}$ & $\begin{array}{c}58.8 \\
(57.7,59.9)\end{array}$ & $\begin{array}{c}72.6^{\dagger} \\
(64.3,80.9)\end{array}$ & $\begin{array}{c}58.9 \\
(57.8,59.9)\end{array}$ \\
\hline $\begin{array}{l}\text { Desde que se cerraron las } \\
\text { instalaciones escolares, ha } \\
\text { tenido los medios } \\
\text { necesarios para completar } \\
\text { y entregar las tareas y las } \\
\text { asignaciones }\end{array}$ & $\begin{array}{c}65.0 \\
(64.0,66.1)\end{array}$ & $\begin{array}{c}64.8 \\
(63.4,66.3)\end{array}$ & $\begin{array}{c}64.9 \\
(64.1,65.8)\end{array}$ & $\begin{array}{c}66.0 \\
(59.3,72.7)\end{array}$ & $\begin{array}{c}64.9 \\
(64.0,65.7)\end{array}$ & $\begin{array}{c}62.3 \\
(60.2,64.5)\end{array}$ & $\begin{array}{c}60.0 \\
(57.5,62.6)\end{array}$ & $\begin{array}{c}61.2 \\
(59.6,62.9)\end{array}$ & $\begin{array}{c}81.5^{\dagger} \\
(71.1,91.9)\end{array}$ & $\begin{array}{c}61.5 \\
(59.8,63.1)\end{array}$ & $\begin{array}{c}63.3 \\
(61.9,64.7)\end{array}$ & $\begin{array}{c}61.9 \\
(60.2,63.5)\end{array}$ & $\begin{array}{c}62.6 \\
(61.5,63.7)\end{array}$ & $\begin{array}{c}76.5^{\dagger} \\
(68.9,84.2)\end{array}$ & $\begin{array}{c}62.7 \\
(61.7,63.8)\end{array}$ \\
\hline
\end{tabular}




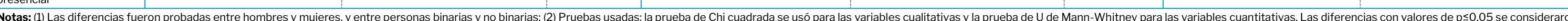

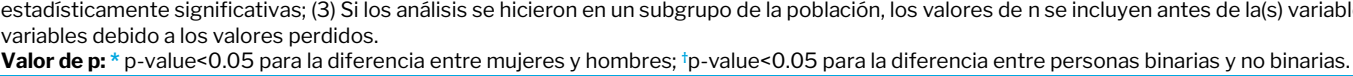

TABLA 10 Impacto de las medidas de mitigación de COVID-19 en las experiencias de educación y aprendizaje, por grupo de edad y origen étnico

\begin{tabular}{|c|c|c|c|c|c|c|c|c|c|}
\hline \multirow{2}{*}{ Variable } & \multicolumn{3}{|c|}{ 15-17 años } & \multicolumn{3}{|c|}{ 18-24 años } & \multicolumn{3}{|c|}{ Total } \\
\hline & $\begin{array}{l}\text { Participantes indigenas y/o } \\
\text { afrodescendientes }\end{array}$ & $\begin{array}{l}\text { Participantes no indigenas } \\
\text { y/o afrodescendientes }\end{array}$ & Total & $\begin{array}{l}\text { Participantes indigenas } y / o \\
\text { afrodescendientes }\end{array}$ & $\begin{array}{l}\text { Participantes no } \\
\text { indigenasy } / / \\
\text { afrodescendientes }\end{array}$ & Total & $\begin{array}{l}\text { Participantes indigenas } \\
\text { y/o afrodescendientes }\end{array}$ & $\begin{array}{l}\text { Participantes no } \\
\text { indigenas y/o } \\
\text { afrodescendientes }\end{array}$ & Total \\
\hline \multicolumn{10}{|c|}{ Deserción escolar y asistencia a clases \% $(95 \% \mathrm{Cl})$} \\
\hline & $\mathrm{n}=55$ & $\mathrm{n}=102$ & $\mathrm{n}=157$ & $\mathrm{n}=\mathbf{3 8 3}$ & $\mathrm{n}=954$ & $\mathrm{n}=1, \mathbf{3 3 7}$ & $\mathrm{n}=438$ & $\mathrm{n}=1,056$ & $\mathrm{~N}=1,494$ \\
\hline $\begin{array}{l}\text { Dejó la escuela especíificamente debido a la } \\
\text { pandemia de COVID-19 (entre las personas que } \\
\text { no estân inscritas en la escuela) }\end{array}$ & $\begin{array}{c}13.7 \\
(4.4,23.0)\end{array}$ & $\begin{array}{c}60.7 * \\
(41.5,79.8)\end{array}$ & $42.3(26.6,58.1)$ & $\begin{array}{c}9.5 \\
(5.7,13.2)\end{array}$ & $\begin{array}{c}9.1 \\
(6.8,11.4)\end{array}$ & $\begin{array}{c}9.2 \\
(7.3,11.2)\end{array}$ & $\begin{array}{c}9.5 \\
(5.8,13.2)\end{array}$ & $\begin{array}{c}9.5 \\
(7.2,11.8)\end{array}$ & $\begin{array}{l}9.5 \\
(7.5,11.4)\end{array}$ \\
\hline & $\mathrm{n}=12,373$ & $\mathrm{n}=31,106$ & $\mathrm{n}=43,479$ & $\mathrm{n}=2,447$ & $\mathrm{n}=6,673$ & $\mathrm{n}=9,120$ & $n=14,820$ & $\mathrm{n}=\mathbf{3 7 , 7 7 9}$ & $\mathrm{N}=52,599$ \\
\hline $\begin{array}{l}\text { Han asistido al menos al } 70 \% \text { de sus clases } \\
\text { desde que se ecrraron las instalaciones de } \\
\text { escuela (entre las personas actualmente } \\
\text { inscritas en la escuela) }\end{array}$ & $\begin{array}{c}90.3 \\
(89.2,91.4)\end{array}$ & $\begin{array}{c}92.5^{*} \\
(91.9,93.1)\end{array}$ & $\begin{array}{c}91.8 \\
(91.2,92.3)\end{array}$ & $\begin{array}{c}86.4 \\
(84.1,88.6)\end{array}$ & $91.1^{*}(89.9,92.2)$ & $\begin{array}{c}89.8 \\
(88.7,90.8)\end{array}$ & $88.0(86.6,89.4)$ & $\begin{array}{c}91.6^{*} \\
(90.8,92.3)\end{array}$ & $\begin{array}{c}90.5 \\
(89.8,91.2)\end{array}$ \\
\hline \multicolumn{10}{|c|}{ Participantes que informan recibir clases a través de cada una de las siguientes modalidades (entre las personas actualmente inscritas en la escuela) \% (95\% Cl) } \\
\hline & $\mathrm{n}=12,373$ & $\mathrm{n}=31,106$ & $\mathrm{n}=43,479$ & $\mathrm{n}=\mathbf{2 , 4 4 7}$ & $\mathrm{n}=6,673$ & $\mathrm{n}=9,120$ & $n=14,820$ & $\mathrm{n}=37,779$ & $\mathrm{~N}=52,599$ \\
\hline En linea & $\begin{array}{c}98.4 \\
(97.8,99.0)\end{array}$ & $\begin{array}{c}99.2^{\star} \\
(99.1,99.4)\end{array}$ & $99.0(98.8,99.2)$ & $\begin{array}{l}97.7 \\
(96.5,98.8)\end{array}$ & $\begin{array}{c}98.7 \\
(98.2,99.2)\end{array}$ & $98.4(98.0,98.9)$ & $\begin{array}{c}98.0 \\
(97.3,98.7)\end{array}$ & $\begin{array}{c}98.9^{*} \\
(98.6,99.2)\end{array}$ & $\begin{array}{c}98.6 \\
(98.3,98.9)\end{array}$ \\
\hline Televisión & $\begin{array}{c}3.1 \\
(2.3,3.8)\end{array}$ & $\begin{array}{c}2.5 \\
(2.1,2.9)\end{array}$ & $2.7(2.3,3.1)$ & $\begin{array}{c}0.9 \\
(0.1,1.6)\end{array}$ & $\begin{array}{c}0.4 \\
(0.2,0.6)\end{array}$ & $\begin{array}{c}0.6 \\
(0.3,0.8)\end{array}$ & $\begin{array}{c}1.8 \\
(1.2,2,3)\end{array}$ & $\begin{array}{c}1.2 \\
(1.0,1.4)\end{array}$ & $\begin{array}{l}1.4 \\
(1.2,1.6)\end{array}$ \\
\hline Radio & $\begin{array}{c}0.1 \\
(0.0,0.2)\end{array}$ & $0.1(0.0,0.2)$ & $0.1(0.1,0.2)$ & $\begin{array}{c}0.8 \\
(0.0,1.6)\end{array}$ & $\begin{array}{c}0.1 \\
(0.0,0.3)\end{array}$ & $\begin{array}{c}0.3 \\
(0.1,0.6)\end{array}$ & $\begin{array}{c}0.5 \\
(0.1,1.0)\end{array}$ & $0.1(0.0,0.2)$ & $\begin{array}{c}0.2 \\
(0.1,0.4)\end{array}$ \\
\hline \multicolumn{10}{|c|}{ Percepciones de las personas participantes sobre el acceso y el aprendizaje (entre las personas actualmente inscritas en la escuela) $\%$ (95\% Cl) } \\
\hline & $\mathrm{n}=12,373$ & $\mathrm{n}=31,106$ & $\mathrm{n}=43,479$ & $\mathrm{n}=2,447$ & $\mathrm{n}=6,673$ & $\mathrm{n}=9,120$ & $\mathrm{n}={ }_{14,820}$ & $\mathrm{n}=37,779$ & $\mathrm{~N}=52,599$ \\
\hline $\begin{array}{l}\text { Desde que se cerraron las instalaciones } \\
\text { escolares, ha tenido los medios necesarios para } \\
\text { acceder a las tareas y las asignaturas }\end{array}$ & $\begin{array}{c}53.3 \\
(51.6,55.0)\end{array}$ & $63.1^{*}(62.1,64.1)$ & $60.0(59.1,60.9)$ & $\begin{array}{c}46.0 \\
(42.9,49.1)\end{array}$ & $\begin{array}{c}62.9^{*} \\
(61.0,64.8)\end{array}$ & $58.2(56.5,59.8)$ & $\begin{array}{c}48.9 \\
(47.0,50.9)\end{array}$ & $63.0^{*}(61.7,64.2)$ & $\begin{array}{c}58.9 \\
(57.8,59.9)\end{array}$ \\
\hline
\end{tabular}




\begin{tabular}{|c|c|c|c|c|c|c|c|c|c|}
\hline $\begin{array}{l}\text { Desde que se cerraron las instalaciones } \\
\text { escolares, ha tenido los medios necesarios para } \\
\text { compleary entregar las tareas y las } \\
\text { asignaciones }\end{array}$ & $\begin{array}{c}58.8 \\
(57.1,60.5)\end{array}$ & $\begin{array}{c}67.7^{*} \\
(66.7,68.7)\end{array}$ & $\begin{array}{c}64.9 \\
(64.0,65.7)\end{array}$ & $\begin{array}{c}51.3 \\
(48.2,54.4)\end{array}$ & $65.4^{*}(63.5,67.3)$ & $\begin{array}{c}61.5 \\
(59.8,63.1)\end{array}$ & $54.3(52.3,56.3)$ & $\begin{array}{c}66.2^{\star} \\
(65.0,67.5)\end{array}$ & $\begin{array}{c}62.7 \\
(61.7,63.8)\end{array}$ \\
\hline $\begin{array}{l}\text { Desde que se cerraron las instalaciones } \\
\text { escolares, percibe que aprende más que cuando } \\
\text { la escuela era presencial }\end{array}$ & $13.8(12.5,15.0)$ & $\begin{array}{c}11.4^{*} \\
(10.7,12.1)\end{array}$ & $\begin{array}{c}11.1 \\
(11.5,12.8)\end{array}$ & $\begin{array}{c}14.0 \\
(11.9,16.1)\end{array}$ & $\begin{array}{c}12.2 \\
(10.8,13.5)\end{array}$ & $12.7(11.5,13.8)$ & $\begin{array}{c}13.9 \\
(12.5,15.3)\end{array}$ & $\begin{array}{c}11.9^{*} \\
(11.0,012.8)\end{array}$ & $\begin{array}{c}12.5 \\
(11.7,13.2)\end{array}$ \\
\hline
\end{tabular}

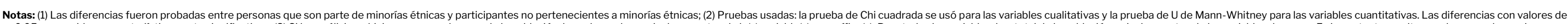

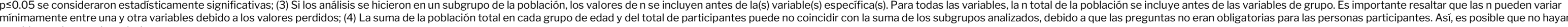
Valorde p: * $p^{2}$ sulurigen étic

TABLA 11 Impacto de las medidas de mitigación de COVID-19 en las experiencias de educación y aprendizaje, por grupos de edad y NSE

\begin{tabular}{|c|c|c|c|c|c|c|c|c|c|}
\hline \multirow{2}{*}{ Variable } & \multicolumn{3}{|c|}{ 15-17 años } & \multicolumn{3}{|c|}{ 18-24 años } & \multicolumn{3}{|c|}{ Total } \\
\hline & $\begin{array}{c}\text { Hogares de ingresos más } \\
\text { bajos (primer quintil) }\end{array}$ & $\begin{array}{c}\text { Hogares de ingresos más } \\
\text { altos (quinto quintil) }\end{array}$ & Total & $\begin{array}{c}\text { Hogares de ingresos más } \\
\text { bajos (primer quintil) }\end{array}$ & $\begin{array}{l}\text { Hogares de ingresos más } \\
\text { altos (quinto quintil) }\end{array}$ & Total & $\begin{array}{c}\text { Hogares de ingresos más } \\
\text { bajos (primer quintil) }\end{array}$ & $\begin{array}{l}\text { Hogares de ingresos más } \\
\text { altos (quinto quintil) }\end{array}$ & Total \\
\hline \multicolumn{10}{|c|}{ Deserción escolar y asistencia a clases \% (95\% Cl) } \\
\hline & $\mathrm{n}=47$ & $\mathrm{n}=19$ & $\mathrm{n}=157$ & $\mathrm{n}=319$ & $\mathrm{n}=\mathbf{2 9 0}$ & $\mathrm{n}=1,337$ & $\mathrm{n}=366$ & $\mathrm{n}=309$ & $\mathrm{~N}=1,494$ \\
\hline $\begin{array}{l}\text { Dejól la escuela especificamente debido ala } \\
\text { pandemia dec coviD-19 (entre las personas que no } \\
\text { estän inscritas en la escuela) }\end{array}$ & $12.8(2.6,23.1)$ & $\begin{array}{c}88.1^{\star} \\
(73.0,103.3)\end{array}$ & $42.3(26.6,58.1)$ & $10.2(5.7,14.7)$ & $\begin{array}{c}5.5 \\
(2.3,8.8)\end{array}$ & $\begin{array}{c}9.2 \\
(7.3,11.2)\end{array}$ & $\begin{array}{c}10.2 \\
(5.8,14.7)\end{array}$ & $\begin{array}{c}6.0 \\
(2.7,9.3)\end{array}$ & $\begin{array}{c}9.5 \\
(7.5,11.4)\end{array}$ \\
\hline & $\mathrm{n}=8,354$ & $\mathrm{n}=8,613$ & $\mathrm{n}=43,453$ & $\mathrm{n}=\mathbf{1 , 8 5 6}$ & $\mathrm{n}=2,006$ & $\mathrm{n}=9,116$ & $n=10,210$ & $\mathrm{n}=10,619$ & $\mathrm{~N}=52,569$ \\
\hline $\begin{array}{l}\text { Han asistido al menos al } 70 \% \text { de sus clases desde } \\
\text { que se cerraron las instalaciones de su escuuela } \\
\text { (entre las personas actualmente inscritas en la } \\
\text { escuela) }\end{array}$ & $\begin{array}{c}86.9 \\
(85.2,88.5)\end{array}$ & $\begin{array}{c}94.8^{*} \\
(94.0,95.6)\end{array}$ & $\begin{array}{c}91.8 \\
(91.2,92.3)\end{array}$ & $\begin{array}{c}82.3 \\
(79.3,85.2)\end{array}$ & $\begin{array}{c}93.1^{*} \\
(91.2,95.0)\end{array}$ & $\begin{array}{c}89.8 \\
(88.7,90.8)\end{array}$ & $\begin{array}{c}84.0 \\
(82.0,06.0)\end{array}$ & $\begin{array}{c}93.6^{*} \\
(92.3,94.9)\end{array}$ & $\begin{array}{c}90.5 \\
(89.8,91.2)\end{array}$ \\
\hline \multicolumn{10}{|c|}{ Participantes que informan recibir clases a través de cada una de las siguientes modalidades (entre las personas actualmente inscritas en la escuela) \% (95\% Cl) } \\
\hline & $\mathrm{n}=8,354$ & $\mathrm{n}=\mathbf{8 , 6 1 3}$ & $\mathrm{n}=43,453$ & $\mathrm{n}=\mathbf{1 , 8 5 6}$ & $\mathrm{n}=2,006$ & $\mathrm{n}=9,116$ & $n=10,210$ & $\mathrm{n}=10,619$ & $\mathrm{~N}=52,569$ \\
\hline En línea & $\begin{array}{c}97.7 \\
(96.9,98.5)\end{array}$ & $\begin{array}{c}99.6^{*} \\
(99.4,99.9)\end{array}$ & $99.0(98.8,99.2)$ & $\begin{array}{c}97.9 \\
(96.8,99.0)\end{array}$ & $\begin{array}{c}98.8 \\
(98.1,99.5)\end{array}$ & $98.4(98.0,98.9)$ & $\begin{array}{c}97.8 \\
(97.1,98.6)\end{array}$ & $99.1^{*}(98.6,99.6)$ & $\begin{array}{c}98.6 \\
(98.3,98.9)\end{array}$ \\
\hline Televisión & $\begin{array}{c}2.9 \\
(2.0,3.8)\end{array}$ & $\begin{array}{c}2.8 \\
(2.2,3.4)\end{array}$ & $2.7(2.3,3.1)$ & $\begin{array}{c}1.3 \\
(0.2,2.3)\end{array}$ & $\begin{array}{c}0.3 \\
(0.1,0.5)\end{array}$ & $\begin{array}{c}0.6 \\
(0.3,0.8)\end{array}$ & $\begin{array}{c}1.9 \\
(1.1,2.6)\end{array}$ & $\begin{array}{c}1.1 \\
(0.9,1.4)\end{array}$ & $\begin{array}{l}1.4 \\
(1.2,1.6)\end{array}$ \\
\hline
\end{tabular}




\begin{tabular}{|c|c|c|c|c|c|c|c|c|c|}
\hline Radio & $\begin{array}{c}0.3 \\
(0.1,0.5)\end{array}$ & $\begin{array}{c}0.2 \\
(0.0,0.3)\end{array}$ & $0.1(0.1,0.2)$ & $\begin{array}{c}1.3 \\
(0.0,2.5)\end{array}$ & $\begin{array}{c}0.0^{*} \\
(0.0,0.0)\end{array}$ & $\begin{array}{c}0.3 \\
(0.1,0.6)\end{array}$ & $\begin{array}{c}0.9 \\
(0.1,1.7)\end{array}$ & $\begin{array}{c}0.1^{*} \\
(0.0,0.1)\end{array}$ & $\begin{array}{c}0.2 \\
(0.1,0.4)\end{array}$ \\
\hline Materiales para llevar a casa & $\begin{array}{c}4.1 \\
(3.2,5.0)\end{array}$ & $\begin{array}{c}5.0 \\
(4.2,5.7)\end{array}$ & $\begin{array}{c}4.6 \\
(4.2,5.0)\end{array}$ & $\begin{array}{c}3.3 \\
(1.7,4.9)\end{array}$ & $\begin{array}{c}1.3^{*} \\
(0.5,2,2.2)\end{array}$ & $\begin{array}{c}2.0 \\
(1.5,2.5)\end{array}$ & $\begin{array}{c}3.6 \\
(2.5,4.6)\end{array}$ & $\begin{array}{c}2.5 \\
(1.9,3,3.1)\end{array}$ & $\begin{array}{c}3.0 \\
(2.6,3.3)\end{array}$ \\
\hline \multicolumn{10}{|c|}{ Percepciones de las personas participantes sobre el acceso y el aprendizaje (entre las personas actualmente inscritas en la escuela) \% (95\% Cl) } \\
\hline & $\mathrm{n}=8,354$ & $\mathrm{n}=8,613$ & $\mathrm{n}=43,453$ & $\mathrm{n}=1,856$ & $\mathrm{n}=2,006$ & $\mathrm{n}=9,116$ & $n=10,210$ & $\mathrm{n}=10,619$ & $\mathrm{~N}=52,569$ \\
\hline $\begin{array}{l}\text { Desde que se cerraron las instalaciones escolares, } \\
\text { hat enindo os mestios necesarios para acceder a las } \\
\text { tareas y las asignaturas }\end{array}$ & $\begin{array}{c}35.8 \\
(33.9,37.7)\end{array}$ & $\begin{array}{c}77.4^{*} \\
(75.6,79.1)\end{array}$ & $60.0(59.1,60.9)$ & $\begin{array}{c}27.8 \\
(24.6,31.0)\end{array}$ & $\begin{array}{c}79.8^{*} \\
(77.0,02.7)\end{array}$ & $58.2(56.5,59.8)$ & $\begin{array}{c}30.8 \\
(28.6,32.9)\end{array}$ & $\begin{array}{c}79.0^{*} \\
(77.1,81.0)\end{array}$ & $\begin{array}{c}58.9 \\
(57.8,59.9)\end{array}$ \\
\hline $\begin{array}{l}\text { Desde que se cerraron las instalaciones escolares, } \\
\text { ha tenido los medios necesarios para completary } \\
\text { entregar las tareas y las asignaciones }\end{array}$ & $\begin{array}{c}40.3 \\
(38.4,42.3)\end{array}$ & $\begin{array}{c}81.0^{*} \\
(79.3,82.6)\end{array}$ & $\begin{array}{c}64.9 \\
(64.0,65.7)\end{array}$ & $\begin{array}{c}32.0 \\
(28.7,35.3)\end{array}$ & $81.1^{*}(78.3,83.8)$ & $\begin{array}{c}61.5 \\
(59.8,63.1)\end{array}$ & $\begin{array}{c}35.0 \\
(32.8,37.3)\end{array}$ & $\begin{array}{c}81.0^{*} \\
(79.1,83.0)\end{array}$ & $\begin{array}{c}62.7 \\
(61.7,63.8)\end{array}$ \\
\hline $\begin{array}{l}\text { Desde que se cerraron las instalaciones escolares, } \\
\text { percibe que aprende mâs que cuando la escuela } \\
\text { era presencial }\end{array}$ & $\begin{array}{c}13.9 \\
(122.3,15.4)\end{array}$ & $\begin{array}{c}11.6^{*} \\
(10.3,12.8)\end{array}$ & $\begin{array}{c}12.1 \\
(11.5,12.8)\end{array}$ & $\begin{array}{c}12.4 \\
(10.1,14.6)\end{array}$ & $\begin{array}{c}12.7 \\
(10.4,15.1)\end{array}$ & $12.7(11.5,13.8)$ & $\begin{array}{c}12.9 \\
(11.4,14.5)\end{array}$ & $\begin{array}{c}12.3 \\
(10.7,14.0)\end{array}$ & $\begin{array}{l}12.5 \\
(11.7,13.2)\end{array}$ \\
\hline
\end{tabular}

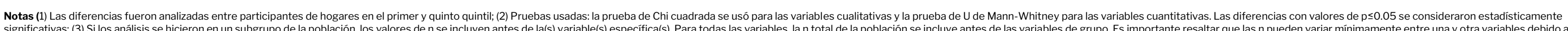
Valor de $\mathbf{p}$ : ${ }^{\star}$ - -value $<0.05$ 
E. EMPLEO E INGRESOS 
TABLA 12 Impacto de las medidas de mitigación de COVID-19 en el empleo y la salud financiera familiar, por grupo de edad y género

\begin{tabular}{|c|c|c|c|c|c|c|c|c|c|c|c|c|c|c|c|}
\hline \multirow{3}{*}{ Variable } & \multicolumn{5}{|c|}{ 15-17 años } & \multicolumn{5}{|c|}{ 18-24 años } & \multicolumn{5}{|c|}{ Total } \\
\hline & Mujeres & Hombres & Binarias & No binarias & Total & Mujeres & Hombres & Binarias & $\begin{array}{c}\text { No } \\
\text { binarias } \\
\end{array}$ & Total & Mujeres & Hombres & Binarias & No binarias & Total \\
\hline & $\mathrm{n}=27,112$ & $\mathrm{n}=16,548$ & $\mathrm{n}=43,660$ & $\mathrm{n}=501$ & $\mathrm{n}=\mathbf{4 4 , 9 5 5}$ & $\mathrm{n}=6,367$ & $\mathrm{n}=4,107$ & $\mathrm{n}=\mathbf{1 0 , 4 7 4}$ & $\mathrm{n}=137$ & $\mathrm{n}=10,737$ & $\mathrm{n}=33,479$ & $\mathrm{n}=20,655$ & $n=54,134$ & $\mathrm{n}=638$ & $\mathrm{~N}=55,692$ \\
\hline \multicolumn{16}{|c|}{ Situación laboral de la persona participante $\%(95 \%$ Cl) } \\
\hline $\begin{array}{l}\text { Actualmente tiene un trabajo } \\
\text { o negocio }\end{array}$ & $18.3(17.5,19.2)$ & $\begin{array}{c}26.7^{*} \\
(25.5,27.9)\end{array}$ & $\begin{array}{c}22.5 \\
(21.8,23.3)\end{array}$ & $\begin{array}{c}19.5 \\
(13.6,25.4)\end{array}$ & $22.5(21.8,23.3)$ & $\begin{array}{c}40.5 \\
(38.5,42.5) \\
\end{array}$ & $\begin{array}{c}48.3^{*} \\
(45.9,50.8) \\
\end{array}$ & $44.2(42.6,45.8)$ & $\begin{array}{c}40.7 \\
(26.2,55.1 \\
1\end{array}$ & $44.1(42.5,45.6)$ & $\begin{array}{c}34.0 \\
(32.5,35.4) \\
\end{array}$ & $\begin{array}{c}41.4^{*} \\
(39.7,43.2)\end{array}$ & $\begin{array}{c}37.6 \\
(36.4,38.7)\end{array}$ & $34.5(23.8,45.1)$ & $\begin{array}{c}37.5 \\
(36.3,38.6) \\
\end{array}$ \\
\hline \multicolumn{16}{|c|}{ Situación laboral de la persona participante $\%(95 \% \mathrm{Cl})$} \\
\hline & $\mathrm{n}=513$ & $\mathrm{n}=\mathbf{4 4 7}$ & $n=960$ & $\mathrm{n}=20$ & $n=999$ & $\mathrm{n}=291$ & $\mathrm{n}=232$ & $\mathrm{n}=523$ & $n=5$ & $\mathrm{n}=531$ & $n=804$ & $n=679$ & $\mathrm{n}=1,483$ & $\mathrm{n}=25$ & $\mathrm{n}=1,530$ \\
\hline $\begin{array}{l}\text { Personas con empleo que } \\
\text { citaron las medidas de } \\
\text { contingenciaia por COVID-19 } \\
\text { como razón principal para no } \\
\text { haber trabajajado al menos una } \\
\text { hora en la semana anterior a } \\
\text { la realización de la encuesta }\end{array}$ & $\begin{array}{l}47.0 \\
(38.5,55.5)\end{array}$ & $\begin{array}{c}4.9 \\
(37.5,52.2)\end{array}$ & $\begin{array}{c}45.7 \\
(40.1,51.3)\end{array}$ & $\begin{array}{c}6.5^{4} \\
(-1.1,14.2)\end{array}$ & $\begin{array}{l}43.4 \\
(37.6,49.3)\end{array}$ & $\begin{array}{c}39.2 \\
(31.2,47.1)\end{array}$ & $\begin{array}{c}52.4 * \\
(42.9,62.0)\end{array}$ & $\begin{array}{c}45.9 \\
(39.652 .2)\end{array}$ & $\begin{array}{c}31.4 \\
(- \\
12.4,75.2)\end{array}$ & $\begin{array}{c}45.9 \\
(39.6,52.1)\end{array}$ & $\begin{array}{c}40.2 \\
(33.2,47.2)\end{array}$ & $\begin{array}{c}51.0 * \\
(43.1,58.9)\end{array}$ & $\begin{array}{c}45.9 \\
(40.51 .31 .3)\end{array}$ & $\begin{array}{c}20.4+ \\
(-1.2,41.9)\end{array}$ & $\begin{array}{l}45.5 \\
(40.2,50.7)\end{array}$ \\
\hline \multicolumn{16}{|c|}{ Actividad de las personas participantes desempleadas $\%(95 \% \mathrm{Cl})$} \\
\hline & $\mathrm{n}=10,586$ & $\mathrm{n}=5,176$ & $\mathrm{n}=15,762$ & $\mathrm{n}=\mathbf{1 9 0}$ & $\mathrm{n}=\mathbf{1 6 , 1 5 8}$ & $\mathrm{n}=1,504$ & $\mathrm{n}=715$ & $\mathrm{n}=2,219$ & $n=34$ & $\mathrm{n}=\mathbf{2 , 2 7 2}$ & $n=12,090$ & $\mathrm{n}=5,891$ & $\mathrm{n}=17,981$ & $\mathrm{n}=224$ & $\mathrm{n}=\mathbf{1 8 , 4 3 0}$ \\
\hline $\begin{array}{l}\text { Personas desempleadas que } \\
\text { citaron las medidas de } \\
\text { contingencia por COVID-19 } \\
\text { como razón prinicial para no } \\
\text { haber buscado trabajo en la } \\
\text { semana anterior al a } \\
\text { realización de le a encuesta }\end{array}$ & $\begin{array}{l}35.4 \\
(33.8,37.0)\end{array}$ & $\begin{array}{c}42.9^{*} \\
(40.5,45.3)\end{array}$ & $\begin{array}{l}38.7 \\
(37.37,40.1)\end{array}$ & $\begin{array}{c}17.1^{\dagger} \\
(8.9,25.3)\end{array}$ & $38.4(37.0,39.8)$ & $\begin{array}{c}48.7 \\
(44.5,52.8)\end{array}$ & $\begin{array}{c}55.5 \\
(49.6,61.5)\end{array}$ & $\begin{array}{c}51.5 \\
(48.1,55.0)\end{array}$ & $\begin{array}{c}37.6 \\
(12.3,62.8 \\
)\end{array}$ & $\begin{array}{c}51.3 \\
(47.9,54.7)\end{array}$ & $\begin{array}{c}42.6 \\
(40.2,44.9)\end{array}$ & $\begin{array}{c}49.4^{*} \\
(46.2,52.7)\end{array}$ & $\begin{array}{c}45.5 \\
(43.6,47.4)\end{array}$ & $\begin{array}{c}28.1^{\dagger} \\
(13.4,42.8)\end{array}$ & $\begin{array}{c}45.2 \\
(43.3,47.1)\end{array}$ \\
\hline \multicolumn{16}{|c|}{ Condiciones de empleo e ingresos de los hogares $\%(95 \% \mathrm{Cl})$} \\
\hline & $\mathrm{n}=27,112$ & $\mathrm{n}=16,548$ & $\mathrm{n}=43,660$ & $n=501$ & $\mathrm{n}=44,955$ & $n=6,367$ & $\mathrm{n}=4,107$ & $\mathrm{n}=10,474$ & $\mathrm{n}=137$ & $\mathrm{n}=\mathbf{1 0 , 7 3 7}$ & $\mathrm{n}=33,479$ & $\mathrm{n}=20,655$ & $n=54,134$ & $\mathrm{n}=638$ & $\mathrm{~N}=55,692$ \\
\hline $\begin{array}{l}\text { Considera que ella/ellu utro } \\
\text { miembro de su hogar } \\
\text { perderí ingresos en los } \\
\text { proxximos meseses debido a la } \\
\text { pandemia }\end{array}$ & $\begin{array}{c}37.1 \\
(36.1,38.2)\end{array}$ & $\begin{array}{c}30.4^{*} \\
(29.1,31.8)\end{array}$ & $\begin{array}{c}33.7 \\
(32.9,34.6)\end{array}$ & $\begin{array}{c}34.4 \\
(26.7,42.2)\end{array}$ & $33.8(33.0,34.7)$ & $\begin{array}{c}43.4 \\
(41.4,45.4)\end{array}$ & $\begin{array}{c}38.8^{*} \\
(36.5,41.2)\end{array}$ & $41.2(39.7,42.8)$ & $\begin{array}{c}44.2 \\
(30.4,58 . \\
0)\end{array}$ & $41.3(39.8,42.8)$ & $\begin{array}{c}41.5 \\
(40.1,43.0)\end{array}$ & $\begin{array}{c}36.1^{*} \\
(34.5,37.8)\end{array}$ & $38.9(37.8,40.0)$ & $41.4(31.4,51.5)$ & $\begin{array}{l}39.0 \\
(37.9,40.1)\end{array}$ \\
\hline $\begin{array}{l}\text { Informa que al menos un } \\
\text { miembro del hogar perdió su } \\
\text { trabajo o cerró su negocio } \\
\text { debido a las medidas de } \\
\text { CoVID-19 en el mes anterior } \\
\text { a la realización de la encuesta }\end{array}$ & $\begin{array}{c}40.2 \\
(39.1,41.3)\end{array}$ & $\begin{array}{c}31.0 * \\
(29.6,32.3)\end{array}$ & $\begin{array}{c}35.5 \\
(34.6,36.4)\end{array}$ & $\begin{array}{c}35.4 \\
(28.0,42.9)\end{array}$ & $35.6(34.7,36.5)$ & $\begin{array}{c}45.0 \\
(42.9,47.0)\end{array}$ & $\begin{array}{c}36.8^{*} \\
(34.4,39.2)\end{array}$ & $41.0(39.5,42.6)$ & $\begin{array}{c}29.5 \\
(16.3,42.7 \\
)\end{array}$ & $40.9(39.3,42.4)$ & $\begin{array}{c}43.6 \\
(42.1,45.1)\end{array}$ & $\begin{array}{c}35.0^{*} \\
(33.3,36.7)\end{array}$ & $39.4(38.2,40.5)$ & $31.2(21.4,40.9)$ & $\begin{array}{c}39.3 \\
(38.2,40.4)\end{array}$ \\
\hline
\end{tabular}




\begin{tabular}{|c|c|c|c|c|c|c|c|c|c|c|c|c|c|c|c|}
\hline $\begin{array}{l}\text { Afirma que es algo probable } \\
\text { o muy probable que su hogagar } \\
\text { tenga menoss ingresos en el } \\
\text { añó en cursoso, en } \\
\text { comparación con el año }\end{array}$ & $\begin{array}{c}63.8 \\
(62.8,64.9)\end{array}$ & $\begin{array}{c}61.99^{*} \\
(60.5,63.3)\end{array}$ & $\begin{array}{c}62.9 \\
(62.0,63.7)\end{array}$ & $\begin{array}{c}62.5 \\
(54.8,70.1)\end{array}$ & $62.8(61.9,63.6)$ & $\begin{array}{c}76.4 \\
(74.7,78.1)\end{array}$ & $\begin{array}{c}73.8 \\
(71.7,75.9)\end{array}$ & $75.2(73.8,76.5)$ & $\begin{array}{l}(60.8,85 . \\
3)\end{array}$ & $75.1(73.8,76.5)$ & $72.7(71.4,73.9)$ & $\begin{array}{c}70.0^{*} \\
(68.5,71.5)\end{array}$ & $71.4(70.4,72.4)$ & $70.1(61.0,79.1)$ & $\begin{array}{c}71.3 \\
(70.3,72.3)\end{array}$ \\
\hline $\begin{array}{l}\text { La familia tomó alguna } \\
\text { medida financiera (vender } \\
\text { articulos, pedir dinero } \\
\text { prestado u otra cosa) para } \\
\text { hacerf rrente a las medidas de } \\
\text { COVID-19 }\end{array}$ & $\begin{array}{c}47.5 \\
(46.4,48.6)\end{array}$ & $\begin{array}{l}39.7 \\
(38.2,41.1)\end{array}$ & $\begin{array}{c}43.6 \\
(42.6,44.5)\end{array}$ & $\begin{array}{c}45.7 \\
(37.5,53.8)\end{array}$ & $\begin{array}{c}43.7 \\
(42.8,44.6)\end{array}$ & $\begin{array}{c}61.1 \\
(59.1,63.1)\end{array}$ & $\begin{array}{c}55.8 \\
(53.3,58.3)\end{array}$ & $\begin{array}{c}58.6 \\
(57.0,60.2)\end{array}$ & $\begin{array}{l}68.2 \\
(48.6,75 . \\
8)\end{array}$ & $\begin{array}{c}58.7 \\
(57.1,60.3)\end{array}$ & $\begin{array}{c}57.2 \\
(55.7,58.7)\end{array}$ & $\begin{array}{c}50.7 \\
(48.9,52.5)\end{array}$ & $\begin{array}{c}54.1 \\
(52.9,55.2)\end{array}$ & $\begin{array}{c}57.8 \\
(47.4,68.1)\end{array}$ & $\begin{array}{c}54.2 \\
(53.0,55.3)\end{array}$ \\
\hline $\begin{array}{l}\text { La familia empezó a recibir } \\
\text { ayudas de un programa } \\
\text { gubernamental desde el } \\
\text { inicio de la pandemia (frente } \\
\text { a no o no sê) }\end{array}$ & $14.1(13.4,14.8)$ & $\begin{array}{c}17.8^{*} \\
(16.6,18.9)\end{array}$ & $15.9(15.3,16.6)$ & $15.6(10.0,21.1)$ & $15.9(15.2,16.6)$ & $\begin{array}{c}9.3 \\
(8.1,10.5)\end{array}$ & $\begin{array}{c}12.4 * \\
(10.8,13.9)\end{array}$ & $10.7(9.8,11.7)$ & $\begin{array}{c}9.0 \\
(2.9,15.0)\end{array}$ & $10.7(9.8,11.7)$ & $10.7(9.8,11.6)$ & $\begin{array}{c}14.1^{*} \\
(13.0,15.2)\end{array}$ & $12.4(11.6,13.1)$ & $10.9(6.2,15.6)$ & $\begin{array}{l}12.3 \\
(11.6,13.0)\end{array}$ \\
\hline \multicolumn{16}{|c|}{ Las personas que afirman que desde el comienzo de la pandemia, sus hogares casi nunca o nunca han podido hacer lo siguiente $\%(95 \% \mathrm{Cl})$} \\
\hline $\begin{array}{l}\text { Comprar suficientes } \\
\text { alimentos para las personas } \\
\text { del hogar }\end{array}$ & $2.8(2.4,3.2)$ & $2.2(1.9,2.6)$ & $2.5(2.2,2.8)$ & $2.6(0.5,4.7)$ & $2.5(2.2,2.8)$ & $\begin{array}{l}3.9 \\
(3.1,4.6)\end{array}$ & $3.2(2.4,4.1)$ & $\begin{array}{l}3.6 \\
(3.0,4.1)\end{array}$ & $\begin{array}{c}1.5{ }^{\dagger} \\
(-0.3,3.3)\end{array}$ & $3.6(3.0,4.2)$ & $3.5(3.0,4.1)$ & $2.9(2.3,3.5)$ & $\begin{array}{l}3.2 . \\
(2.8,3.6)\end{array}$ & $1.8(0.4,3.3)$ & $\begin{array}{c}3.3 \\
(2.9,3.6)\end{array}$ \\
\hline $\begin{array}{l}\text { Pagar las facturas } \\
\text { importantes, como la renta }\end{array}$ & $7.1(6.5,7.7)$ & $7.3(6.4,8.1)$ & $7.2(6.6,7.7)$ & $6.8(3.1,10.5)$ & $7.3(6.8,7.9)$ & $\begin{array}{c}8.0 \\
(6.9,9.1)\end{array}$ & $7.4(6.1,8.7)$ & $\begin{array}{c}7.7 \\
(6.9,8.6)\end{array}$ & $\begin{array}{c}0.7^{\dagger} \\
(-0.3,1.7)\end{array}$ & $7.6(6.8,8.4)$ & $7.7(7.0,8.5)$ & $7.4(6.4,8.3)$ & $\begin{array}{c}7.6 \\
(6.9,8.2)\end{array}$ & $2.5^{\dagger}(1.1,3.8)$ & $\begin{array}{c}7.5 \\
(6.9,8.1)\end{array}$ \\
\hline $\begin{array}{l}\text { Comprar los medicamentos } \\
\text { necesarios para los } \\
\text { miembros de la familia }\end{array}$ & $7.5(6.8,8.2)$ & $6.8(6.0,7.6)$ & $7.1(6.6,7.6)$ & $5.8(2.9,8.8)$ & $7.2(6.7,7.7)$ & $\begin{array}{c}8.1 \\
(7.0,9.1)\end{array}$ & $6.9(5.7,8.2)$ & $\begin{array}{c}7.5 \\
(6.7,8.3)\end{array}$ & $\begin{array}{c}6.1 \\
(-0.1,12.3)\end{array}$ & $7.5(6.7,8.3)$ & $7.9(7.1,8.7)$ & $6.9(6.0,7.8)$ & $\begin{array}{c}7.4 \\
(6.8,8.0)\end{array}$ & $6.0(1.5,10.5)$ & $\begin{array}{c}7.4 \\
(6.8,8.0)\end{array}$ \\
\hline
\end{tabular}

TABLA 13 Impacto de las medidas de mitigación de COVID-19 en el empleo y la salud financiera familiar, por grupo de edad y origen étnico

\begin{tabular}{|c|c|c|c|c|c|c|c|c|c|}
\hline \multirow{3}{*}{ Variable } & \multicolumn{3}{|c|}{ 15-17 años } & \multicolumn{3}{|c|}{ 18-24 años } & \multicolumn{3}{|c|}{ Total } \\
\hline & $\begin{array}{l}\text { Participantes indigenas } y / 0 \\
\text { afrodescendientes }\end{array}$ & $\begin{array}{l}\text { Participantes no indigenas } \\
\text { y/o afrodescendientes }\end{array}$ & Total & $\begin{array}{l}\text { Participantes indigenas y } y / 0 \\
\text { afrodescendientes }\end{array}$ & $\begin{array}{l}\text { Participantes no indigenas } \\
\text { y/o afrodescendientes }\end{array}$ & Total & $\begin{array}{l}\text { Participantes indigenas } y / 0 \\
\text { afrodescendientes }\end{array}$ & $\begin{array}{l}\text { Participantes no indigenas } \\
\text { y/o afrodescendientes }\end{array}$ & Total \\
\hline & $\mathrm{n}=12,843$ & $\mathrm{n}=32,112$ & $\mathrm{n}=44,955$ & $n=2,930$ & $n=7,807$ & $\mathrm{n}=10,737$ & $\mathrm{n}=15,773$ & $\mathrm{n}=39,919$ & $\mathrm{n}=55,692$ \\
\hline \multicolumn{10}{|c|}{ Situación laboral de la persona participante $\%(95 \% \mathrm{Cl})$} \\
\hline Actualmente tiene un trabajo o negocio & $\begin{array}{c}27.5 \\
(26.0,29.1)\end{array}$ & $\begin{array}{c}20.1^{\star} \\
(19.3,20.9)\end{array}$ & $22.5(21.8,23.3)$ & $\begin{array}{c}47.4 \\
(44.6,50.3)\end{array}$ & $\begin{array}{c}42.7^{*} \\
(40.9,44.6)\end{array}$ & 44.1(42.5,45.6) & $\begin{array}{c}40.8 \\
(38.8,42.8)\end{array}$ & $\begin{array}{c}36.0^{*} \\
(34.7,37.4)\end{array}$ & $37.5(36.3,38.6)$ \\
\hline \multicolumn{10}{|c|}{ Actividad de las personas participantes empleadas $\%(95 \% \mathrm{Cl})$} \\
\hline & $n=352$ & $n=647$ & $\mathrm{n}=999$ & $\mathrm{n}=159$ & $\mathrm{n}=372$ & $\mathrm{n}=531$ & $\mathrm{n}=511$ & $\mathrm{n}=1,019$ & $\mathrm{n}=1,530$ \\
\hline
\end{tabular}




\begin{tabular}{|c|c|c|c|c|c|c|c|c|c|}
\hline $\begin{array}{l}\text { Personas con empleo que citaron las medidas de } \\
\text { contingencia por CoVID-19 como razón principal } \\
\text { para no haber trabajado al menos una hora en la } \\
\text { semana anterior a la realizacion de la encuesta }\end{array}$ & $\begin{array}{l}47.6 \\
(36.8,58.4)\end{array}$ & $\begin{array}{c}40.7 \\
(34.0,47.4)\end{array}$ & $\begin{array}{l}43.4 \\
(37.6,49.3)\end{array}$ & $\begin{array}{c}52.9 \\
(42.0,63.8)\end{array}$ & $\begin{array}{l}42.3 \\
(34.7,49.8)\end{array}$ & $\begin{array}{c}45.9 \\
(39.6,52.1)\end{array}$ & $\begin{array}{c}55.9 \\
(42.8,60.9)\end{array}$ & $\begin{array}{l}42.0 \\
(35.6,48.5)\end{array}$ & $\begin{array}{l}45.5 \\
(40.2,50.7)\end{array}$ \\
\hline \multicolumn{10}{|c|}{ Actividad de las personas participantes desempleadas $\%(95 \% \mathrm{Cl})$} \\
\hline & $\mathrm{n}=3,952$ & $\mathrm{n}=12,206$ & $\mathrm{n}=16,158$ & $\mathrm{n}=482$ & $\mathrm{n}=1,790$ & $\mathrm{n}=2,272$ & $\mathrm{n}=4, \mathbf{4 3 4}$ & $\mathrm{n}=13,996$ & $\mathrm{n}=\mathbf{1 8 , 4 3 0}$ \\
\hline $\begin{array}{l}\text { Personas desempleadas que citaron las medidas } \\
\text { de contingencia por CoVID-19 como razón } \\
\text { priniciapl para no haber buscado trabajo en la } \\
\text { semana anterior a la realización de la encuesta }\end{array}$ & $\begin{array}{c}43.1 \\
(40.1,46.1)\end{array}$ & $\begin{array}{c}36.6 \\
(35.0,38.1)\end{array}$ & $\begin{array}{l}38.4 \\
(37.0,39.8)\end{array}$ & $\begin{array}{c}55.4 \\
(48.1,62.7)\end{array}$ & $\begin{array}{c}50.2 \\
(46.3,54.0)\end{array}$ & $\begin{array}{l}51.3 \\
(47.9,54.7)\end{array}$ & $\begin{array}{c}48.8 \\
(45.1,52.5)\end{array}$ & $\begin{array}{c}44.0 \\
(41.8,46.2)\end{array}$ & $\begin{array}{c}45.2 \\
(43.3,47.1)\end{array}$ \\
\hline \multicolumn{10}{|c|}{ Condiciones de empleo e ingresos de los hogares $\%(95 \% \mathrm{Cl})$} \\
\hline & $\mathrm{n}=12,843$ & $\mathrm{n}=32,112$ & $\mathrm{n}=44,955$ & $\mathrm{n}=2,930$ & $\mathrm{n}=7,807$ & $\mathrm{n}=10,737$ & $\mathrm{n}=15,773$ & $\mathrm{n}=39,919$ & $\mathrm{n}=55,692$ \\
\hline $\begin{array}{l}\text { Considera que ella/el u otro miembro de su hogar } \\
\text { perderíi ingresos en los proxximos meses debido a } \\
\text { la pandemia }\end{array}$ & $\begin{array}{c}39.8 \\
(38.2,41.5)\end{array}$ & $\begin{array}{l}31.0 * \\
(30.0,31.9)\end{array}$ & $33.8(33.0,34.7)$ & $\begin{array}{c}49.4 \\
(46.6,52.2)\end{array}$ & $\begin{array}{c}38.1^{*} \\
(36.3,39.9)\end{array}$ & $41.3(39.8,42.8)$ & $\begin{array}{c}46.2 \\
(44.2,48.1)\end{array}$ & $\begin{array}{c}36.0^{*} \\
(34.7,37.2)\end{array}$ & $39.0(37.9,40.1)$ \\
\hline $\begin{array}{l}\text { Informa que al menos un miembro del hogar } \\
\text { perdió su trabajo o cerró su negocio debido a las } \\
\text { medidas de coviD -19 en el mes anterior a la } \\
\text { realización de la encuesta }\end{array}$ & $\begin{array}{l}41.0 \\
(39.3,42.8)\end{array}$ & $\begin{array}{c}33.0^{*} \\
(32.0,34.0)\end{array}$ & $35.6(34.7,36.5)$ & $\begin{array}{c}50.2 \\
(47.3,53.1)\end{array}$ & $\begin{array}{c}37.1^{*} \\
(35.3,38.9)\end{array}$ & $40.9(39.3,42.4)$ & $\begin{array}{c}47.2 \\
(45.2,49.3)\end{array}$ & $\begin{array}{c}35.9 * \\
(34.6,37.3)\end{array}$ & $39.3(38.2,40.4)$ \\
\hline $\begin{array}{l}\text { Afirma que es algo probable o muy probable que } \\
\text { su hogar tenga menos ingresos en el año en curso, } \\
\text { en comparación con el año anterior }\end{array}$ & $\begin{array}{c}67.3 \\
(65.8,68.8)\end{array}$ & $\begin{array}{l}60.6^{*} \\
(59.6,61.6)\end{array}$ & $62.8(61.9,63.6)$ & $\begin{array}{c}80.1 \\
(78.0,82.3)\end{array}$ & $\begin{array}{l}73.1^{*} \\
(71.5,74.8)\end{array}$ & $75.1(73.8,76.5)$ & $\begin{array}{c}75.8 \\
(74.3,77.4)\end{array}$ & $\begin{array}{l}69.4^{*} \\
(68.2,70.6)\end{array}$ & $71.3(70.3,72.3)$ \\
\hline $\begin{array}{l}\text { La familia había tomado alguna medida financiera } \\
\text { (vender articulos, pedir dinero prestaddo o otra } \\
\text { cosa) para hacer frente alas medidas de coviD-19 }\end{array}$ & $47.4(45.6,49.1)$ & $\begin{array}{ll}41.9 * \\
(40.9,43.0)\end{array}$ & $\begin{array}{l}43.7 \\
(42.8,44.6)\end{array}$ & $65.2(62.5,67.9)$ & $56.1^{\star}(54.2,58.0)$ & $\begin{array}{c}58.7 \\
(57.1,60.3)\end{array}$ & $59.4(57.4,61.3)$ & $52.0 *(50.6,53.4)$ & $\begin{array}{c}54.2 \\
(53.0,55.3)\end{array}$ \\
\hline $\begin{array}{l}\text { La famililia empezzó a recibiri ayudas de un programa } \\
\text { gubernamental desde el inicio de la pandemia } \\
\text { (frente a no o o o sê) }\end{array}$ & $\begin{array}{c}18.3 \\
(17.1,19.5)\end{array}$ & $(14.0,15.6)$ & $15.9(15.2,16.6)$ & $\begin{array}{l}12.0 \\
(10.2,13.7)\end{array}$ & $\begin{array}{l}10.2 \\
(9.1,11.4)\end{array}$ & $10.7(9.8,11.7)$ & $\begin{array}{l}114.1 \\
(12.9,15.3)\end{array}$ & $\begin{array}{c}11.6^{*} \\
(10.8,22.4)\end{array}$ & $12.3(11.6,13.0)$ \\
\hline \multicolumn{10}{|c|}{ Las personas que afirman que desde el comienzo de la pandemia, sus hogares casi nunca o nunca han podido hacer lo siguiente $\%(95 \% \mathrm{Cl})$} \\
\hline $\begin{array}{l}\text { Comprar suficientes alimentos para las personas } \\
\text { del hogar }\end{array}$ & $\begin{array}{c}3.4 \\
(2.9 .4 .0)\end{array}$ & $\begin{array}{l}2.1^{*} \\
(1.8,2.3)\end{array}$ & $\begin{array}{c}2.5 \\
(2.2,2.8)\end{array}$ & $\begin{array}{c}4.6 \\
(3.4,5.7)\end{array}$ & $\begin{array}{c}3.2^{\star} \\
(2.6,3.8)\end{array}$ & $3.6(3.0,4.2)$ & $\begin{array}{c}4.2 \\
(3.4,5.0)\end{array}$ & $\begin{array}{l}2.9 * \\
(2.4,3.3)\end{array}$ & $\begin{array}{c}3.3 \\
(2.9,3.6)\end{array}$ \\
\hline Pagar las facturas importantes, como la renta & $\begin{array}{l}10.2 \\
(8.9,11.5)\end{array}$ & $\begin{array}{c}6.0^{*} \\
(5.5,6.5)\end{array}$ & $\begin{array}{c}7.3 \\
(6.8,7.9)\end{array}$ & $\begin{array}{c}11.0 \\
(9.2,12.9)\end{array}$ & $\begin{array}{c}6.3^{*} \\
(5.4,7.2)\end{array}$ & $7.6(6.8,8.4)$ & $\begin{array}{c}10.8 \\
(9.5,12.1)\end{array}$ & $\begin{array}{c}6.2^{\star} \\
(5.5,6.8)\end{array}$ & $\begin{array}{c}7.5 \\
(6.9,8.1)\end{array}$ \\
\hline
\end{tabular}


Comprar los medicamentos necesarios para los

9.3
$(8.2,10.4)$

$\frac{6.1^{*}}{(5.6,6.7)}$

7.2
$(6.7,7.7)$

9.4
$(7.7,11.0)$

$6.7 *$
$(5.8,7.6)$

$7.5(6.7,8.3)$

$9.3(8.2,10.5)$

$6.6^{*}(5.9,7.2)$

7.4
$(6.8,8.0)$

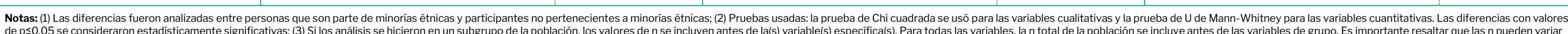

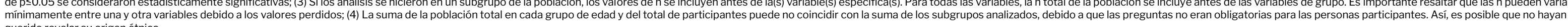
querido revelar su origen étnico.
Valor de $\mathbf{p}$ : $\mathrm{p}$-value $<0.05$

TABLA 14 Impacto de las medidas de mitigación de COVID-19 en el empleo y la salud familiar financiera, por grupo de edad y NSE

\begin{tabular}{|c|c|c|c|c|c|c|c|c|c|}
\hline \multirow{3}{*}{ Variable } & \multicolumn{3}{|c|}{ 15-17 años } & \multicolumn{3}{|c|}{ 18-24 años } & \multicolumn{3}{|c|}{ Total } \\
\hline & $\begin{array}{c}\text { Hogares de ingresos más } \\
\text { bajos (primer quintil) }\end{array}$ & $\begin{array}{c}\text { Hogares de ingresos más } \\
\text { altos (quinto quintil) }\end{array}$ & Total & $\begin{array}{c}\text { Hogares de ingresos más } \\
\text { bajos (primer quintil) }\end{array}$ & $\begin{array}{l}\text { Hogares de ingresos más } \\
\text { altos (quinto quintil) }\end{array}$ & Total & $\begin{array}{c}\text { Hogares de ingresos más } \\
\text { bajos (primer quintil) }\end{array}$ & $\begin{array}{c}\text { Hogares de ingresos más } \\
\text { altos (quinto quintil) }\end{array}$ & Total \\
\hline & $\mathrm{n}=8,852$ & $\mathrm{n}=8,778$ & $n=44,955$ & $\mathrm{n}=2,288$ & $\mathrm{n}=2,331$ & $\mathrm{n}=10,737$ & $\mathrm{n}=11,140$ & $\mathrm{n}=11,109$ & $\mathrm{n}=55,692$ \\
\hline \multicolumn{10}{|c|}{ Situación laboral de la persona participante $\%(95 \% \mathrm{Cl})$} \\
\hline Actualmente tiene un trabajo o negocio & $\begin{array}{c}27.1 \\
(25.1,29.0)\end{array}$ & $\begin{array}{c}21.2^{*} \\
(19.7,22.6)\end{array}$ & $22.5(21.8,23.3)$ & $\begin{array}{c}44.4 \\
(41.1,47.6)\end{array}$ & $\begin{array}{c}44.8 \\
(41.4,48.1)\end{array}$ & $44.1(42.5,45.6)$ & $\begin{array}{c}39.3 \\
(36.9,41.7)\end{array}$ & $\begin{array}{c}38.5 \\
(36.0,41.0)\end{array}$ & $37.5(36.3,38.6)$ \\
\hline \multicolumn{10}{|c|}{ Situación laboral de la persona participante $\%(95 \% \mathrm{Cl})$} \\
\hline & $\mathrm{n}=208$ & $\mathrm{n}=229$ & $\mathrm{n}=999$ & $\mathrm{n}=118$ & $\mathrm{n}=136$ & $\mathrm{n}=531$ & $\mathrm{n}=326$ & $\mathrm{n}=365$ & $\mathrm{n}=\mathbf{1 , 5 3 0}$ \\
\hline $\begin{array}{l}\text { Personas con empleo que citaron las medidas de } \\
\text { contingencia por CovilD-19 como razón principal } \\
\text { para no haber trabajado al menos una hora en la } \\
\text { semana anterior a la realizacion de la encuesta }\end{array}$ & $\begin{array}{c}59.7 \\
(48.9,70.5)\end{array}$ & $\begin{array}{c}32.7 * \\
(23.9,41.5)\end{array}$ & $\begin{array}{l}43.4 \\
(37.6,49.3)\end{array}$ & $\begin{array}{c}55.3 \\
(42.4,68.2)\end{array}$ & $\begin{array}{c}32.7 * \\
(21.7,43.7)\end{array}$ & $\begin{array}{l}45.9 \\
(39.6,52.1)\end{array}$ & $\begin{array}{c}56.0 \\
(45.1,67.0)\end{array}$ & $32.7^{*}(23.3,42.1)$ & $\begin{array}{c}45.5 \\
(40.2,50.7)\end{array}$ \\
\hline \multicolumn{10}{|c|}{ Actividad de los participantes empleados $\%(95 \% \mathrm{Cl})$} \\
\hline & $\mathrm{n}=2,707$ & $\mathrm{n}=3,610$ & $\mathrm{n}=16,158$ & $\mathrm{n}=368$ & $\mathrm{n}=627$ & $\mathrm{n}=2,272$ & $\mathrm{n}=3,075$ & $\mathrm{n}=4,237$ & $\mathrm{n}=\mathbf{1 8 , 4 3 0}$ \\
\hline $\begin{array}{l}\text { Personas desempleadas que citaron las medidas } \\
\text { de contingencia por coviD-19 como razón } \\
\text { princiaal para no haber buscado trabajo en la } \\
\text { semana anterior a la realización de la encuesta }\end{array}$ & $\begin{array}{c}43.3 \\
(39.8 .46 .9)\end{array}$ & $\begin{array}{c}32.4^{*} \\
(29.9,35.0)\end{array}$ & $\begin{array}{c}38.4 \\
(37.0,39.8)\end{array}$ & $\begin{array}{c}59.5 \\
(51.9,67.2)\end{array}$ & $\begin{array}{c}46.5^{*} \\
(40.0,53.0)\end{array}$ & $\begin{array}{c}51.3 \\
(47.9,54.7)\end{array}$ & $51.5(47.2,55.8)$ & $41.0^{*}(36.9,45.0)$ & $\begin{array}{c}45.2 \\
(43.3 .47 .1)\end{array}$ \\
\hline \multicolumn{10}{|c|}{ Condiciones de empleo e ingresos de los hogares $\%(95 \% \mathrm{Cl})$} \\
\hline & $\mathrm{n}=8,852$ & $\mathrm{n}=8,778$ & $n=44,955$ & $\mathrm{n}=2,288$ & $\mathrm{n}=2,331$ & $\mathrm{n}=\mathbf{1 0 , 7 3 7}$ & $\mathrm{n}=11,140$ & $\mathrm{n}=11,109$ & $\mathrm{n}=55,692$ \\
\hline $\begin{array}{l}\text { Considera que ella/el u utro miembro de su hogar } \\
\text { perdería ingresos en los proxximos meses debido a } \\
\text { la pandemia }\end{array}$ & $\begin{array}{c}47.7 \\
(45.7,49.7)\end{array}$ & $\begin{array}{c}22.3^{*} \\
(20.8,23.9)\end{array}$ & $33.8(33.0,34.7)$ & $\begin{array}{c}58.2 \\
(55.0,01.3)\end{array}$ & $\begin{array}{c}24.8^{*} \\
(22.0,27.5)\end{array}$ & $41.3(39.8,42.8)$ & $\begin{array}{c}55.0 \\
(52.7,57.3)\end{array}$ & $\begin{array}{c}24.1^{*} \\
(22.0,26.2)\end{array}$ & $39.0(37.9,40.1)$ \\
\hline $\begin{array}{l}\text { Informa que al menos un miembro del hogar perdió } \\
\text { sut trabajio o cerrós su negocio debida a las medidas } \\
\text { de covid } 19 \text { en el mes anterior a la realización de } \\
\text { la encuesta }\end{array}$ & $\begin{array}{c}53.7 \\
(51.5,55.9)\end{array}$ & $\begin{array}{c}20.4^{*} \\
(18.8,21.9)\end{array}$ & $35.6(34.7,36.5)$ & $\begin{array}{c}60.4 \\
(57.1,63.7)\end{array}$ & $\begin{array}{c}22.5^{*} \\
(19.6,25.3)\end{array}$ & $40.9(39.3,42.4)$ & $\begin{array}{c}58.4 \\
(56.0,60.8)\end{array}$ & $\begin{array}{c}21.99^{*} \\
(19.8,24.1)\end{array}$ & $39.3(38.2,40.4)$ \\
\hline
\end{tabular}




\begin{tabular}{|c|c|c|c|c|c|c|c|c|c|}
\hline $\begin{array}{l}\text { Afirma que es algo probable o muy probable que su } \\
\text { hogar tenga menos ingresos en el año en curso, en } \\
\text { comparación con el año anterior }\end{array}$ & $\begin{array}{c}68.9 \\
(66.9,70.8)\end{array}$ & $\begin{array}{l}53.3^{*} \\
(51.4,55.2)\end{array}$ & $62.8(61.9,63.6)$ & $\begin{array}{c}82.3 \\
(80.0,84.7)\end{array}$ & $\begin{array}{c}63.2^{*} \\
(60.0,66.4)\end{array}$ & $75.1(73.8,76.5)$ & $\begin{array}{c}78.4 \\
(76.6,80.1)\end{array}$ & $\begin{array}{c}60.5^{*} \\
(58.1,62.9)\end{array}$ & $71.3(70.3,72.3)$ \\
\hline $\begin{array}{l}\text { La familia había tomado alguna medida financiera } \\
\text { (vender articulos, pedir dinero prestado uo otra } \\
\text { cosa) para hacer frente as medidas de COVID-19 }\end{array}$ & $\begin{array}{c}58.8 \\
(56.8,60.8)\end{array}$ & $\begin{array}{c}29.3^{*} \\
(27.6,31.1)\end{array}$ & $\begin{array}{l}43.7 \\
(42.8844 .6)\end{array}$ & $\begin{array}{c}77.7 \\
(75.1,80.3)\end{array}$ & $38.5 *(35.2,41.9)$ & $\begin{array}{l}58.7 \\
(57.1,60.3)\end{array}$ & $\begin{array}{c}72.3 \\
(70.3,74.3)\end{array}$ & $\begin{array}{l}36.1^{*} \\
(33.6,38.6)\end{array}$ & $\begin{array}{c}54.2 \\
(53.0,55.3)\end{array}$ \\
\hline $\begin{array}{l}\text { La familia empezóa a recibir ayudas de un programa } \\
\text { gubernamental desde el inicio de la pandemia } \\
\text { (frente a no o no sé) }\end{array}$ & $\begin{array}{c}15.7 \\
(14.4,17.0)\end{array}$ & $\begin{array}{c}14.3 \\
(13.0,15.6)\end{array}$ & $15.9(15.2,16.6)$ & $\begin{array}{c}10.0 \\
(8.1,12.0)\end{array}$ & $\begin{array}{c}8.9 \\
(7.0,10.8)\end{array}$ & $10.7(9.8,11.7)$ & $\begin{array}{c}11.7 \\
(10.3,13.1)\end{array}$ & $\begin{array}{l}10.4 \\
(8.9,11.8)\end{array}$ & $12.3(11.6,13.0)$ \\
\hline \multicolumn{10}{|c|}{ Las personas que afirman que desde el comienzo de la pandemia, sus hogares casi nunca o nunca han podido hacer lo siguiente $\%(95 \% \mathrm{Cl})$} \\
\hline $\begin{array}{l}\text { Comprar suficientes alimentos para las personas } \\
\text { del hogar }\end{array}$ & $\begin{array}{c}5.5 \\
(4.6 .6,6.4)\end{array}$ & $\begin{array}{l}1.11^{*} \\
(0.7,1.5)\end{array}$ & $\begin{array}{c}2.5 \\
(2.2,2.8)\end{array}$ & $\begin{array}{c}9.6 \\
(7.5,11.6)\end{array}$ & $\begin{array}{c}1.2^{*} \\
(0.5,1.9)\end{array}$ & $3.6(3.0,4.2)$ & $\begin{array}{c}8.3 \\
(6.9,9.8)\end{array}$ & $\begin{array}{l}1.2^{\star} \\
(0.6,1.7)\end{array}$ & $\begin{array}{c}3.3 \\
(2.9,3.6)\end{array}$ \\
\hline Pagar las facturas importantes, como la renta & $\begin{array}{l}15.1 \\
(13.2,16.9)\end{array}$ & $\begin{array}{l}2.99^{*} \\
(2.4,3.5)\end{array}$ & $\begin{array}{c}7.3 \\
(6.8,7.9)\end{array}$ & $\begin{array}{l}15.9 \\
(13.4,18.4)\end{array}$ & $\begin{array}{l}2.5^{*} \\
(1.5,3.4)\end{array}$ & $7.6(6.8,8.4)$ & $\begin{array}{c}15.7 \\
(13.8,17.5)\end{array}$ & $\begin{array}{l}2.6^{*} \\
(1.9,3.3)\end{array}$ & $\begin{array}{c}7.5 \\
(6.9,8.1)\end{array}$ \\
\hline $\begin{array}{l}\text { Comprar los medicamentos necesarios para los } \\
\text { miembros de la familia }\end{array}$ & $\begin{array}{c}13.1 \\
(11.6,14.6)\end{array}$ & $\begin{array}{c}2.9^{*} \\
(2.4,3.4)\end{array}$ & $\begin{array}{c}7.2 \\
(6.7,7.7)\end{array}$ & $\begin{array}{c}14.8 \\
(12.5,17.2)\end{array}$ & $\begin{array}{c}2.77^{*} \\
(1.7,3.8)\end{array}$ & $7.5(6.7,8.3)$ & $\begin{array}{c}14.4 \\
(12.6,16.1)\end{array}$ & $\begin{array}{c}2.8^{*} \\
(2.0,3.6)\end{array}$ & $\begin{array}{c}7.4 \\
(6.88 .0)\end{array}$ \\
\hline
\end{tabular}


TABLA 15 Impacto de las medidas de mitigación de COVID-19 en aspectos de resiliencia, por grupo de edad y género

\begin{tabular}{|c|c|c|c|c|c|c|c|c|c|c|c|c|c|c|c|}
\hline \multirow{3}{*}{ Variable } & \multicolumn{5}{|c|}{ 15-17 años } & \multicolumn{5}{|c|}{ 18-24 años } & \multicolumn{5}{|c|}{ Total } \\
\hline & Mujeres & Hombres & Binarias & No binarias & Total & Mujeres & Hombres & Binarias & No binarias & Total & Mujeres & Hombres & Binarias & No binarias & Total \\
\hline & $\mathrm{n}=27,112$ & $\mathrm{n}=16,548$ & $\mathrm{n}=43,660$ & $n=501$ & $\mathrm{n}=44,955$ & $n=6,367$ & $\mathrm{n}=4,107$ & $\mathrm{n}=10,474$ & $n=137$ & $n=10,737$ & $n=33,479$ & $n=20,655$ & $\mathrm{n}=54,134$ & $\mathrm{n}=638$ & $\mathrm{~N}=55,692$ \\
\hline \multicolumn{16}{|c|}{ Indicadores de resiliencia \% (95\% Cl) } \\
\hline $\begin{array}{l}\text { Afirman que el tiempo que } \\
\text { pasan en las redes sociales } \\
\text { ha aummentado desde el } \\
\text { inicio de la pandemia }\end{array}$ & $52.3(51.2,253.3)$ & $51.6(50.2,53.1)$ & $52.0(51.1,52.8)$ & $56.7(49.1,64.3)$ & $51.8(51.0,52.7)$ & $58.6(56.6,600.5)$ & $\begin{array}{c}55.4^{*} \\
(53.0,57.8)\end{array}$ & $\begin{array}{c}57.1 \\
(55.5,58.6)\end{array}$ & $\begin{array}{c}58.1 \\
(44.1,72.1)\end{array}$ & $57.1(55.6,58.6)$ & $56.7(55.3,58.1)$ & $54.2^{*}(52.5,55.9)$ & $55.5(54.4,56.6)$ & $\begin{array}{c}57.7 \\
(47.5,67.9)\end{array}$ & $\begin{array}{l}55.4 \\
(54.4,56.5)\end{array}$ \\
\hline $\begin{array}{l}\text { Declaran estar menos en } \\
\text { contacto con sus amistades } \\
\text { que antes del comienzo de la } \\
\text { pandemia }\end{array}$ & $56.9(55.8,57.9)$ & $43.9^{*}(42.5,545.3)$ & $50.4(49.5,51.3)$ & $51.7(43.8,59.6)$ & $50.5(49.7,51.4)$ & $54.0(52.0,056.0)$ & $47.3^{*}(44.9,99.7)$ & $50.8(49.2,52.4)$ & $\begin{array}{l}48.4 \\
(34.5,62.3)\end{array}$ & $50.8(49.2,52.3)$ & $54.9(53.4,56.3)$ & $46.2^{*}(44.5,47.9)$ & $50.7(49.6,51.8)$ & $\begin{array}{c}49.3 \\
(39.1,59.5)\end{array}$ & $\begin{array}{c}50.7 \\
(49.6,51.8)\end{array}$ \\
\hline $\begin{array}{l}\text { Ha utilizado al menos un } \\
\text { servicici de a paovo desde el } \\
\text { inicio de la pandemia (por } \\
\text { ejemplo, el } 9111 \text {, lineas } \\
\text { telefónicas desalud mental, } \\
\text { programas sociales) }\end{array}$ & $70.7(69.7,71.6)$ & $67.2^{*}(65.8,868.6)$ & $68.9(68.1,169.8)$ & $73.5(65.8,81.1)$ & $69.0(68.1,69.8)$ & $46.7(44.7,78.7)$ & $\begin{array}{c}48.8 \\
(46.3,51.2)\end{array}$ & $\begin{array}{c}47.7 \\
(46.1,49.2)\end{array}$ & $\begin{array}{c}48.6 \\
(34.5,62.6)\end{array}$ & $47.8(46.2,49.3)$ & $53.9(52.4,55.3)$ & $54.7(53.0,56.4)$ & $54.3(53.1,55.4)$ & $\begin{array}{c}55.8 \\
(45.3,66.3)\end{array}$ & $\begin{array}{c}54.4 \\
(53.3 .55 .5)\end{array}$ \\
\hline \multicolumn{16}{|c|}{ Las personas encuestadas que afirman que desde el comienzo de la pandemia han utilizado las siguientes estrategias de afrontamiento $\%(95 \% \mathrm{Cl})$} \\
\hline $\begin{array}{l}\text { Ha hablado con sus } \\
\text { amistades sobre los } \\
\text { problemas que les } \\
\text { preocupan como estrategia } \\
\text { de afrontamiento durante la } \\
\text { pandemia }\end{array}$ & $36.1(35.1,37.1)$ & $\begin{array}{c}32.6^{*} \\
(31.2,33.9)\end{array}$ & $34.3(33.5,35.2)$ & $38.1(30.3,46.0)$ & $34.3(33.5,35.1)$ & $37.0(35.2,38.9)$ & $36.3(34.0,38.6)$ & $36.7(35.2,38.2)$ & $46.8(33.0,60.6)$ & $36.7(35.3,38.2)$ & $36.8(35.4,38.1)$ & $35.1(33.5,36.7)$ & $35.9(34.9,37.0)$ & 44.2 (34.2.54.3) & $\begin{array}{c}36.0 \\
(34.9,37.0)\end{array}$ \\
\hline $\begin{array}{l}\text { la hablado con su familia } \\
\text { sobre los problemas suu le } \\
\text { preocupan como estrategia } \\
\text { de afrontamiento durante la } \\
\text { pandemia }\end{array}$ & $28.1(27.129 .0)$ & $25.0^{*}(23.7,26.3)$ & $\begin{array}{l}26.5 \\
(25.7,27.3)\end{array}$ & $13.5^{5}(9.1,17.9)$ & $26.2(25.4,26.9)$ & $\begin{array}{c}34.5 \\
(32.5,36.4)\end{array}$ & $31.2^{*}(29.0,33.5)$ & $32.9(31.4,34.4)$ & $25.7(12.8,38.5)$ & $32.7(31.3,34.2)$ & $32.5(31.2,33.9)$ & $29.2^{*}(27.6,30.8)$ & $30.9(29.9,32.0)$ & $22.0(12.8,312.2)$ & $\begin{array}{c}30.7 \\
(29.6,31.7)\end{array}$ \\
\hline $\begin{array}{l}\text { Ha recibido terapia } \\
\text { (psicológica o ode otro tipo) a } \\
\text { traves de sesiones } \\
\text { telefónicas ovirtuales }\end{array}$ & $\begin{array}{c}4.1 \\
(3.7,4.6)\end{array}$ & $\begin{array}{l}2.77^{*} \\
(2.3,3.1 .1)\end{array}$ & $\begin{array}{l}3.4 \\
(3.1,3.7)\end{array}$ & $\begin{array}{c}7.3^{+} \\
(4.2,10.4)\end{array}$ & $\begin{array}{c}3.5 \\
(3.2,3.3)\end{array}$ & $\begin{array}{l}10.0 \\
(8.8,11.3)\end{array}$ & $\begin{array}{c}7.2^{*} \\
(5.9,8.6)\end{array}$ & $\begin{array}{c}8.7 \\
(7.89 .96)\end{array}$ & $\begin{array}{r}5.1 \\
(1.5,8.6)\end{array}$ & $\begin{array}{l}8.7 \\
(7.7,9.6)\end{array}$ & $\begin{array}{c}8.3 \\
(7.49 .92)\end{array}$ & $\begin{array}{l}5.8^{*} \\
(4.8,6.7)\end{array}$ & $\begin{array}{c}7.0 \\
(6.4,7.7)\end{array}$ & $\begin{array}{c}5.7 \\
(3.0,8.4)\end{array}$ & $\begin{array}{c}7.0 \\
(6.4,7.7)\end{array}$ \\
\hline $\begin{array}{l}\text { Ha tomadoo medicamentos } \\
\text { recetados para la a nsiedadad o } \\
\text { la depresión }\end{array}$ & $\begin{array}{c}1.9 \\
(1.6,2.1)\end{array}$ & $\begin{array}{c}1.3^{*} \\
(1.0,1.5)\end{array}$ & $\begin{array}{c}1.6 \\
(1.4,1.7)\end{array}$ & $\begin{array}{c}10.2^{+} \\
(3.1,17.3)\end{array}$ & $\begin{array}{c}1.7 \\
(1.5,1.9)\end{array}$ & $\begin{array}{c}3.4 \\
(2.7,4.2)\end{array}$ & $\begin{array}{c}3.1 \\
(2.2,3.9)\end{array}$ & $\begin{array}{c}3.2 \\
(2.7,3.8)\end{array}$ & $\begin{array}{c}9.4 \\
(-1.2,20.0)\end{array}$ & $\begin{array}{c}3.3 \\
(2.7,3.9)\end{array}$ & $\begin{array}{c}2.9 \\
(2.4,3.5)\end{array}$ & $\begin{array}{c}2.5 \\
(1.9,3.1)\end{array}$ & $\begin{array}{c}2.7 \\
(2.3,3.1 .1)\end{array}$ & $\begin{array}{c}9.7 \\
(2.0,17.4)\end{array}$ & $\begin{array}{c}2.8 \\
(2.4,3.2)\end{array}$ \\
\hline $\begin{array}{l}\text { Ha buscado en Internet } \\
\text { estrategias parar lidiar con } \\
\text { los sentimientos } \\
\text { perturbadores }\end{array}$ & $\begin{array}{c}14.3 \\
(13.5,15.0)\end{array}$ & $\begin{array}{c}10.4^{*} \\
(9.5,11.3)\end{array}$ & $\begin{array}{c}12.3 \\
(11.8,12.9)\end{array}$ & $\begin{array}{c}24.1^{+} \\
(16.9,31.4)\end{array}$ & $\begin{array}{c}12.4 \\
(11.9,13.0)\end{array}$ & $\begin{array}{c}21.1 \\
(19.4,22.8)\end{array}$ & $\begin{array}{c}16.9^{*} \\
(15.0,18.8)\end{array}$ & $\begin{array}{c}19.1 \\
(17.8,20.4)\end{array}$ & $\begin{array}{c}28.5 \\
(14.8,42.3)\end{array}$ & $\begin{array}{c}19.2 \\
(17.9,20.4)\end{array}$ & $\begin{array}{c}19.0 \\
(17.8,20.3)\end{array}$ & $\begin{array}{c}14.8^{*} \\
(13.5,16.2)\end{array}$ & $\begin{array}{c}17.0 \\
(16.1,17.9)\end{array}$ & $\begin{array}{c}27.2^{+} \\
(17.37,37.1)\end{array}$ & $\begin{array}{c}17.1 \\
(16.2,17.9)\end{array}$ \\
\hline $\begin{array}{l}\text { Ha participado en grupos de } \\
\text { apoyo mutuo en linea }\end{array}$ & $\begin{array}{c}1.0 \\
(0.8,1.2)\end{array}$ & $\begin{array}{c}1.4 \\
(0.9,1.8)\end{array}$ & $\begin{array}{c}1.2 \\
(0.9,1.4)\end{array}$ & $\begin{array}{c}1.9 \\
(0.5,3.4)\end{array}$ & $\begin{array}{c}1.2 \\
(1.0,1.4)\end{array}$ & $\begin{array}{c}3.1 \\
(2.2,3.9)\end{array}$ & $\begin{array}{c}3.2 \\
(2.3,4.1)\end{array}$ & $\begin{array}{r}3.1 \\
(2.5,3.7)\end{array}$ & $\begin{array}{c}4.4 \\
(-0.8,9.7)\end{array}$ & $\begin{array}{c}3.1 \\
(2.5,3.7)\end{array}$ & $\begin{array}{c}2.4 \\
(1.9,3.0)\end{array}$ & $\begin{array}{c}2.6 \\
(2.0,3.2)\end{array}$ & $\begin{array}{c}2.5 \\
(2.1,2.9)\end{array}$ & $\begin{array}{r}3.7 \\
(-0.0,7.4)\end{array}$ & $\begin{array}{c}2.5 \\
(2.1,2.9)\end{array}$ \\
\hline
\end{tabular}




\begin{tabular}{|c|c|c|c|c|c|c|c|c|c|c|c|c|c|c|c|}
\hline $\begin{array}{l}\text { Ha empezado a hacer más } \\
\text { ejercicio }\end{array}$ & $\begin{array}{c}25.6 \\
(24.8,26.5)\end{array}$ & $\begin{array}{c}25.1 \\
(23.9,26.3)\end{array}$ & $\begin{array}{c}25.4 \\
(24.6,26.1)\end{array}$ & $\begin{array}{c}21.7 \\
(16.0,27.4)\end{array}$ & $\begin{array}{c}25.2 \\
(24.5,25.9)\end{array}$ & $\begin{array}{c}29.3 \\
(27.5,31.2)\end{array}$ & $\begin{array}{l}30.8 \\
(28.6,33.1)\end{array}$ & $\begin{array}{c}30.0 \\
(28.6,31.5)\end{array}$ & $\begin{array}{c}22.2 \\
(11.8,32.7)\end{array}$ & $\begin{array}{c}29.8 \\
(28.4,31.2)\end{array}$ & $\begin{array}{c}28.2 \\
(26.9,29.5)\end{array}$ & $\begin{array}{c}29.0 \\
(27.4,30.6)\end{array}$ & $\begin{array}{c}28.6 \\
(27.6,29.6)\end{array}$ & $\begin{array}{c}22.1 \\
(14.6,29.6)\end{array}$ & $\begin{array}{c}28.4 \\
(27.4,29.4)\end{array}$ \\
\hline $\begin{array}{l}\text { Ha empezado a tomar clases } \\
\text { de yoga y/o meditación }\end{array}$ & $\begin{array}{c}3.5 \\
(3.1,3.9)\end{array}$ & $\begin{array}{c}1.6^{*} \\
(1.3,1.8)\end{array}$ & $\begin{array}{c}2.5 \\
(2.3,2.8)\end{array}$ & $\begin{array}{c}6.1 \\
(2.0,10.2)\end{array}$ & $\begin{array}{c}2.6 \\
(2.4,2.8)\end{array}$ & $\begin{array}{c}7.2 \\
(6.1,8.3)\end{array}$ & $\begin{array}{c}3.6^{*} \\
(2.8 .45)\end{array}$ & $\begin{array}{c}5.5 \\
(4.8,6.2)\end{array}$ & $\begin{array}{c}9.1 \\
(1.5,16.7)\end{array}$ & $\begin{array}{c}5.5 \\
(4.8,6.2)\end{array}$ & $\begin{array}{c}6.1 \\
(5.3,6.8)\end{array}$ & $\begin{array}{c}3.0^{*} \\
(2.4,3.6)\end{array}$ & $\begin{array}{c}4.6 \\
(4.1,5.1)\end{array}$ & $\begin{array}{c}8.2 \\
(2.7,13.6)\end{array}$ & $\begin{array}{c}4.6 \\
(4.1,5.1)\end{array}$ \\
\hline
\end{tabular}

TABLA 16 Impacto de las medidas de mitigación de COVID-19 en aspectos de resiliencia, por grupo de edad y origen étnico

\begin{tabular}{|c|c|c|c|c|c|c|c|c|c|}
\hline \multirow{3}{*}{ Variable } & \multicolumn{3}{|c|}{ 15-17 años } & \multicolumn{3}{|c|}{ 18-24 años } & \multicolumn{3}{|c|}{ Total } \\
\hline & $\begin{array}{l}\text { Participantes indigenas } y / 0 \\
\text { afrodescendientes }\end{array}$ & $\begin{array}{l}\text { Participantes no indigenas } \\
\text { y/o afrodescendientes }\end{array}$ & Total & $\begin{array}{l}\text { Participantes indigenas } y / \% \\
\text { afrodescendientes }\end{array}$ & $\begin{array}{l}\text { Participantes no indigenas } y / 0 \\
\text { afrodescendientes }\end{array}$ & Total & $\begin{array}{l}\text { Participantes indigenas } y / 0 \\
\text { afrodescendientes }\end{array}$ & $\begin{array}{l}\text { Participantes no indigenas } y / 0 \\
\text { afrodescendientes }\end{array}$ & Total \\
\hline & $\mathrm{n}=12,843$ & $\mathrm{n}=32,112$ & $\mathrm{n}=44,955$ & $\mathrm{n}=2,930$ & $\mathrm{n}=7,807$ & $\mathrm{n}=10,737$ & $\mathrm{n}=15,773$ & $\mathrm{n}=39,919$ & $\mathrm{n}=55,692$ \\
\hline \multicolumn{10}{|c|}{ Indicadores de resiliencia \% $(95 \% \mathrm{Cl})$} \\
\hline $\begin{array}{l}\text { Afirman que el tiempo que pasan en las redes sociales ha aumentado desde el } \\
\text { inicio de la pandemia }\end{array}$ & $48.4(46.7,50.0)$ & $\begin{array}{c}53.5^{*} \\
(52.5,54.5)\end{array}$ & $51.8(51.0,52.7)$ & $50.3(47.5,53.1)$ & $59.8^{*}(58.0,61.5)$ & $57.1(55.6,58.6)$ & $49.6(47.7,51.6)$ & $57.9^{*}(56.6,59.1)$ & $55.4(54.4,56.5)$ \\
\hline $\begin{array}{l}\text { Declaran estar menos en contacto con sus amistades que antes del comienzo de la } \\
\text { pandemia }\end{array}$ & $49.8(48.2,51.5)$ & $50.9(49.9,51.9)$ & $50.5(49.7,51.4)$ & $49.5(46.7,52.3)$ & $\begin{array}{c}51.3 \\
(49.4,53.1)\end{array}$ & $50.8(49.2,52.3)$ & $49.6(47.7,51.6)$ & $51.2(49.8,52.5)$ & $50.7(49.6,51.8)$ \\
\hline $\begin{array}{l}\text { Ha utilizado al menos un servicio de apoyo desde el inicio de la pandemia (por } \\
\text { ejemplo, el } 911 \text {, lineas telefónicas de salud mental, programas sociales) }\end{array}$ & $67.7(66.1,69.3)$ & $69.6^{*}(68.6,70.6)$ & $69.0(68.1,69.8)$ & $52.5(49.7,55.3)$ & $45.9 *(44.1,47.7)$ & $47.8(46.2,49.3)$ & $57.6(55.6,59.6)$ & $53.0^{*}(51.7,54.4)$ & $54.4(53.3,55.5)$ \\
\hline \multicolumn{10}{|c|}{ Las personas encuestadas que afirman que desde el comienzo de la pandemia han utilizado las siguientes estrategias de afrontamiento \% (95\% Cl) } \\
\hline $\begin{array}{l}\text { Ha hablado con sus amistades sobre los problemas que les preocupan como } \\
\text { estratagia de afrontamiento durante la pandemia }\end{array}$ & $35.5(33.9,37.1)$ & $33.7(32.8,34.7)$ & $34.3(33.5,35.1)$ & $35.2(32.6,37.8)$ & $37.3(35.6,39.1)$ & $36.7(35.3,38.2)$ & $35.3(33.5,37.1)$ & $36.3(35.0,37.5)$ & $36.0(34.9,37.0)$ \\
\hline $\begin{array}{l}\text { Ha recibido terapia (psicológica o de otro tipo) a través de sesiones telefónicas o } \\
\text { virtuales }\end{array}$ & $3.4(2.9,3.9)$ & $3.5(3.2,3.9)$ & $\begin{array}{l}3.5 \\
(3.2,3.8)\end{array}$ & $\begin{array}{c}7.0 \\
(5.6,8.4)\end{array}$ & $\begin{array}{c}9.3^{*} \\
(8.2,10.5)\end{array}$ & $\begin{array}{l}8.7 \\
(7.7,9.6)\end{array}$ & $5.8(4.8,6.8)$ & $\begin{array}{c}7.6^{*} \\
(6.7,8.4)\end{array}$ & $\begin{array}{l}7.0 \\
(6.4,7.7)\end{array}$ \\
\hline Ha tomado medicamentos recetados para la ansiedad ola depresión & $1.6(1.3,1.9)$ & $1.8(1.5,2.0)$ & $\begin{array}{c}1.7 \\
(1.5,1.9)\end{array}$ & $\begin{array}{l}2.7 \\
(1.7,3.7)\end{array}$ & $\begin{array}{c}3.5 \\
(2.8,4.3)\end{array}$ & $\begin{array}{c}3.3 \\
(2.7,3.9)\end{array}$ & $2.3(1.7,3.0)$ & $\begin{array}{c}3.0 \\
(2.5,3.5)\end{array}$ & $\begin{array}{c}2.8 \\
(2.4,3.2)\end{array}$ \\
\hline
\end{tabular}




\begin{tabular}{|c|c|c|c|c|c|c|c|c|c|}
\hline Ha buscado en Internet estrategias para lidiar con los sentimientos perturbadores & $11.8(10.9,12.8)$ & $12.7(12.0,13.4)$ & $\begin{array}{c}12.4 \\
(11.9,13.0)\end{array}$ & $18.1(15.9,20.4)$ & $19.6(18.0,21.1)$ & $\begin{array}{c}19.2 \\
(177.9,20.4)\end{array}$ & $16.0(14.5,17.5)$ & $\begin{array}{c}17.5 \\
(16.4,18.6)\end{array}$ & $\begin{array}{c}17.1 \\
(16.2,17.9)\end{array}$ \\
\hline Ha participado en grupos de apoyo mutuo en línea & $1.2(0.9,1.4)$ & $1.2(0.9,1.5)$ & $\begin{array}{c}1.2 \\
(1.0,1.4)\end{array}$ & $\begin{array}{c}3.1 \\
(2.1,4.2)\end{array}$ & $\begin{array}{c}3.1 \\
(2.4,3.8)\end{array}$ & $\begin{array}{c}3.1 \\
(2.5,3.7)\end{array}$ & $2.5(1.8,3.2)$ & $\begin{array}{c}2.5 \\
(2.0,3.0)\end{array}$ & $\begin{array}{c}2.5 \\
(2.1,2.9)\end{array}$ \\
\hline Ha empezado a hacer más jejrcicio & $25.8(24.4,27.2)$ & $24.9(24.0,25.7)$ & $\begin{array}{c}25.2 \\
(24.5,25.9)\end{array}$ & $27.3(24.9,29.8)$ & $30.8^{*}(29.1,32.5)$ & $\begin{array}{c}29.8 \\
(28.4,31.21\end{array}$ & $26.8(25.1,28.5)$ & $\begin{array}{c}29.0 * \\
(27.8,30.2)\end{array}$ & $\begin{array}{c}28.4 \\
(27.4,29.4)\end{array}$ \\
\hline Ha empezado a tomar clases de yoga y/o meditación & $2.8(2.3,3.2)$ & $2.5(2.2,2.8)$ & $\begin{array}{c}2.6 \\
(2.4,2.8)\end{array}$ & $\begin{array}{c}4.4 \\
(3.3,5.5)\end{array}$ & $\begin{array}{c}5.9^{*} \\
(5.0,6.8)\end{array}$ & $\begin{array}{c}5.5 \\
(4.8,6.2)\end{array}$ & $3.8(3.1,4.6)$ & $\begin{array}{c}4.9^{*} \\
(4.3,5.5)\end{array}$ & $\begin{array}{c}4.6 \\
(4.1,5.1)\end{array}$ \\
\hline
\end{tabular}

TABLA 17 Impacto de las medidas de mitigación de COVID-19 en aspectos de resiliencia, por grupo de edad y NSE

\begin{tabular}{|c|c|c|c|c|c|c|c|c|c|}
\hline \multirow{3}{*}{ Variable } & \multicolumn{3}{|c|}{ 15-17 años } & \multicolumn{3}{|c|}{ 18-24 años } & \multicolumn{3}{|c|}{ Total } \\
\hline & $\begin{array}{l}\text { Hogares de ingresos más bajos } \\
\text { (primer quintil) }\end{array}$ & $\begin{array}{l}\text { Hogares de ingresos más altos } \\
\text { (quinto quintil) }\end{array}$ & Total & $\begin{array}{l}\text { Hogares de ingreses más bajos } \\
\text { (primer quintili) }\end{array}$ & $\begin{array}{l}\text { Hogares de ingresos más altos (quinto } \\
\text { quintili) }\end{array}$ & Total & $\begin{array}{c}\text { Hogares de ingressos más bajos } \\
\text { (primer quintil) }\end{array}$ & $\begin{array}{l}\text { Hogares de ingresesos más altos } \\
\text { (quinto quintil) }\end{array}$ & Total \\
\hline & $n=8,852$ & $n=8,778$ & $\mathrm{n}=44,955$ & $n=2,288$ & $n=2,331$ & $n=10,737$ & $\mathrm{n}=11,140$ & $n=11,109$ & $\mathrm{n}=55,692$ \\
\hline \multicolumn{10}{|c|}{ Indicadores de resiliencia \% (95\% Cl) } \\
\hline $\begin{array}{l}\text { Afirman que el titempo que pasan en las redes sociales ha } \\
\text { aumentado desde el inicio de la pandemia }\end{array}$ & $40.9(39.0,42.8)$ & $61.0^{*}(59.1,62.8)$ & $51.8(51.0,52.7)$ & $43.5(40.3,46.7)$ & $67.2^{*}(64.1,70.2)$ & $57.1(55.6,58.6)$ & $42.8(40.4,45.1)$ & $\begin{array}{c}65.5^{*} \\
(63.2,67.8)\end{array}$ & $55.4(54.4,56.5)$ \\
\hline $\begin{array}{l}\text { Declaran estar menos en contacto con sus amistades que } \\
\text { antes del comienzo del la pandemia }\end{array}$ & $53.8(51.9,55.8)$ & $47.9^{*}(46.0,49.7)$ & $50.5(49.7,51.4)$ & $53.2(49.9,56.4)$ & $51.1(47.8,54.4)$ & $50.8(49.2,52.3)$ & $53.4(51.0,05.7)$ & $50.2(47.7,52.7)$ & $50.7(49.6,51.8)$ \\
\hline 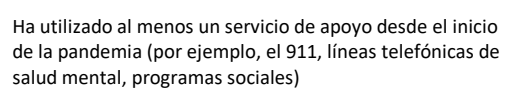 & $64.4(62.6,66.3)$ & $70.7^{*}(68.9,72.6)$ & $69.0(68.1,69.8)$ & $\begin{array}{c}49.8 \\
(46.5,53.0)\end{array}$ & $39.2^{*}(36.1,42.4)$ & $47.8(46.2,49.3)$ & $54.1(51.8,56.5)$ & $47.8^{*}(45.3,350.2)$ & $54.4(53.3,35.5)$ \\
\hline
\end{tabular}

Las personas encuestadas que afirman que desde el comienzo de la pandemia han utilizado las siguientes estrategias de afrontamiento \% $(95 \% \mathrm{Cl})$ 


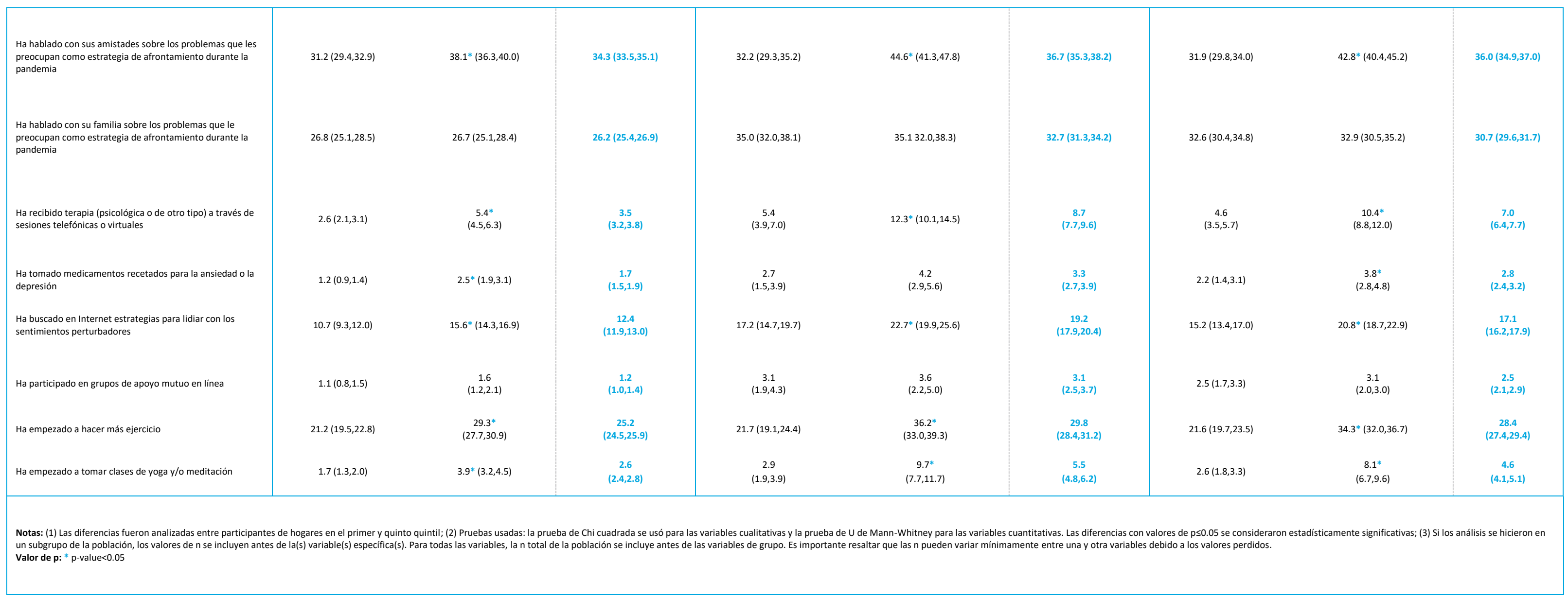


F. ACCESO A LA SALUD Y USO DE SUSTANCIAS 
TABLa 18. Impacto de las medidas de mitigación de COVID-19 en aspectos relacionados a la salud, por grupo de edad y género

\begin{tabular}{|c|c|c|c|c|c|c|c|c|c|c|c|c|c|c|c|}
\hline \multirow{3}{*}{ Variable } & \multicolumn{5}{|c|}{ 15-17 años } & \multicolumn{5}{|c|}{ 18-24 años } & \multicolumn{5}{|c|}{ Total } \\
\hline & Mujeres & Hombres & Binarias & No binarias & Total & Mujeres & Hombres & Binarias & No binarias & Total & Mujeres & Hombres & Binarias & No binarias & Total \\
\hline & $\mathrm{n}=27,112$ & $\mathrm{n}=16,548$ & $\mathrm{n}=43,660$ & $n=501$ & $\mathrm{n}=44,955$ & $n=6,367$ & $\mathrm{n}=4,107$ & $\mathrm{n}=10,474$ & $n=137$ & $\mathrm{n}=10,737$ & $\mathrm{n}=33,479$ & $n=20,655$ & $n=54,134$ & $n=638$ & $\mathrm{~N}=55,692$ \\
\hline \multicolumn{16}{|c|}{ Acceso a servicios de salud $\%(95 \% \mathrm{Cl})$} \\
\hline \multicolumn{2}{|r|}{$\mathrm{n}=18,679$} & $\mathrm{n}=12,113$ & $\mathrm{n}=30,792$ & $n=363$ & $\mathrm{n}=31,576$ & $\mathrm{n}=4,844$ & $\mathrm{n}=3,079$ & $n=7,923$ & $n=116$ & $\mathrm{n}=8,113$ & $\mathrm{n}=23,523$ & $n=7,977$ & $\mathrm{n}=38,715$ & $\mathrm{n}=479$ & $N=39,689$ \\
\hline $\begin{array}{l}\text { Perciben que su acceso (o el de un } \\
\text { familiar) a los servicios de salud } \\
\text { generales se ha visto afectado de } \\
\text { alguna manera }\end{array}$ & $\begin{array}{c}56.6 \\
(55.3 ., 57.8)\end{array}$ & $\begin{array}{c}49.3^{*} \\
(47.7,51.0)\end{array}$ & $\begin{array}{c}52.8 \\
(51.8,53.9)\end{array}$ & $\begin{array}{c}72.7^{+} \\
(644.1,79.9)\end{array}$ & $\begin{array}{c}53.1 \\
(52.1,54.1)\end{array}$ & $\begin{array}{c}78.9 \\
(77.2,80.6)\end{array}$ & $\begin{array}{c}70.5^{*} \\
(68.0,72.9)\end{array}$ & $\begin{array}{c}74.9 \\
(73.4,76.4)\end{array}$ & $\begin{array}{c}78.1 \\
(61.9,88.7)\end{array}$ & $\begin{array}{c}74.8 \\
(73.4,76.3)\end{array}$ & $\begin{array}{c}72.8 \\
(71.5,74.1)\end{array}$ & $\begin{array}{c}63.9^{*} \\
(62.1,65.7)\end{array}$ & $\begin{array}{c}68.5 \\
(67.4,69.6)\end{array}$ & $\begin{array}{c}76.6 \\
(65.3,85.1)\end{array}$ & $\begin{array}{l}68.5 \\
(67.4,69.6)\end{array}$ \\
\hline \multicolumn{2}{|r|}{$\mathrm{n}=1,105$} & $n=808$ & $n=1,913$ & $\mathrm{n}=42$ & $\mathrm{n}=1,974$ & $\mathrm{n}=891$ & $\mathrm{n}=521$ & $\mathrm{n}=1,412$ & $\mathrm{n}=22$ & $\mathrm{n}=1,443$ & $\mathrm{n}=1,996$ & $\mathrm{n}=1,329$ & $\mathrm{n}=3,325$ & $\mathrm{n}=64$ & $N=3,416$ \\
\hline $\begin{array}{l}\text { Perciben que su acceso a los } \\
\text { servicios de salud sexual y } \\
\text { reproductiva se ha visto afectado } \\
\text { de alguna manera }\end{array}$ & $\begin{array}{c}18.8 \\
(14.9,23.5)\end{array}$ & $\begin{array}{c}19.2 \\
(15.3,23.7)\end{array}$ & $\begin{array}{c}19.0 \\
(16.2,22.2)\end{array}$ & $\begin{array}{c}37.5 \\
(17.0,63.7)\end{array}$ & $\begin{array}{c}19.5 \\
(16.7,22.7)\end{array}$ & $\begin{array}{c}38.6 \\
(33.8,43.8)\end{array}$ & $\begin{array}{c}36.9 \\
(30.80 .43 .3)\end{array}$ & $\begin{array}{c}37.8 \\
(33.9,41.9)\end{array}$ & $\begin{array}{c}32.6 \\
(10.9,65.5)\end{array}$ & $\begin{array}{c}37.6 \\
(33.7,41.6)\end{array}$ & $\begin{array}{c}36.7 \\
(32.2,41.4)\end{array}$ & $\begin{array}{c}34.6 \\
(29.3,40.4)\end{array}$ & $\begin{array}{c}35.7 \\
(32.2,39.3)\end{array}$ & $\begin{array}{c}33.3 \\
(13.3,61.8)\end{array}$ & $\begin{array}{c}35.5 \\
(32.1,39.1)\end{array}$ \\
\hline \multicolumn{16}{|c|}{ Sintomas de ansiedad y depresión $\%(95 \% \mathrm{Cl})$} \\
\hline & $\mathrm{n}=27,112$ & $n=16,548$ & $\mathrm{n}=43,660$ & $n=501$ & $n=44,955$ & $n=6,367$ & $\mathrm{n}=4,107$ & $\mathrm{n}=10,474$ & $\mathrm{n}=137$ & $\mathrm{n}=10,737$ & $n=33,479$ & $n=20,655$ & $n=54,134$ & $n=638$ & $\mathrm{~N}=55,692$ \\
\hline
\end{tabular}




\begin{tabular}{|c|c|c|c|c|c|c|c|c|c|c|c|c|c|c|c|}
\hline $\begin{array}{l}\text { Según I la escala de puntuación del } \\
\text { PHA-9, mostrósintomas } \\
\text { depresivos en las dos semanas } \\
\text { anteriores a la realización de la } \\
\text { encuesta }\end{array}$ & $71.4(70.3,72.5)$ & $55.7^{*}(54.1,57.3)$ & $63.2(62.2,64.3)$ & $89.4^{\dagger}(84.1,94.6)$ & $63.7(62.7,64.7)$ & $76.2(74.5,78.0)$ & $64.0^{*}(61.5,66.5)$ & $70.4(68.8,71.9)$ & $93.6^{\dagger}(88.0,99.2)$ & $70.7(69.2,72.2)$ & $74.9(73.6,76.3)$ & $61.5^{*}(59.7,63.3)$ & $68.3(67.2,69.4)$ & $92.5^{\dagger}(88.1,96.9)$ & $68.7(67.6,69.8)$ \\
\hline $\begin{array}{l}\text { Según la escala de puntuación del } \\
\text { GAD-7, mostrósintomams de } \\
\text { ansiedad en las dos semanas } \\
\text { anteriorers a la realización de la } \\
\text { encuesta }\end{array}$ & $65.4(64.3,66.5)$ & $48.6^{*}(47.1,50.1)$ & $56.9(56.0,57.9)$ & $83.2^{\dagger}(76.3,90.2)$ & $57.3(56.3,58.2)$ & $70.6(68.8,72.5)$ & $57.0^{*}(54.4,59.5)$ & $64.1(62.5,65.7)$ & $78.1^{\dagger}(64.4,91.9)$ & $64.3(62.7,65.8)$ & $69.1(67.8,70.5)$ & $54.4^{*}(52.6,56.2)$ & $62.0(60.8,63.1)$ & $79.5^{\dagger}(69.1,89.9)$ & $62.2(61.1,63.3)$ \\
\hline $\begin{array}{l}\text { Informa haber tenido } \\
\text { persamientos de que estaría } \\
\text { mejor muerta/o o pensamientos } \\
\text { de hacerse daño de alguna manera } \\
\text { en las dos semanas anteriores a } \\
\text { completar la encuesta }\end{array}$ & $29.7(28.7,30.6)$ & $21.3^{*}(20.1,22.4)$ & $25.4(24.6,26.1)$ & $\begin{array}{c}60.9^{\prime} \\
(53.0,68.8)\end{array}$ & $26.1(25.4,26.9)$ & $29.2(27.3,31.1)$ & $26.0 *(23.8,28.2)$ & $27.7(26.2,29.1)$ & $62.4^{\dagger}(48.3,76.5)$ & $28.3(26.9,29.7)$ & $29.3(28.0,30.7)$ & $24.6^{*}(23.0,26.1)$ & $27.0(26.0,28.0)$ & $62.0^{\dagger}(51.5,72.5)$ & $27.6(26.6,28.7)$ \\
\hline $\begin{array}{l}\text { Informa que los } \\
\text { sentimientoss/sintomas de } \\
\text { depresión/ansiedad les han } \\
\text { molestado maśs deste el comienzo } \\
\text { de la pandemia que antes }\end{array}$ & $58.6(57.5,59.7)$ & $42.4^{*}(40.9,43.9)$ & $50.6(49.6,51.5)$ & $56.5(48.5,64.6)$ & $50.7(49.8,51.6)$ & $65.8(63.9,67.7)$ & $\begin{array}{c}52.4^{*} \\
(49.9,54.9)\end{array}$ & $59.5(57.9,61.1)$ & $66.2(52.1,80.2)$ & $59.5(57.9,61.1)$ & $63.7(62.3,65.1)$ & $49.3^{*}(47.5,51.2)$ & $56.8(55.7,58.0)$ & $63.4(53.2,73.7)$ & $56.9(55.7,58.0)$ \\
\hline \multicolumn{16}{|c|}{ Preocupaciones relacionadas con el futuro desde el inicio de la pandemia $\%(95 \% \mathrm{Cl})$} \\
\hline $\begin{array}{l}\text { Informa que la pérdida de un } \\
\text { familiar o amistad ha sido una de } \\
\text { sus tres principales } \\
\text { preocupaciones relacionadas con } \\
\text { su futuro desde el comienzo de la } \\
\text { pandemia }\end{array}$ & $50.0(48.9,51.0)$ & $38.0 *(36.7,39.4)$ & $44.0(43.1,44.8)$ & $52.6^{\dagger}(45.1,60.1)$ & $(43.2,44.9)$ & $54.4(52.4,56.3)$ & $43.7^{*}(41.3,46.1)$ & $49.3(47.7,50.8)$ & $64.6^{\dagger}(51.6,77.6)$ & $49.4(47.9,50.9)$ & $53.1(51.6,54.5)$ & $41.9 *(40.2,43.6)$ & $47.6(46.5,48.7)$ & $61.1^{\dagger}(51.6,70.7)$ & $47.7(46.6,48.8)$ \\
\hline $\begin{array}{l}\text { Informa que la situación financiera } \\
\text { personal ha sido ona de las stres } \\
\text { principales preocupaciones para su } \\
\text { futuro odede el comienzo de la } \\
\text { pandemia }\end{array}$ & $28.8(27.9,29.8)$ & $33.6^{*}(32.3,34.9)$ & $31.3(30.4,32.1)$ & $\begin{array}{c}40.9^{\dagger} \\
(33.3,48.4)\end{array}$ & $31.3(30.5,32.1)$ & $56.4(54.5,58.3)$ & $61.0^{*}(58.7,63.3)$ & $58.6(57.1,60.1)$ & $70.9(58.7,83.0)$ & $58.7(57.3,60.2)$ & $48.1(46.7,49.6)$ & $52.2^{*}(50.5,53.9)$ & $50.1(49.0,51.2)$ & $62.1^{\dagger}(52.9,71.4)$ & $50.2(49.1,51.3)$ \\
\hline $\begin{array}{l}\text { Informá que la situación } \\
\text { económica de su fanilia ha sido } \\
\text { una de las tres principales } \\
\text { preecupacicioses para susuturo } \\
\text { desde el comienzo de la pandemia }\end{array}$ & $38.0(37.0,39.0)$ & $33.8 *(32.4,35.2)$ & $35.9(35.0,36.7)$ & $35.4(28.6,42.2)$ & $35.8(35.0,36.6)$ & $53.1(51.2,55.1)$ & $47.0^{*}(44.6,49.4)$ & $50.2(48.7,51.7)$ & $47.5(33.5,61.5)$ & $50.0(48.5,51.6)$ & $48.6(47.2,50.0)$ & $42.8^{*}(41.1,44.5)$ & $45.8(44.7,46.9)$ & $44.0(33.8,54.1)$ & 45.6 (44.5,46.7) \\
\hline
\end{tabular}

Uso de sustancias $\%(95 \%$ CI)

\begin{tabular}{|c|c|c|c|c|c|c|c|c|c|c|c|c|c|c|c|}
\hline $\begin{array}{l}\text { Informa algún nivel de consumo de } \\
\text { alcohol }\end{array}$ & $\begin{array}{c}25.5 \\
(24.6,26.4)\end{array}$ & $\begin{array}{l}24.7 \\
(23.6,25.8)\end{array}$ & $\begin{array}{l}25.1 \\
(24.4,25.8)\end{array}$ & $\begin{array}{c}26.3 \\
(20.5,33.1)\end{array}$ & $\begin{array}{c}25.1 \\
(24.4,25.8)\end{array}$ & $\begin{array}{c}50.2 \\
(48.3,52.2)\end{array}$ & $\begin{array}{c}55.4^{*} \\
(53.0,57.7)\end{array}$ & $\begin{array}{c}52.7 \\
(51.1,54.2)\end{array}$ & $\begin{array}{c}70.9^{\dagger} \\
(56.0,82.3)\end{array}$ & $\begin{array}{c}52.8 \\
(51.3,54.3)\end{array}$ & $\begin{array}{c}42.8 \\
(41.4,44.3)\end{array}$ & $\begin{array}{c}45.5 * \\
(43.8,47.2)\end{array}$ & $\begin{array}{c}44.1 \\
(43.0,45.2)\end{array}$ & $\begin{array}{c}58.0^{+} \\
(47.9,67.4)\end{array}$ & $\begin{array}{c}44.2 \\
(43.1,45.3)\end{array}$ \\
\hline $\begin{array}{l}\text { onsumo de alcohol una o más } \\
\text { cese a la semana }\end{array}$ & $\begin{array}{c}1.5 \\
(1.2,1.9)\end{array}$ & $\begin{array}{c}2.0^{*} \\
(1.7,2.3)\end{array}$ & $\begin{array}{c}1.7 \\
(1.5,2.0)\end{array}$ & $\begin{array}{c}2.8 \\
(1.2,6.7)\end{array}$ & $\begin{array}{c}1.8 \\
(1.5,2.0)\end{array}$ & $\begin{array}{c}5.0 \\
(4.1,6.1)\end{array}$ & $\begin{array}{l}8.0^{*} \\
(6.7,9.5)\end{array}$ & $\begin{array}{c}6.4 \\
(5.6 .7 .3)\end{array}$ & $\begin{array}{c}15.1 \\
(6.6,30.9)\end{array}$ & $\begin{array}{c}6.5 \\
(5.7,7.4)\end{array}$ & $\begin{array}{c}3.9 \\
(3.3,4.7)\end{array}$ & $\begin{array}{c}6.1^{*} \\
(5.2,7.1)\end{array}$ & $\begin{array}{c}5.0 \\
(4.4,5.6)\end{array}$ & $\begin{array}{c}11.5 \\
(5.3,23.2)\end{array}$ & $\begin{array}{c}5.0 \\
(4.5,5.6)\end{array}$ \\
\hline
\end{tabular}




\begin{tabular}{|c|c|c|c|c|c|c|c|c|c|c|c|c|c|c|c|}
\hline Consumo diario de alcohol & $\begin{array}{c}0.09 \\
(0.05,0.1)\end{array}$ & $\begin{array}{c}0.1 \\
(0.09,0.2)\end{array}$ & $\begin{array}{c}0.1 \\
(0.08,0.1)\end{array}$ & $\begin{array}{c}0.1 \\
(0.02,1.0)\end{array}$ & $\begin{array}{c}0.1 \\
(0.09,0.1)\end{array}$ & $\begin{array}{c}0.1 \\
(0.04,0.3)\end{array}$ & $\begin{array}{c}0.7 * \\
(0.3,1.3)\end{array}$ & $\begin{array}{c}0.4 \\
(0.2,0.7)\end{array}$ & $\begin{array}{c}0.1 \\
(0.04,0.7)\end{array}$ & $\begin{array}{c}0.4 \\
(0.2,0.6)\end{array}$ & $\begin{array}{c}0.1 \\
(0.05,0.2)\end{array}$ & $\begin{array}{c}0.5^{*} \\
(0.3,0.9)\end{array}$ & $\begin{array}{c}0.3 \\
(0.1,0.5)\end{array}$ & $\begin{array}{c}0.1 \\
(0.05,0.5)\end{array}$ & $\begin{array}{c}0.3 \\
(0.1,0.5)\end{array}$ \\
\hline $\begin{array}{l}\text { Informa de algún nivel de consumo } \\
\text { de cannabis }\end{array}$ & $\begin{array}{c}2.5 \\
(2.1,2.9)\end{array}$ & $\begin{array}{l}4.2^{*} \\
(3.6,5.0)\end{array}$ & $\begin{array}{c}3.4 \\
(3.0,3.8)\end{array}$ & $\begin{array}{c}6.6^{+} \\
(4.2,10.3)\end{array}$ & $\begin{array}{c}3.4 \\
(3.0,3.8)\end{array}$ & $\begin{array}{c}6.2 \\
(5.3,7.4)\end{array}$ & $\begin{array}{c}10.5^{*} \\
(9.1,12.2)\end{array}$ & $\begin{array}{c}8.3 \\
(7.4,9.2)\end{array}$ & $\begin{array}{c}19.4 \\
(10.2,33.9)\end{array}$ & $\begin{array}{c}8.5 \\
(7.6,9.9)\end{array}$ & $\begin{array}{c}5.1 \\
(4.4,5.9)\end{array}$ & $\begin{array}{c}8.5^{*} \\
(7.5,9.6)\end{array}$ & $\begin{array}{c}6.8 \\
(6.1,7.4)\end{array}$ & $\begin{array}{c}15.7 \\
(8.9,26.3)\end{array}$ & $\begin{array}{c}6.9 \\
(6.3,7.6)\end{array}$ \\
\hline $\begin{array}{l}\text { Consumo de cannabis una o más } \\
\text { veces a la semana }\end{array}$ & $\begin{array}{c}0.3 \\
(0.2,0.5)\end{array}$ & $\begin{array}{c}0.8^{*} \\
(0.6,1.0)\end{array}$ & $\begin{array}{c}0.6 \\
(0.5,0.7)\end{array}$ & $\begin{array}{c}1.9 \\
(0.6,5.5)\end{array}$ & $\begin{array}{c}0.6 \\
(0.5 .0 .7)\end{array}$ & $\begin{array}{c}1.0 \\
(0.6,1.6)\end{array}$ & $\begin{array}{c}2.7^{*} \\
(2.0,3.6)\end{array}$ & $\begin{array}{c}1.8 \\
(1.4,2.3)\end{array}$ & $\begin{array}{c}3.4 \\
(0.7,15.4)\end{array}$ & $\begin{array}{c}1.8 \\
(1.4,2,2.3)\end{array}$ & $\begin{array}{c}0.8 \\
(0.5,1.2)\end{array}$ & $\begin{array}{c}2.1^{*} \\
(1.6,2.7)\end{array}$ & $\begin{array}{c}1.4 \\
(1.1,1.8)\end{array}$ & $\begin{array}{c}3.0 \\
(0.8,10.6)\end{array}$ & $\begin{array}{l}1.4 \\
(1.2,1.8)\end{array}$ \\
\hline Consumo diario de cannabis & $\begin{array}{c}0.1 \\
(0.08,0.2)\end{array}$ & $\begin{array}{l}0.3^{*} \\
(0.2,0.4)\end{array}$ & $\begin{array}{c}0.2 \\
(0.1,0.3)\end{array}$ & $\begin{array}{c}0.08^{+} \\
(0.02,0.3)\end{array}$ & $\begin{array}{c}0.2 \\
(0.1,0.3)\end{array}$ & $\begin{array}{c}0.3 \\
(0.1,0.6)\end{array}$ & $\begin{array}{c}1.3^{*} \\
(0.7,2.1)\end{array}$ & $\begin{array}{c}0.7 \\
(0.5,1.2)\end{array}$ & $\begin{array}{c}3.0 \\
(0.4,16.6)\end{array}$ & $\begin{array}{c}0.8 \\
(0.5,1.2)\end{array}$ & $\begin{array}{c}0.2 \\
(0.1,0.5)\end{array}$ & $\begin{array}{c}0.9^{*} \\
(0.6,1.5)\end{array}$ & $\begin{array}{c}0.6 \\
(0.4,0.9)\end{array}$ & $\begin{array}{l}2.1 \\
(0.3,12.1)\end{array}$ & $\begin{array}{c}0.6 \\
(0.4,0.9)\end{array}$ \\
\hline $\begin{array}{l}\text { Informa de algún nivel de consumo } \\
\text { de opiáceos y otras drogas duras }\end{array}$ & $\begin{array}{c}0.5 \\
(0.4,0.7)\end{array}$ & $\begin{array}{l}1.1^{*} \\
(0.9,1.4)\end{array}$ & $\begin{array}{c}0.8 \\
(0.7,1.0)\end{array}$ & $\begin{array}{l}3.7^{7} \\
(1.7,7.7)\end{array}$ & $\begin{array}{c}0.9 \\
(0.8,1.0)\end{array}$ & $\begin{array}{c}0.6 \\
(0.4,1.0)\end{array}$ & $\begin{array}{l}1.9^{*} \\
(1.4,2.5)\end{array}$ & $\begin{array}{c}1.2 \\
(0.9,1.6)\end{array}$ & $\begin{array}{c}0.1^{+} \\
(0.04,0.7)\end{array}$ & $\begin{array}{c}1.2 \\
(0.9,1.5)\end{array}$ & $\begin{array}{c}0.6 \\
(0.4,0.8)\end{array}$ & $\begin{array}{l}1.6^{*} \\
(1 ., 2.1)\end{array}$ & $\begin{array}{c}1.1 \\
(0.9,1.3)\end{array}$ & $\begin{array}{c}1.2 \\
(0.6,2.4)\end{array}$ & $\begin{array}{c}1.1 \\
(0.9,1.3)\end{array}$ \\
\hline $\begin{array}{l}\text { Consumo de opiáceos y otras } \\
\text { drogas duras una o más veces por } \\
\text { semana }\end{array}$ & $\begin{array}{c}0.1 \\
(0.1,0.3)\end{array}$ & $\begin{array}{c}0.4^{*} \\
(0.3,0.5)\end{array}$ & $\begin{array}{c}0.3 \\
(0.2,0.3)\end{array}$ & $\begin{array}{c}2.0 \\
(0.6,6.2)\end{array}$ & $\begin{array}{c}0.3 \\
(0.2,0.4)\end{array}$ & $\begin{array}{c}0.05 \\
(0.02,0.1)\end{array}$ & $\begin{array}{c}0.7^{*} \\
(0.4,1.2)\end{array}$ & $\begin{array}{c}0.3 \\
(0.2,0.6)\end{array}$ & $\begin{array}{c}0.09^{+} \\
(0.01,0.6)\end{array}$ & $\begin{array}{c}0.3 \\
(0.2,0.6)\end{array}$ & $\begin{array}{c}0.09 \\
(0.05,0.1)\end{array}$ & $\begin{array}{c}0.6^{*} \\
(0.3,0.9)\end{array}$ & $\begin{array}{c}0.3 \\
(0.2,0.5)\end{array}$ & $\begin{array}{c}0.6 \\
(0.2,1.9)\end{array}$ & $\begin{array}{c}0.3 \\
(0.2,0.5)\end{array}$ \\
\hline $\begin{array}{l}\text { Consumo diario de opiáceos y otras } \\
\text { drogas duras }\end{array}$ & $\begin{array}{c}0.07 \\
(0.03,0.1)\end{array}$ & $\begin{array}{c}0.2^{*} \\
(0.1,0.3)\end{array}$ & $\begin{array}{c}0.1 \\
(0.09,0.2)\end{array}$ & $\mathrm{N} / \mathrm{O}$ & $\begin{array}{c}0.1 \\
(0.09,0.2)\end{array}$ & $\begin{array}{c}0.03 \\
(0.008,0.1)\end{array}$ & $\begin{array}{c}0.2^{*} \\
(0.1,0.8)\end{array}$ & $\begin{array}{c}0.1 \\
(0.06,0.4)\end{array}$ & $\mathrm{N} / \mathrm{O}$ & $\begin{array}{c}0.1 \\
(0.06,0.4)\end{array}$ & $\begin{array}{c}0.04 \\
(0.02,0.1)\end{array}$ & $\begin{array}{c}0.2^{*} \\
(0.1,0.6)\end{array}$ & $\begin{array}{c}0.1 \\
(0.07,0.3)\end{array}$ & $\mathrm{N} / \mathrm{O}$ & $\begin{array}{c}0.1 \\
(0.07,0.3)\end{array}$ \\
\hline \multicolumn{16}{|c|}{ Aumento en el consumo de sustancias desde la pandemia $\%(95 \% \mathrm{Cl})$} \\
\hline & $\mathrm{n}=6,647$ & $\mathrm{n}=4,130$ & $\mathrm{n}=10,777$ & $\mathrm{n}=137$ & $\mathrm{n}=11,087$ & $\mathrm{n}=3,044$ & $\mathrm{n}=2,087$ & $n=5,131$ & $n=92$ & $n=5,270$ & $n=9,691$ & $\mathrm{n}=6,217$ & $\mathrm{n}=15,908$ & $n=229$ & $\mathrm{n}=16,357$ \\
\hline \multirow[t]{2}{*}{$\begin{array}{l}\text { Aumento en el consumo de alcohol } \\
\text { desde el inicio de la pandemia }\end{array}$} & $\begin{array}{c}14.5 \\
(13.2,15.9)\end{array}$ & $\begin{array}{c}13.2 \\
(11.7,14.9)\end{array}$ & $\begin{array}{c}13.8 \\
(12.8,14.9)\end{array}$ & $\begin{array}{l}16.2 \\
(8.6,28.4)\end{array}$ & $\begin{array}{c}14.0 \\
(13.0,15.1)\end{array}$ & $\begin{array}{c}13.8 \\
(11.8,15.9)\end{array}$ & $\begin{array}{c}14.4 \\
(12.2,17.0)\end{array}$ & $\begin{array}{c}14.1 \\
(12.6,15.8)\end{array}$ & $\begin{array}{c}24.5 \\
(12.0,43.6)\end{array}$ & $\begin{array}{c}14.3 \\
(12.8,15.9)\end{array}$ & $\begin{array}{c}13.9 \\
(12.3,15.7)\end{array}$ & $\begin{array}{c}14.2 \\
(12.3,16.4)\end{array}$ & $\begin{array}{c}14.1 \\
(12.8,15.5)\end{array}$ & $\begin{array}{c}23.6 \\
(12.2,40.6)\end{array}$ & $\begin{array}{c}14.2 \\
(13.0,15.6)\end{array}$ \\
\hline & $\mathrm{n}=1,028$ & $\mathrm{n}=1,190$ & $\mathrm{n}=2,218$ & $n=55$ & $\mathrm{n}=2,313$ & $\mathrm{n}=494$ & $n=576$ & $\mathrm{n}=1,070$ & $\mathrm{n}=35$ & $\mathrm{n}=1,119$ & $\mathrm{n}=1,522$ & $\mathrm{n}=1,766$ & $n=3,288$ & $n=90$ & $n=3,432$ \\
\hline \multirow[t]{2}{*}{$\begin{array}{l}\text { Aumento en el consumo de } \\
\text { cannabis desde el inicio de la } \\
\text { pandemia }\end{array}$} & $\begin{array}{c}18.7 \\
(15.3,22.6)\end{array}$ & $\begin{array}{c}15.3 \\
(12.3,18.8)\end{array}$ & $\begin{array}{c}16.5 \\
(14.1,19.1)\end{array}$ & $\begin{array}{c}15.2 \\
(4.8,28.9)\end{array}$ & $\begin{array}{c}16.6 \\
(14.3,19.2)\end{array}$ & $\begin{array}{c}20.6 \\
(14.9,27.8)\end{array}$ & $\begin{array}{c}21.7 \\
(16.7,27.7)\end{array}$ & $\begin{array}{c}21.3 \\
(17.4,25.8)\end{array}$ & $\begin{array}{c}11.4 \\
(2.6,38.1)\end{array}$ & $\begin{array}{c}20.8 \\
(17.0,25.1)\end{array}$ & $\begin{array}{c}20.3 \\
(15.4,26.3)\end{array}$ & $\begin{array}{c}20.5 \\
(16.4,55.4)\end{array}$ & $\begin{array}{c}20.4 \\
(17.2,24.1)\end{array}$ & $\begin{array}{c}11.8 \\
(3.3 .34 .2)\end{array}$ & $\begin{array}{c}20.0 \\
(16.9,23.6)\end{array}$ \\
\hline & $\mathrm{n}=488$ & $\mathrm{n}=636$ & $\mathrm{n}=1,124$ & $n=24$ & $\mathrm{n}=1,173$ & $\mathrm{n}=192$ & $\mathrm{n}=244$ & $\mathrm{n}=436$ & $\mathrm{n}=10$ & $\mathrm{n}=451$ & $n=680$ & $n=880$ & $\mathrm{n}=1,560$ & $n=34$ & $\mathrm{n}=1,624$ \\
\hline
\end{tabular}




\begin{tabular}{|c|c|c|c|c|c|c|c|c|c|c|c|c|c|c|c|}
\hline $\begin{array}{l}\text { Aumento en el consumo de } \\
\text { opiáceos, heroína, cocaina, crack o } \\
\text { anfetaminas desde el inicio de la } \\
\text { pandemia }\end{array}$ & $\begin{array}{c}15.3 \\
(10.8,21.1)\end{array}$ & $\begin{array}{c}18.6 \\
(12.9,26.1)\end{array}$ & $\begin{array}{c}17.5 \\
(13.2,22.9)\end{array}$ & $\begin{array}{c}29.9 \\
(10.6,60.5)\end{array}$ & $\begin{array}{c}18.3 \\
(14.1,1,23.5)\end{array}$ & $\begin{array}{c}9.7 \\
(4.9 .18 .2)\end{array}$ & $\begin{array}{c}15.8 \\
(9.8,24.4)\end{array}$ & $\begin{array}{c}13.7 \\
(9.3,19.9)\end{array}$ & $\begin{array}{c}1.4 \\
(0.1,14.3)\end{array}$ & $\begin{array}{c}13.4 \\
(9.0,0,19.4)\end{array}$ & $\begin{array}{c}10.9 \\
(6.8,17.1)\end{array}$ & $\begin{array}{c}11.5 \\
(11.5,23.0)\end{array}$ & $\begin{array}{c}14.6 \\
(10.9,19.3)\end{array}$ & $\begin{array}{c}8.4 \\
(1.8,30.8)\end{array}$ & $\begin{array}{c}14.5 \\
(10.9,19.1)\end{array}$ \\
\hline
\end{tabular}

TABLA 19 Impacto de las medidas de mitigación de COVID-19 en aspectos relacionados a la salud, por grupo de edad y origen étnico

\begin{tabular}{|c|c|c|c|c|c|c|c|c|c|}
\hline \multirow{3}{*}{ Variable } & \multicolumn{3}{|c|}{ 15-17 años } & \multicolumn{3}{|c|}{ 18-24 años } & \multicolumn{3}{|c|}{ Total } \\
\hline & $\begin{array}{l}\text { Participantes indigenas } y / o \\
\text { arrodescendientes }\end{array}$ & $\begin{array}{l}\text { Participantes no indigenas } y / 0 \\
\text { afrodescendientes }\end{array}$ & Total & $\begin{array}{l}\text { Participantes indigenas } y / 0 \\
\text { afrodescendientes }\end{array}$ & $\begin{array}{l}\text { Participantes no indigenas } y / 0 \\
\text { afrodescendientes }\end{array}$ & Total & $\begin{array}{l}\text { Participantes indigenas } y / 0 \\
\text { afrodescendientes }\end{array}$ & $\begin{array}{l}\text { Participantes no indigenas } y / 0 \\
\text { afrodescendientes }\end{array}$ & Total \\
\hline & $\mathrm{n}=12,843$ & $\mathrm{n}=32,112$ & $\mathrm{n}=44,955$ & $\mathrm{n}=2,930$ & $\mathrm{n}=7,807$ & $n=10,737$ & $\mathrm{n}=15,773$ & $\mathrm{n}=39,919$ & $\mathrm{n}=55,692$ \\
\hline \multicolumn{10}{|c|}{ Acceso a servicios de salud $\%(95 \% \mathrm{Cl})$} \\
\hline & $\mathrm{n}=9,285$ & $\mathrm{n}=22,291$ & $n=31,576$ & $\mathrm{n}=2,236$ & $n=5,877$ & $n=8,113$ & $n=11,521$ & $n=28,168$ & $n=39,689$ \\
\hline $\begin{array}{l}\text { Perciben que su acceso (o el de un } \\
\text { familiar) a los servicios de salud generales } \\
\text { se ha visto afectado de alguna manera }\end{array}$ & $\begin{array}{c}54.3 \\
(52.4,56.2)\end{array}$ & $\begin{array}{c}52.5 \\
(51.3 .53 .7)\end{array}$ & $\begin{array}{c}53.1 \\
(52.1,54.1)\end{array}$ & $\begin{array}{c}74.8 \\
(72.1,77.3)\end{array}$ & $\begin{array}{c}74.9 \\
(73.1,76.5)\end{array}$ & $\begin{array}{c}74.8 \\
(73.4,76.3)\end{array}$ & $\begin{array}{c}68.2 \\
(66.2,70.1)\end{array}$ & $\begin{array}{c}68.6 \\
(67.3,69.9)\end{array}$ & $\begin{array}{c}68.5 \\
(67.4,69.6)\end{array}$ \\
\hline & $n=652$ & $n=1,322$ & $\mathrm{n}=1,974$ & $\mathrm{n}=416$ & $n=1,027$ & $n=1,443$ & $n=1,067$ & $n=2,349$ & $n=3,417$ \\
\hline $\begin{array}{l}\text { Perciben que su acceso a los servicios de } \\
\text { salud sexual y reproductiva se hiv visto } \\
\text { afectado de alguna manera }\end{array}$ & $\begin{array}{c}20.4 \\
(15.8,25.9)\end{array}$ & $\begin{array}{c}19.0 \\
(15.6,23.1)\end{array}$ & $\begin{array}{c}19.5 \\
(16.7,22.7)\end{array}$ & $\begin{array}{c}42.2 \\
(35.3 ., 49.4)\end{array}$ & $\begin{array}{c}35.8 \\
(35.3,49.4)\end{array}$ & $\begin{array}{c}37.6 \\
(33.7,41.6)\end{array}$ & $\begin{array}{c}39.3 \\
(33.3,45.7)\end{array}$ & $\begin{array}{c}34.0 \\
(29.9,38.3)\end{array}$ & $\begin{array}{c}35.5 \\
(32.139 .1)\end{array}$ \\
\hline \multicolumn{10}{|c|}{ Sintomas de ansiedad y depresión $\%(95 \% \mathrm{Cl})$} \\
\hline & $\mathrm{n}=12,843$ & $\mathrm{n}=32,112$ & $\mathrm{n}=44,955$ & $\mathrm{n}=2,930$ & $\mathrm{n}=7,807$ & $n=10,737$ & $n=15,773$ & $\mathrm{n}=39,919$ & $n=55,692$ \\
\hline $\begin{array}{l}\text { Según la escala de puntuación del PHQ-g, } \\
\text { mostró sintomas depresivos en las dos } \\
\text { semanas anteriores a la realización de la } \\
\text { encuesta }\end{array}$ & $\begin{array}{c}63.1 \\
(61.2,65.0)\end{array}$ & $64.0(62.9,65.2)$ & $63.7(62.7,64.7)$ & $\begin{array}{c}68.6 \\
(65.7,71.5)\end{array}$ & $71.4(69.7,73.2)$ & $70.7(69.2,72.2)$ & $\begin{array}{c}66.9 \\
(64.8,68.9)\end{array}$ & $69.4^{*}(68.1,70.7)$ & $68.7(67.6,69.8)$ \\
\hline
\end{tabular}




\begin{tabular}{|c|c|c|c|c|c|c|c|c|c|}
\hline $\begin{array}{l}\text { Según la escala de puntuación del GAD-7, } \\
\text { mostró sintomas de ansiedadd en las dos } \\
\text { semanas anteriores a la realización de la } \\
\text { encuesta }\end{array}$ & $\begin{array}{c}57.9 \\
(56.1,59.6)\end{array}$ & $57.0(55.9,58.1)$ & $57.3(56.3,58.2)$ & $\begin{array}{c}64.4 \\
(61.6,67.3)\end{array}$ & $64.2(62.4,66.0)$ & $64.3(62.7,65.8)$ & $\begin{array}{c}62.3 \\
(60.3,64.3)\end{array}$ & $62.1(60.8,63.5)$ & $62.2(61.1,63.3)$ \\
\hline $\begin{array}{l}\text { Informa haber tenido pensamientos de } \\
\text { que estaráí mejor muertato o } \\
\text { pensamientos de hacerse daño de alguna } \\
\text { manera en las doss semanas anteriores a } \\
\text { completar la encuesta }\end{array}$ & $\begin{array}{c}25.5 \\
(25.0,27.9)\end{array}$ & $26.0(25.1,26.9)$ & $26.1(25.4,26.9)$ & $\begin{array}{c}27.9 \\
(25.3,30.5)\end{array}$ & $28.5(26.7,30.2)$ & $28.3(26.9,29.7)$ & $\begin{array}{c}27.4 \\
(25.6,29.2)\end{array}$ & $27.7(26.5,29.0)$ & $27.6(26.6,28.7)$ \\
\hline $\begin{array}{l}\text { Informa que los sentimientos/sintomas de } \\
\text { depresión/ansiedad les han molestado } \\
\text { más dessde el comienzo de la pandemia } \\
\text { que antes }\end{array}$ & $\begin{array}{c}47.7 \\
(45.9,49.4)\end{array}$ & $\begin{array}{c}52.1^{*} \\
(51.1,53.2)\end{array}$ & $50.7(49.8,51.6)$ & $\begin{array}{c}55.1 \\
(52.2,58.0)\end{array}$ & $61.2^{*}(59.4,63.1)$ & $59.5(57.9,61.1)$ & $\begin{array}{c}50.7 \\
(50.6,54.7)\end{array}$ & $58.6^{*}(57.3,60.0)$ & $56.9(55.7,58.0)$ \\
\hline \multicolumn{10}{|c|}{ Preocupaciones relacionadas con el futuro desde el inicio de la pandemia $\%(95 \% \mathrm{Cl})$} \\
\hline & $\mathrm{n}=12,843$ & $\mathrm{n}=32,112$ & $\mathrm{n}=44,955$ & $\mathrm{n}=2,930$ & $\mathrm{n}=7,807$ & $\mathrm{n}=10,737$ & $\mathrm{n}=15,773$ & $n=39,919$ & $\mathrm{n}=55,692$ \\
\hline 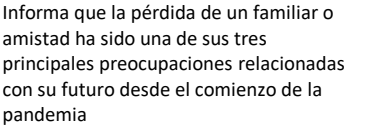 & $\begin{array}{c}42.6 \\
(41.0,44.2)\end{array}$ & $44.7^{*}(43.7,45.7)$ & $44.0(43.2,44.9)$ & $\begin{array}{c}42.7 \\
(40.0,45.5)\end{array}$ & $52.0^{*}(50.2,53.8)$ & $49.4(47.9,50.9)$ & $\begin{array}{c}42.7 \\
(40.8444 .6)\end{array}$ & $49.8^{*}(48.5,51.1)$ & $47.7(46.6,48.8)$ \\
\hline $\begin{array}{l}\text { Informa que la situación financiera } \\
\text { personal ha sido una de las tres } \\
\text { prinicipales preocupaciones para su futuro } \\
\text { desde el comienzo de la pandemia }\end{array}$ & $\begin{array}{c}32.7 \\
(31.1,34.2)\end{array}$ & $30.7^{*}(29.8,31.6)$ & $31.3(30.5,32.1)$ & $\begin{array}{c}57.5 \\
(54.8,60.3)\end{array}$ & $59.2(57.5,61.0)$ & $58.7(57.3,60.2)$ & $\begin{array}{c}49.1 \\
(47.2,51.1)\end{array}$ & $50.6(49.3,51.9)$ & $50.2(49.1,51.3)$ \\
\hline $\begin{array}{l}\text { Informa que la situación económica de su } \\
\text { familia ha sido una de las tres principales } \\
\text { preocupaciones para su futuro desde el } \\
\text { comienzo de la pandemia }\end{array}$ & $\begin{array}{c}38.4 \\
(36.7,40.0)\end{array}$ & $34.6^{*}(33.6,35.5)$ & $35.8(35.0,36.6)$ & $\begin{array}{c}51.2 \\
(48.4,54.0)\end{array}$ & $49.6(47.7,51.4)$ & $50.0(48.5,51.6)$ & $\begin{array}{c}46.9 \\
(44.9,48.8)\end{array}$ & $45.0(43.7,46.4)$ & $45.6(44.5,46.7)$ \\
\hline \multicolumn{10}{|c|}{ Aumento en el consumo de sustancias desde la pandemia $\%(95 \% \mathrm{Cl})$} \\
\hline & $\mathrm{n}=3,437$ & $\mathrm{n}=8,892$ & $\mathrm{n}=11,087$ & $\mathrm{n}=1,305$ & $\mathrm{n}=4,014$ & $n=5,270$ & $\mathrm{n}=4,742$ & $\mathrm{n}=12,906$ & $\mathrm{n}=17,648$ \\
\hline $\begin{array}{l}\text { Aumento en el consumo de alcohol desde } \\
\text { el inicio de la pandemia }\end{array}$ & $\begin{array}{c}14.2 \\
(12.3,16.3)\end{array}$ & $\begin{array}{c}13.9 \\
(12.8,15.2)\end{array}$ & $\begin{array}{c}14.0 \\
(13.0,15.1)\end{array}$ & $\begin{array}{c}14.9 \\
(12.1,18.2)\end{array}$ & $\begin{array}{c}14.1 \\
(12.3,16.0)\end{array}$ & $\begin{array}{c}14.3 \\
(12.8,15.9)\end{array}$ & $\begin{array}{c}14.8 \\
(12.5,17.4)\end{array}$ & $\begin{array}{c}14.1 \\
(12.6,15.77)\end{array}$ & $\begin{array}{c}14.2 \\
(13.0,015.6)\end{array}$ \\
\hline & $\mathrm{n}=480$ & $\mathrm{n}=1,015$ & $\mathrm{n}=2,313$ & $\mathrm{n}=255$ & $n=574$ & $\mathrm{n}=1,119$ & $\mathrm{n}=735$ & $\mathrm{n}=1,589$ & $\mathrm{n}=2,324$ \\
\hline $\begin{array}{l}\text { Aumento en el consumo de cannabis } \\
\text { desde el inicio de la pandemia }\end{array}$ & $\begin{array}{c}15.5 \\
(12.0,19.9)\end{array}$ & $\begin{array}{c}17.2 \\
(14.4,20.5)\end{array}$ & $\begin{array}{c}16.6 \\
(14.3,19.2)\end{array}$ & $\begin{array}{c}21.5 \\
(15.2,29.5)\end{array}$ & $\begin{array}{c}20.5 \\
(16.1,25.8)\end{array}$ & $\begin{array}{c}20.8 \\
(17.0,25.1)\end{array}$ & $\begin{array}{c}20.1 \\
(15.1,26.3)\end{array}$ & $\begin{array}{c}20.0 \\
(16.2,24.5)\end{array}$ & $\begin{array}{c}20.0 \\
(16.9,23.6)\end{array}$ \\
\hline & $\mathrm{n}=140$ & $\mathrm{n}=277$ & $\mathrm{n}=1,173$ & $\mathrm{n}=64$ & $\mathrm{n}=105$ & $\mathrm{n}=451$ & $n=204$ & $n=382$ & $n=586$ \\
\hline $\begin{array}{l}\text { Aumento en el consumo de opiáceos, } \\
\text { heroina, cocaina, crack o anfetaminas } \\
\text { desde el inicio de la pandemia }\end{array}$ & $\begin{array}{c}21.2 \\
(12.9,32.7)\end{array}$ & $\begin{array}{c}16.6 \\
(12.6,21.7)\end{array}$ & $\begin{array}{c}18.3 \\
(14.1,23.5)\end{array}$ & $\begin{array}{c}20.6 \\
(11.7,33.5)\end{array}$ & $\begin{array}{c}9.5 \\
(5.7,15.6)\end{array}$ & $\begin{array}{l}13.4 \\
(9.0,19.4)\end{array}$ & $\begin{array}{c}20.7 \\
(13.5,30.6)\end{array}$ & $\begin{array}{c}11.2^{*} \\
(7.8,15.7)\end{array}$ & $\begin{array}{c}14.5 \\
(10.9,19.1)\end{array}$ \\
\hline
\end{tabular}




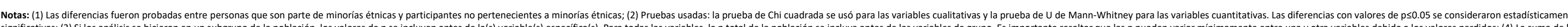
Sus analisis se hicieron en un subgrupo de la población, los valores de n se incluyen antes de la(s) variable(s) especifica(s). Para todas las variables, lan total de la población se incluye antes de las variables de grupo. Es importante resaltar que las n pueden variar minimamente entre una y otra variables debido a los valores perdidos; (4) La suma de la

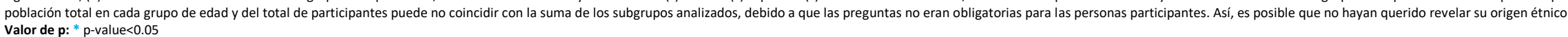

TABLA 20 Impacto de las medidas de mitigación de COVID-19 en aspectos relacionados a la salud, por grupo de edad y NSE

\begin{tabular}{|c|c|c|c|c|c|c|c|c|c|}
\hline \multirow{3}{*}{ Variable } & \multicolumn{3}{|c|}{ 15-17 años } & \multicolumn{3}{|c|}{ 18-24 años } & \multicolumn{3}{|c|}{ Total } \\
\hline & $\begin{array}{l}\text { Hogares de ingresoso más bajos } \\
\text { (primer quintil) }\end{array}$ & $\begin{array}{l}\text { Hogares de eingresos más altos } \\
\text { (quinto quintil) }\end{array}$ & Total & $\begin{array}{l}\text { Hogares de eingresos más bajos } \\
\text { (primer quintil) }\end{array}$ & $\begin{array}{l}\text { Hogares de ingresos más altos } \\
\text { (quinto quintil) }\end{array}$ & Total & $\begin{array}{l}\text { Hogares de ingresos más bajos } \\
\text { (primer quintil) }\end{array}$ & $\begin{array}{l}\text { Hogares de ingresoss más altos } \\
\text { (quinto quintil) }\end{array}$ & Total \\
\hline & $n=8,852$ & $n=8,778$ & $\mathrm{n}=44,955$ & $n=8,852$ & $n=8,778$ & $\mathrm{n}=44,955$ & $n=8,852$ & $n=8,778$ & $\mathrm{n}=55,692$ \\
\hline \multicolumn{10}{|c|}{ Acceso a servicios de salud $\%(95 \% \mathrm{Cl})$} \\
\hline & $n=5,920$ & $n=6,559$ & $n=31,576$ & $\mathrm{n}=1,626$ & $n=1,873$ & $n=8,113$ & $n=7,546$ & $n=8,432$ & $\mathrm{n}=39,689$ \\
\hline $\begin{array}{l}\text { Perciben que su acceso (o el de un } \\
\text { familiar) a los servicios de salud generales } \\
\text { se hav visto afectado de alguna manera }\end{array}$ & $\begin{array}{c}57.5 \\
(55.2,59.8)\end{array}$ & $\begin{array}{c}50.6^{*} \\
(48.4,52.7)\end{array}$ & $\begin{array}{c}53.1 \\
(52.1,54.1)\end{array}$ & $\begin{array}{c}78.7 \\
(75.7,81.4)\end{array}$ & $\begin{array}{c}72.0^{*} \\
(68.7,75.0)\end{array}$ & $\begin{array}{c}74.8 \\
(73.4,76.3)\end{array}$ & $\begin{array}{c}72.8 \\
(70.6,75.0)\end{array}$ & $\begin{array}{c}66.5^{*} \\
(64.0,68.9)\end{array}$ & $\begin{array}{c}68.5 \\
(67.4,69.6)\end{array}$ \\
\hline & $n=353$ & $\mathrm{n}=485$ & $\mathrm{n}=1,974$ & $n=257$ & $n=373$ & $\mathrm{n}=1,443$ & $n=610$ & $n=858$ & $n=3,417$ \\
\hline $\begin{array}{l}\text { Perciben que su acceso a los servicios de } \\
\text { salud sexual y reproductiva se hav visto } \\
\text { afectado de alguna manera }\end{array}$ & $\begin{array}{c}26.4 \\
(18.4,36.5)\end{array}$ & $\begin{array}{c}14.5^{*} \\
(10.1,20.5)\end{array}$ & $\begin{array}{c}19.5 \\
(16.7,22.7)\end{array}$ & $\begin{array}{l}47.5^{*} \\
(38.4,56.7)\end{array}$ & $\begin{array}{c}29.1 \\
(22.5,36.6)\end{array}$ & $\begin{array}{c}37.6 \\
(33.7,41.6)\end{array}$ & $\begin{array}{c}45.2 \\
(37.1,53.6)\end{array}$ & $\begin{array}{l}27.4^{*} \\
(21.5,34.1)\end{array}$ & $\begin{array}{c}35.5 \\
(32.1,39.1)\end{array}$ \\
\hline \multicolumn{10}{|c|}{ Síntomas de ansiedad y depresión $\%(95 \% \mathrm{Cl})$} \\
\hline & $n=8,852$ & $n=8,778$ & $n=44,955$ & $n=8,852$ & $n=8,778$ & $n=44,955$ & $n=8,852$ & $n=8,778$ & $\mathrm{n}=55,692$ \\
\hline $\begin{array}{l}\text { Según la escala de puntuación del PHQ-9, } \\
\text { mostró sintomas depresivos en las dos } \\
\text { semanas anteriores a la realización de la } \\
\text { encuesta }\end{array}$ & $\begin{array}{c}62.0 \\
(59.66464 .4)\end{array}$ & $67.2^{*}(65.2,269.1)$ & $63.7(62.7,64.7)$ & $\begin{array}{c}66.9 \\
(63.5,70.2)\end{array}$ & $70.8(67.6,73.9)$ & $70.7(69.2,72.2)$ & $\begin{array}{c}65.5 \\
(63.0,68.1)\end{array}$ & $69.8^{*}(67.4,72.3)$ & $68.7(67.6,69.8)$ \\
\hline $\begin{array}{l}\text { Según la escala de puntuación del GAD-7, } \\
\text { mostró sintomas de ansiedad en las dos } \\
\text { semanas anteriores a la realización de la } \\
\text { encuesta }\end{array}$ & $\begin{array}{c}58.6 \\
(56.4,60.7)\end{array}$ & $57.9(56.0,59.8)$ & $57.3(56.3,58.2)$ & $\begin{array}{c}64.3 \\
(61.0,67.5)\end{array}$ & $62.5(59.2,65.8)$ & $64.3(62.7,65.8)$ & $\begin{array}{c}62.7 \\
(60.3,55.1)\end{array}$ & $61.3(58.8,63.8)$ & $62.2(61.1,163.3)$ \\
\hline
\end{tabular}




\begin{tabular}{|c|c|c|c|c|c|c|c|c|c|}
\hline $\begin{array}{l}\text { Informa haber tenido pensamientos de } \\
\text { que estaría mejor muerta/o o } \\
\text { pensamientos de hacerse daño de alguna } \\
\text { manera en las dos semanas anteriores a } \\
\text { completar la encuesta }\end{array}$ & $\begin{array}{c}28.5 \\
(26.5,30.5)\end{array}$ & $27.6(25.9,29.3)$ & $26.1(25.4,26.9)$ & $\begin{array}{c}27.3 \\
(24.3,30.3)\end{array}$ & $27.4(24.3,30.5)$ & $28.3(26.9,29.7)$ & $\begin{array}{c}27.7 \\
(25.5,29.9)\end{array}$ & $27.4(25.1,29.8)$ & $27.6(26.6,28.7)$ \\
\hline $\begin{array}{l}\text { Informa que los sentimientos/sintomas de } \\
\text { depresió//ansiedad les han molestado } \\
\text { más desde el comienzo de la pandemia } \\
\text { que antes }\end{array}$ & $\begin{array}{c}49.6 \\
(47.651 .7)\end{array}$ & $53.5^{*}(51.5,55.4)$ & $50.7(49.8,51.6)$ & $\begin{array}{c}56.2 \\
(52.8,59.6)\end{array}$ & $64.4^{*}(61.1,67.6)$ & $59.5(57.9,61.1)$ & $\begin{array}{c}54.3 \\
(51.85,8.8)\end{array}$ & $61.5^{*}(59.1,64.0)$ & $56.9(55.7,58.0)$ \\
\hline \multicolumn{10}{|c|}{ Preocupaciones relacionadas con el futuro desde el inicio de la pandemia \% $(95 \%$ Cl) } \\
\hline & $\mathrm{n}=8,852$ & $\mathrm{n}=8,778$ & $\mathrm{n}=44,955$ & $\mathrm{n}=8,852$ & $\mathrm{n}=8,778$ & $\mathrm{n}=44,955$ & $\mathrm{n}=8,852$ & $\mathrm{n}=8,778$ & $\mathrm{n}=55,692$ \\
\hline $\begin{array}{l}\text { Informa que la pérdida de un familiar o } \\
\text { amistad ha sido una de sus tres principales } \\
\text { preocupaciones para su futuro desde el } \\
\text { comienzo de la pandemia }\end{array}$ & $\begin{array}{c}37.0 \\
(35.2,38.8)\end{array}$ & $47.2^{*}(45.4,49.1)$ & $44.0(43.2,44.9)$ & $\begin{array}{c}41.2 \\
(38.0,44.3)\end{array}$ & $58.2^{*}(55.0,61.4)$ & $49.4(47.9,50.9)$ & $\begin{array}{c}39.9 \\
(37.7,42.2)\end{array}$ & $55.2^{*}(52.8,57.6)$ & $47.7(46.6,48.8)$ \\
\hline 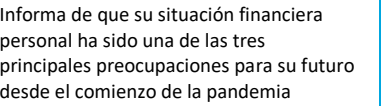 & $\begin{array}{c}30.5 \\
(28.8,32.2)\end{array}$ & $32.3(30.5,34.2)$ & $31.3(30.5,32.1)$ & $\begin{array}{c}53.8 \\
(50.7,57.0)\end{array}$ & $61.6^{*}(58.5,64.7)$ & $58.7(57.3,60.2)$ & $\begin{array}{c}46.9 \\
(44.5,99.2)\end{array}$ & $53.6^{*}(51.2,56.0)$ & $50.2(49.1,51.3)$ \\
\hline $\begin{array}{l}\text { Ifforma que la situación económica de su } \\
\text { familia ha sido una de las tres principales } \\
\text { preocupaciones para su futuro desde el } \\
\text { comienzo de la pandemia }\end{array}$ & $\begin{array}{c}38.1 \\
(36.2,40.0)\end{array}$ & $29.3^{*}(27.6,31.1)$ & $35.8(35.0,36.6)$ & $\begin{array}{c}57.0 \\
(53.9,60.2)\end{array}$ & $41.6^{*}(38.3,44.8)$ & $50.0(48.5,51.6)$ & $\begin{array}{c}51.4 \\
(49.1,53.7)\end{array}$ & $38.3^{*}(35.8,40.7)$ & $45.6(44.5,46.7)$ \\
\hline \multicolumn{10}{|c|}{ Aumento en el consumo de sustancias desde la pandemia \% (95\% Cl) } \\
\hline & $\mathrm{n}=2,108$ & $\mathrm{n}=2,792$ & $\mathrm{n}=11,087$ & $\mathrm{n}=868$ & $\mathrm{n}=1,450$ & $n=5,270$ & $\mathrm{n}=2,976$ & $\mathrm{n}=4,242$ & $\mathrm{n}=17,648$ \\
\hline \multirow[t]{2}{*}{$\begin{array}{l}\text { Aumento en el consumo de alcohol desde } \\
\text { el inicio de la pandemia }\end{array}$} & $\begin{array}{c}12.2 \\
(10.0,14.8)\end{array}$ & $\begin{array}{c}\left.15.8^{*} .2\right) \\
(13.7,18.2)\end{array}$ & $\begin{array}{c}14.0 \\
(13.0,15.1)\end{array}$ & $\begin{array}{c}14.5 \\
(10.8,19.1)\end{array}$ & $\begin{array}{c}16.3 \\
(13.4,19.7)\end{array}$ & $\begin{array}{c}14.3 \\
(12.8,15.9)\end{array}$ & $\begin{array}{c}14.0 \\
(11.0,17.8)\end{array}$ & $\begin{array}{c}16.3 \\
(13.7,19.2)\end{array}$ & $\begin{array}{c}14.2 \\
(13.0,15.6)\end{array}$ \\
\hline & $\mathrm{n}=288$ & $\mathrm{n}=363$ & $\mathrm{n}=2,313$ & $\mathrm{n}=118$ & $\mathrm{n}=268$ & $\mathrm{n}=1,119$ & $n=406$ & $n=631$ & $\mathrm{n}=2,324$ \\
\hline \multirow[t]{2}{*}{$\begin{array}{l}\text { Aumento en el consumo de cannabis } \\
\text { desde el inicio de la pandemia }\end{array}$} & $\begin{array}{c}14.7 \\
(10.1,20.9)\end{array}$ & $\begin{array}{c}17.2 \\
(12.8,22.7)\end{array}$ & $\begin{array}{c}16.6 \\
(14.3,19.2)\end{array}$ & $\begin{array}{c}20.6 \\
(11.8,33.5)\end{array}$ & $\begin{array}{c}21.3 \\
(14.9,29.6)\end{array}$ & $\begin{array}{c}20.8 \\
(17.0,25.1)\end{array}$ & $\begin{array}{c}19.0 \\
(12.2,28.4)\end{array}$ & $\begin{array}{c}20.8 \\
(15.1,28.0)\end{array}$ & $\begin{array}{c}20.0 \\
(16.9,23.6)\end{array}$ \\
\hline & $\mathrm{n}=107$ & $n=96$ & $\mathrm{n}=1,173$ & $n=39$ & $\mathrm{n}=48$ & $\mathrm{n}=451$ & $\mathrm{n}=146$ & $\mathrm{n}=144$ & $n=586$ \\
\hline $\begin{array}{l}\text { Aumento en el consumo de opiáceos, } \\
\text { heroina, cocaina, crack o anfetaminas } \\
\text { desde el inicio de la pandemia }\end{array}$ & $\begin{array}{c}15.1 \\
(10.2,21.8)\end{array}$ & $\begin{array}{c}14.5 \\
(8.9,22.7)\end{array}$ & $\begin{array}{c}18.3 \\
(14.1,23.5)\end{array}$ & $\begin{array}{c}21.6 \\
(9.5,42.0)\end{array}$ & $\begin{array}{c}13.3 \\
(6.9,23.9)\end{array}$ & $\begin{array}{c}13.4 \\
(9.0,19.4)\end{array}$ & $\begin{array}{c}19.9 \\
(10.3,35.1)\end{array}$ & $\begin{array}{c}13.5 \\
(8.1,21.8)\end{array}$ & $\begin{array}{c}14.5 \\
(10.9,19.1)\end{array}$ \\
\hline \multicolumn{10}{|c|}{ 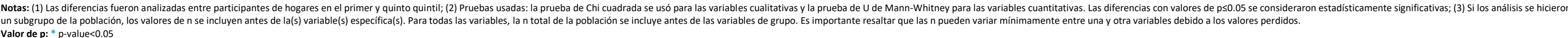 } \\
\hline
\end{tabular}



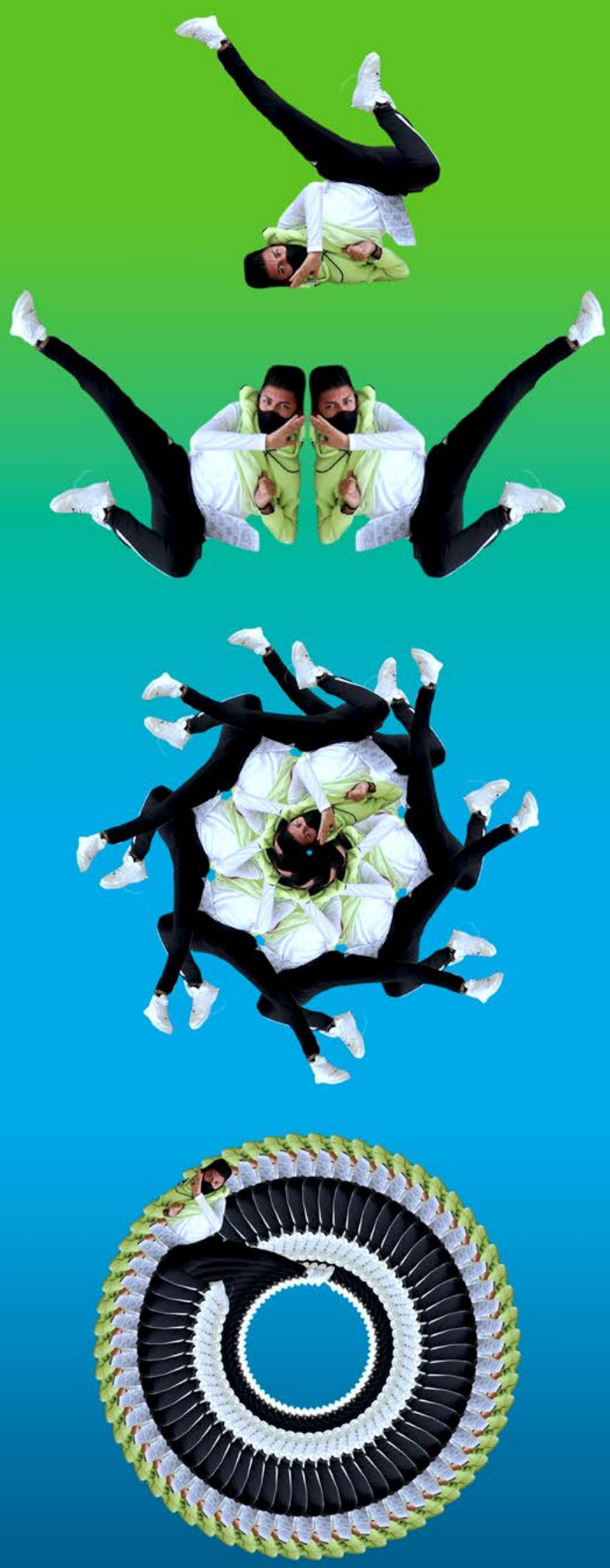

@ @ Voces-19 